This document is

UBLICLY RELEASABLE Lany \& gulliam uthorizing Official

ate: $12106 / 2005$

\section{STATISTICAL STUDY \\ OF THE STRENGTH OF NEAR-ISOTROPIC GRAPHITE}

by

R. J. PRICE

This report wotice

Tonsored by was prepared as an account of work

the United States nor the Uniternment. Neither

Research and Development Administration, nor any of

their employees, nor any of their contractors,

subcontractors, or their employees, makes any

liabity, express or impled, or assumes any legal

or usefuless of any inf for the accuracy, completeness

process disclosed, or reprosents that its us, product or infringe privately owned rights.
Prepared under

Contract E(04-3)-167

Project Agreement No. 17

for the San Francisco Operations Office

U.S. Energy Research and Development Administration 


\section{DISCLAIMER}

This report was prepared as an account of work sponsored by an agency of the United States Government. Neither the United States Government nor any agency Thereof, nor any of their employees, makes any warranty, express or implied, or assumes any legal liability or responsibility for the accuracy, completeness, or usefulness of any information, apparatus, product, or process disclosed, or represents that its use would not infringe privately owned rights. Reference herein to any specific commercial product, process, or service by trade name, trademark, manufacturer, or otherwise does not necessarily constitute or imply its endorsement, recommendation, or favoring by the United States Government or any agency thereof. The views and opinions of authors expressed herein do not necessarily state or reflect those of the United States Government or any agency thereof. 


\section{DISCLAIMER}

Portions of this document may be illegible in electronic image products. Images are produced from the best available original document. 


\section{ABSTRACT}

More than 2000 tensile and four-point bend tests were made at ambient temperature on specimens from one $10 \mathrm{~g}$ of extruded near-isotropic petroleumcoke-based nuclear graphite (Great Lakes Carbon Corporation grade H-451). The mean strengths showed the expected systematic dependence on orientation and location, with axial specimens stronger than radial specimens and material near the edge of the log stronger than material near the centerline. There were additional local fluctuations in strength which, in some cases, corresponded to local variations in density. The coefficient of variation was lower for axial specimens than for radial specimens, and lower for bend specimens than for tensile specimens. The cumulative strength distribution could be fitted equally well by a normal (Gaussian) distribution or by a Weibull distribution. The value of the Weibull modulus, $\mathrm{m}$, was lower for tensile tests than for bend tests, which conflicts with predictions of the Weibull model for the strength of brittle solids. The mean tensile strength of small tensile specimens (volume $724 \mathrm{~mm}^{3}$ ) was higher than that of large tensile specimens (volume $9847 \mathrm{~mm}^{3}$ ) by $3 \%$ (axial orientation) or $8 \%$ (radial orientation). These numbers disagree with differences of $28 \%$ and $38 \%$, respectively, predicted by the Weibull model. The mean flexural strength correlated well with the mean tensile strength of companion specimens. Flexural strengths (corrected for the nonlinear stress-strain relationship of graphite) averaged $52 \%$ higher than the corresponding tensile strengths for the axial orientation, and 55\% higher for the radial orientation. These values agree well with Weibull theory predictions of $51 \%$ and $64 \%$, respectively. However, the other inconsistencies mentioned above prevent the material from qualifying as a Weibull solid. 
CONTENT:S

ABSTRACT. . . . . . . . . . . . . . . . . . . . . iii

1. INTRODUCTION . . . . . . . . . . . . . . . . 1

2. EXPERIMENTAL METHODS . . . . . . . . . . . . . . 3

3. RESULTS . . . . . . . . . . . . . . . . . . . 6

3.1. Data Tabulation . . . . . . . . . . . . . 6

3.2. Dependence of Strength on Orientation and Location . . . 6

3.3. Statistical Distribution of Strengths . . . . . . . . . 8

3.4. Dependence of Strength on Specinen Size . . . . . . . 10

3.5. Relationship Between Flexural Strength and

Tensile Strength .................. 10

4. SUMMARY AND CONCLUSIONS . . . . . . . . . . . . . . 13

REFERENCES ........................ 16

\section{TABLES}

1. Strengths of smal1-sized tensile specimens, slab 1, axial

orientation, end-edge location . . . . . . . . . . . . 17

2. Strengths of large-sized tensile specimens, slab 1, axial

orientation, end-edge location ............ . 18

3. Strengths of four-point bend specimens, slab 1, axial

orientation, end-edge location . . . . . . . . . . . 19

4. Strengths of small-sized tensile specimens, slab 1 , axial orientation, end-center location . . . . . . . . . 20

5. Strengths of large-sized tensile specimens, slab 1 , axial orientation, end-center location . . . . . . . . . . . 21

6. Strengths of four-point bend specimens, slab 1 , axial orientation, end-center location . . . . . . . . . . . . 22

7. Strengths of small-sized tensile specimens, slab 1 , radial orientation, end-edge location . . . . . . . . 23

8. Strengths of large-sized tensile specimens, slab 1 , radial orientation, end-edge location . . . . . . . . . . 24

9. Strengths of four-point bend specimens, slab 1, radial orientation, end-edge location . . . . . . . . . . . 25 


\section{TABLES (Continued)}

10. Strengths of small-sized tensile specimens, slab 1, radial orientation, end-center location . . . . . . . . . 26

11. Strengths of large-sized tensile specimens, slab 1 , radial orientation, end-center location . . . . . . . . 27

12. Strengths of four-point bend specimens, slab 1 , radial orientation, end-center location . . . . . . . . . . 28

13. Strengths of small-sized tensile specimens, slab 2, axia1 orientation, midlength-edge location . . . . . . . . . . 29

14. Strengths of large-sized tensile specimens, slab 2, axia1 orientation, midlength-edge location . . . . . . . . . 30

15. Strengths of four-point bend specimens, slab 2, axial orientation, midlength-edge location . . . . . . . . . . . . 31

16. Strengths of small-sized tensile specimens, slab 2 , axial orientation, midlength-center location . . . . . . . 32

17. Strengths of large-sized tensile specimens, slab 2, axial orientation, midlength-center location . . . . . . . 33

18. Strengths of four-point bend specimens, slab 2, axial orientation, midlength-center location . . . . . . . . . . 34

19. Strengths of small-sized tensile specimens, slab 2, radial orientation, midlength-edge location . . . . . . . 35

20. Strengths of large-sized tensile specimens, slab 2 , radial orientation, midlength-edge location . . . . . . . 36

21. Strengths of four-point specimens, slab 2, radial orientation, midlength-edge location . . . . . . . . . . 37

22. Strengths of small-sized tensile specimens, slab 2 , radial orientation, midlength-center location . . . . . . 38

23. Strengths of large-sized tensile specimens, slab 2 , radial orientation, midlength-center location . . . . . . . . . 39

24. Strengths of four-point bend specimens, slab 2, radial orientation, midlength-center location . . . . . . . . 40

25. Strengths of smal1-sized tensile specimens, slab 3, axial orientation, midlength-edge location . . . . . . . . . . 41

26. Strengths of large-sized tensile specimens, slab 3 , axial orientation, midlength-edge location . . . . . . . . 42

27. Strengths of four-point bend specimens, slab 3 , axial orientation, midlength-edge location . . . . . . . . . 43

28. Strengths of small-sized tensile specimens, slab 3 , axial orientation, midlength-center location . . . . . . . . . 4 44

29. Strengths of large-sized tensile specimens, slab 3 , axial orientation, midlength-center location ........... 45 
TABLES (Continued)

30. Strengths of four-point bend specimens, slab 3, axial orientation, midlength-center location . . . . . . . . . 46

31. Strengths of small-sized tensile specimens, slab 3 , radial orientation, midlength-edge location . . . . . . . . 47

32. Strengths of large-sized tensile specimens, slab 3 , radial orientation, midlength-edge location . . . . . . . 48

33. Strengths of four-point bend specimens, slab 3, radial orientation, midlength-edge location . . . . . . . . 49

34. Strengths of small-sized tensile specimens, slab 3 , radial orientation, midlength-center location . . . . . . 50

35. Strengths of large-sized tensile specimens, slab 3 , radial orientation, midlength-center location . . . . . . . 51

36. Strengths of four-point bend specimens, slab 3 , radial orientation, midlength-center location . . . . . . . 52

37. Strengths of sma11-sized tensile specimens, slab 4 , axial orientation, end-edge location ... . . . . . . 53

38. Strengths of large-sized tensile specimens, slab 4 , axial orientation, end-edge location . . . . . . . . . . 54

39. Strengths of four-point bend specimens, slab 4 , axial orientation, end-edge location . . . . . . . . . 55

40. Strengths of small-sized tensile specimens, slab 4, axial orientation, end-center location . . . . . . . . . 56

41. Strengths of large-sized tensile specimens, slab 4, axial orientation, end-center location . . . . . . . . 57

42. Strengths of four-point bend specimens, slab 4 , axial orientation, end-center location . . . . . . . . . 58

43. Strengths of small-sized tensile specimens, slab 4, radial orientation, end-edge location ... . . . . . . 59

44. Strengths of large-sized tensile specimens, slab 4, radia1 orientation, end-edge location . . . . . . . . 60

45. Strengths of four-point bend specimens, slab 4, radial orientation, end-edge location . . . . . . . . . 61

46. Strengths of small-sized tensile specimens, slab 4, radial orientation, end-center location . . . . . . . . . 62

47. Strengths of large-sized tensile specimens, slab 4 , radial orientation, end-center location . . . . . . . . 63

48. Strengths of four-point bend specimens, slab 4, radial orientation, end-center location . . . . . . . . . 64

49. Summary of statistical study of the strength of $\mathrm{H}-451$ graphite, $\log 5651-90$ (GLCC og 48), slab 1 (end of parent $1 \circ \mathrm{g}$ ) 


\section{TABLES (Continued)}

50. Summary of statistical study of the strength of $\mathrm{H}-451$ graphite, log 5651-90 (GLCC $\log 48$ ), slab 2

(midlength of parent $1 \mathrm{og}$ ) ............... 66

51. Summary of statistical study of the strength of H-451 graphite, $\log 5651-90$ (GLCC $\log 48$ ), slab 3

(midlength of parent log) . . . . ......... 67

52. Summary of statistical study of the strength of H-451

graphite, log 5651-90 (GLCC log 48), slab 4

(end of parent log) . . . . . . . . . . . . . 68

53. Mean values of coefficient of variation and Weibull

modulus for strength of H-451 graphite, $\log 5651-90$. . . . . 69

FIGURES

1. Locations of slabs (shaded) for statistical strength

testing in $\log 5651-90$ of H-451 graphite . . . . . . . . . 70

2. Coring plan for edge zone of slab . . . . . . . . . . . 71

3. Coring plan for center zone of slab . . . . . . . . . . 72

4. Correction factors for bend-test data to allow for nonlinear stress-strain relationship (H-451 graphite) . . . . . 73

5. Map of the distribution of density in slab 1, edge zone . . . 74

6. Map of the distribution of strength in slab 1, edge zone . . . 75

7. Map of the distribution of density in slab 1, center zone . . 76

8. Map of the distribution of strength in slab 1, center zone . . 77

9. Map of the distribution of density in slab 2, edge zone . . . 78

10. Map of the distribution of strength in slab 2, edge zone . . . 79

11. Map of the distribution of density in slab 2, center zone . . . 80

12. Map of the distribution of strength in slab 2, center zone . . 81

13. Map of the distribution of density in slab 3, edge zone . . . 82

14. Map of the distribution of strength in slab 3, edge zone . . . 83

15. Map of the distribution of density in slab 3, center zone . . 84

16. Map of the distribution of strength in slab 3, center zone . . 85

17. Map of the distribution of density in slab 4, edge zone . . . 86

18. Map of the distribution of strength in slab 4, edge zone . . . 87

19. Map of the distribution of density in slab 4 , center zone . . 88 


\section{FIGURES (Continued)}

20. Map of the distribution of strength in slab 4, center zone . . 89

21. Cumulative distribution curve for strength of smal1-sized

tensile specimens, slab 1 , axial orientation, end-edge

location . . . . . . . . . . . . . . . . . . 90

22. Cumulative distribution curve for strength of large-sized

tensile specimens, slab 1, axial orientation, end-edge

location . . . . . . . . . . . . . . . . . . 91

23. Cumulative distribution curve for strength of four-point

bend specimens, slab 1, axial orientation, end-edge location . . 92

24. Cumulative distribution curve for strength of sma11-sized

tensile specimens, slab 1, axial orientation, end-center

location....................... 93

25. Cumulative distribution curve for strength of large-sized tensile specimens, slab 1, axial orientation, end-center location . . . . . . . . . . . . . . . . . . . 9 94

26. Cumulative distribution curve for strength of four-point bend specimens, slab 1, axial orientation, end-center location . . . . . . . . . . . . . . . . . . . 95

27. Cumulative distribution curve for strength of sma11-sized tensile specimens, slab 1 , radial orientation, end-edge location . . . . . . . . . . . . . . . . . 96

28. Cumulative distribution curve for strength of large-sized tensile specimens, slab 1 , radial orientation, end-edge location . . . . . . . . . . . . . . . . . . 97

29. Cumulative distribution curve for strength of four-point bend specimens, slab 1 , radial orientation, end-edge location . . . . . . . . . . . . . . . . . 98

30. Cumulative distribution curve for strength of small-sized tensile specimens, slab 1, radial orientation, end-center location . . . . . . . . . . . . . . . . . . . . 99

31. Cumulative distribution curve for strength of large-sized tensile specimens, slab 1, radial orientation, end-center 1ocation ...................... 100

32. Cumulative distribution curve for strength of four-point bend specimens, slab 1, radial orientation, end-center location ...................... 101

33. Cumulative distribution curve for strength of small-sized tensile specimens, slab 2, axial orientation, midlengthedge location .................... . 102

34. Cumulative distribution curve for strength of large-sized tensile specimens, slab 2, axial orientation, midlengthedge location . . . . . . . . . . . . . . . 103 


\section{FIGURES (Continued)}

35. Cumulative distribution curve for strength of four-point bend specimens, slab 2 , axial orientation, midlengthedge location .................... 104

36. Cumulative distribution curve for strength of sma11-sized tensile specimens, slab 2 , axial orientation, midlengthcenter location . . . . . . . . . . . . . . 105

37. Cumulative distribution curve for strength of large-sized tensile specimens, slab 2, axial orientation, midlengthcenter location . . . . . . . . . . . . . . . 106

38. Cumulative distribution curve for strength of four-point bend specimens, slab 2, axial orientation, midlength-center location .................... 107

39. Cumulative distribution curve for strength of small-sized tensile specimens, slab 2, radial orientation, midlengthedge location . . . . . . . . . . . . . . . . 108

40. Cumulative distribution curve for strength of large-sized tensile specimens, slab 2, radial orientation, midlengthedge location . . . . . . . . . . . . . . . . . 109

41. Cumulative distribution curve for strength of four-point bend specimens, slab 2, radial orientation, midlength-edge location . . . . . . . . . . . . ...... 110

42. Cumulative distribution curve for strength of small-sized tensile specimens, slab 2, radial orientation, midlengthcenter location . . . . . . . . . . . . . . . . . . 111

43. Cumulative distribution curve for strength of large-sized tensile specimens, slab 2, radial orientation, midlengthcenter location . . . . . . . . . . . . . . . . . 112

44. Cumulative distribution curve for strength of four-point bend specimens, slab 2, radial orientation, midlengthcenter location ...................... 113

45. Cumulative distribution curve for strength of small-sized tensile specimens, slab 3 , axial orientation, midlengthedge location . . . . . . . . . . . . . . . . . 114

46. Cumulative distribution curve for strength of large-sized tensile specimens, slab 3 , axial orientation, midlengthedge location . . . . . . . . . . . . . . . . . . 115

47. Cumulative distribution curve for strength of four-point bend specimens, slab 3, axial orientation, midlengthedge location . . . . . . . . . . . . . . . . . 116

48. Cumulative distribution curve for strength of small-sized tensile specimens, slab 3 , axial orientation, midlengthcenter location . . . . . . . . . . . . . . . 117 
FIGURES (Continued)

49. Cumulative distribution curve for strength of large-sized tensile specimens, slab 3, axial orientation, midlengthcenter location . . . . . . . . . . . . . . . . 118

50. Cumulative distribution curve for strength of four-point bend specimens, slab 3, axial orientation, midlength-center location . . . . . . . . . . . . . . . . . . . 119

51. Cumulative distribution curve for strength of small-sized tensile specimens, slab 3 , radial orientation, midlengthedge location .. . . . . . . . . . . . . . 12

52. Cumulative distribution curve for strength of large-sized tensile specimens, slab 3 , radial orientation, midlengthedge location .. . . . . . . . . . . . . . . 121

53. Cumulative distribution curve for strength of four-point bend specimens, slab 3 , radial orientation, midlength-edge location . . . . . . . . . . . . . . . . . . 122

54. Cumulative distribution curve for strength of small-sized tensile specimens, slab 3, radial orientation, midlengthcenter location . . . . . . . . . . . . . . . . . 123

55. Cumulative distribution curve for strength of large-sized tensile specimens, slab 3, radial orientation, midlengthcenter location . . . . . . . . . . . . . . . . . . 124

56. Cumulative distribution curve for strength of four-point bend specimens, slab 3, radial orientation, midlength-

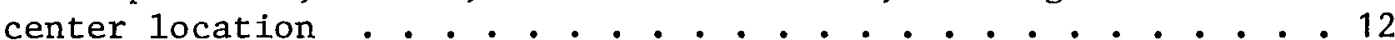

57. Cumulative distribution curve for strength of sma11-sized tensile specimens, slab 4, axial orientation, end-edge location................... . 126

58. Cumulative distribution curve for strength of large-sized tensile specimens, slab 4, axial orientation, end-edge location . . . . . . . . . . . . . . . . . 127

59. Cumulative distribution curve for strength of four-point bend specimens, slab 4, axial orientation, end-edge location . . 128

60. Cumulative distribution curve for strength of small-sized tensile specimens, slab 4, axial orientation, end-center

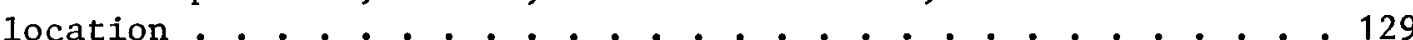

61. Cumulative distribution curve for strength of large-sized tensile specimens, slab 4, axial orientation, end-center location . . . . . . . . . . . . . . . . 130

62. Cumulative distribution curve for strength of four-point bend specimens, slab 4, axial orientation, end-center

location . . . . . . . . . . . . . . . . . . 131 
FIGURES (Continued)

63. Cumulative distribution curve for strength of small-sized tensile specimens, slab 4, radial orientation, end-edge location . . . . . . . . . . . . . . . . . 132

64. Cumulative distribution curve for strength of large-sized tensile specimens, slab 4, radial orientation, end-edge location . . . . . . . . . . . . . . . . . . 133

65. Cumulative distribution curve for strength of four-point bend specimens, slab 4, radial orientation, end-edge location . . . . . . . . . . . . . . . . . . 134

66. Cumulative distribution curve for strength of sma11-sized tensile specimens, slab 4, radial orientation, end-center location . . . . . . . . . . . . .... . 135

67. Cumulative distribution curve for strength of large-sized tensile specimens, slab 4, radial orientation, end-center location . . . . . . . . . . . . . . . . . 136

68. Cumulative distribution curve for strength of four-point bend specimens, slab 4, radial orientation, end-center location. . . . . . . . . . . . . . . . . . 137

69. Correlation between strength of flexural specimens and sma11 (6.4 mm diameter) tensile specimens . . . . . . . . 138

70. Correlation between strength of flexural specimens and large (12.8 mm diameter) tensile specimens . . . . . . . 139 


\section{INTRODUCTION}

Mechanical design of the graphite moderator and reflector blocks of a high-temperature gas-cooled nuclear reactor (HTGR) requires a detailed knowledge of the statistical distribution of tensile and bend strength within a graphite log. Factors which must be defined include:

1. The systematic variation of strength with orientation and location throughout the $\log$.

2. For a given orientation and location, the statistical distribution of strengths and the mean, standard deviation, coefficient of variation, and Weibull modulus which characterize the population.

3. The dependence of strength on specimen size.

4. The relationship between flexural strength and tensile strength.

An additional factor to be determined is the validity cf the Weibull statistical theory (Ref. 1) for the type of graphite to be used. The Weibull theory, in which the strength of a brittle solid is assumed to be controlled by flaws, has potential uses in the engineering design of loadbearing structures made from brittle materials because it relates the probability of failure to the volume of material under load, the stress gradient, and multiaxial stress states. It can be combined with finite element stress analysis to predict the probability of failure as a function of position in components under complex stress states. These features of the Weibull model have led to its use in the design of ceramic aerospace (Ref. 2) and gas turbine (Ref. 3) components. However, previous studies of the strength of a coarse-grained needle-coke-based nuclear graphite (Great Lakes Carbon Corporation grade H-327) (Ref. 4) and near-isotropic 
Gilsocarbon-based graphites (Ref. 5) showed that while the ratios relating the strength of flexural specimens and internally pressurized tubes to the tensile strength were correctly predicted by the Weibull model, the dependence of strength on specimen volume was overestimated.

In the present study a single log of extruded near-isotropic petroleumcoke-based nuclear graphite (Great Lakes Carbon Corporation grade H-451) was cut into sections. Tensile specimens of two sizes and flexural specimens were taken in both axial and radial orientations from locations covering most of the log. More than 2000 specimens were tested to failure at ambient temperature. The dependence of strength on orientation, log location, specimen size, and type of test was determined and the results were compared with predictions of the Weibull model. 


\section{EXPERIMENTAL METHODS}

A11 specimens were taken from the same log of Great Lakes Carbon Corporation H-451 graphite (GLCC lot No. 408, piece No. 48, GA log No. 5651-90). Four 127-mm (5-in.) deep slabs were cut transverse to the axis. Two slabs ( 1 and 4) were located within $25 \mathrm{~mm}$ ( 1 in.) of the two ends of the $\log$, and two slabs (2 and 3 ) were located adjacent to the midlength plane of the log. The locations of the slabs are shown shaded in Fig. 1. Each slab was cut into a center section (C) and an edge section (E) on a radius of $108 \mathrm{~mm}$ ( $4.25 \mathrm{in.)}$.

Cylindrical cores for test specimens were core drilled in axial and radial orientations from the central zone and the edge zone of each slab according to the plan shown in Figs. 2 and 3 . Large tensile specimens [right cylinders $12.8 \mathrm{~mm}$ (0.505 in.) diameter by $76 \mathrm{~mm}$ ( 3 in.) 1ong], small tensile specimens $[6.4 \mathrm{~mm}(0.25 \mathrm{in.})$ diameter by $23 \mathrm{~mm}(0.9 \mathrm{in.})$ long], and flexural specimens [6.4 mm (0.25 in.) diameter by $51 \mathrm{~mm}$ (2 in.) long] were machined from the cores. Identification was retained throughout by use of the slab number (Fig. 1), followed by the core number (Figs. 2 and 3). This sampling plan gave approximately equal numbers of the three types of specimens, with each type spread uniformly over the sampling zone.

The tensile specimens were cemented between aluminum end pieces with epoxy cement, using V-block jigs to ensure axial alignment. The specimens were tested to failure in an Instron tensile testing machine, using rollerlink chains to apply the load to the specimen end pieces. Stress-strain curves were measured on four representative $12.8-\mathrm{mm}$-diameter specimens out of each batch using a 51-mm (2-in.) gauge-length extensometer; on the remainder of the specimens only the failure load was measured. 
The flexural specimens were tested in four-point bending with the loading points equally spaced $12.7 \mathrm{~mm}$ ( $0.5 \mathrm{in.})$ apart. The modulus of rupture was calculated from the failure load using simple beam theory. Because of nonlinear elastic behavior, the modulus of rupture overestimates the outer fiber stress at failure and a correction needs to be applied. The graphite stress-strain curve is fairly well represented by the expression (Ref. 6):

$$
\sigma=E \varepsilon_{0}\left[1-\exp \left(-\frac{\varepsilon}{\varepsilon_{0}}\right)\right]
$$

where $\sigma$ is the stress, $E$ is the slope of the stress-strain curve at zero strain, $\varepsilon$ is the strain, and $\varepsilon_{o}$ is a constant for a given type of graphite which characterizes the curvature of the stress-strain curve. If Eq. 1 is used in place of Hooke's Law to calculate the relationship between bending moment and outer fiber strain in a beam, the following relationships are obtained between the modulus of rupture, MOR (bend strength calculated assuming elastic behavior) and the true outer fiber strain at fracture, $\varepsilon_{\mathrm{f}}:$

Rectangular cross-section beam:

$$
\text { MOR }=E \varepsilon_{o}\left\{1.5-\frac{3 \varepsilon_{o}^{2}}{\varepsilon_{f}^{2}}\left[1-\left(1+\frac{\varepsilon_{f}}{\varepsilon_{o}}\right) \exp \left(-\frac{\varepsilon_{f}}{\varepsilon_{o}}\right)\right]\right\}
$$

Cylindrical beam:

$$
\begin{aligned}
\text { MOR } & =E \varepsilon_{f}\left[1-0.340\left(\frac{\varepsilon_{f}}{\varepsilon_{o}}\right)+8.33 \times 10^{-2}\left(\frac{\varepsilon_{f}}{\varepsilon_{o}}\right)^{2}\right. \\
& \left.-1.62 \times 10^{-2}\left(\frac{\varepsilon_{f}}{\varepsilon_{o}}\right)^{3}+2.60 \times 10^{-3}\left(\frac{\varepsilon_{f}}{\varepsilon_{o}}\right)^{4}\right]
\end{aligned}
$$


Correction factors to be applied to convert the conventionally calculated modulus of rupture to the true outer fiber stress at fracture are plotted in Fig. 4 for a graphite with $\varepsilon_{0}=0.004$. This value of $\varepsilon_{0}$ is an average obtained from stress-strain curves on both axial and radial specimens. 


\section{RESULTS}

\section{1. DATA TABULATION}

The results of the tests are listed in Tables 1 through 48. Tables 1 through 12 contain data from slab 1; Tables 13 through 24 data from slab 2; Tables 25 through 36 data from slab 3; and Tables 37 through 48 data from slab 4. The density of most specimens was calculated from the weight and dimensions and is included in the tables. Young's modulus was obtained on some specimens by loading to $7 \mathrm{MPa}$ (1000 psi), unloading to $0.7 \mathrm{MPa}$ (100 psi), and reloading to fallure. The modulus was calculated from the $0.7 \mathrm{MPa}$ to $7 \mathrm{MPa}$ reloading curve. The tables of flexural test data include both the modulus of rupture and the flexural strength corrected for nonlinearity of the stress-strain curve. A gap in a table indicates a specimen lost or broken during handling.

The test data from slabs 1, 2, 3, and 4 are summarized in Tables 49 through 52. The data summaries include the number of specimens in a group, the mean strength and standard deviation, the coefficient of variation (standard deviation divided by the mean), and the Weibull modulus. Derivation of the Weibull modulus is described in Section 3.3.

\subsection{DEPENDENCE OF STRENGTH ON ORIENTATION AND LOCATION}

The mean strengths listed in Tables 49 through 52 show the expected dependence on orientation. In all specimen groups but one, the axial specimens were stronger than the radial specimens (confidence levels greater than 99\%). The exception was the central zone of slab 4, where the difference between axial strength and radial strength was not significant (Table 52). The ratio between axial and radial tensile strengths averaged 1.19; the ratio between axial and radial flexural strengths 
averaged 1.13. In all tensile specimen groups except the axial specimens from slab 1, material from the edge zone was stronger than that from the central zone (confidence levels greater than 99\%). The strength difference between edge and center axial tensile specimens from slab 1 was not statistically significant. The average ratio between the edge tensile strength and center tensile strength was 1.16 ; for flexural strength the average ratio was 1.07 .

These systematic differences between axial and radial strength, and between edge and center strength, are common in extruded graphite logs and result from the alignment of coke particles during extrusion and the distribution of impregnant carbon following the impregnation process.

Strength variations along the length of the $\log$ were less systematic. With the exception of axial specimens from the central zone there was a progressive increase in strength in passing from slab 1 to slab 4 . Among axial specimens from the center zone the trend was reversed, with the strength decreasing in passing from slab 1 to slab 4 (all confidence levels greater than 99\%). Thus, the degree of orientation (axial strength divided by radial strength) was lowest in the center of slab 4 .

When the strengths of individual specimens were correlated with their locations in the $1 \mathrm{og}$, further local variations became evident in some regions. These local variations in strength, together with local variations in density, are illustrated in Figs. 5 through 20. Maps showing the locations of individual specimens are shown in Figs. 5 through 8 for slab 1 , Figs. 9 through 12 for slab 2, Figs. 13 through 16 for slab 3, and Figs. 17 through 20 for slab 4. The large circles in the figures represent the cores which were machined into 12.8-mm-diameter tensile specimens. The small circles mark the cores for the 6.4-mm-diameter tensile specimens and bend specimens and are divided horizontally into halves; the halves closest to the center of the figure represent the bend specimens and the outer halves represent the small tensile specimens. Open circles or semicircles indicate specimens whose strength or density is lower than half a standard 
deviation below the mean for their slab, zone, orientation, and specimen type; half-filled circles or semicircles indicate about average strength or density (within half a standard deviation); and completely filled circles show specimens with high strength or density.

The presence of local variations is evident from the figures. For example, in the edge zone of slab 1 (Fig. 6) the radial specimens from the upper left hand quadrant tended to be weaker than average, while the axial specimens from the lowest quadrant tended to be strong. Analysis of variance confirmed that the quadrant-to-quadrant variations were statistically significant. The corresponding map of densities (Fig. 5) showed a similar trend in density for the same two specimen groups. The tendency for axial specimens from the lowest quadrant of the edge zones to be stronger than average was evident in all four slabs (Figs. 6, 10, 14, and 18), indicating that a band of higher strength material ran through the length of the log. This suggests that one cause of local variations is inhomogeneity in the mix charged to the extrusion press during fabrication.

In some, but not all cases, the local variations in strength were correlated with variations in density. Such variations can be caused either by inhomogeneity in the mix or by nonuniform impregnation.

\subsection{STATISTICAL DISTRIBUTION OF STRENGTHS}

The standard deviation and coefficient of variation for each group of specimens are included in Tables 49 through 52. In most cases the differences between the standard deviations of different specimen groups are not statistically significant. However, when the coefficients of variation are compared, some trends are apparent. For most groups of radial specimens the coefficients of variation were higher than those of comparable axial specimens, and in most cases the differences are significant at the $95 \%$ confidence level. The mean values for the coefficients of variation are summarized in Table 53. Coefficients of variation for the flexural strengths were consisently lower than for the tensile strengths; these differences are significant at the $95 \%$ or $99 \%$ confidence leve1 in the majority of cases. 
Weibull's model for the strength of brittle materials (Ref. 1) gives the following expression for the probability of survival, $S$, under a tensile stress:

$$
S=\exp \left[-\mathcal{L}_{\mathrm{v}}\left(\frac{\sigma-\sigma_{\mathrm{u}}}{\sigma_{0}}\right)^{\mathrm{m}} \mathrm{dV}\right],
$$

where $\sigma$ is the tensile stress in an element of volume $d V, \sigma_{u}$ is a stress below which the failure probability is zero $\left(\sigma_{u}\right.$ is normally taken as zero for graphite), $\sigma_{0}$ is the scale factor for the distribution function, and $\mathrm{m}$ is the shape factor for the distribution and is known as the Weibull modulus. When $\sigma_{\mathrm{u}}$ is zero and the specinen is under uniform tension, Eq. 4 can be linearized:

$$
\ln \ln \left(\frac{1}{s}\right)=\ln v-m \ln \sigma_{0}+m \ln \sigma
$$

Equation 5 was used to estimate $m$ values for each set of strength data by means of a least-squares linear regression analysis of $\ln \ln$ (1/S) versus In $\sigma$. The results are included in Tables 49 through 53. According to the Weibull model, a series of bend tests should yield the same value of $\mathrm{m}$ as a series of tensile tests on the same material. However, the observed $\mathrm{m}$ values were consistently higher for the bend tests than for the tensile tests (Tables 49 through 53), which does not agree with the Weibull model.

Cumulative distribution curves showing the probability of survival versus the normalized fracture stress for each group of data are shown in Figs. 21 through 68. The strength data were normalized by dividing by the median strength and were plotted on probability paper. When plotted in this way, data conforming to a normal. (Gaussian) distribution function would fall on a straight line. Data following a Weibull distribution function would fall on a convex-downward curve whose curvature depends on the value of $\mathrm{m}$. Figures 21 through 68 include best-fit lines for both a Gaussian and a Weibull distribution. Because of the form of Eq. 5, the 
low strength data points are more heavily weighted than the high strength data in the fitting of the Weibull function. Taken as a whole, the data showed no preferential tendency to conform more closely to one distribution than to the other. Within the experimental scatter, the results could be represented equally well by a Gaussian or a Weibull distribution.

\subsection{DEPENDENCE OF STRENGTH ON SPECIMEN SIZE}

The ratios between the mean tensile strength of small-sized specimens and large-sized specimens from the same location and orientation are included in Tables 49 through 52. The mean ratio was 1.03 for the axial orientation and 1.08 for the radial orientation.

The Weibull model predicts that the strength, $S_{1}$, of tensile specimens with volume $v_{1}$ is related to the strength, $s_{2}$, of specimens with volume $v_{2}$ by the relationship (Ref. 4):

$$
\frac{s_{1}}{s_{2}}=\left(\frac{v_{2}}{v_{1}}\right)^{\frac{1}{m}}
$$

assuming that $\sigma_{\mathrm{u}}$ is zero. In the present case $\mathrm{V}_{1}$ and $\mathrm{V}_{2}$ are $724 \mathrm{~mm}^{3}$ and $9847 \mathrm{~mm}^{3}$, respectively. Using the mean m values from Table 53, Eq. 6 predicts a strength ratio of 1.28 for the axial orientation and 1.38 for the radial orientation. It is evident that the Weibull model grossly overestimates the volume dependence of the strength of $\mathrm{H}-451$ graphite.

\subsection{RELATIONSHIP BETWEEN FLEXURAL STRENGTH AND TENSILE STRENGTH}

The ratios between the four-point flexural strength (corrected for the nonlinear stress-strain relationship) and the tensile strength of companion 6.4-mm-diameter specimens are listed in Tables 49 through 52 . The mean values are 1.52 for axial specimens and 1.55 for radial specimens. Weibull theory predicts (Ref. 4) the following relationships between the four-point bend strength, $S_{B}$, of cylindrical specimens where the volume between each 
of the support points is $\mathrm{V}_{\mathrm{B}}$ and the tensile strength, $\mathrm{S}_{\mathrm{T}}$, of companion specimens of volume $\mathrm{V}_{\mathrm{T}}$ :

$$
\begin{aligned}
& \frac{S_{B}}{S_{T}}=\left[\frac{2 \times 4 \times 6 \cdots(m+2)}{1 \times 3 \times 5 \cdots(m-1)}\right]^{\frac{1}{m}}\left[\frac{V_{T}(m+1)}{V_{B}(m+3)}\right]^{\frac{1}{m}} \\
& \text { (nn an even integer) }
\end{aligned}
$$

and

$$
\frac{S_{B}}{S_{T}}=\left[\frac{1 \times 3 \times 5 \cdots(m+2)}{2 \times 4 \times 6 \cdots(m-1)} \times \frac{\pi}{2}\right]^{\frac{1}{m}}\left[\frac{V_{T}(m+1)}{V_{B}(m+3)}\right]^{\frac{1}{m}}
$$

(m an odd integer)

Values for the first term in Eq. $7 \mathrm{a}$ and $\mathrm{Eq}$. $7 \mathrm{~b}$ are given in Ref. 4. Using the values $724 \mathrm{~mm}^{3}$ and $402 \mathrm{~mm}^{3}$ for $V_{T}$ and $V_{B}$, respectively, and taking $\mathrm{m}$ values from Table 53, Eq. 6 predicts bend strength to tensile strength ratios of 1.51 for axial specimens and 1.64 for radial specimens. These values are in good agreement with the observed ratios of 1.52 and 1.55 for the axial and radial orientations.

The mean four-point bend strength (corrected for the nonlinear stressstrain relationship) is plotted against the mean tensile strength of companion 6.4-mm-diameter tensile specimens in Fig. 69. Each datum point represents the mean strength for one orientation, slab, and zone (center or edge). The bend and tensile strengths correlate well. A least-squares linear regression analysis gives the following relation between the bend strength, $S_{B}$, and the tensile strength, $S_{T}(M P a)$ :

$$
\mathrm{S}_{\mathrm{B}}=9.47+0.886 \mathrm{~S}_{\mathrm{T}}(6.4-\mathrm{mm}-\mathrm{d} \text { iameter tensile specimens }) \text {. }
$$

The correlation coefficient was 0.88. A similar plot of bend strength versus the tensile strength of $12.8-\mathrm{mm}$-diameter tensile specimens is 
shown in Fig. 70. The least-squares linear relationship between bend strength and tensile strength in this case is:

$$
\mathrm{S}_{\mathrm{B}}=11.18+0.808 \mathrm{~S}_{\mathrm{T}}(12.8-\mathrm{mm} \text {-diameter tensile specimens), }
$$

with a correlation coefficient of 0.92 . 


\section{SUMMARY AND CONCLUSIONS}

More than 2000 tensile and four-point bend tests were made at ambient temperature on specimens from one $10 \mathrm{~g}$ of extruded near-isotropic petroleumcoke-based nuclear graphite (Great Lakes Carbon Corporation grade H-451). The following conclusions were drawn:

1. Axial specimens averaged $19 \%$ stronger than radial specimens when tested in tension. In bending axial specimens averaged $13 \%$ stronger than radial specimens.

2. Specimens taken near the edge of the $\log$ averaged $16 \%$ stronger than those from near the centerline when tested in tension, and $7 \%$ stronger when tested in bending.

3. In addition to these expected and systematic strength variations, additional local fluctuations in strength were found. In some cases they corresponded to local variations in density. These local variations were probably caused during fabrication by inhomogeneity in the mix charged to the extrusion press or by nonuniform impregnation.

4. The coefficient of variation for axial tensile strengths from the same zone in the parent $\log$ averaged $11.2 \%$, compared with $14.7 \%$ for radial tensile strengths. For bend strengths the coefficient of variation was lower than for tensile strengths, averaging $7.9 \%$ for the axial orientation and $9.0 \%$ for the radial orientation.

5. Cumulative strength distribution curves were plotted for each specimen group. Within experimental scatter the data were equally well represented by a normal (Gaussian) distribution 
or by the distribution predicted by the Weibull theory for the strength of brittle solids.

6. When fitted to the Weibull distribution, the value of the Weibull modulus, $m$, was lower for tensile tests (mean values of 10.7 for axial specimens and 8.1 for radial specimens) than for bend tests (mean values of 15.8 for axial specimens and 13.6 for radial specimens). Such a difference is contrary to predictions based on the Weibull model.

7. Tensile specimens of two sizes (volumes $9847 \mathrm{~mm}^{3}$ and $724 \mathrm{~mm}^{3}$ ) were tested. The small specimens averaged $3 \%$ stronger than the large specimens for the axial orientation, and $8 \%$ stronger for the radial orientation. The observed "size effect" was much lower than expected from the Weibull model, which would predict differences of $28 \%$ and $38 \%$ for the axial and radial directions, respectively.

8. The mean flexural strength showed good correlation with the mean tensile strength of companion specimens (correlation coefficient 0.9). Flexural strengths (corrected for the nonlinear stressstrain relationship of graphite) averaged $52 \%$ higher than the corresponding tensile strengths for the axial orientation, and $55 \%$ higher for the radial orientation. These values are in good agreement with the Weibull model (predicted values of $51 \%$ axial and $64 \%$ radial).

9. In spite of the agreement between the observed bend-to-tensile strength ratio and that predicted by the Weibull model, both the observed "size effect" and the difference in Weibull modulus between tensile tests and bend tests are inconsistent with the Weibull model. Thus, the graphite does not meet the criteria which would allow it to be treated as a Weibull solid. 
10. The variability in graphite strength must be considered in the mechanical design of graphite: components. The present work shows that a large part of the variability is attributable to local fluctuations over distances on the order of $100 \mathrm{~mm}$, which suggests that reductions in the scatter of strength data could result from improvements in the uniformity of the mixing and impregnation processes. 


\section{REFERENCES}

1. Weibull, W., "A Statistical Theory for the Strength of Materials," Hand. Ing. Vet. Akad. (Proc. Royal Swedish Institute for Engineering Research, Stockholm), Nr. 151 (1939).

2. Dukes, W. H., "Handbook of Brittle Material Design Technology," Advisory Group for Aerospace Research and Development Report AGARD-AG-152-71, 1966.

3. Paluszny, A., "Design with Brittle Materials," Mater. Sci. Eng. 15, 39 (1974).

4. Price, R. J., and H. R. W. Cobb, "Application of Weibull Statistical Theory to the Strength of Reactor Graphite," Proc. Conf. on Continuum Aspects of Graphite Design (CONF-701105), USAEC Technical Information Center, 1972, p. 547.

5. Brocklehurst, J. E., and M. I. Darby, "Concerning the Fracture of Graphite Under Different Test Conditions," Mater. Sci. Eng. 16, 91 (1974).

6. Woolley, R. L., "The Yield Curve and Compressive Strength of Polycrystalline Graphite," Phil. Mag. 11, 799 (1965). 
TABLE 1

STRENGTHS OF SMALL-SIZED TENSILE SPECIMENS, SLAB 1, AXIAL ORIENTATION, END-EDGE LOCATION

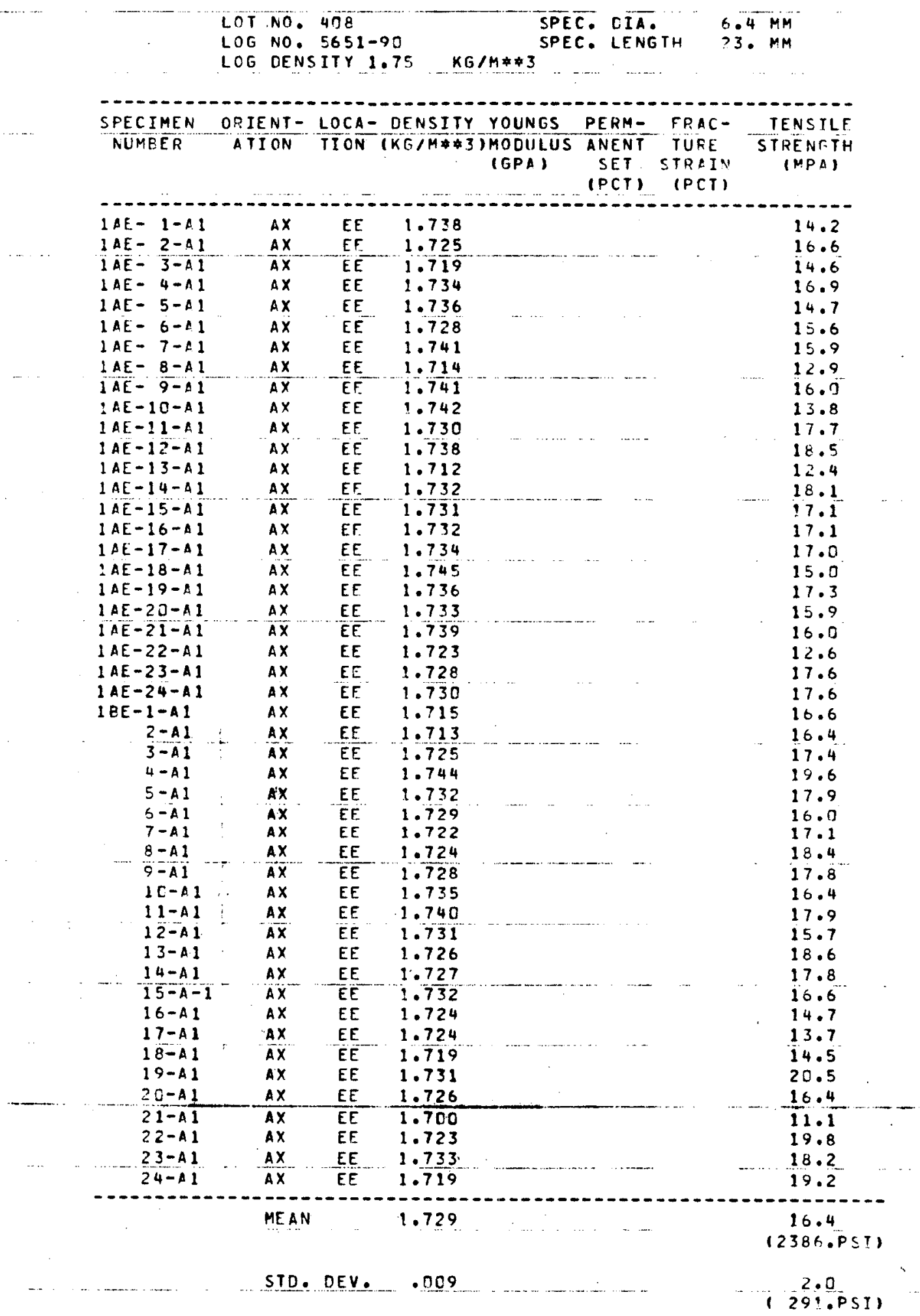


TABLE 2

STRENGTHS OF LARGE-SIZED TENSILE SPECIMENS, SLAB 1, AXIAL ORIENTATION, END-EDGE LOCATION

LOT NO. 458
LOG NO. $5651-93$
LOG OFNSITY $1.75 \quad K G / M * 3$

SPECIMEN ORIENT- LOCA- DFNSITY YOUNGS PERM- FRAC- TENSILE
NUMBER ATION TION (KGSM $\$ 3$ IMODULUS ANENT TURE STRENGTH
(GPA) SET STRAIN S (MPA)

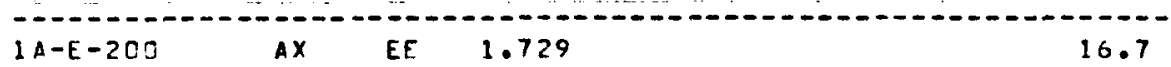

$1.731-9.6-0.012$

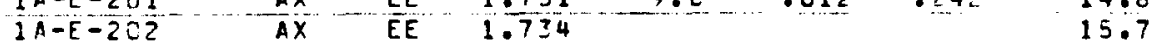

$1 A-E-2[3 \quad A X \quad E E \quad 1.729 \quad A X \quad E E \quad 1.731$

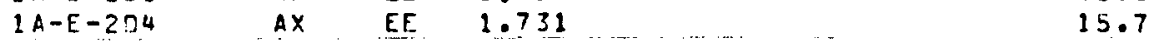

$1 A-E-2 C 5 \quad A X \quad E F \quad 1.734 \ldots \ldots$

$1 A-E-206 \quad A X \quad E E \quad 1.733 \quad 17.1$

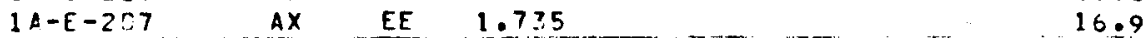

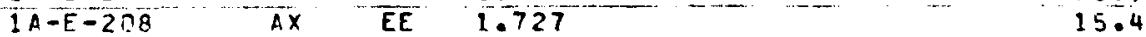

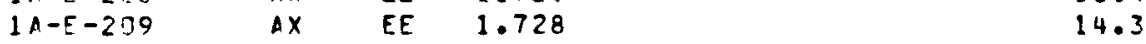

$1 A-E-210$ AX EE $1.734 \quad 18.0$

$\begin{array}{lllllll}1 A-E-211 & A X & E E & 1.736 & & \ldots & 16.4\end{array}$

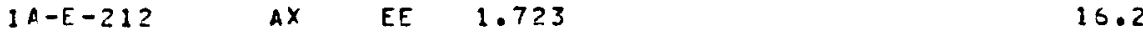

$1 A-E-213 \quad A X \quad E E \quad 1.722 \quad 16.6$

$1 A-E-214 \quad \frac{A X}{E E} \quad 1.718 \cdots 1.0$

$\begin{array}{llll}1 A-E-215 & A X & E E & 1.718\end{array}$

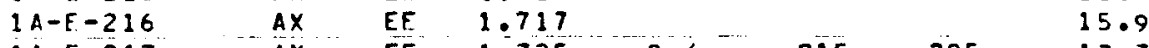

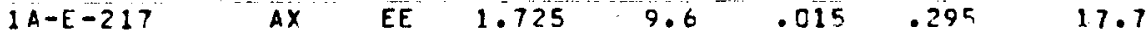

$\begin{array}{lllll}1 A-E-218 & A X & \text { EE } & 1.727 & 14.9\end{array}$

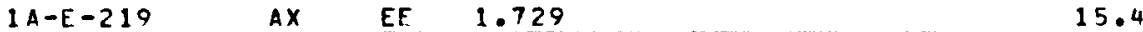

$1 A-E-220 \quad A X$ EE 1.7213

$\begin{array}{lllll}1 A-E-221 & A X & \mathrm{~A} & 1.730 & 13.5\end{array}$

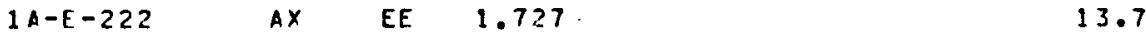

$\begin{array}{llllll}1 A-E-223 & A X & A E & 1.726 & \cdots & 13.3\end{array}$

$\begin{array}{lllll}1 B-E-200 & A X & \mathrm{AE} & 1.734 & 18.6\end{array}$

$1 B-E=201 \quad$ AX EE $1.735 \quad 10.1 \quad .011 \quad .307 \quad 19.2$

$\begin{array}{llll}1 B-E-232 & A X & \text { EE } 1.732 & 19.8\end{array}$

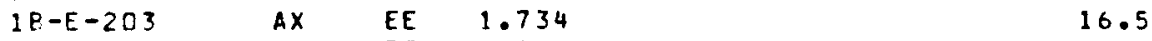

$1 B-E-204 \quad A X \quad E E \quad 1.730 \quad 17.9$

$1 E-E-205 \quad A X \quad E E \quad 1.7334 \cdots 18.1$

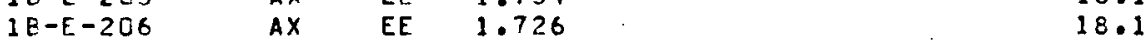

$1 E-E-207 \quad A X \quad$ EE $1.731 \quad 18.0$

$1 B-E-208-A X-\frac{A X}{A}-\frac{1728}{A X}-17.8$

$\begin{array}{lllll}1 B-E-209 & A X & E E & 1.729 & 17.4\end{array}$

$1 B-E-210 \quad \ldots X \quad E E \quad 1.722 \quad 17.1$

$\begin{array}{lllll}1 B-E-211 & A X & E E & 1.725 & 17.0 \\ 1 B-E-212 & A X & E E & 1.729 & 11.7\end{array}$

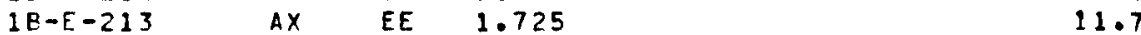

IE-E $-214 \quad$ AX EE $1.726 \quad 16.3$

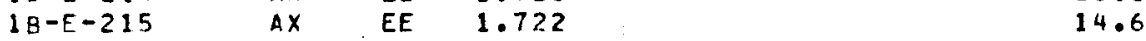

$\begin{array}{lllll}1 B-E-216 & A X & E E & 1.720 & 12.3\end{array}$

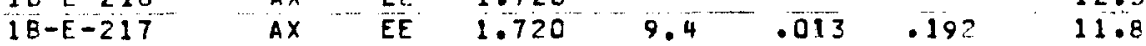

$\begin{array}{lllll}1 B-E-218 & A X & E E & 1.708 & 11.5\end{array}$

$18-E-219 \quad A X \quad E E \quad 1.720 \quad \ldots \quad-15.8$

$1 B-E-220-A X \quad \frac{1}{E E} \quad \frac{1.723}{1.73}-\frac{15}{15.7}$

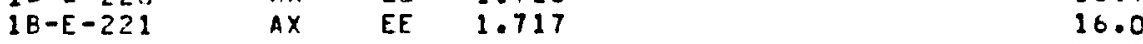

$1 B-E-222 \quad A X \quad E E \quad 1.714 \quad A X \quad E E-1.722$

$1 B-E-223 \quad A X \quad E E \quad 1.722-16.5$

-

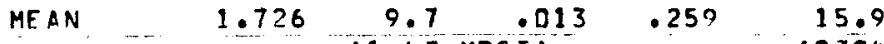

$(1.40$ MPSI $)(2304$ PPSI $)$

STO. OEV. ..006 $\quad .3 \quad .002 \quad .05 ? \quad .2 .2$

( $\frac{2 \cdot 2}{312 \cdot P S I)}$ 
TABLE 3

STRENGTHS OF FOUR-POINT BEND SPECIMENS, SLAB 1, AXIAL ORIENTATION, END-EDGE LOCATION

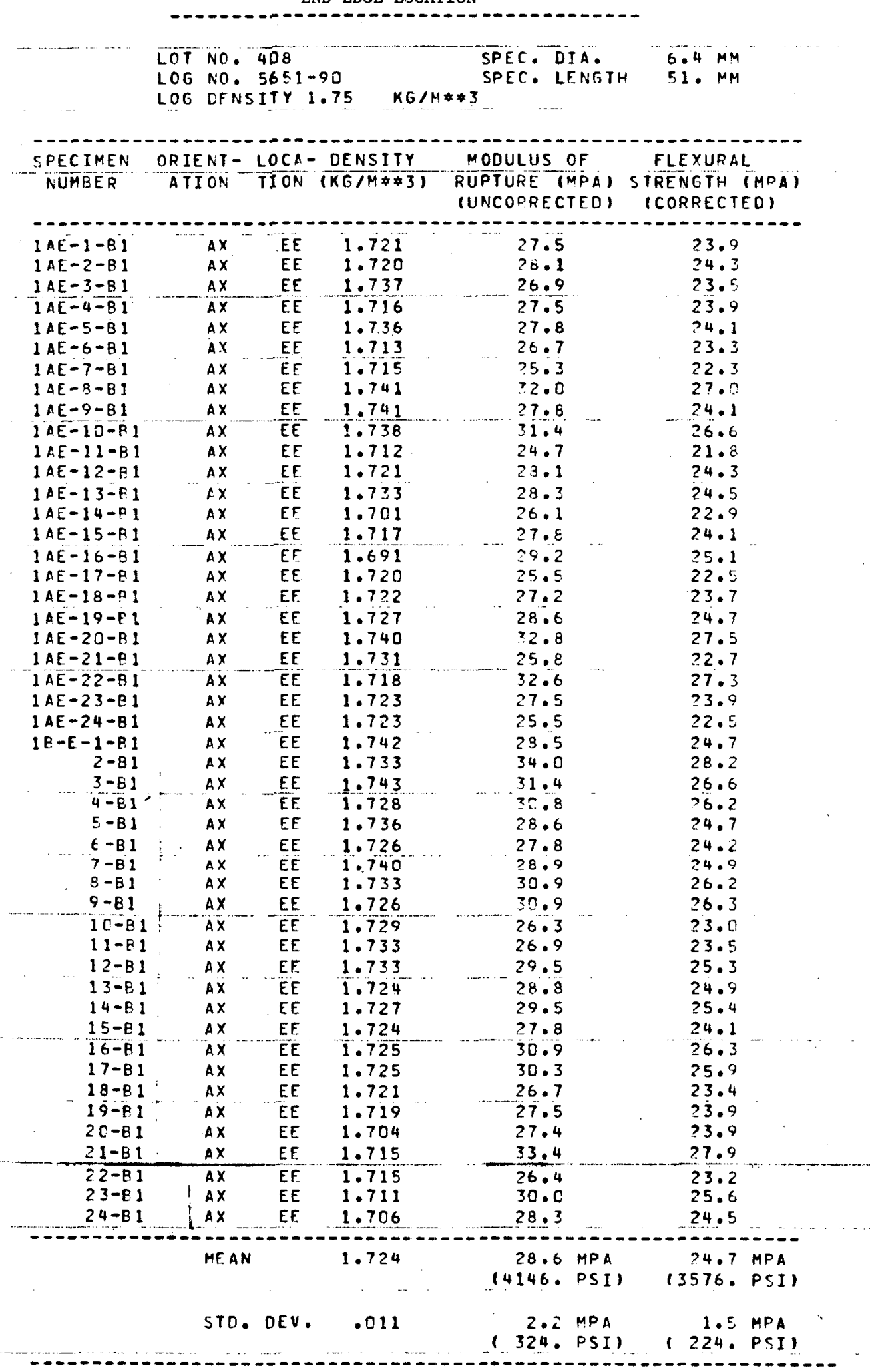


TABLE 4

STRENGTHS OF SMALL-SIZED TENSILE SPECIMENS, SLAB 1 , AXIAL ORIENTATION, END-CENTER LOCATION

$\begin{array}{lll}\text { LOT NO. } 408 & \text { SPEC. OIA. } & 6.4 \mathrm{MM} \\ \text { LOG NO. } 5651-9 . & \text { SPEC. LENCTH } & 23 . \mathrm{MM} \\ \text { LOG OENSITY } 1.75 & \text { KGIM \$3 }\end{array}$

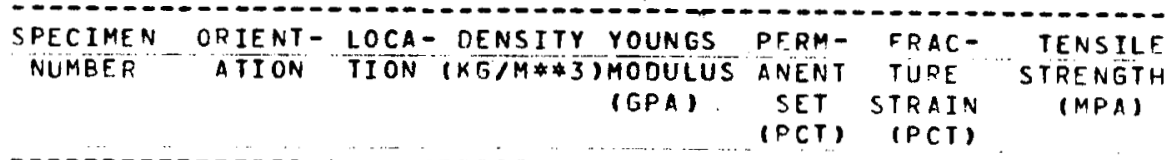

$\mid A-C-1 A 1$ AX $E C \quad 13.3$

$A \geq \quad A X \quad E C \quad A X \quad 17.8$

$\triangle A-C-2 A 1-A X \quad E C \quad 13.1$

$\begin{array}{cccc}A-C & A X & E C & 19.4 \\ 1 A-C-3-A 1 & A X & E C & 19.6\end{array}$

$\begin{array}{lll}1 A-C-4-A D & A X \quad E C & \end{array}$

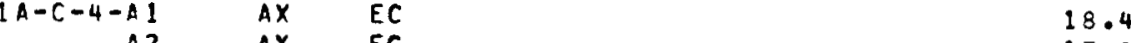

$\begin{array}{ll}1 A-C-5-A 1 & \frac{A X}{A X}-\frac{E C}{E C} \\ A X & 17.8 \\ 16.4\end{array}$

$\begin{array}{rlll}A 2 & A X & E C & 15.5\end{array}$

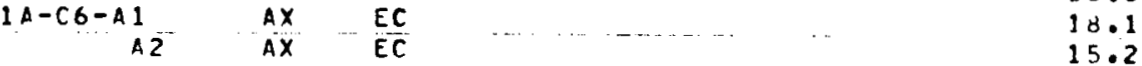

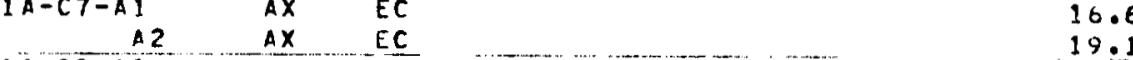

$1 A-C B-A 1 \quad-\frac{A X}{A X}-\frac{E C}{E C} \quad \cdots-\cdots$

$\begin{array}{rlll}1 A 2 & A X & E C & 19.5\end{array}$

$1 A-C 9-A 1 \quad A X \quad E C \quad \ldots X \quad \ldots \ldots$

$\begin{array}{cll}1 A-C 1 D-A 1 & A X & E C \\ & A X & E C\end{array}$

$1 B-C-1-A 1 \quad \frac{A X}{A X}-\frac{E C}{E C}-1.754$

$1-A 2 \quad A X \quad$ EC 1.760

2-A1 AX EC 1.753

$2-A 2 \quad A X \quad E C \quad 1.751$

3-A1 AX EC 1.742

3-A2 AX EC 1.759

4-A1 AX EC 1.760

4-A2 AX EC 1.754

5-A1 AX EC $\quad 1.756$

5-AZ AX EC 1.748

6-A1 AX EC 1.752

$6-A 2 \quad A X \quad E C \quad 1.751$

7-A1 AX EC 1.762

7-A2 AX EC 1.749

8-A1 AX EC 1.750

8-A2 AX EC 1.755

9-A1 AX EC 1.755

9-A2 AX EC 1.751

$10-A 1$ AX EC 1.752

10-A2 AX EC 1.756

16.4

16.9

10.8

$14 \cdot 3$

14.7

16.9

17.1

17.6

17.8

13.8

15.7

12.9

12.2

18.4

14.3

11.8

14.7

16.9

20.8

14.5

12.6

16.6

17.6

MEAN 1.754

15.9

(2299.FSI)

STD. DEV. .0O5 
TABLE 5

STRENGTHS OF LARGE-SIZED TENSILE SPECIMENS, SLAB 1, AXIAL ORIENTATION, END-CENTER LOCATION

$\begin{array}{lll}\text { LOT NO. } 408 & \text { SPEC. DIA. } & 12 . \overline{8} M M \\ \text { LOG NO. } 5651-90 & \text { SPEC. LENGTH } 76 . \mathrm{MM} \\ \text { LOG DENSITY } 1.75 & \text { KG/M*3 }\end{array}$

\begin{tabular}{|c|c|c|c|c|c|c|c|c|}
\hline $\begin{array}{l}\text { SPECIMEN } \\
\text { NUMBER }\end{array}$ & $\begin{array}{l}\text { ORIENT - } \\
\text { ATION }\end{array}$ & $\begin{array}{l}\text { LOCA } \\
\text { TION }\end{array}$ & $\frac{\text { DENSITY }}{(K G / M * 3)}$ & $\begin{array}{l}\text { YOUNGS } \\
\text { IMODULUS } \\
\text { (GPA) }\end{array}$ & $\begin{array}{l}\text { PERM- } \\
\text { ANENT } \\
\text { SET } \\
\text { (PCT) }\end{array}$ & $\begin{array}{l}\text { FRAC- } \\
\text { TURE } \\
\text { STRAIN } \\
\text { (PCT) }\end{array}$ & $\begin{array}{c}\text { TENSILE } \\
\text { STRENGTH } \\
\text { (MPA) }\end{array}$ & \\
\hline---- & - & & $-\infty$ & & ---- & $-\cdots-$ & $----\infty---0$ & \\
\hline $1 A-C-200$ & $A x$ & $E C$ & 1.729 & & & & 17.9 & \\
\hline $1 A-C-201$ & $A X$ & $E C$ & 1.729 & & & & $17 \cdot 1$ & \\
\hline $1 \mathrm{~A}-\mathrm{C}-20 ?$ & $A X$ & $E C$ & 1.731 & & & & 15.1 & \\
\hline $1 A-C-203$ & $A X$ & EC & 1.732 & 10.1 & .013 & .239 & 15.7 & \\
\hline $1 A-C-204$ & $A X$ & $E C$ & 1.723 & & 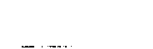 & & $15 \cdot 5$ & \\
\hline $1 A-C-205$ & $A X$ & EC & 1.727 & & & & 14.0 & \\
\hline $1 A-C-206$ & $\Delta x$ & EC & 1.725 & & & & 16.6 & \\
\hline $1 A-C-208$ & $\Delta x$ & EC & 1.719 & & & & 12.8 & \\
\hline $1 A-C-209$ & $A X$ & $E C$ & $1.7 \overline{25}$ & & & & 14.0 & \\
\hline $1 A-C-210$ & $A x$ & $E C$ & 1.725 & 10.0 & .010 & .203 & 14.2 & \\
\hline $1 A-C-211$ & $A x$ & EC & 1.728 & & & & 13.5 & \\
\hline $1 A-C-212$ & $\Delta X$ & $E C$ & 1.733 & & 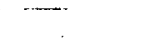 & & 14.2 & \\
\hline $1 A-C-213$ & $A x$ & $E C$ & 1.733 & & & & 15.7 & \\
\hline $1 A-C-214$ & $A x$ & EC & 1.733 & & & & 14.5 & \\
\hline $1 A-C-215$ & $A X$ & $E C$ & 1.730 & & & & 14.6 & \\
\hline $1 B-C-200$ & $A X$ & $E C$ & 1.723 & & & & 13.7 & \\
\hline $1 \mathrm{~B}-\mathrm{C}-201$ & $A X$ & $E C$ & 1.731 & & & & 15.7 & \\
\hline $1 B-C-202$ & $A X$ & EC & 1.737 & & & & 16.9 & \\
\hline $1 \mathrm{~B}-\mathrm{C}-2 \mathrm{C3}$ & $A X$ & $E C$ & 1.729 & 8.3 & .013 & $.28 ?$ & 16.8 & \\
\hline $1 \mathrm{~B}-\mathrm{C}-204$ & $A X$ & EC & 1.720 & & & & 13.1 & \\
\hline $1 B-C-205$ & $A \bar{X}$ & $E C$ & 1.730 & & & & 16.0 & \\
\hline $1 B-C-206$ & $A X$ & $E C$ & 1.731 & & & & 16.7 & \\
\hline $1 B-C-207$ & $A X$ & $E C$ & 1.735 & & 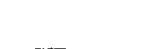 & & 17.3 & \\
\hline $1 B-C-208$ & $A X$ & $E C$ & 1.737 & & 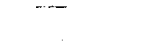 & & 16.3 & \\
\hline $1 B-C-209$ & $A X$ & $E C$ & 1.729 & & & & 14.9 & \\
\hline $1 B-C-210$ & $A X$ & $E C$ & 1.732 & $8 \cdot 5$ & .012 & .250 & 14.7 & - \\
\hline $1 \mathrm{~B}-\mathrm{C}-211$ & $\overline{A X}$ & EC & 1.729 & & & & 16.8 & \\
\hline $1 B-C-212$ & $A X$ & $E C$ & 1.730 & & & & 9.2 & \\
\hline $1 E-C-213$ & $A X$ & EC & 1.728 & & & & 17.5 & \\
\hline $1 B-C-214$ & $A X$ & EC & 1.726 & & & & 16.1 & \\
\hline $1 B-C-215$ & $A X$ & $E C$ & 1.730 & & & & 16.3 & \\
\hline & ME AN & & 1.729 & $\begin{array}{r}9.2 \\
11.34 \mathrm{MI}\end{array}$ & PSII & .244 & $\begin{array}{l}15.3 \\
12214.1\end{array}$ & PSII \\
\hline & STD. & DEV. & .004 & $\begin{array}{l}1.0 \\
1.14 \mathrm{MI}\end{array}$ & PSII & .033 & $\begin{array}{l}1.8 \\
1258.1\end{array}$ & PSII \\
\hline
\end{tabular}


TABLE 6

STRENGTHS OF FOUR-POINT BEND SPECIMENS, SLAB 1, AXIAL ORIENTATION, END-CENTER LOCATION

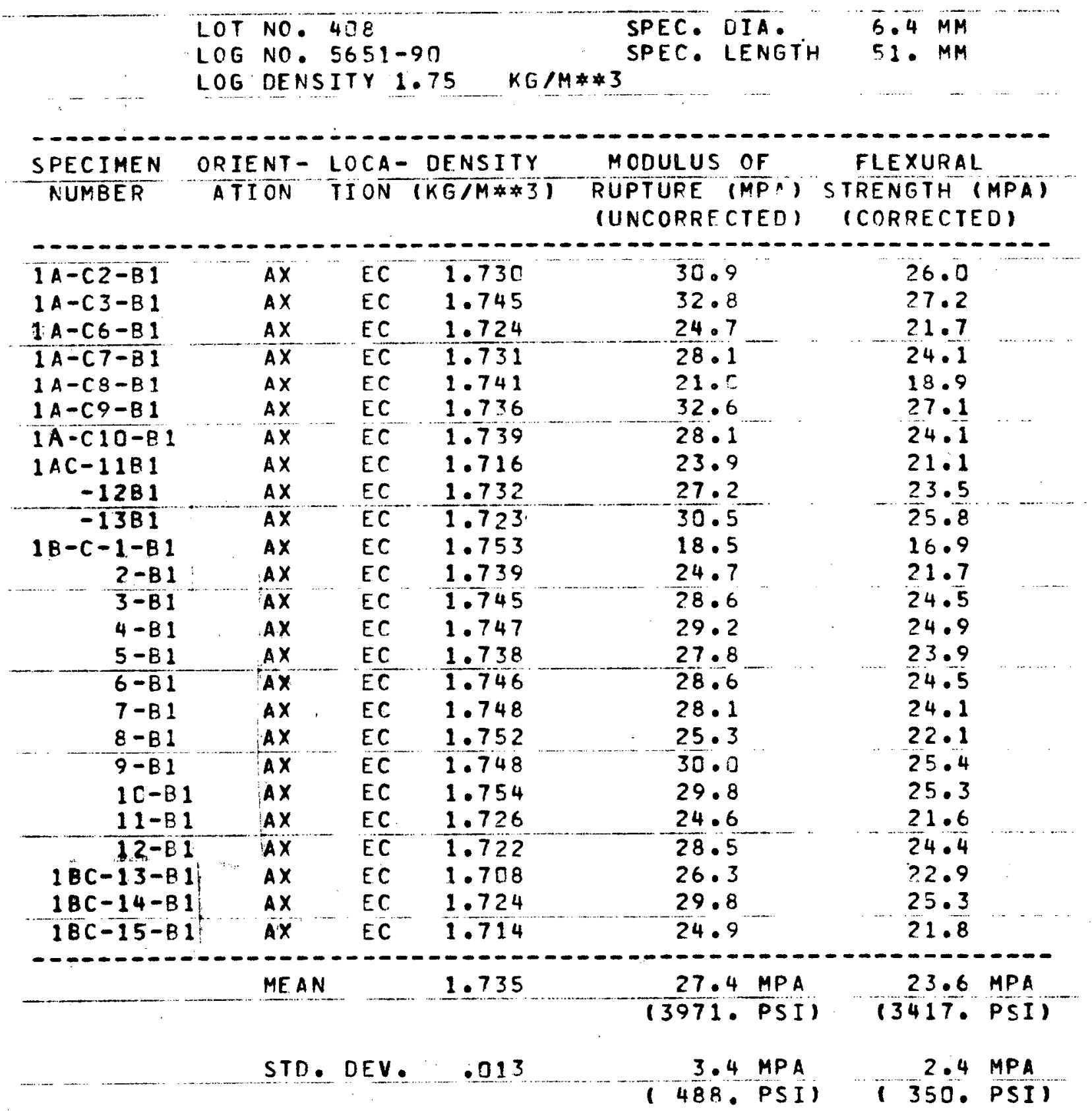


TABLE 7

STRENGTHS OF SMALL-SIZED TENSILE SPECIMENS, SLAB 1, RADIAL ORIENTATION, END-EDGE LOCATION

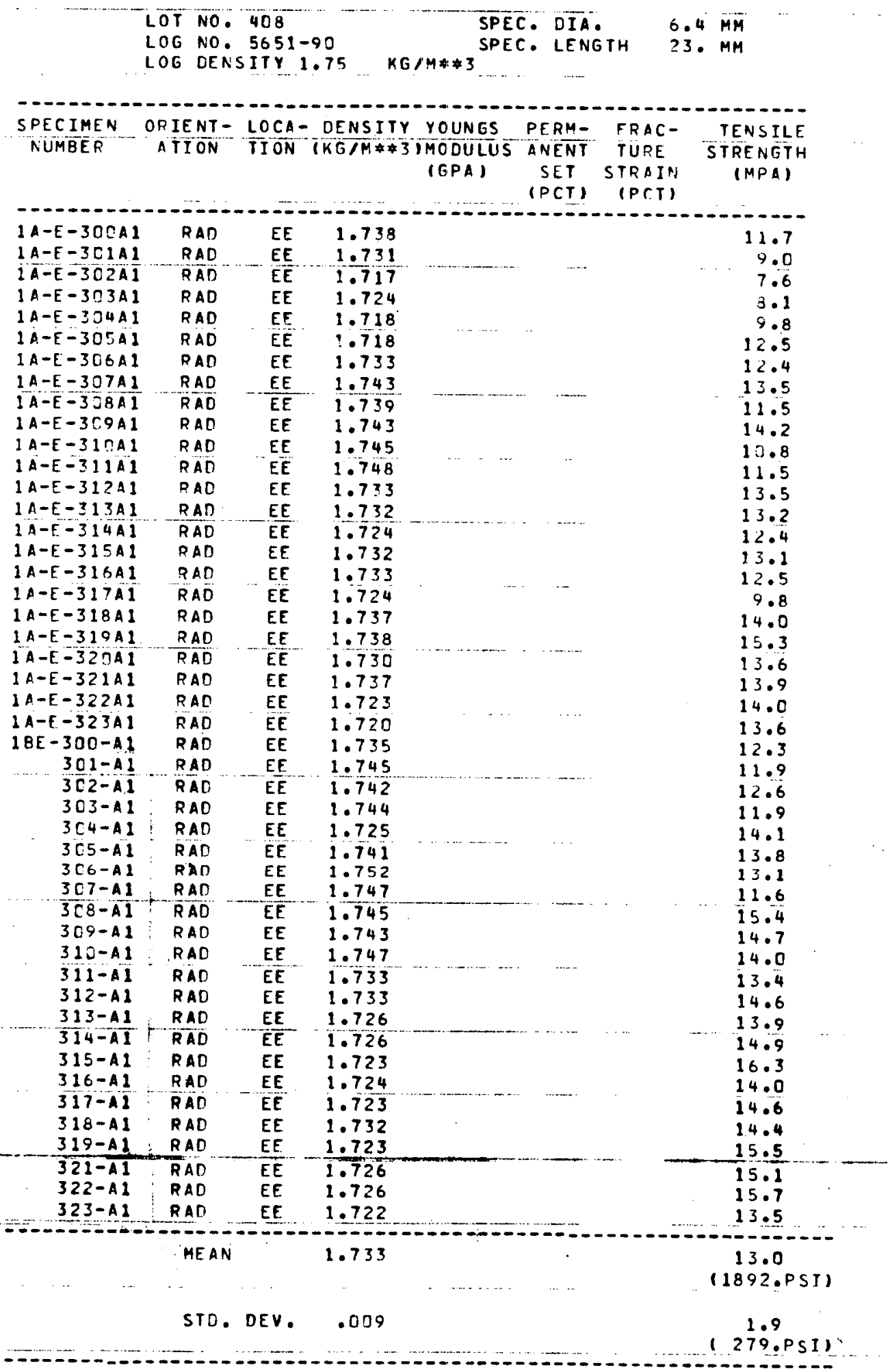


TABLE 8

STRENGTHS OF LARGE-SIZED TENSILE SPECIMENS, SLAB 1, RADIAL ORIENTATION, END-EDGE LOCATION

$\begin{array}{lll}\text { LOT NO. } 408 & \text { SPEC. OIA. } & 12.8 \mathrm{MM} \\ \text { LOG NO. } 5651-90 & \text { SPEC. LENGTH } & 7.6 . M M\end{array}$

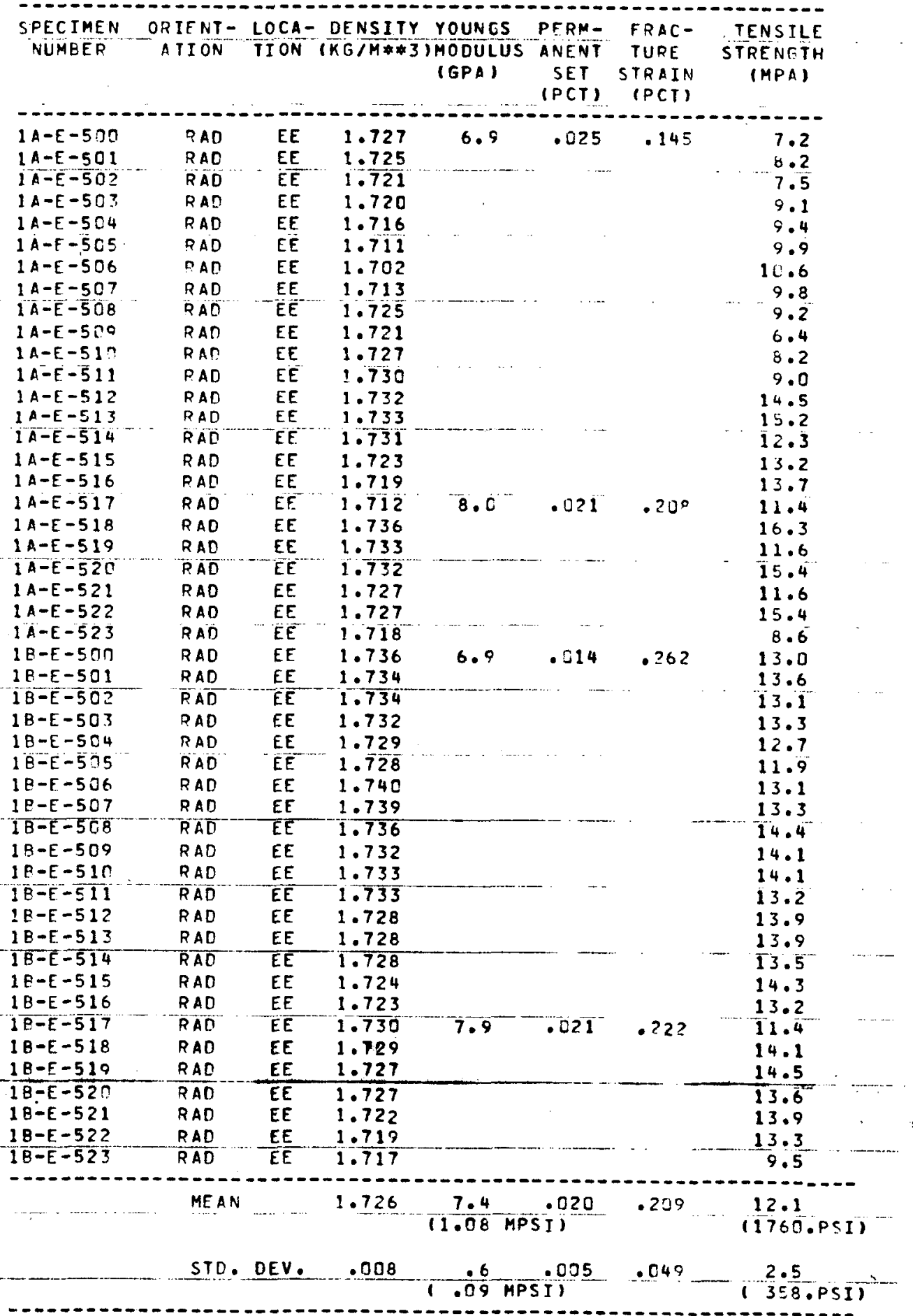


TABLE 9

STRENGTHS OF FOUR-POINT BEND SPECIMENS, SLAB 1, RADIAL ORIENTATION,

END-EDGE LOCATION

LOT NO: 478
LOG NOP $5651-90$
LOG DENSITY 1.75

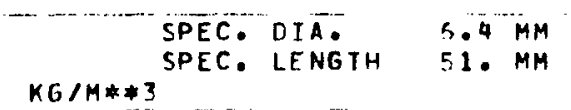

$K G / M * * 3$

SPECIMEN ORIENT- LOCA- OENSITY MODULUS OF FLEXURAL

NUMBER ATION IION (KG/M\#\#) RUPTURE (MPA) STRFNGTH (MEA) (UNCORRECTED) (CORRECTED)

$1 A-E-30 D B 1$ RAD EE $1.741 \quad 17.4 \quad 15.6$

$1 A-E-301 B 1$

$1 A-E-302 B 1$

$1 A-E-303 B 1$

$2 A-E-304 B 1$

$1 A-E-305 B 1$

$1 A-E-306 B 1$

$2 A-E-307 B 1$

$1 A-E-309 B 1$

RAD

EF 1.747

18.2

22.7

PAD

EF 1.738

EE $\quad 1.723$

$\begin{array}{lll}R A D & E E & 1.723 \\ R A D & E E & 1.710\end{array}$

$R A D$

$1 A-E-310-B 1$ RAD

$1 A-E-311-B 1$ RAD

$1 A-E-312-B 1$ PAD

IA $A-E-313-B 1$ RAD

$1 A-E-314-B 1$ RAD

$\mid A-E-315-B 1$ RAD

$1 A-E-316-B 1$

$1 A-E-317-B 1$

$|A-E-318-B|$

$|A-E-3| 9-B \mid$

$\mid A-E-320-B 1$

$1 A-E-321-B 1$

$1 A-E-\overline{32} 2-B \overline{1}$

$1 A-E-323-B 1$

$1 E-E-300-B 1$

$301-B 1$

$302-B 1$

$3 C 3-81$ RAD

-. $\quad 303-81$

$305-81$

$306-B 1$ RAD

$3 \overline{C 7-B 1} R A D$

$3 C 8-B 1$

$309-81$

3 TO-BI

$312-81$

$313-B 1$

$324-81$

\begin{tabular}{l|lll}
$315-B 1$ & $R A D$ & $E E$ & 1.72
\end{tabular}

RAO

EE $\quad 1.727$

EF. 1.721

$\bar{E} F^{-1.727}$

EF $\quad 1.725$

EE $\quad 1.720$

EE 1.741

EE $\quad 1.724$

EE $\quad 1.728$

EE 1.729

EE $\quad 1.716$

EE 1.743

RAD EE 1.742

RAD

EE $\quad 1.718$

EE 1.708

EE 1.723

EE $\quad 1.712$

EE $\quad 1.747$

EF 1.732

EE $\quad 1.739$

EE $\quad 1.731$

EE 1.727

EF 1.736

EE 1.742

$E^{-1.739}$

1.739

1.734

E

EE 1.739

1.739
1.726

$\begin{array}{cr}E E & 1.731 \\ E E & 1.728\end{array}$

$\begin{array}{lll}R A D & E E & 1.728 \\ R A D & E E & 1.727\end{array}$

317-B1 RAD EE 1.715

$318-B 1$ RAD

$319-B 1$ RAD

$321-81$

$322-81$

RAD

EE

EE 1.717

1.725

1.717

1.724

$323-B 1$ RAD EE 1.715

20.5

21.6

20.8

14.9
20.5

12.6

21.9

16.6

27.8

23.3

24.7

24.7

24.7

21.3

28.9

27.2

26.1

27.2

$25 \cdot 5$

19.9

20.9

25.9

25.5

27.5

28.6

29.4

24.3

27.5

27.5

26.5

$26 \cdot 5-22 \cdot 0$

15.6

16.2

19.5

17.9

18.7

18.1

13.6

17.9

11.7

18.9

14.9

22.7

19.9

20.8

20.8

20.8

18.5

23.4

22.4

21.7

22.4

21.0

17.5

18.3

21.6

21.3

22.6

23.2

23.7

20.6

22.6

21.0

22.0

$7.0 \quad 22.3$

26.5

27.6

22.0

20.1

26.9

28.3

$\frac{22.2}{23.0}$

$? 1.6$

$25.3 \quad 21.2$

$24.8 \quad 20.9$

$25.1 \quad 21.1$

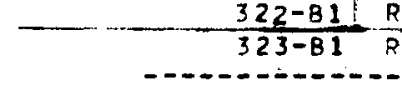

MEAN

27.2

22.4

21.4

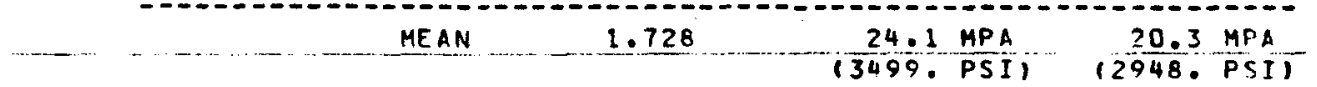

STD. DEV. . . ID

3.8 MPA

2.7 MPA

(555.PSI) (388. PCIJ 
TABLE 10

STRENGTHS OF SMALL-SIZED TENSILE SPECIMENS, SLAB 1, RADIAL ORIENTATION, END-CENTER LOCATION

$\begin{array}{lll}\text { LOT NO. } 408 & \text { SPEC. DIA. } & 6.4 \\ \text { LOG NO. } 5651-90 & \text { SPEC. LENGTH } & 23 . M M \\ \text { LOG DENSITY } 1.75 & \text { KG }\end{array}$

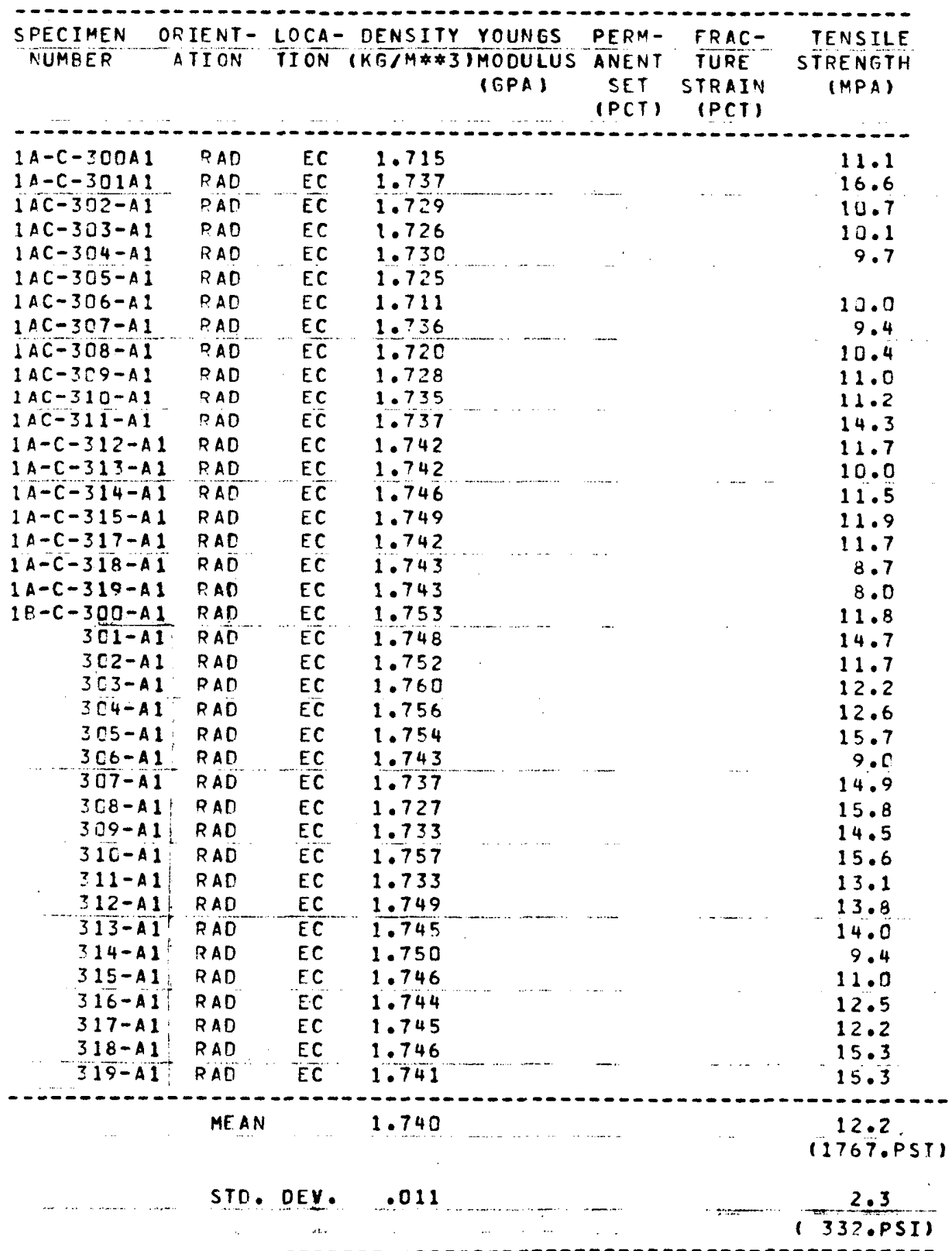


TABLE 11

STRENGTHS OF LARGE-SIZED TENSILE SPECIMENS, SLAB 1, RADIAL ORIENTATION, END-CENTER LOCATION

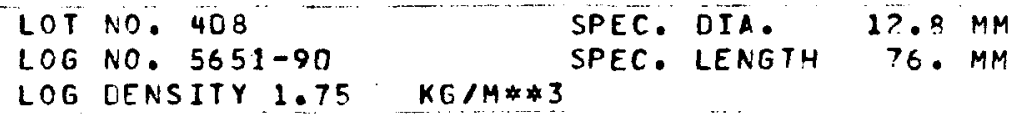


TABLE 12

STRENGTHS OF FOUR-POINT BEND SPECIMENS, SLAB 1, RADIAL ORIENTATION, END-CENTER LOCATION

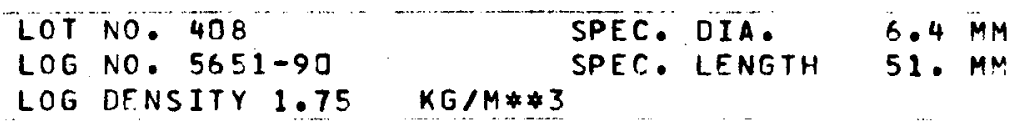

SPECIMEN ORIENT- LOCA-DENSITY MODULUS OF I FLEXURAL
MUMEER ATION TION IKGIM $\$ 3$ I RUPTURE (MPA) STRENGTH (MPA
(UNCORRECTED) (CORRECTED)

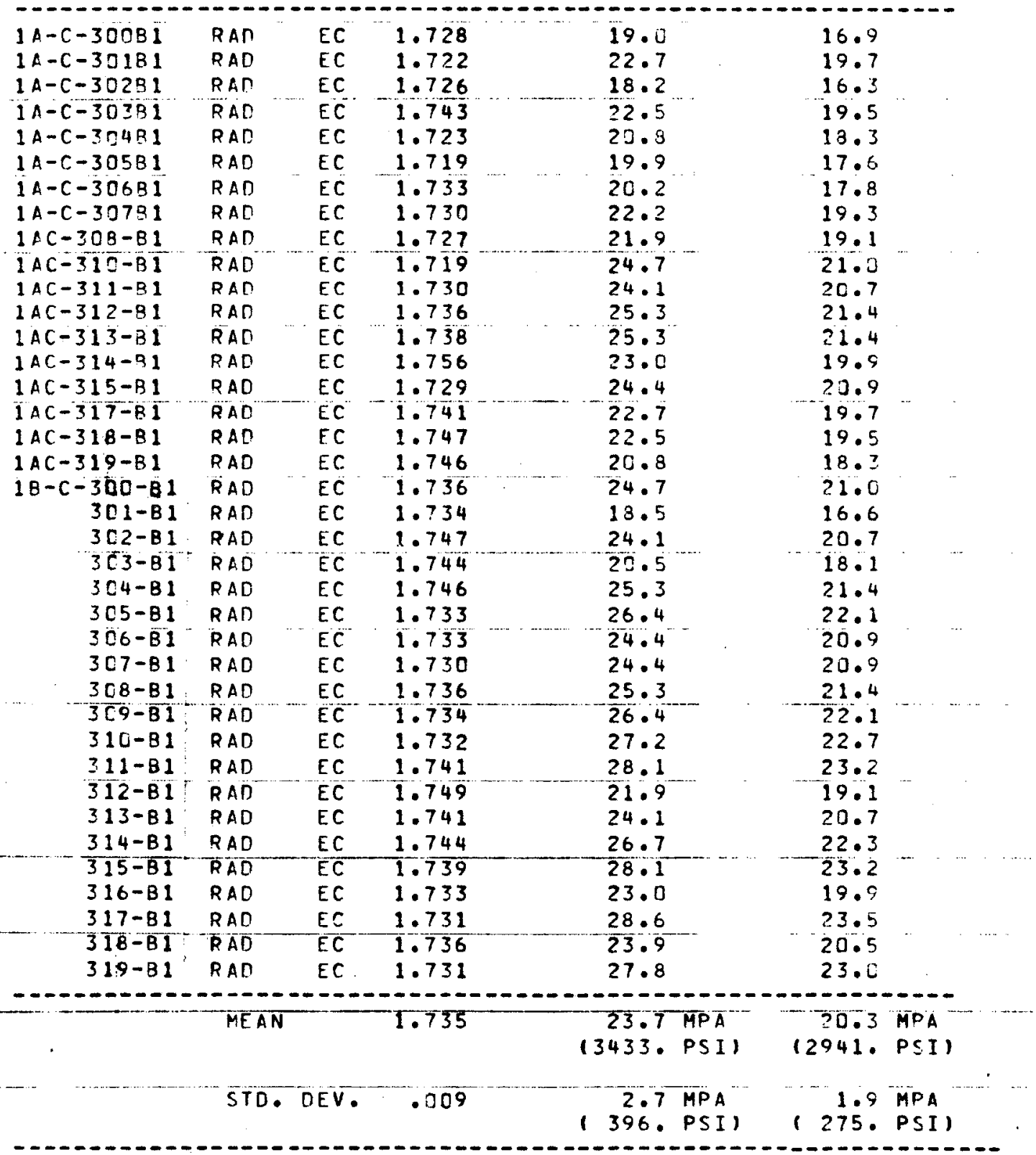


TABLE 13

STRENGTHS OF SMALL-SIZED TENSILE SPECIMENS, SLAB 2, AXIAL ORIENTATION, MIDLENGTH-EDGE LOCATION

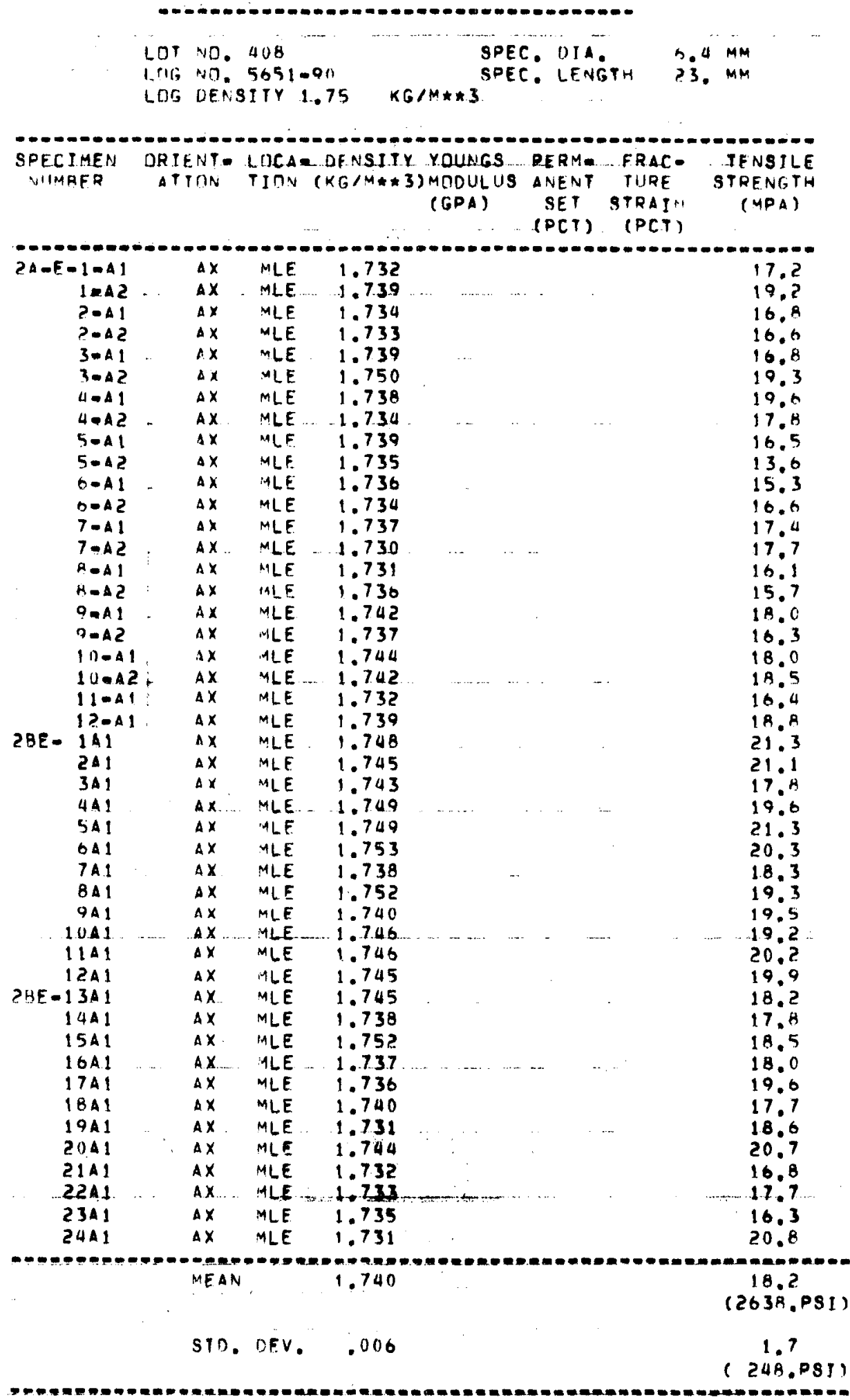


TABLE 14

STRENGTHS OF LARGE-SIZED TENSILE SPECIMENS, SLAB 2, AXIAL ORIENTATION, MIDLENGTH-EDGE LOCATION
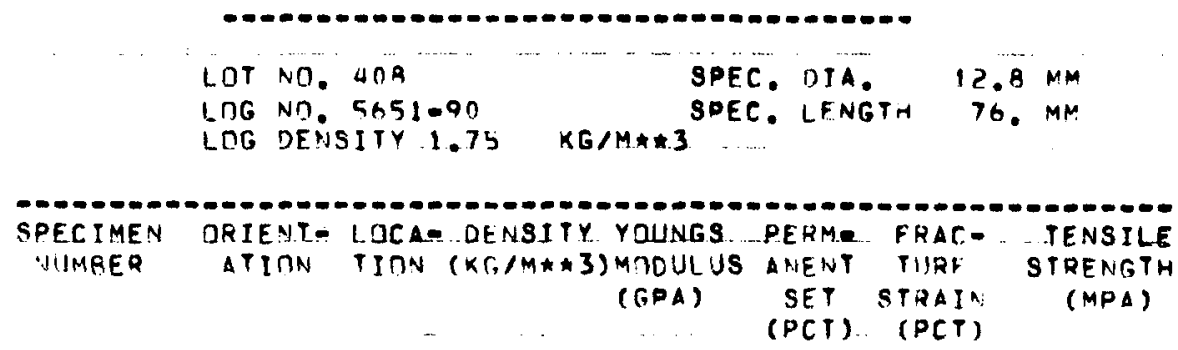

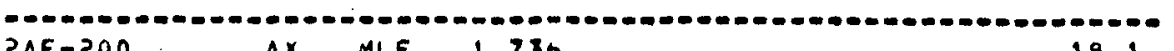

$24 E-200$

$-201$

$-202$

$-203$

$-2011$

$-? 05$

$-206$

$-207$

$-208$

$-209$

$-210$

$-211$

$7 A-F-212$

-213
-214

$-214$

$-215$

$-216$

$-219$

-219
-219

$-220$

- 221

- 222

$-223$

?RF -200

$-201$

- 202

$-203$

$-204$

$-205$

$-206$

$-207$

$-208$

$-209$

$-210$

$-211$

ZAE $-21 ?$

$-213$

$-214$

$-215$

.216

$-217$

$-218$

$-212$

$-220$

$-221$

$-222$

$-223$

$\Delta X \quad M L$

MLE 1.730

MLE 1.738

$\triangle X$ MLE 1.740

$\triangle X$ HLE 1.741

AX MLE 1.TAZ

AX MLE 1.743

MLE 1.742

MLE - 1.236

MLE 1.739

MLE 1.741

MLE 1.740

MLE 1.740

MLE 1.738

YLE $1: 738$

MLE 1.741

MLE 1.733

MLE 1.734

MLE 1.734

MLE 1.740

MLE _ 1.739

MLE 1.738

MLE 1.737

MLE 1.732

MLE 1.739

MLE $1.74 \mathrm{~A}$

MLE 1.748

MLE 1.741

MLE . 1.748

MLE $\quad 1.742$

MLE 1.742

MLE 1.744

MLE 1.740

MLE $\quad 1.750$

MLE 1.745

MLE 1.746

MLE $\quad 1.745$

MLE 1.742

MLE 1.745

MLE 1.735

MLE . 1.751

MLE 1.734

MLE $1.736 \quad 0.4$.

$9.4 \ldots .004 \quad .249$

16.3

17.4

17.9

17.2

16.3

17.5

17.1

16.2

15.6

18.0

14.3

15.4

15.8

$9.7 \quad .013 \quad .294 \quad 18.2$
17.1

17.6

18.0

17.4

15.3

16.4

16.3

$9.7 \quad .015 .352 \quad 21.7$

20.9

20.0

19.0

18.5

19.0

18.4

18.9

17.2

19.2

18.0

$17 \div 9$

20.0

$\begin{array}{lllll}94 & 9.4 & .002 \quad .267 & 18.4\end{array}$

$A X$ MLE $1.729=18.0$

$\triangle X \quad M L E \quad 1.738 \quad 12.2$

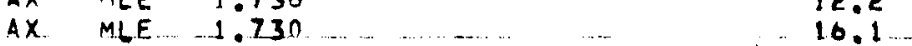

AX MLE $1.737 \quad 15.3$

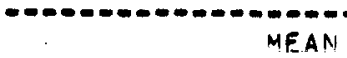

1.740

9.5 ....008

.295

$17.6 \ldots$

( $.38 \mathrm{MPSI}$ )

(2552.P91)

SIR. DEV....005

$.2 \quad .006 \ldots .043$

$1.7 \ldots$

( .02 MPSI)

(253.P54) 
TABLE 15

STRENGTHS OF FOUR-POINT BEND SPECIMENS, SLAB 2, AXIAL ORIENTATION, MIDLENGTH-EDGE LOCATION

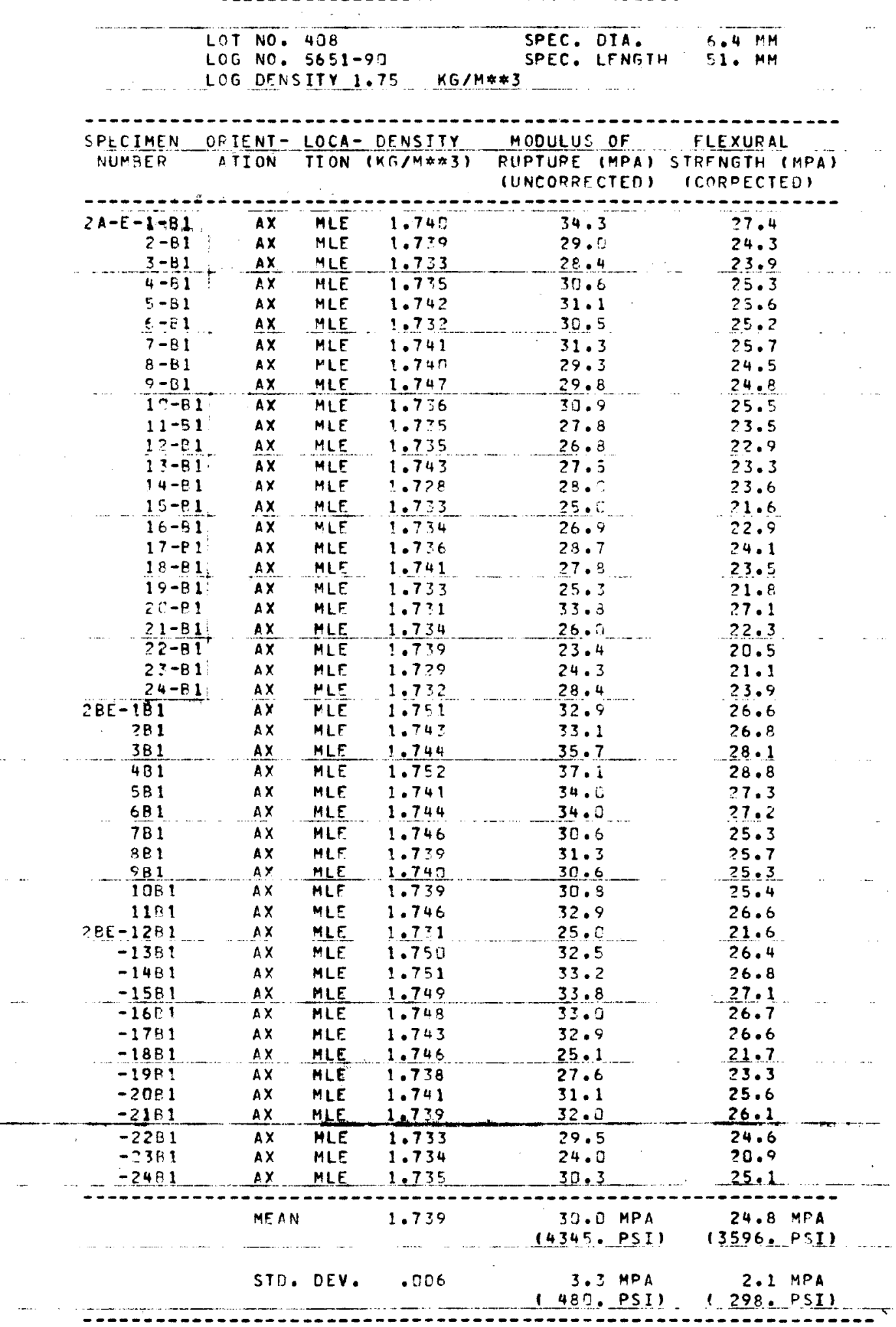


TABLE 16

STRENGTHS OF SMALL-SIZED TENSILE SPECIMENS, SLAB 2, AXIAL ORIENTATION, MIDLENGTH-CENTER LOCATION

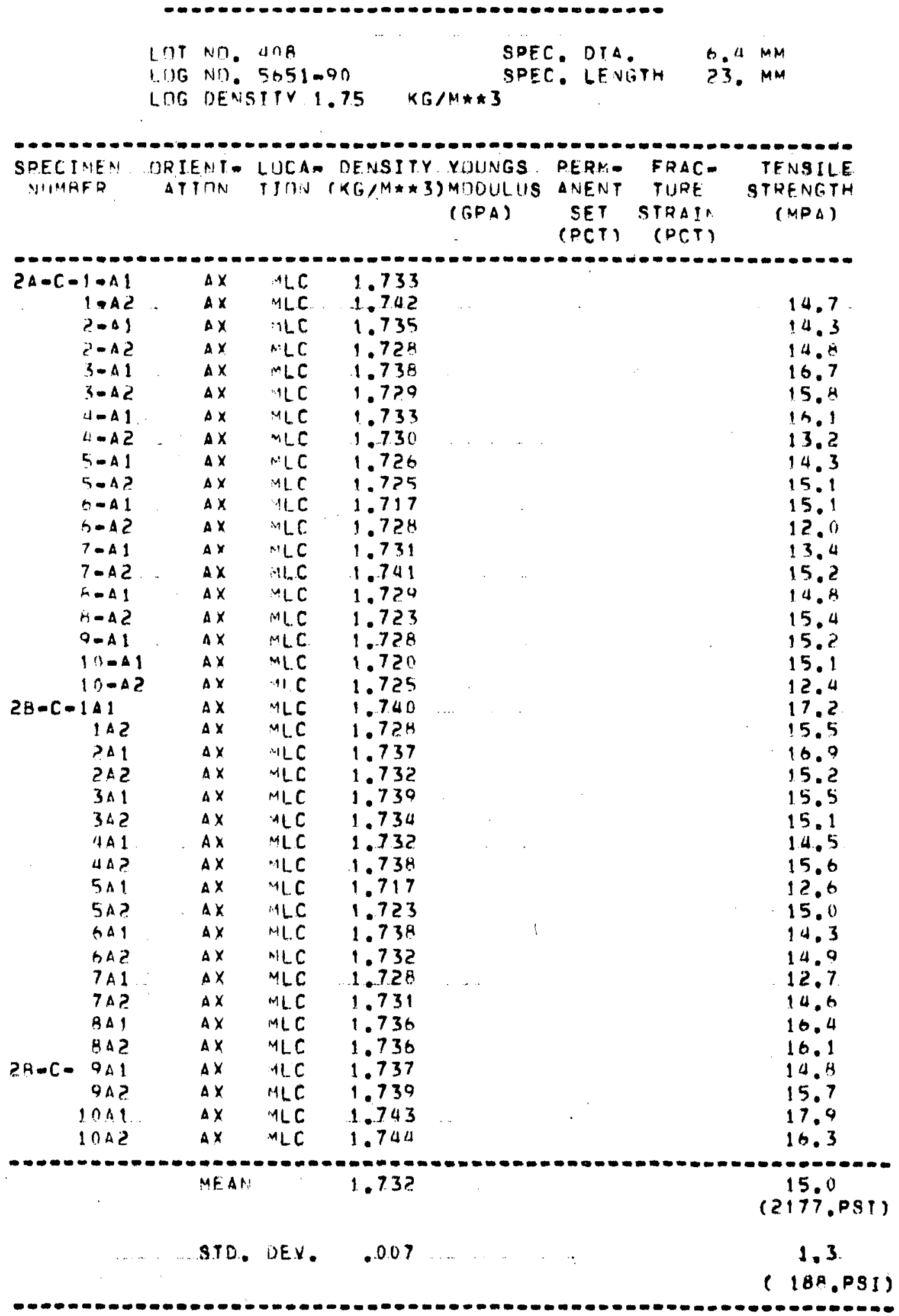


TABLE 17

STRENGTHS OF LARGE-SIZED TENSILE SPECIMENS, SLAB 2, AXIAL ORIENTATION, MIDLENGTH-CENTER LOCATION

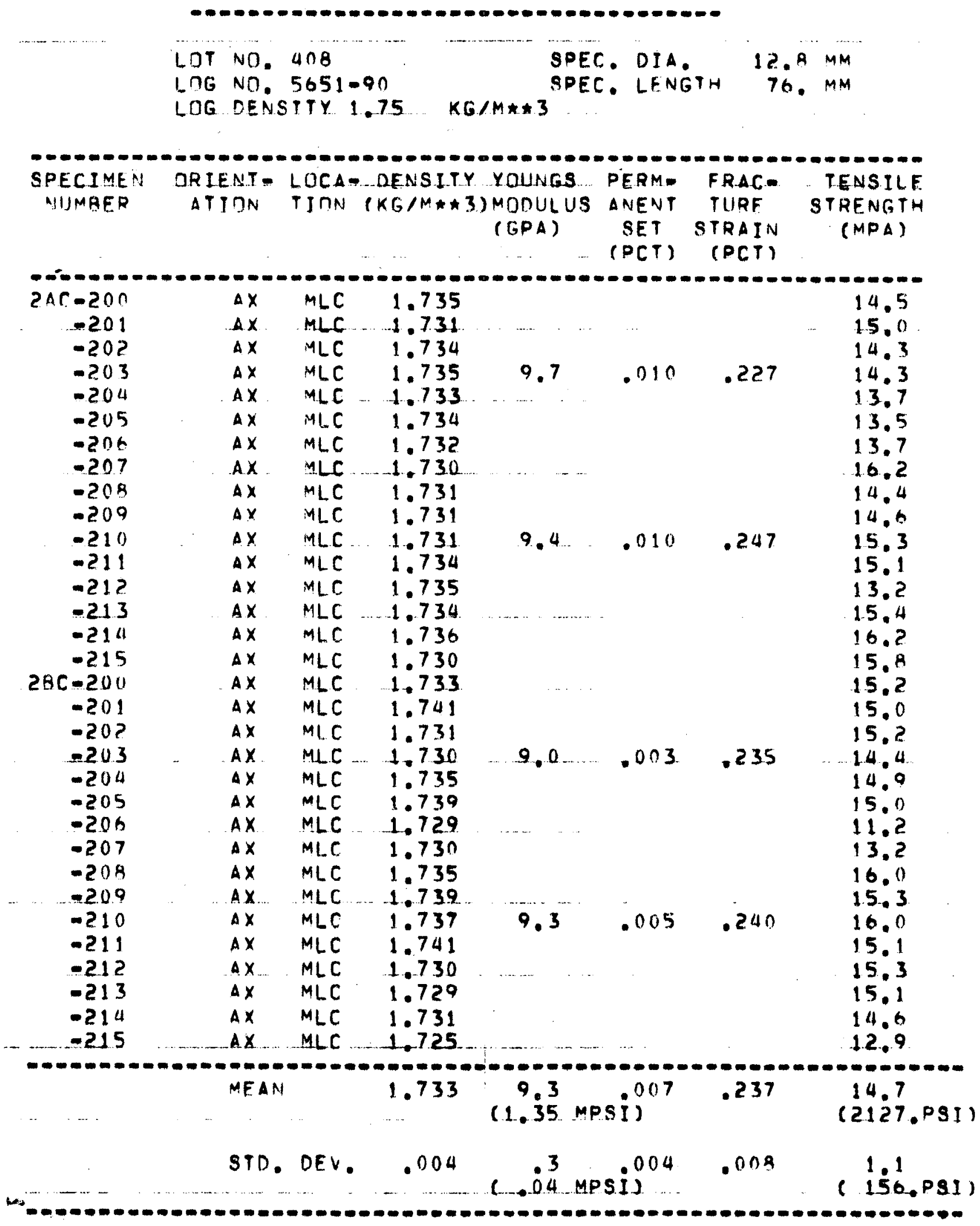


TABLE 18

STRENGTHS OF FOUR-POINT BEND SPECIMENS, SLAB 2, AXIAL ORIENTATION, MIDLENGTH-CENTER LOCATION

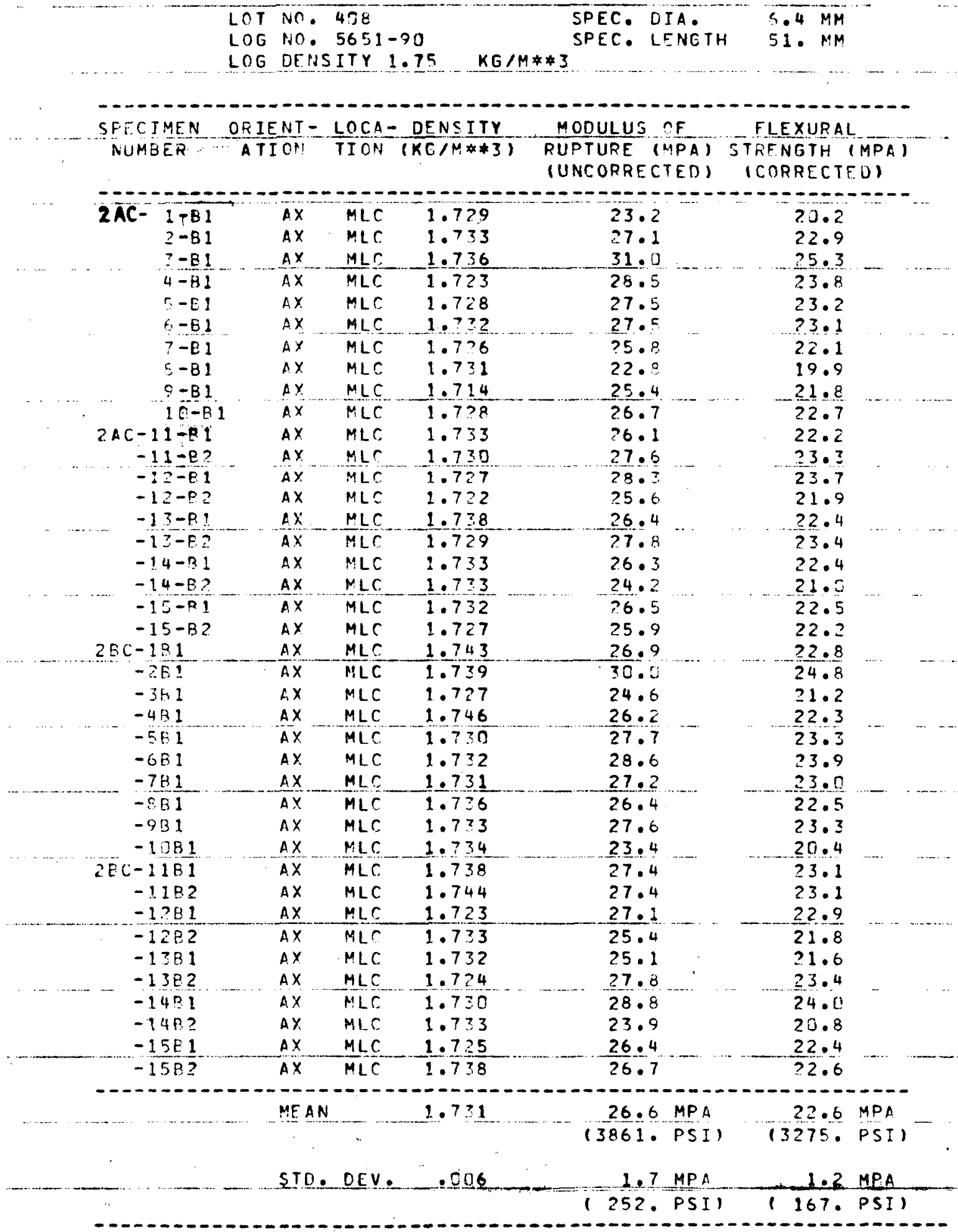


TABLE 19

STRENGTHS OF SMALL-SIZED TENSILE SPECIMENS, SLAB 2, RADIAL ORIENTATION, MIDLENGTH-EDGE LOCATION

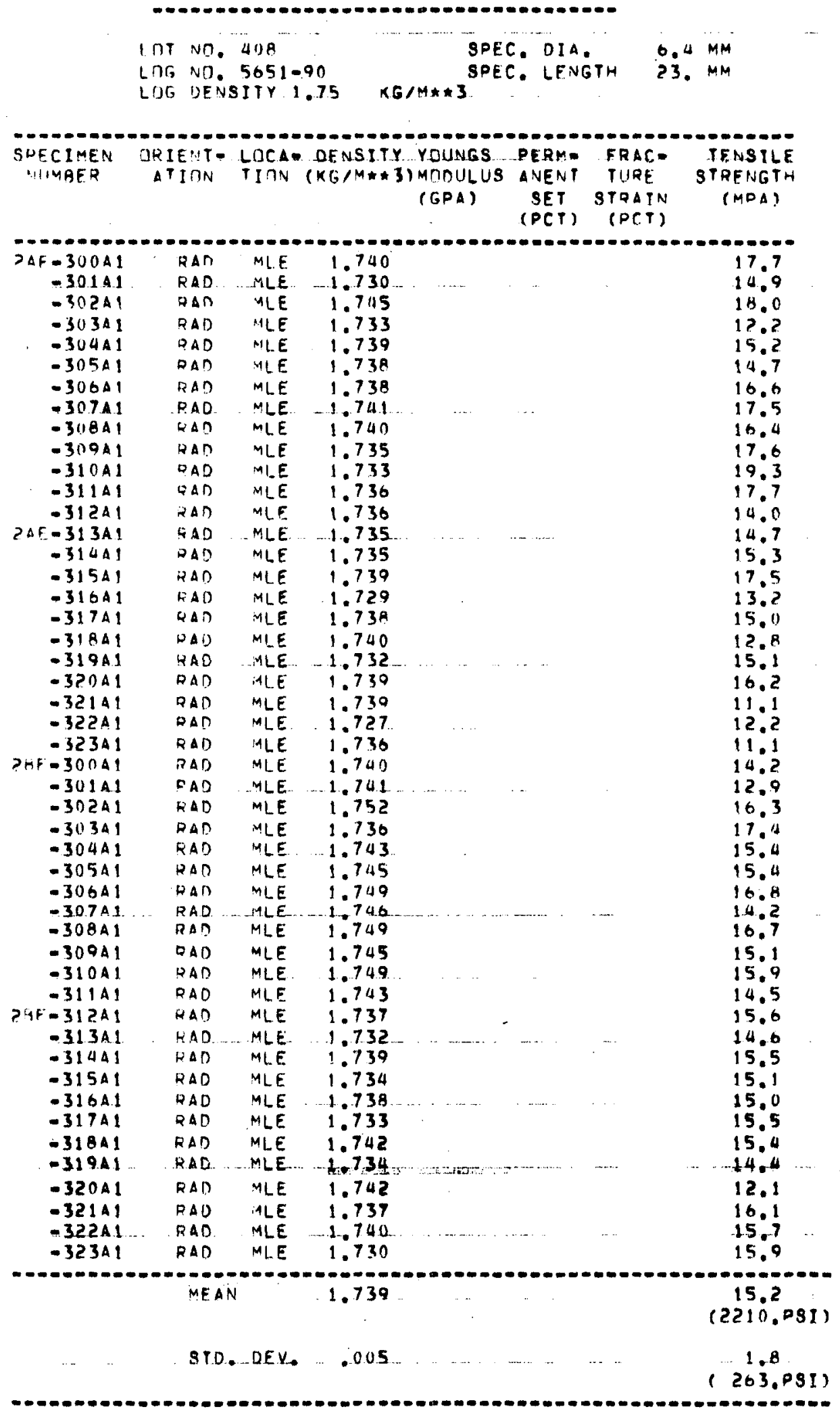


TABLE 20

STRENGTHS OF LARGE-SIZED TENSILE SPECIMENS, SLAB 2, RADIAL ORIENTATION, MIDLENGTH-EDGE LOCATION

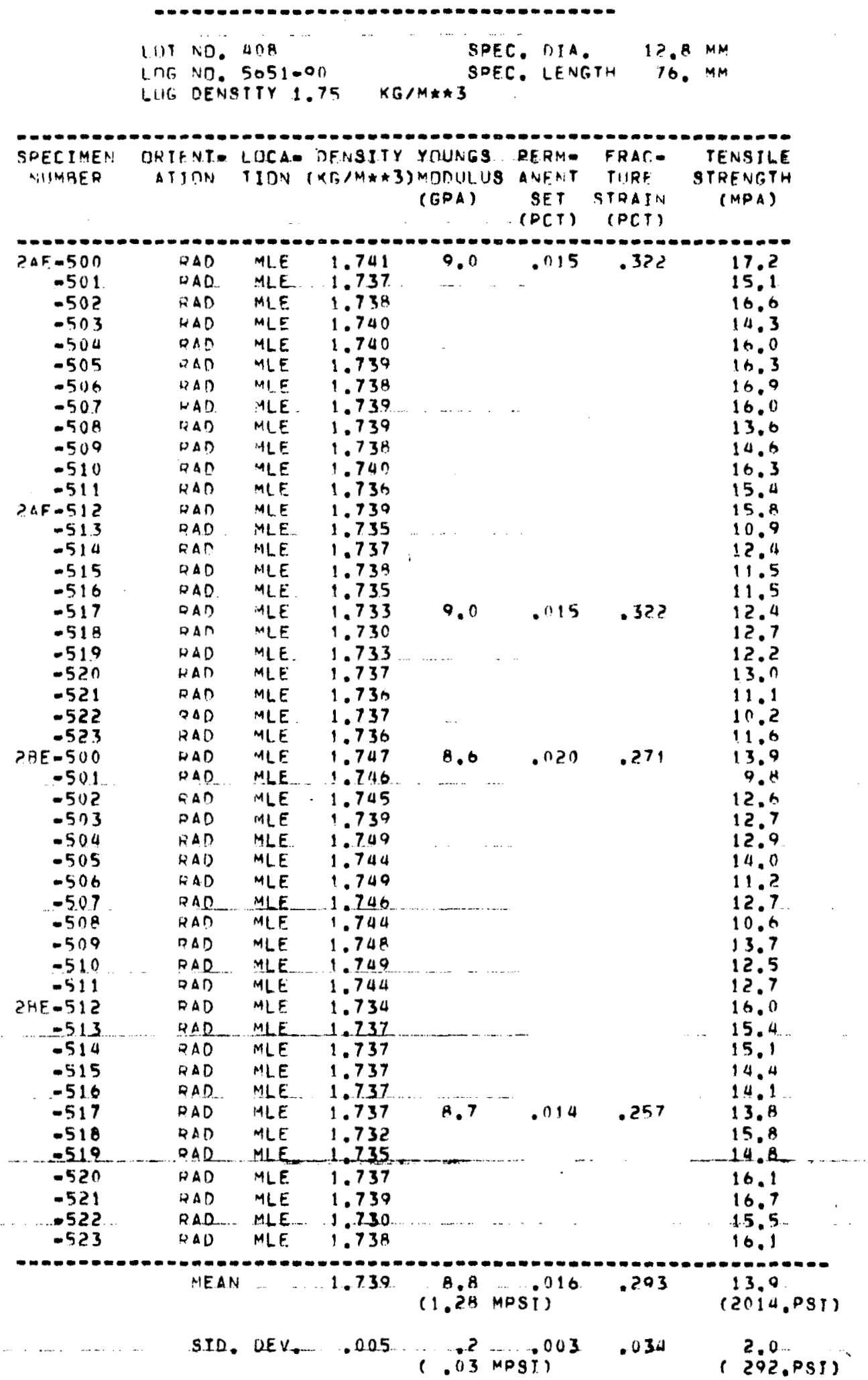


TABLE 21

STRENGTHS OF FOUR-POINT BEND SPECIMENS, SLAB 2, RADIAL ORIENTATION, MIDLENGTH-EDGE LOCATION

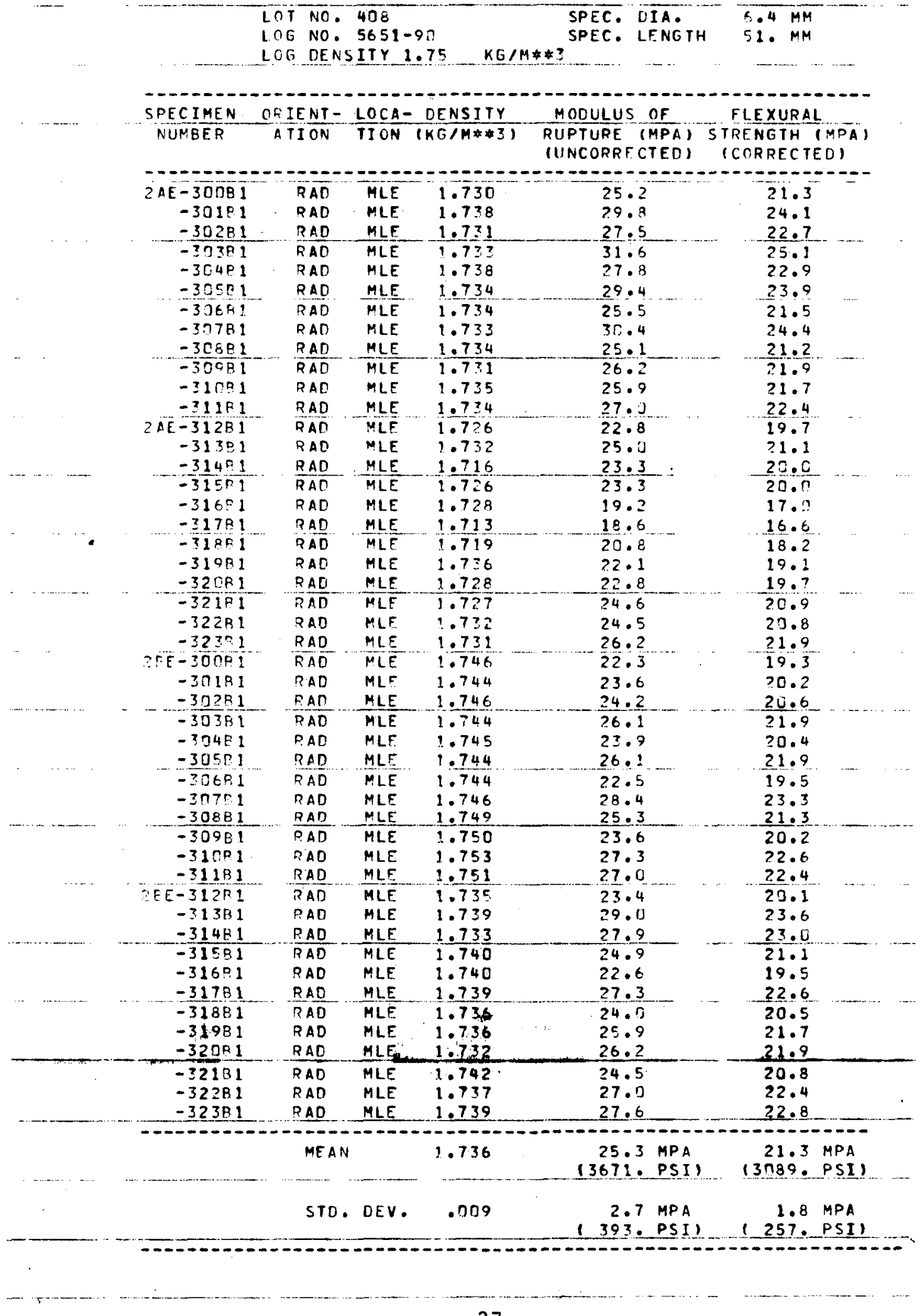


TABLE 22

STRENGTHS OF SMALL-SIZED TENSILE SPECIMENS, SLAB 2, RADIAL ORIENTATION, MIDLENGTH-CENTER LOCATION

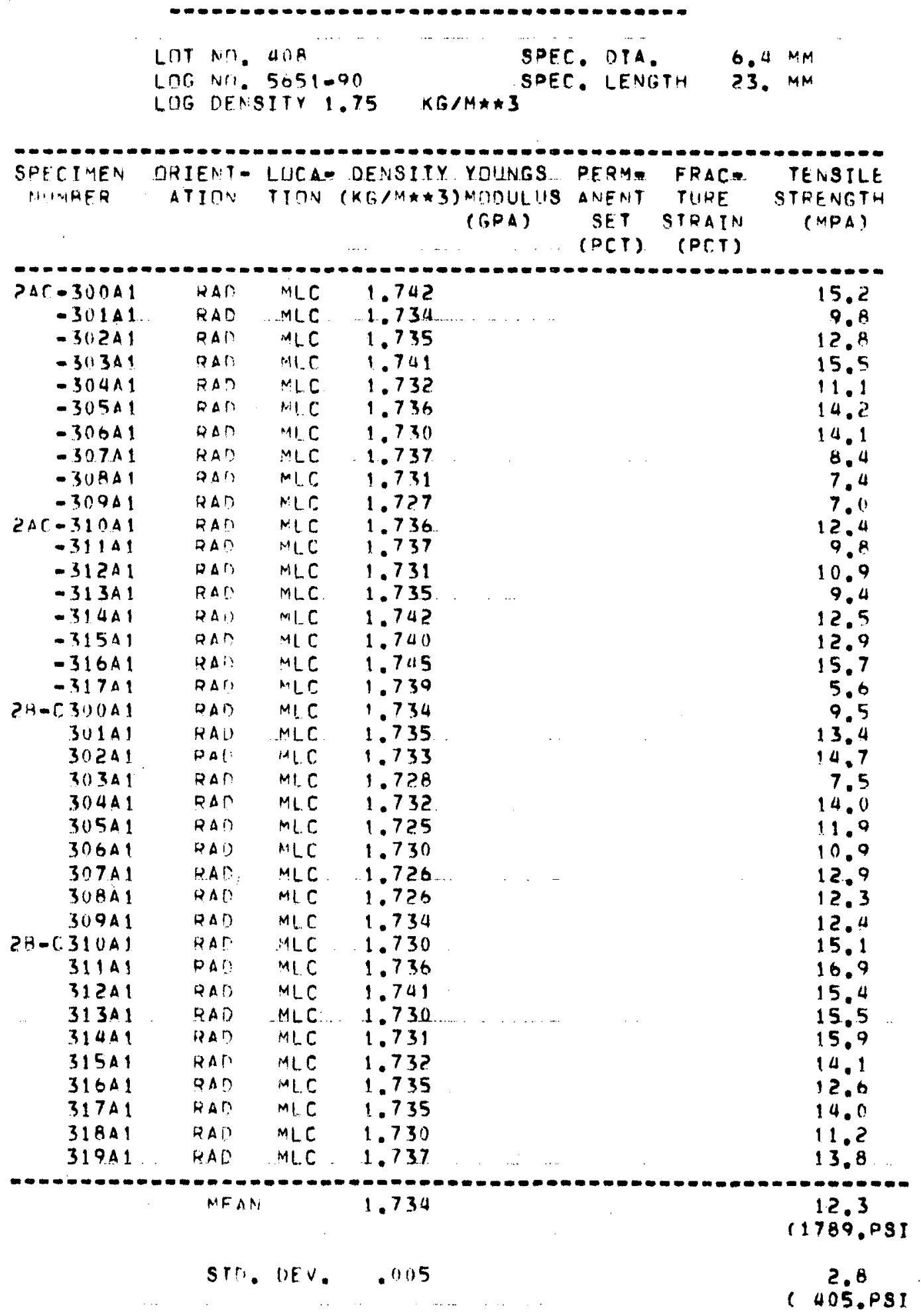


TABLE 23

STRENGTHS OF LARGE-SIZED TENSILE SPECIMENS, SLAB 2, RADIAL ORIENTATION, MIDLENGTH-CENTER LOCATION

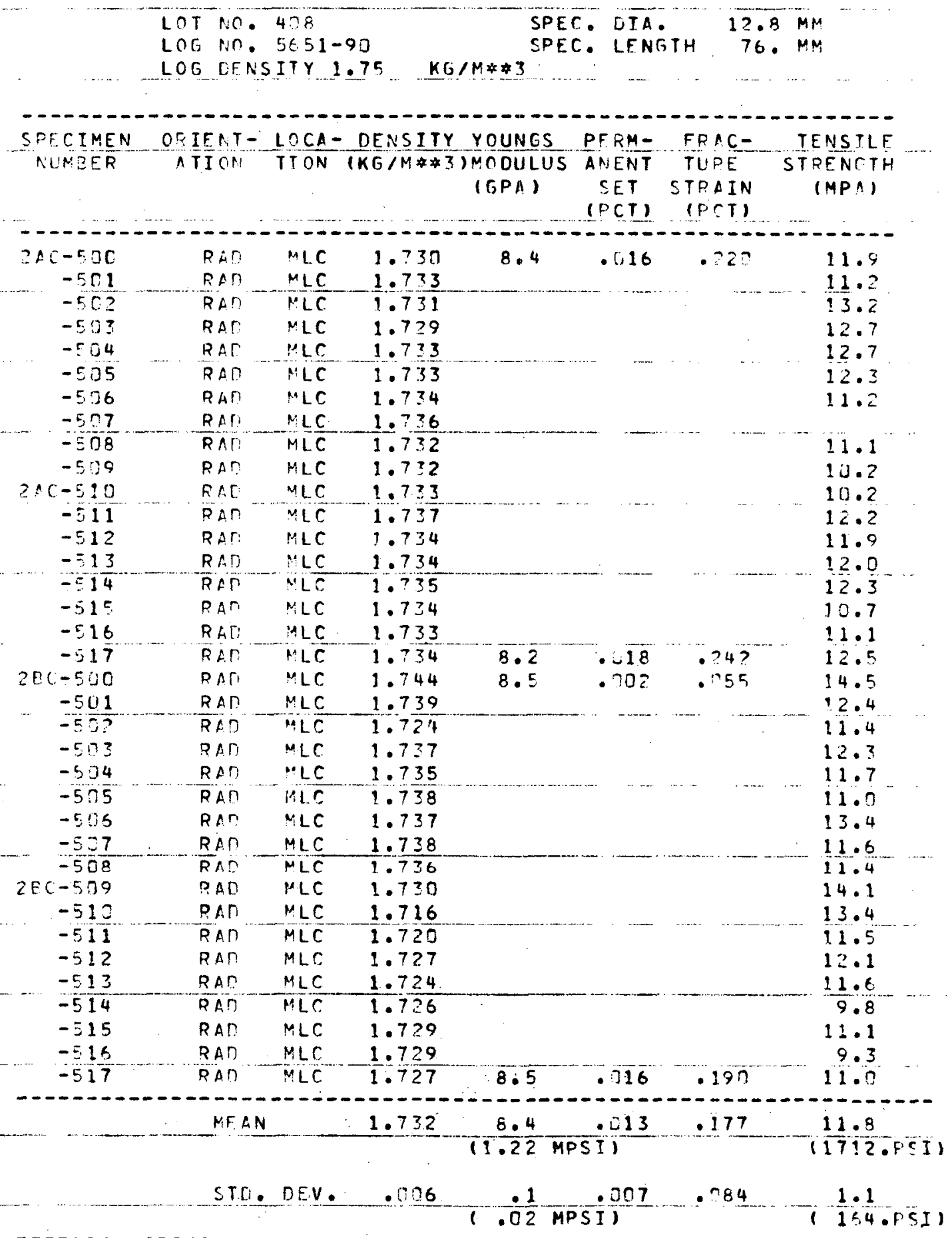


TABLE 24

STRENGTHS OF FOUR-POINT BEND SPECIMENS, SLAB 2, RADIAL ORIENTATION, MIDLENGTH-CENTER LOCATION

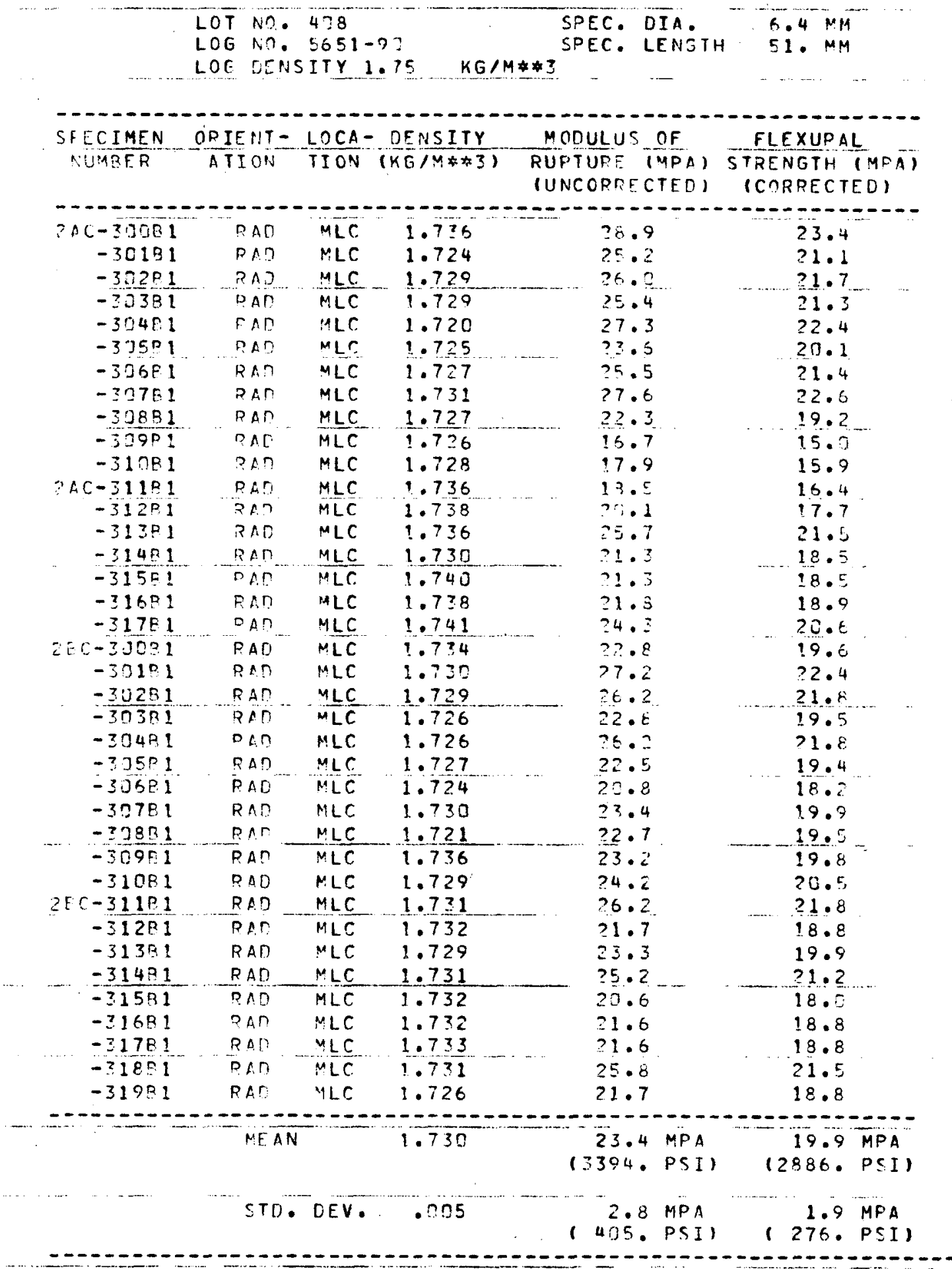


TABLE 25

STRENGTHS OF SMALL-SIZED TENSILE SPECIMENS, SLAB 3, AXIAL ORIENTATION, MIDLENGTH-EDGE LOCATION

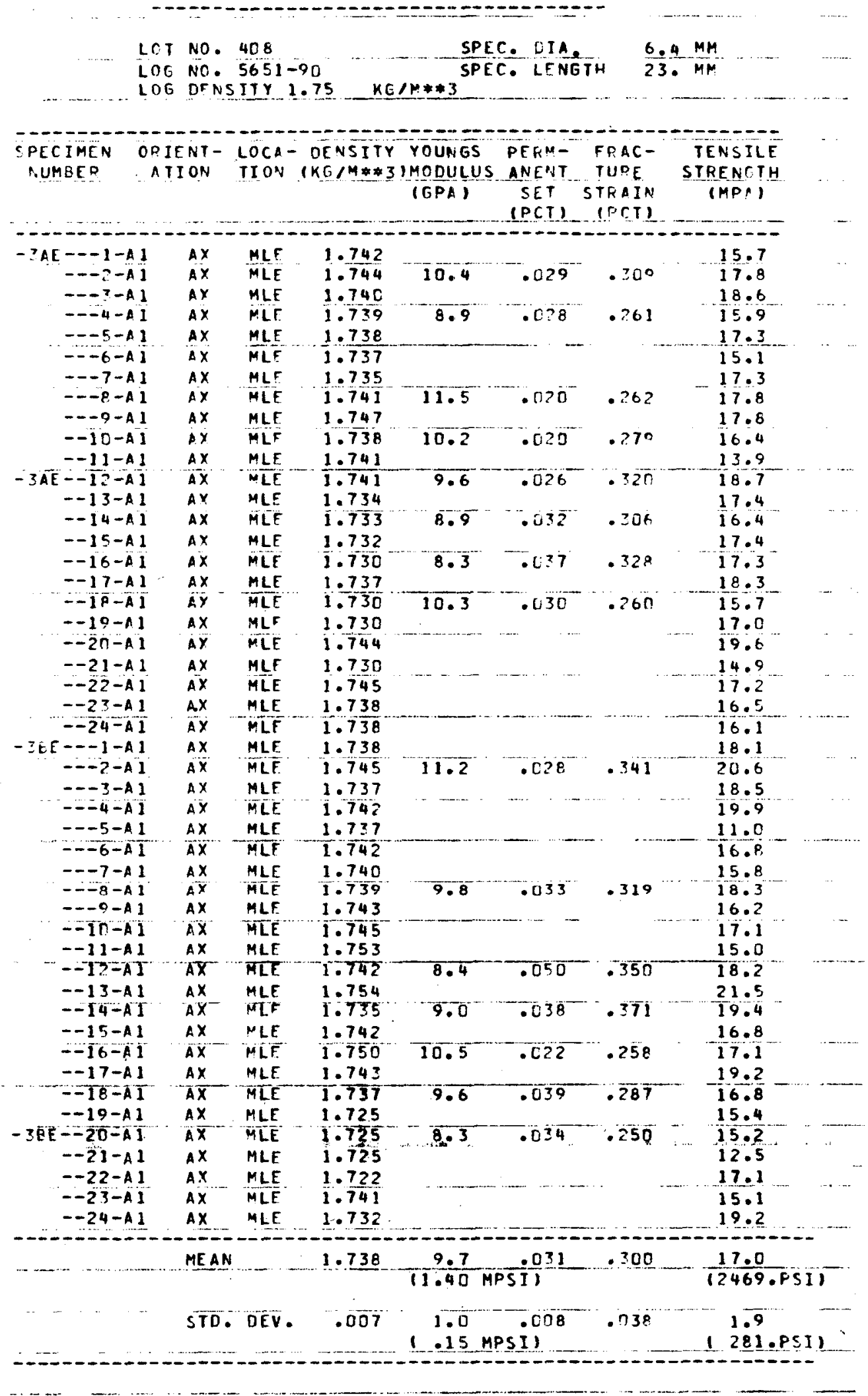


TABLE 26

STRENGTHS OF LARGE-SIZED TENSILE SPECIMENS, SLAB 3, AXIAL ORIENTATION, MIDLENGTH-EDGE LOCATION

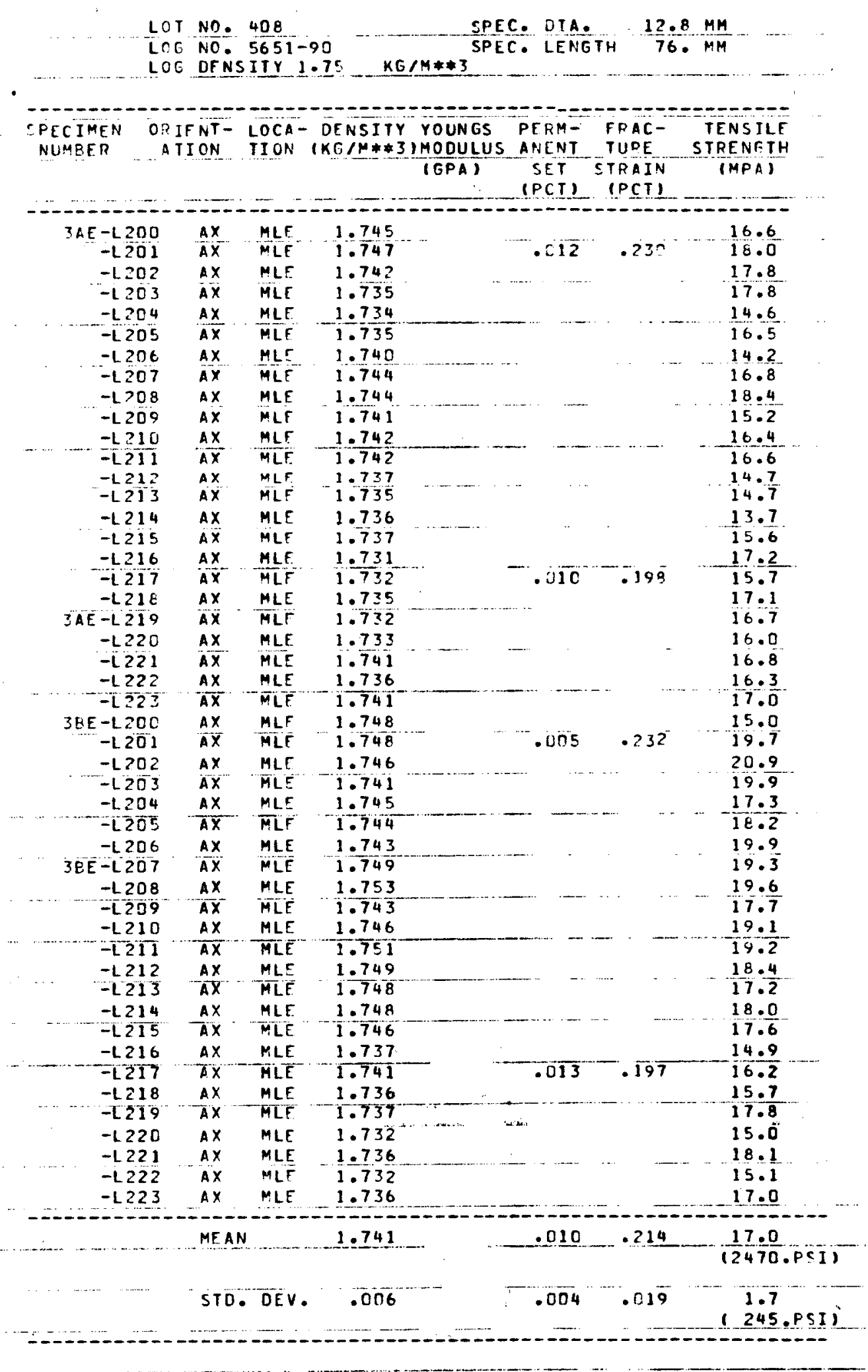


TABLE 27

STRENGTHS OF FOUR-POINT BEND SPECIMENS, SLAB 3, AXIAL ORIENTATION, MIDLENGTH-EDGE LOCATION

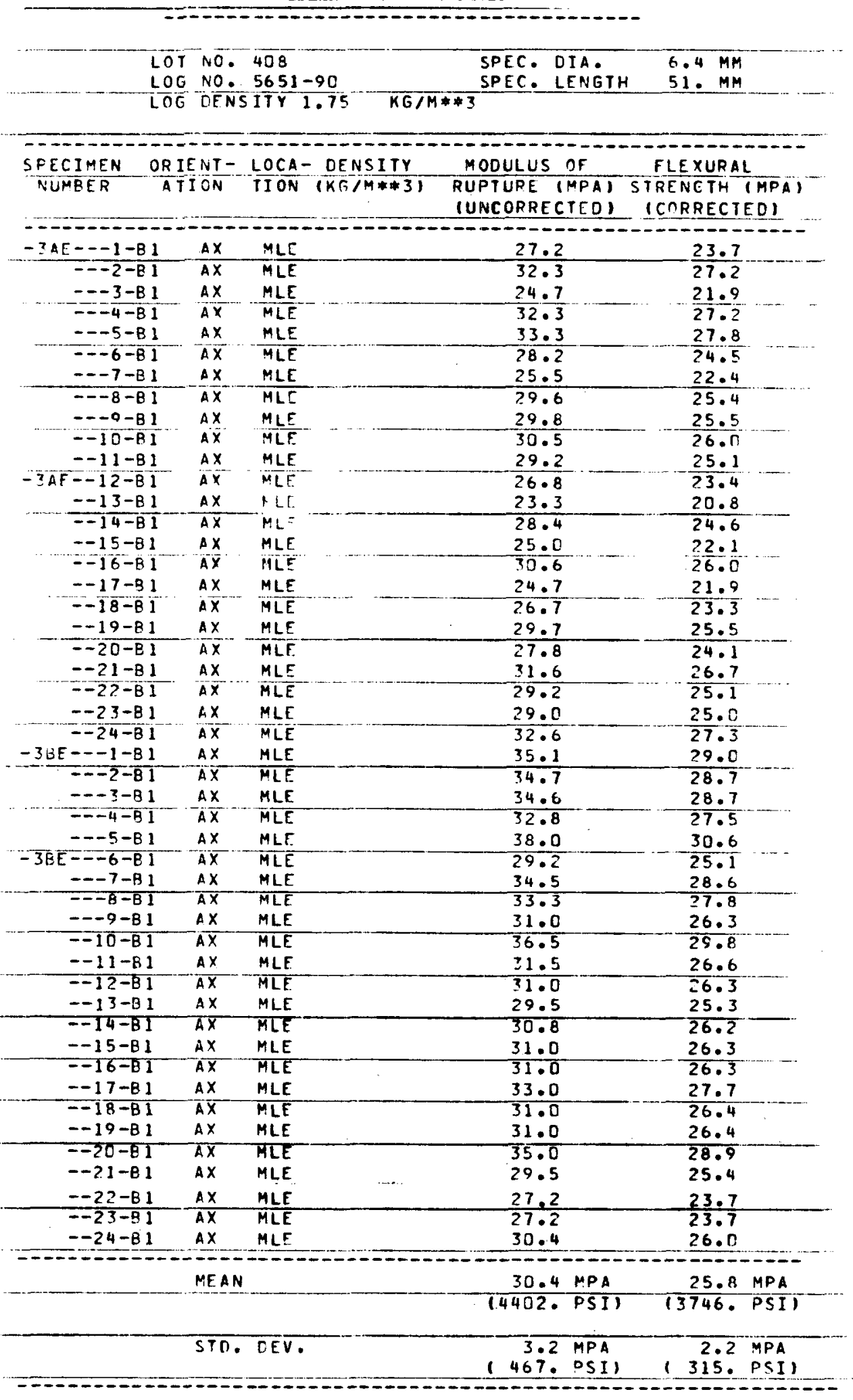


TABLE 28

STRENGTHS OF SMALL-SIZED TENSILE SPECIMENS, SLAB 3, AXIAL ORIENTATION, MIDLENGTH-CENTER LOCATION

LOT NO. 408

SPEC. DIA.

LOF $A 0$. 5651-90

LOG CENSITY 1.75

$K E / M * 3$

\section{SPEC. LENGTH}

$6.4 . M M$

23. $M M$

SPECIMFN ORIENT- LOCA- DENSITY YOUNGS PERM- FRAC- TENSILE
NUMFFR ATION TION (KGIM ZIMODULUS ANENT TUPE SIRENGIH
(GPAI SET STRAIN S IMPA)

3AC-D1-A1 AX MLC 1.744

$\cdots 1-A 2$

$---2-A 1$

$-\cdots-2-A 2$

$A X \quad M L C \quad 1.748$

$9.1 \quad .010 \cdot .271$

16.8

$-\cdots-A 1$

$A X$

$M L C$

1.740

$14 \cdot 0$

$--?-A 2$

$---4-A 1$

$---4-A 2$

$---5-A 1$

$---5-B 2$

$---6-A 1$

$---6-A 2$

$---7-A_{1}$

$--7-A 2$

$--0-41$

$---9-A_{2}$

$---9-A 1$

$--9-42$

$--10-A 1$

$-3 A C--1 C-A 2$

$-3 E C---1-A 1$

$--1-A_{2}$

$M L C$

1.735

$10.1 \quad .020$

.209

14.1

$\frac{A X}{A X}$

$M L C \quad 1.736$

MLC 1.727

MLC $\quad 1.730$

$M L C$

1.727

10 .

.0 .020

.227

$10 \cdot 2$

$A X$

$M L C$

1.730

$8.3 \quad .021$

$A X$ MLC 1.725

MLC 1.731

$M L C \quad 1.730$

e.8 .019

.315

13.9

MLC

1.732

$M L C$

1.732

$9.4-015$

.?1?

15.9

$A X$

ax

$M L C$

1.736

10.3 .018

12.5

$---2-A 1$

$---2-A 2$

$M L C$

1.735

MLC 1.727

MLC 1.733

MLC 1.730

MLC $\quad 1.736$

MLC 1.740

$M L C \quad 1.750$

MLC 1.741

$M L C \quad-1.754$

MLC $\quad 1.744$

$10 \cdot 3$

.018

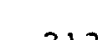

12.9

$---3-A_{1}$

MLC

1.756

$--3-A ?$
$---4-A]$

MLC

1.756

11.1 .020

.212

13.9

$---4-42$

$M L C$

1.741

.196

13.7

$--5-A_{1}$

$-.5-A_{2}$

MLC $\quad 1.733$

10.4 .033

$0.2^{-10.00}$

.21

6.6

$---6-A 1$

$---6-\bar{A} 2$

$---7-A_{1}$

$---7-A_{2}$

$---8-A 1$

$--B-A 2$

$---9-A 1$

$-3 B C-.9-A 2$

$--10-A 1$

$--10-\bar{A} 2$

$M L C \quad 1.732$

$12 \cdot 5$

13.5
11.8

MLC $\quad 1.740$

MLC 1.736

MLC 1.732

$M L C \quad 1.737$

MLC 1.737

$\begin{array}{llll}12.0 & .032 & .212 & 14.4\end{array}$

$-10.7 .033^{-240^{-1}}-15.0$

$10.4 \ldots .040,-15 \cdot 1$

$10.0^{0.041} \cdot .249^{1} \cdot \frac{14.9}{15.3}$

8.9 $.030^{-.263}-12.9$

$8.2 \quad .040^{.288} \quad 14.4$

$A X$

$A X$

$A \ddot{X}$

MLC 1.745

MLC 1.747

MLC 1.739

MLC 1.717

MLC -1.725

$7 \cdot 4$

.04

$12 \cdot 1$

$-A X$

AX

$1.736 \quad 9.7$.028

$10.9: 04$

.18

$-10.7$

$-1-------$

MEAN

.261

10.1

10.1 .01

.241

16.2

$13 \cdot 5$

$(1.41 \mathrm{MPSI}) \quad(1980 . P S I)$.

STD. DEV. .008 $1.1 .011 .035-2.0$ 
TABLE 29

STRENGTHS OF LARGE-SIZED TENSILE SPECIMENS, SLAB 3, AXIAL ORIENTATION, MIDLENGTH-CENTER LOCATION

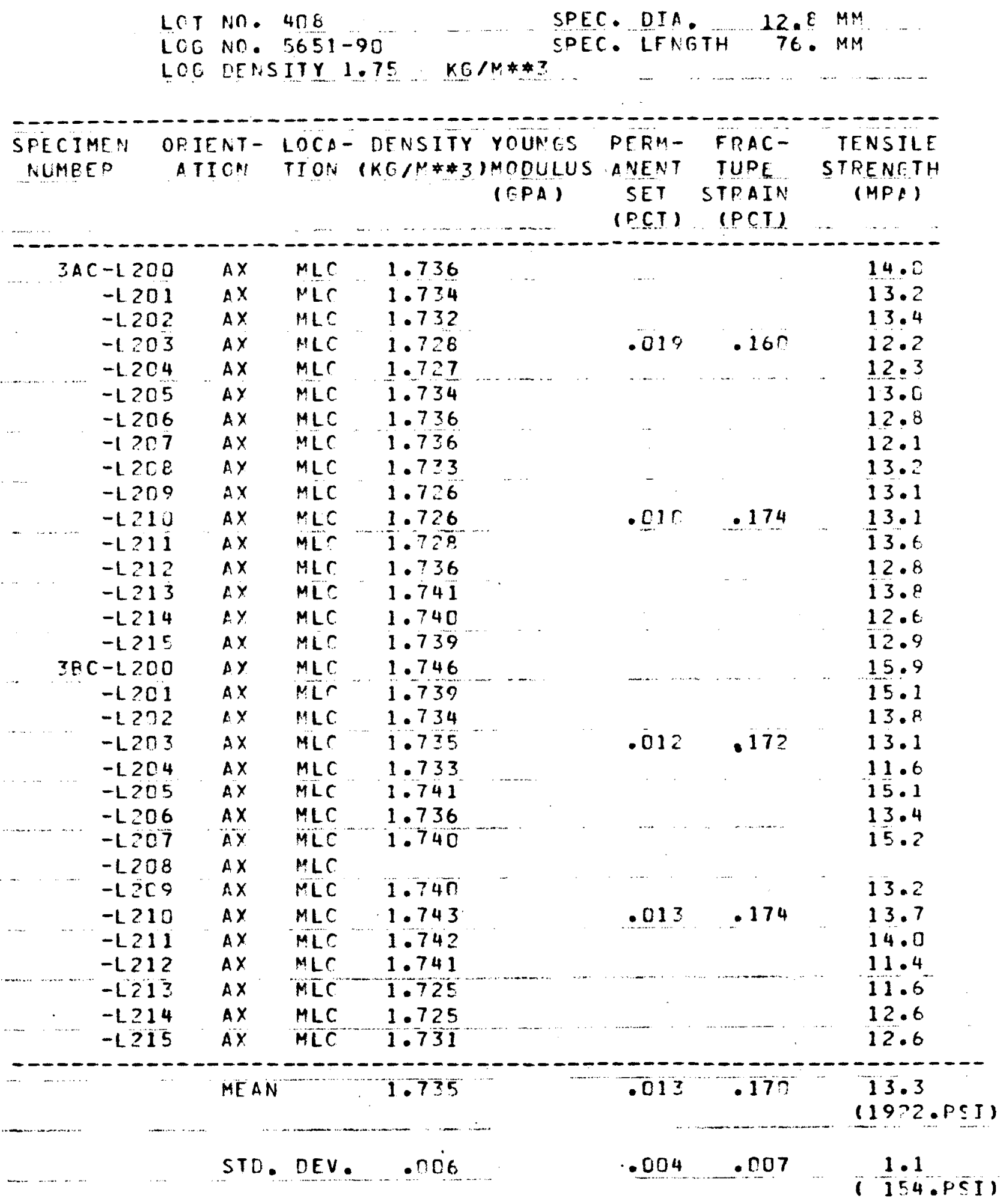


TABLE 30

STRENGTHS OF FOUR-POINT BEND SPECIMENS, SLAB 3, AXIAL ORIENTATION, MIDLENGTH-CENTER LOCATION

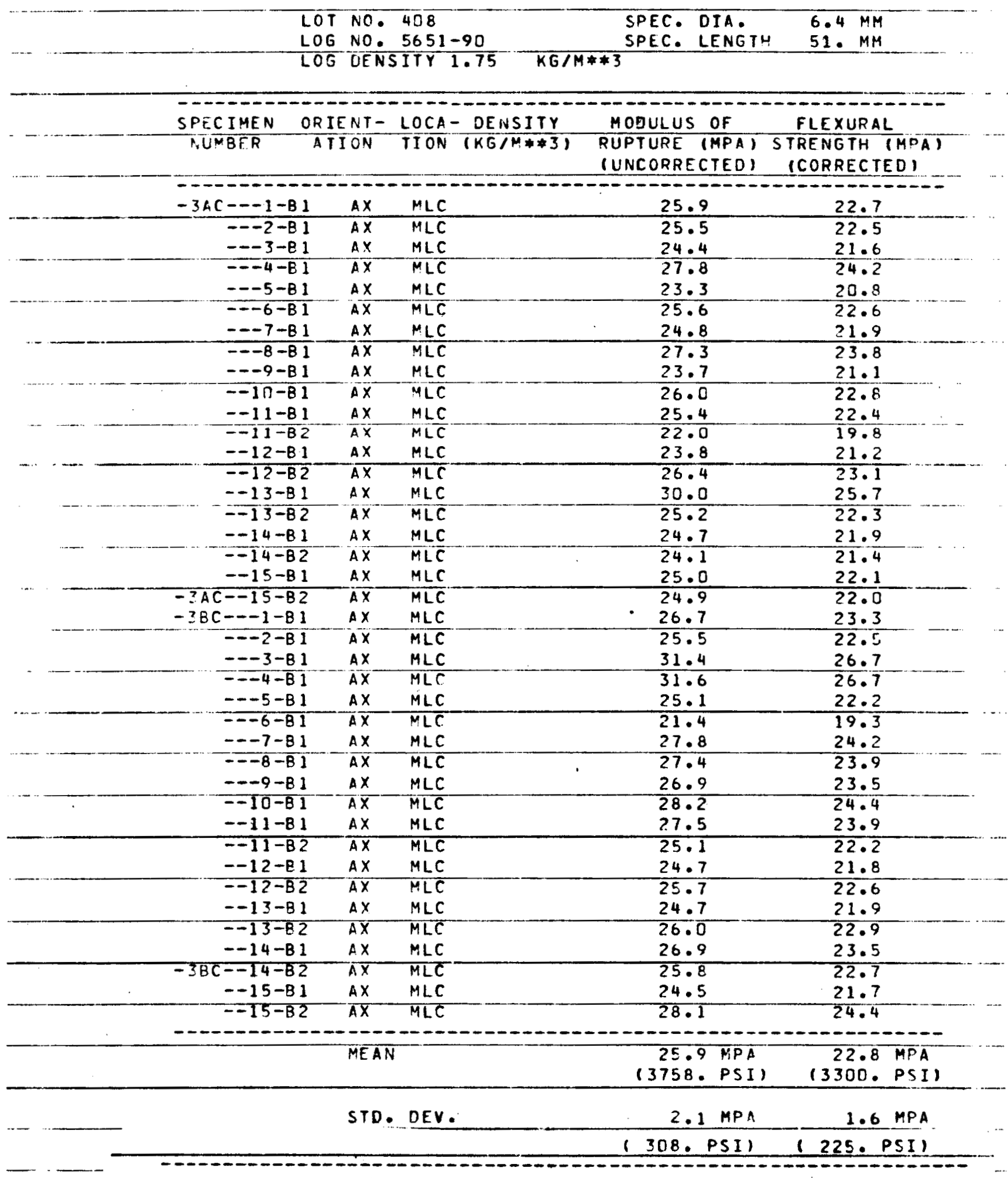


TABLE 31

STRENGTHS OF SMALL-SIZED TENSILE SPECIMENS, SLAB 3, RADIAL ORIENTATION, MIDLENGTH-EDGE LOCATION

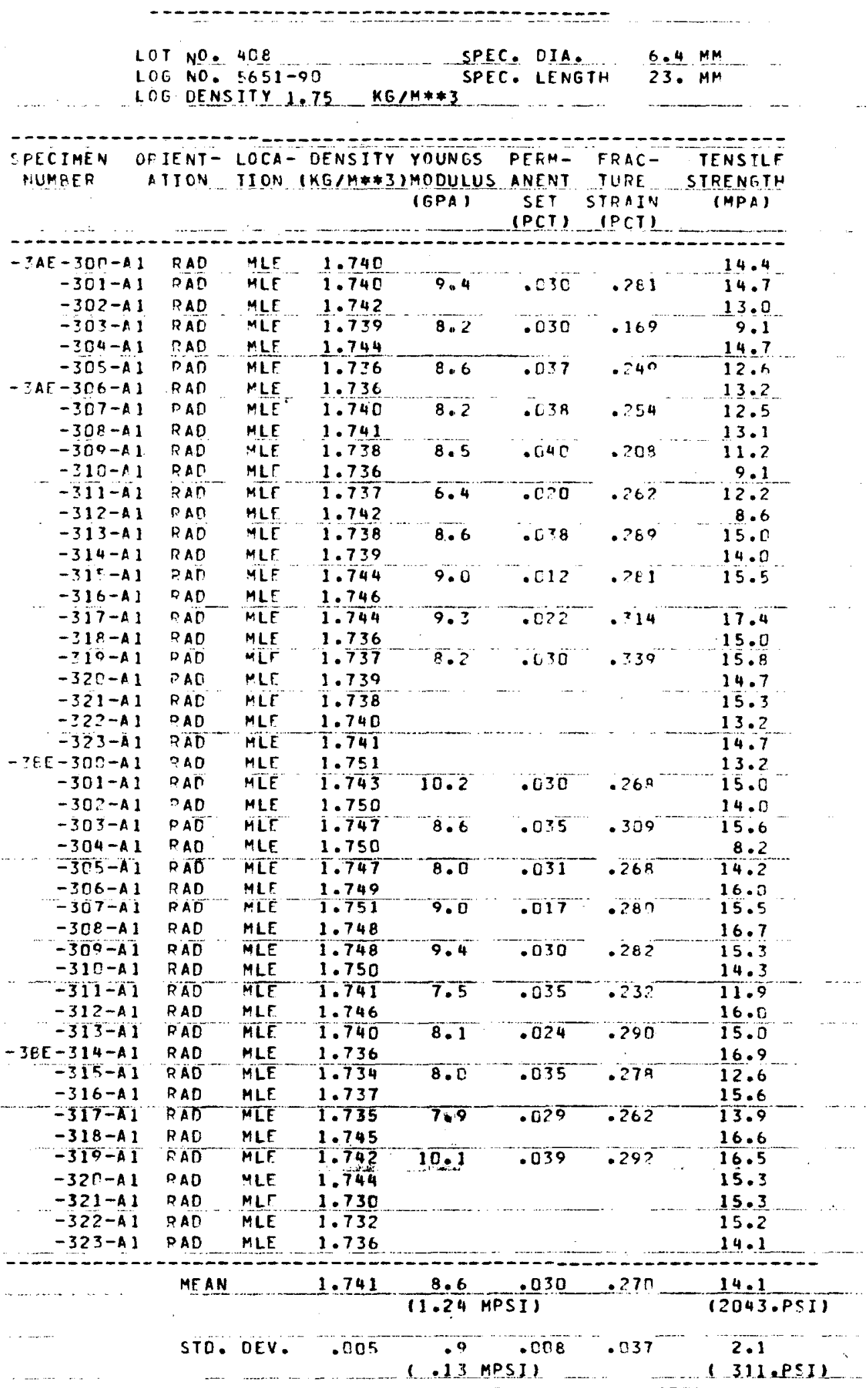


TABLE 32

STRENGTHS OF LARGE-SIZED TENSILE SPECIMENS, SLAB 3, RADIAL ORIENTATION, MIDLENGTH-EDGE LOCATION
LCT NO. $40 \mathrm{t}$
SPEC. DIA.
$12.8 \mathrm{MH}$
LOG NO. $5651-90$
SPEC. LENGTH
76. $M M$

LOG ORNSITY 1.75

$K G / M * * 3$

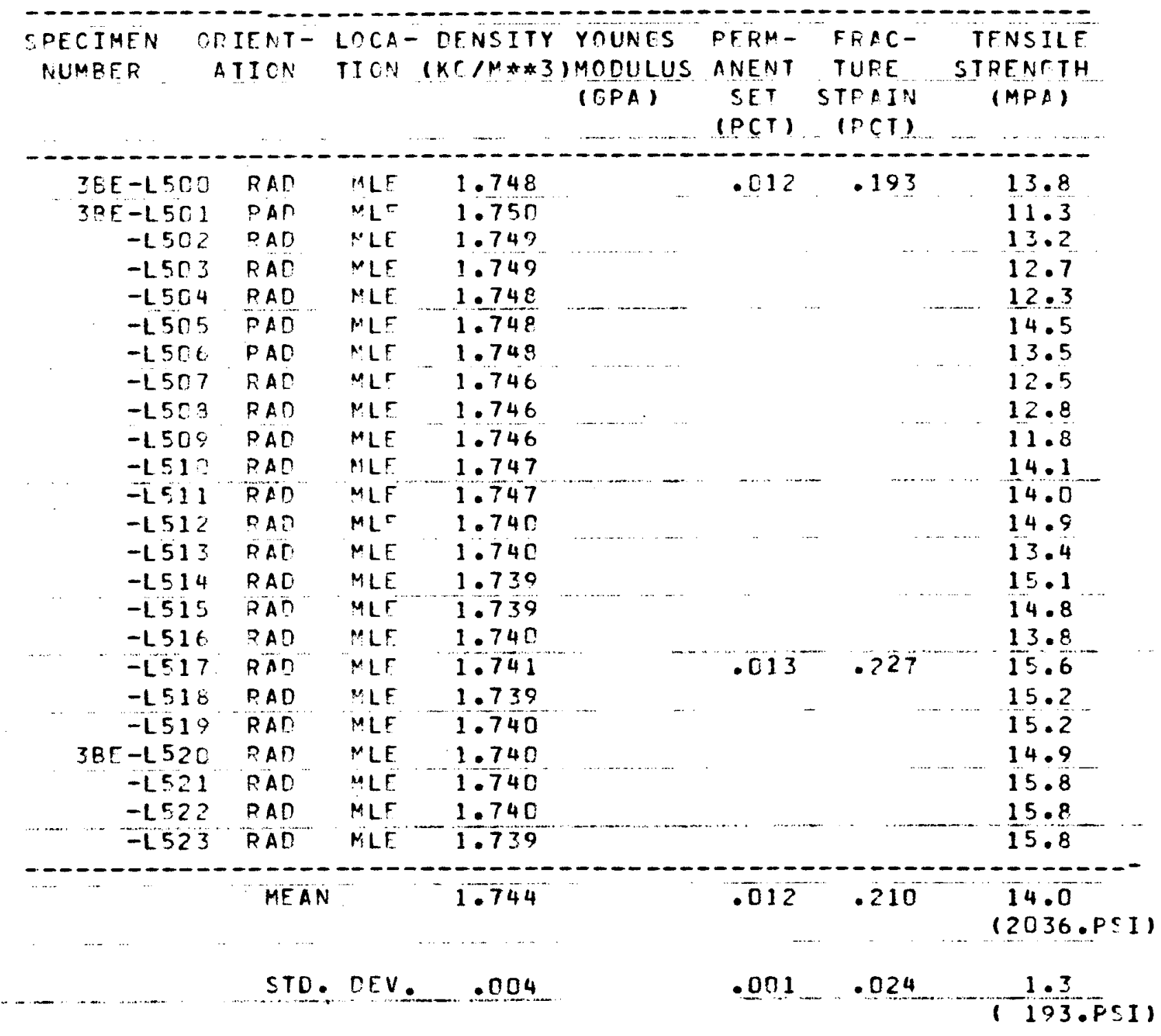


TABLE 33

STRENGTHS OF FOUR-POINT BEND SPECIMENS, SLAB 3, RADIAL ORIENTATION, MIDLENGTH-EDGE LOCATION

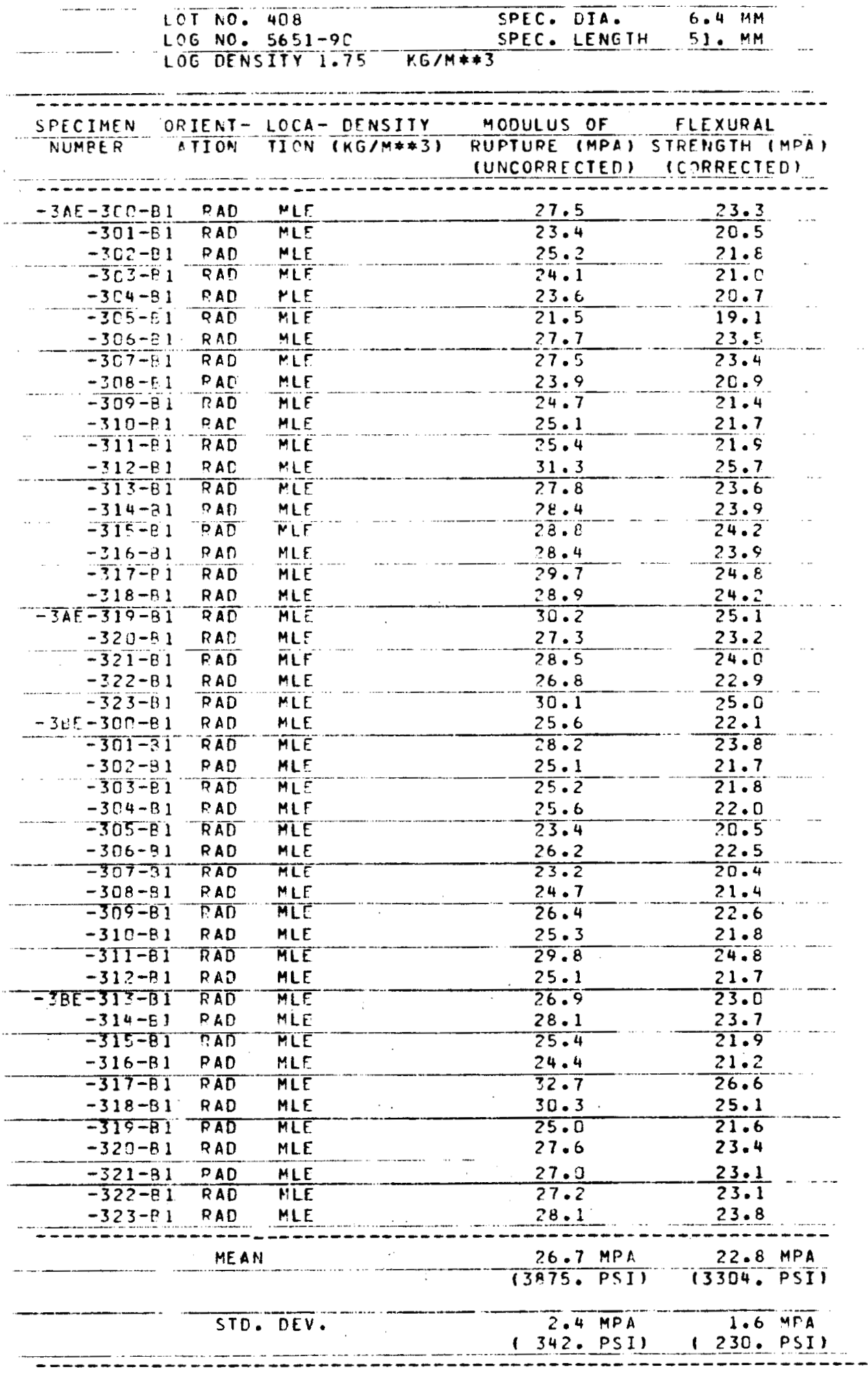


TABLE 34

STRENGTHS OF SMALL-SIZED TENSILE SPECIMENS, SLAB 3, RADIAL ORIENTATION, MIDLENGTH-CENTER LOCATION

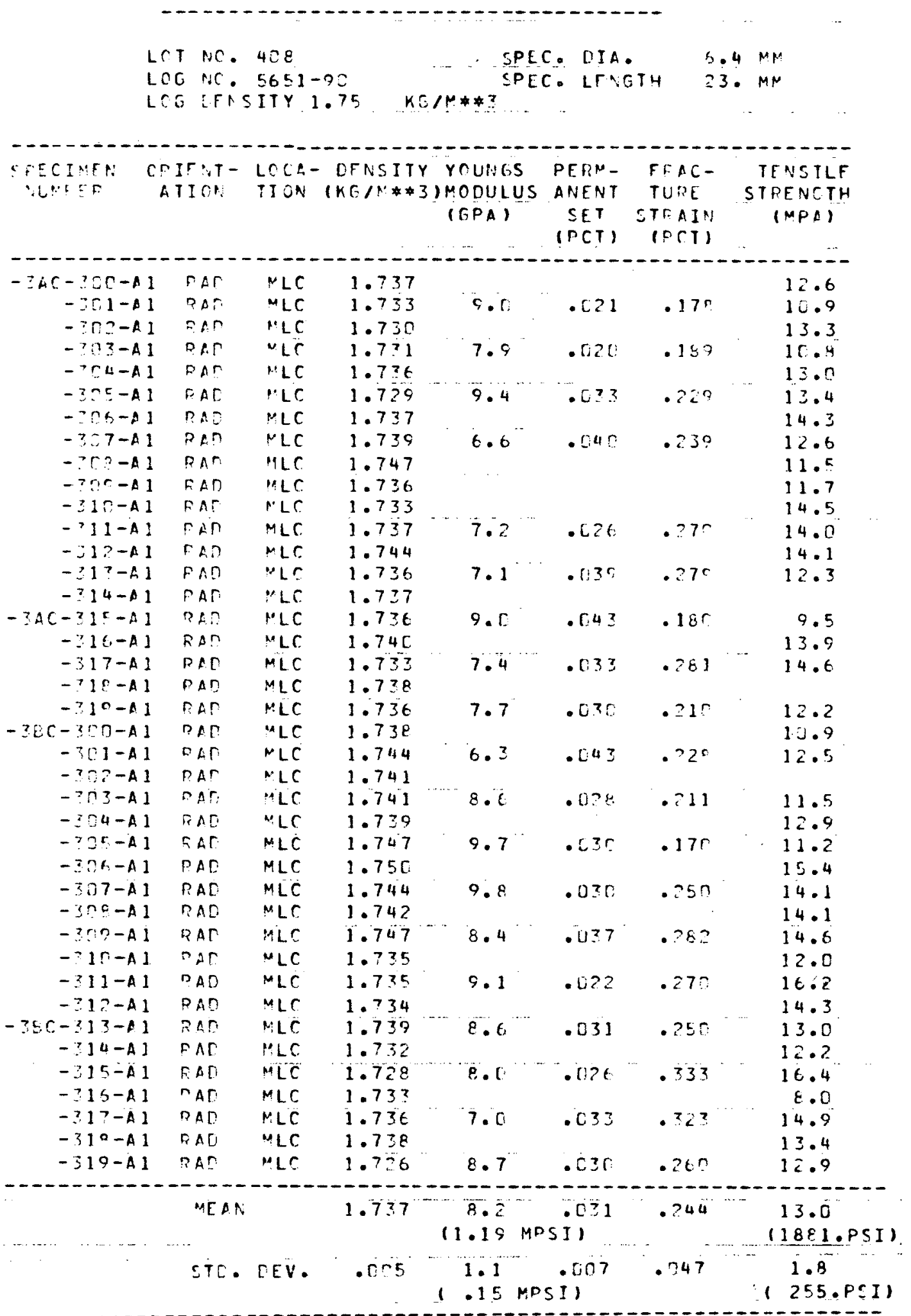


TABLE 35

STRENGTHS OF LARGE-SIZED TENSILE SPECIMENS, SLAB 3, RADIAL ORIENTATION, MIDLENGTH-CENTER LOCATION

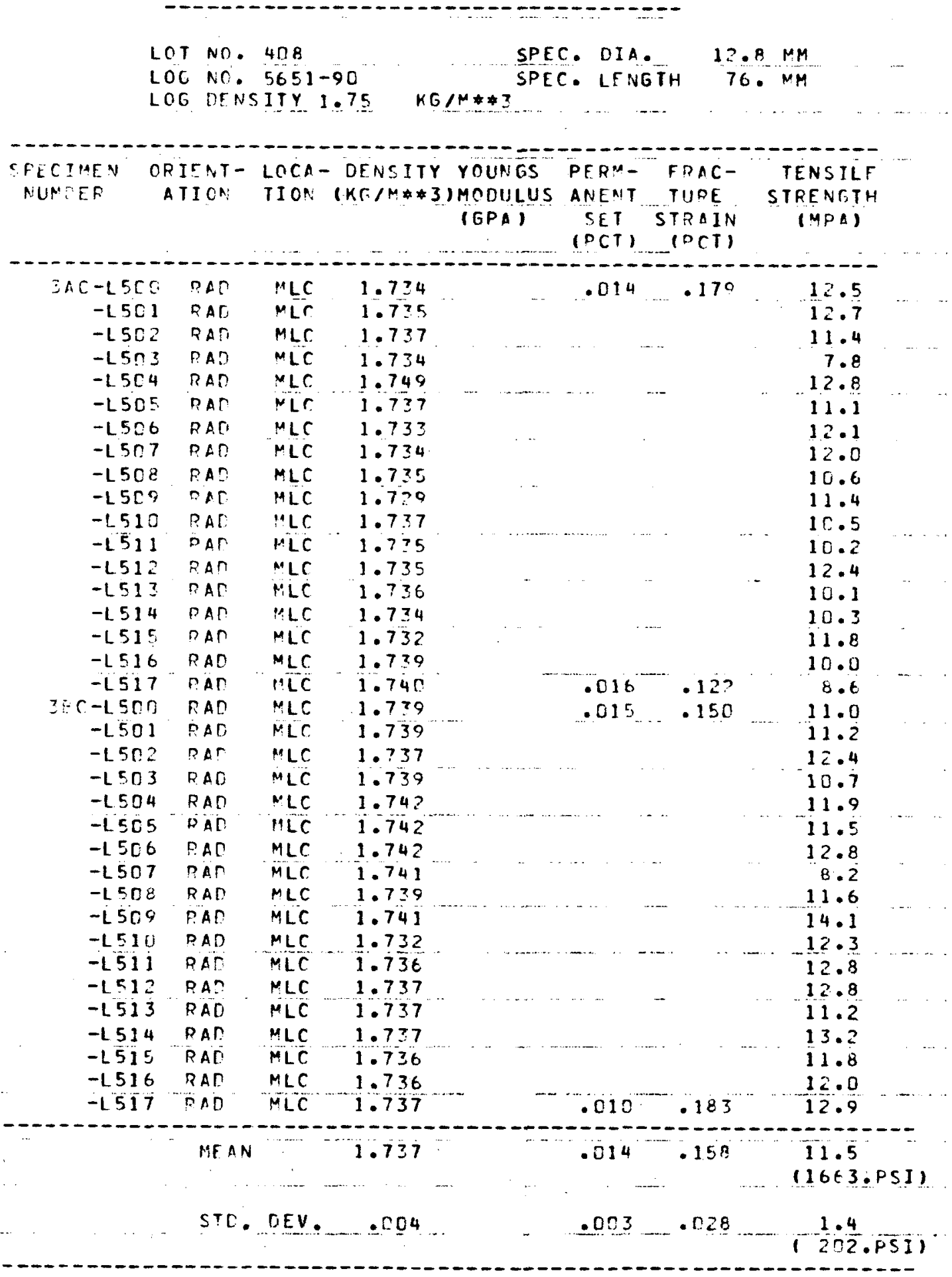


TABLE 36

STRENGTHS OF FOUR-POINT BEND SPECIMENS, SLAB 3, RADIAL ORIENTATION, MIDLENGTH-CENTER LOCATION

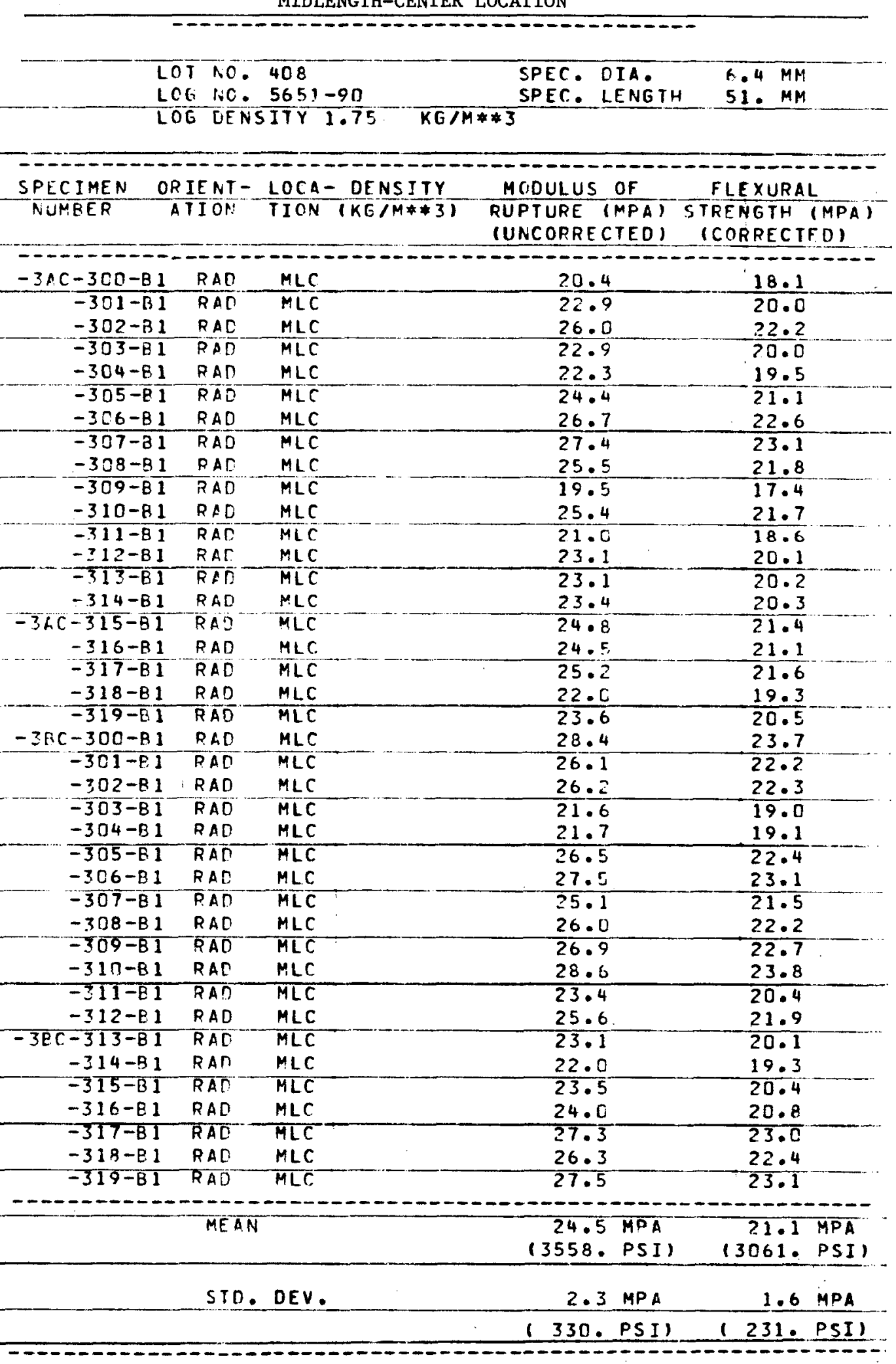


TABLE 37

STRENGTHS OF SMALL-SIZED TENSILE SPECIMENS, SLAB 4, AXIAL ORIENTATION, END-EDGE LOCATION

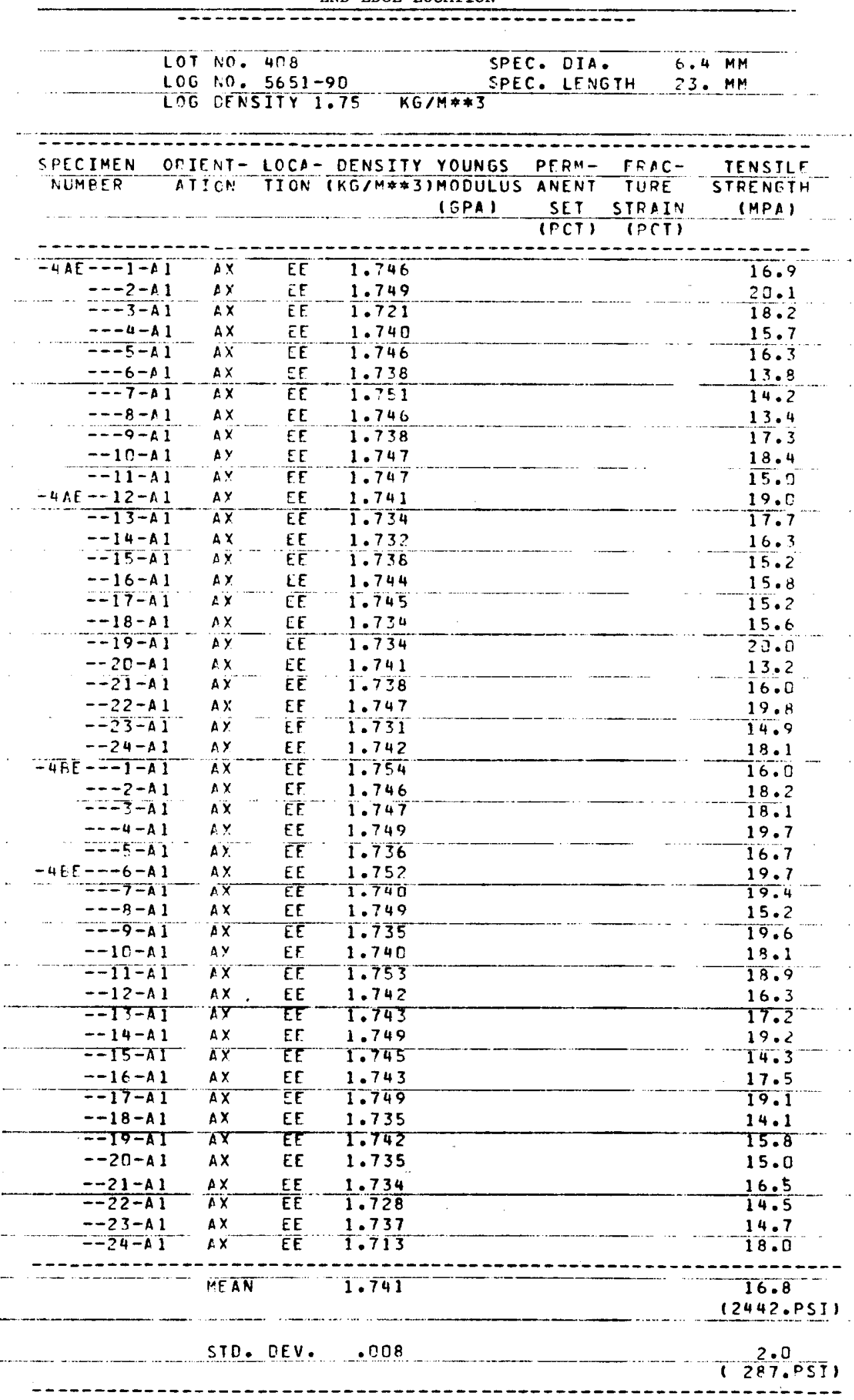


TABLE 38

STRENGTHS OF LARGE-SIZED TENSILE SPECIMENS, SLAB 4, AXIAL ORIENTATION, END-EDGE LOCATION

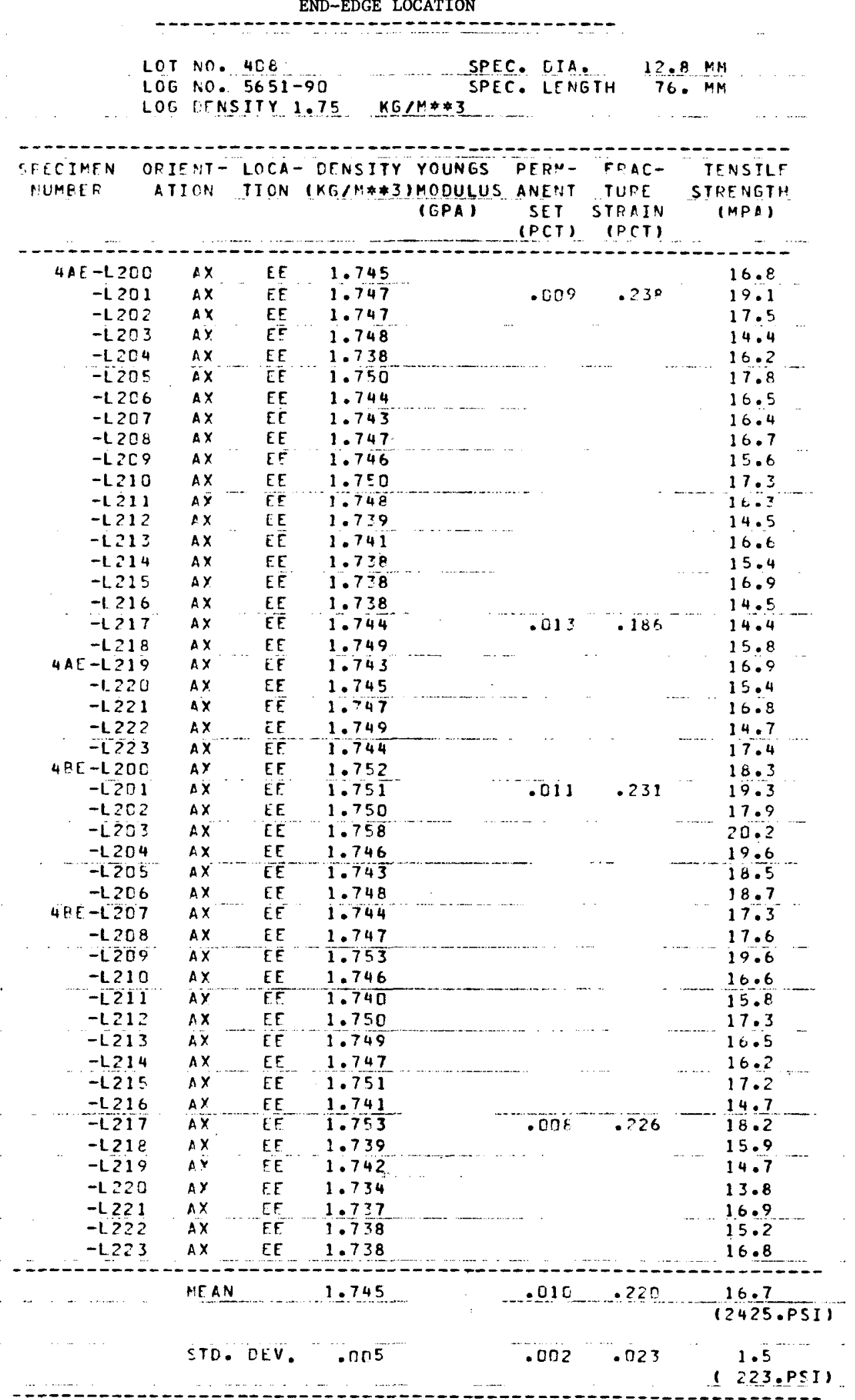


TABLE 39

STRENGTHS OF FOUR-POINT BEND SPECIMENS, SLAB 4, AXIAL ORIENTATION, END-EDGE LOCATION

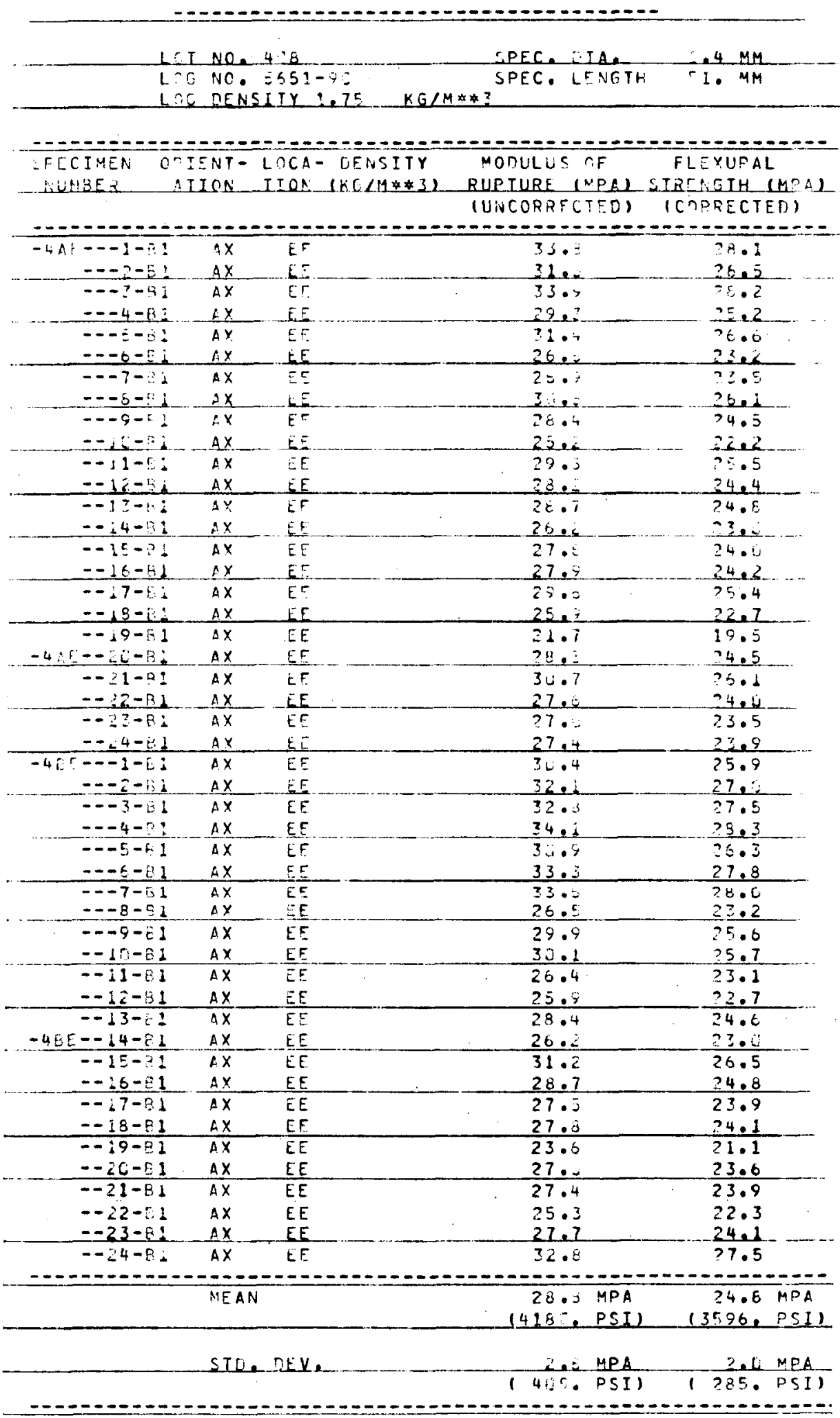


TABLE 40

STRENGTHS OF SMALL-SIZED TENSILE SPECIMENS, SLAB 4, AXIAL ORIENTATION, END-CENTER LOCATION

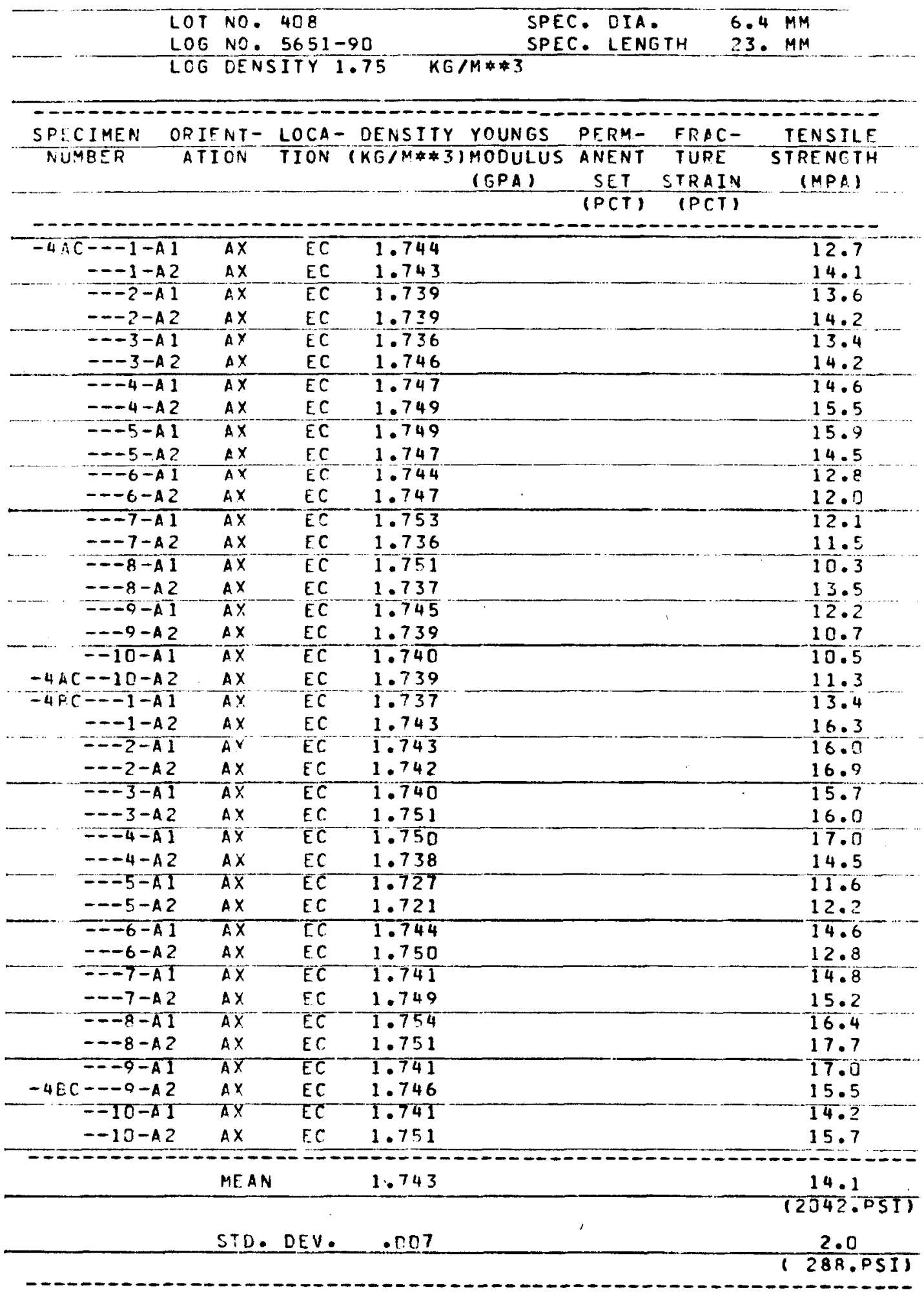


TABLE 41

STRENGTHS OF LARGE-SIZED TENSILE SPECIMENS, SLAB 4, AXIAL ORIENTATION, END-CENTER LOCATION

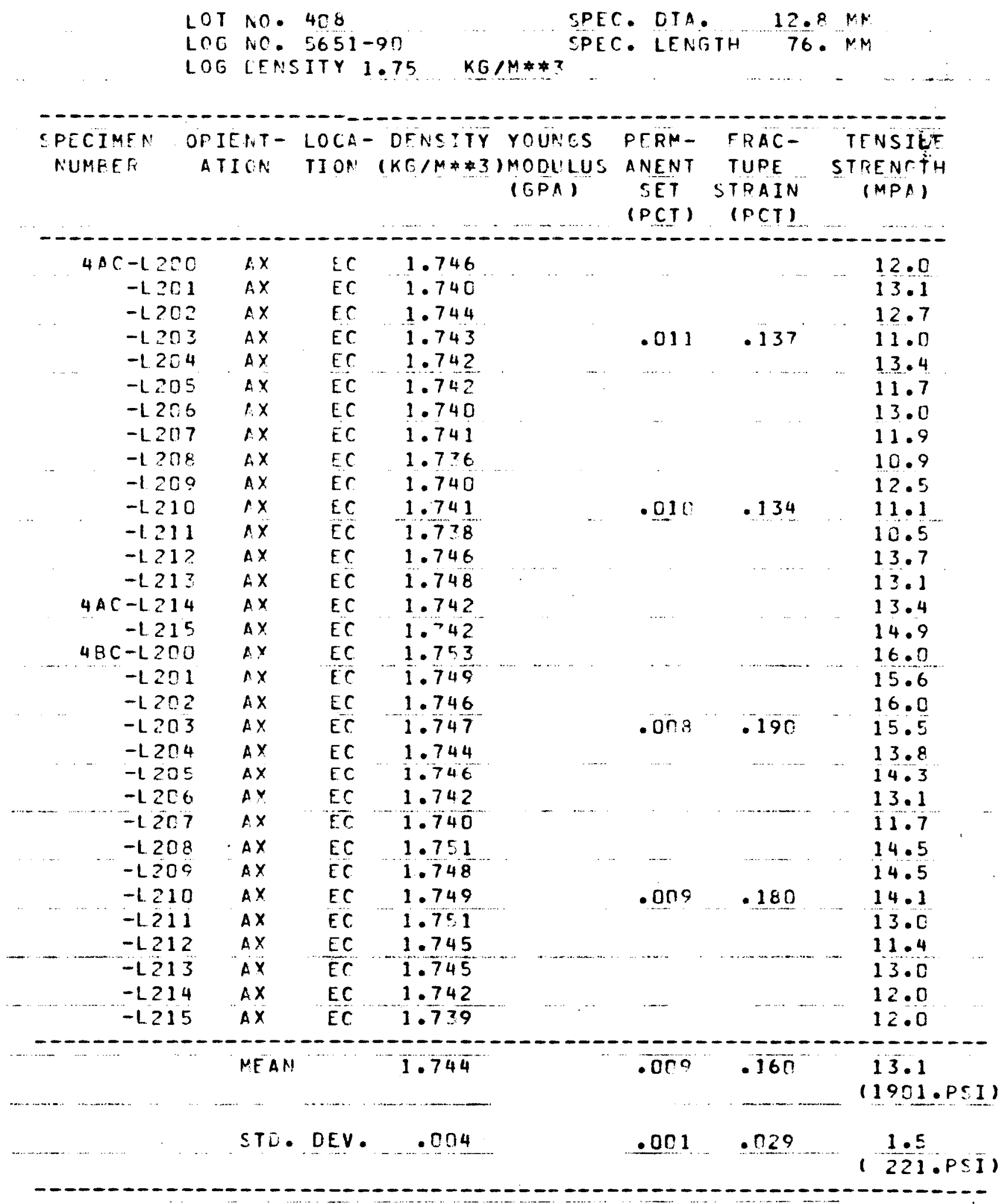


TABLE 42

STRENGTHS OF FOUR-POINT BEND SPECIMENS, SLAB 4, AXIAL ORIENTATION, END-CENTER LOCATION

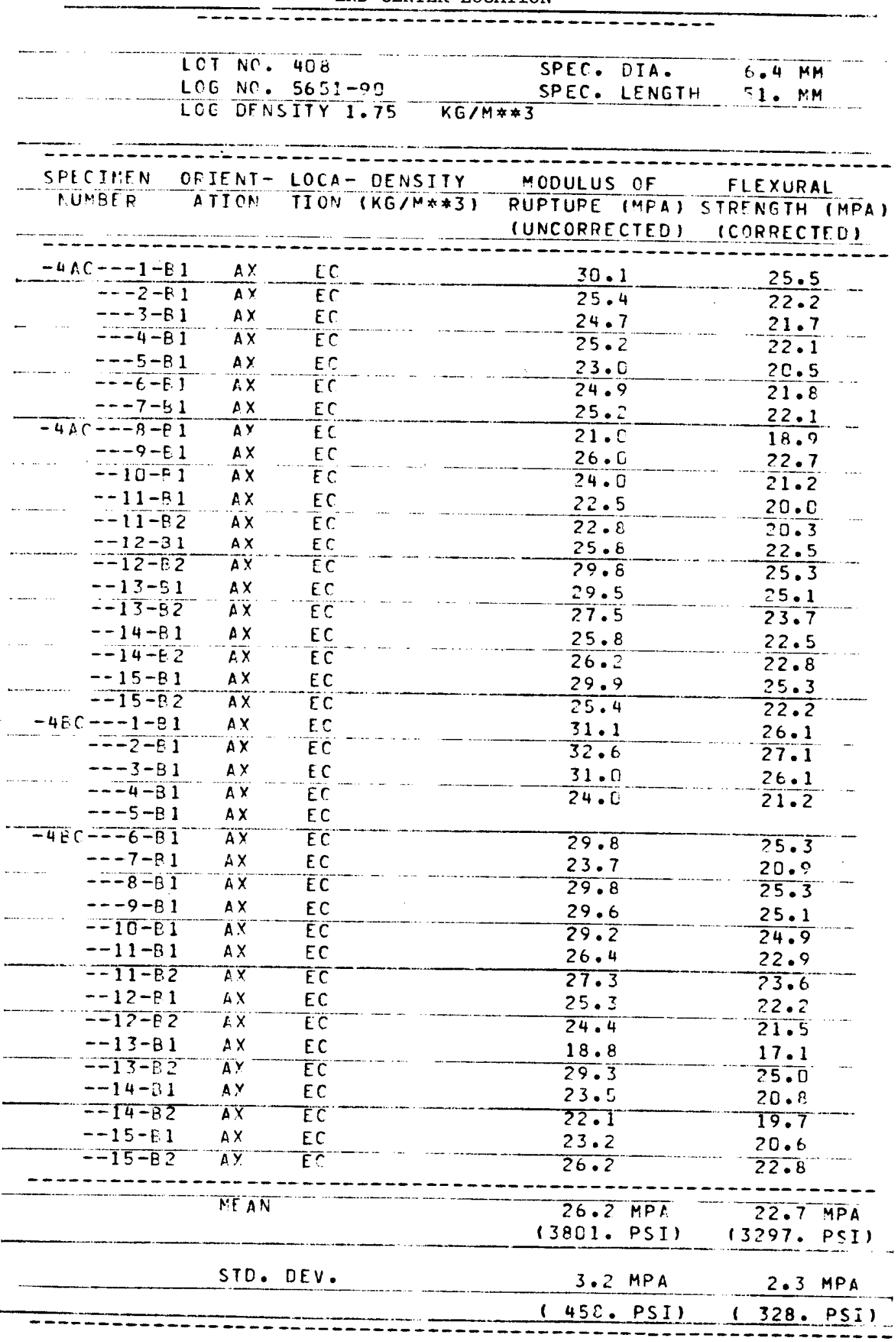


TABLE 43

STRENGTHS OF SMALL-SIZED TENSILE SPECIMENS, SLAB 4, RADIAL ORIENTATION, END-EDGE LOCATION

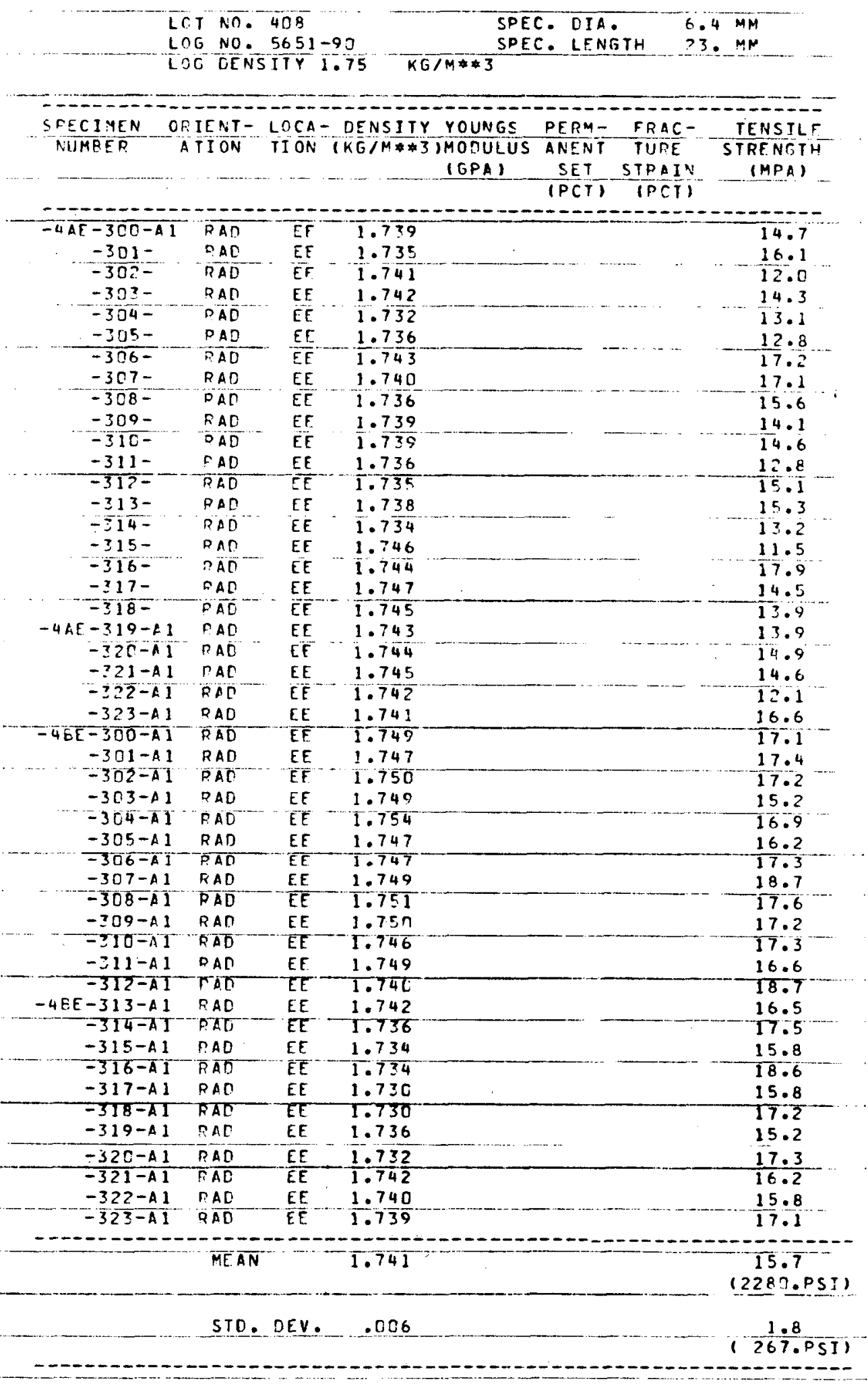


TABLE 44

STRENGTHS OF LARGE-SIZED TENSILE SPECIMENS, SLAB 4, RADIAL ORIENTATION, END-EDGE LOCATION

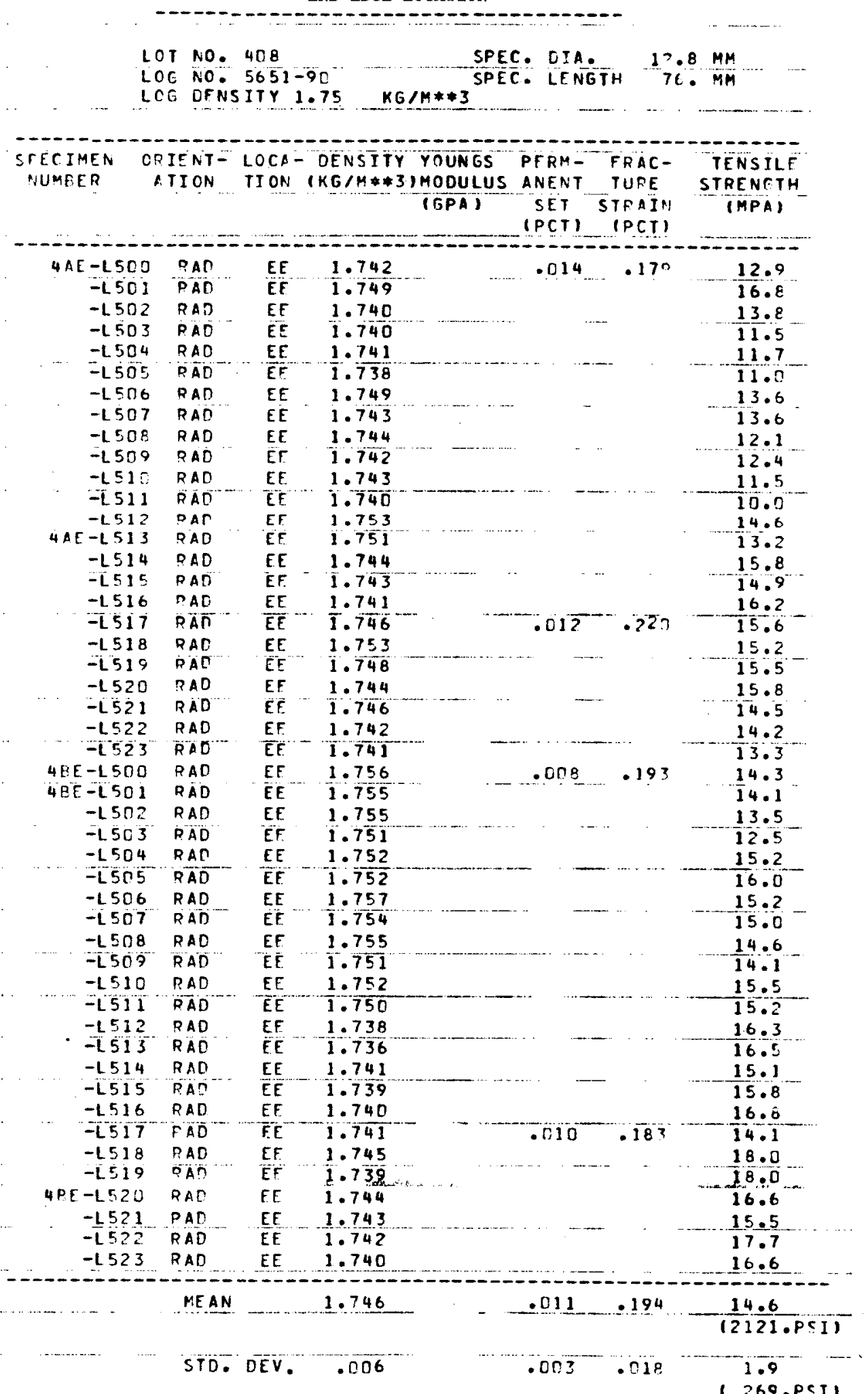


TABLE 45

STRENGTHS OF FOUR-POINT BEND SPECIMENS, SLAB 4, RADIAL ORIENTATION, END-EDGE LOCATION

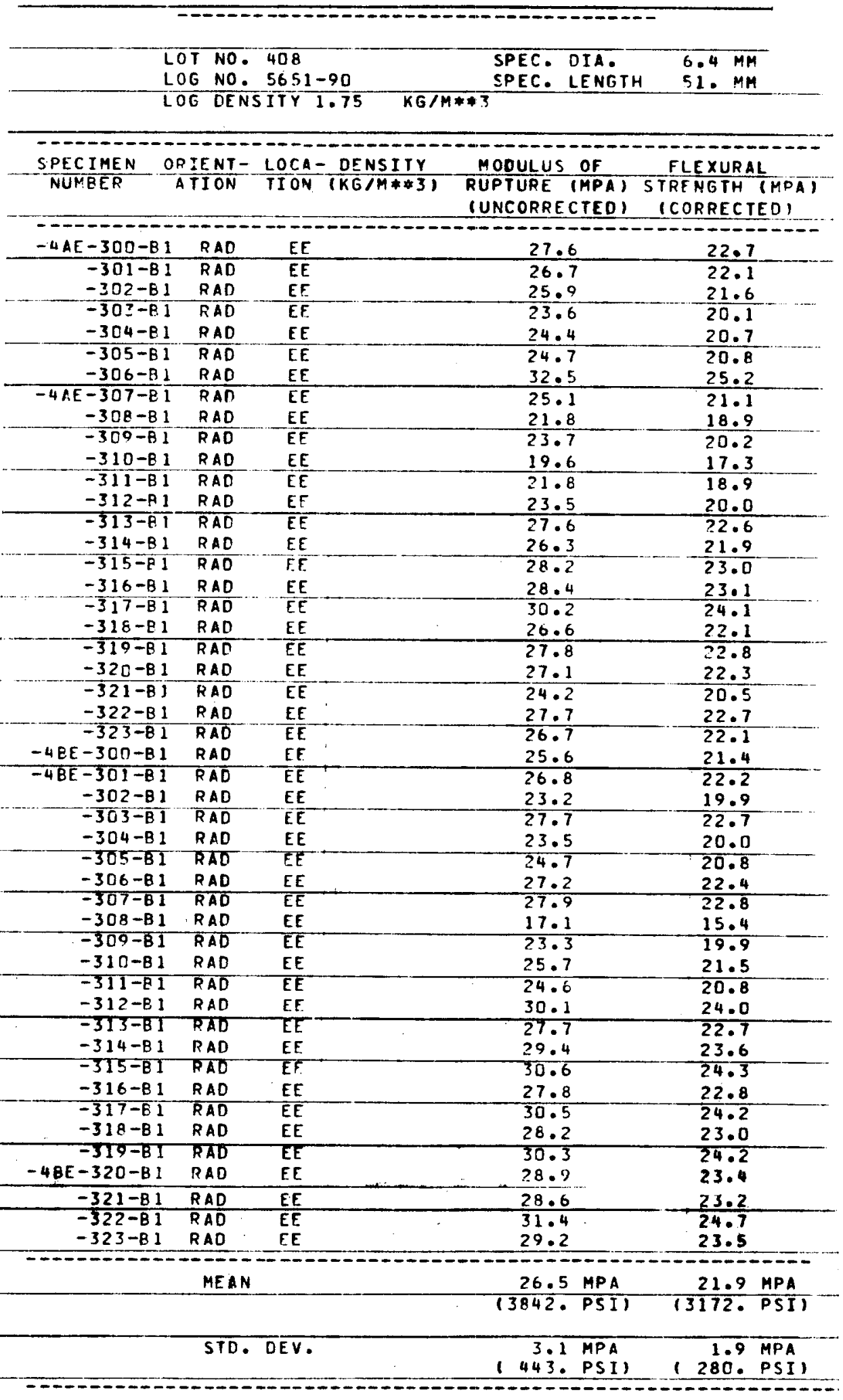


TABLE 46

STRENGTHS OF SMALL-SIZED TENSILE SPECIMENS, SLAB 4, RADIAL ORIENTATION, END-CENTER LOCATION

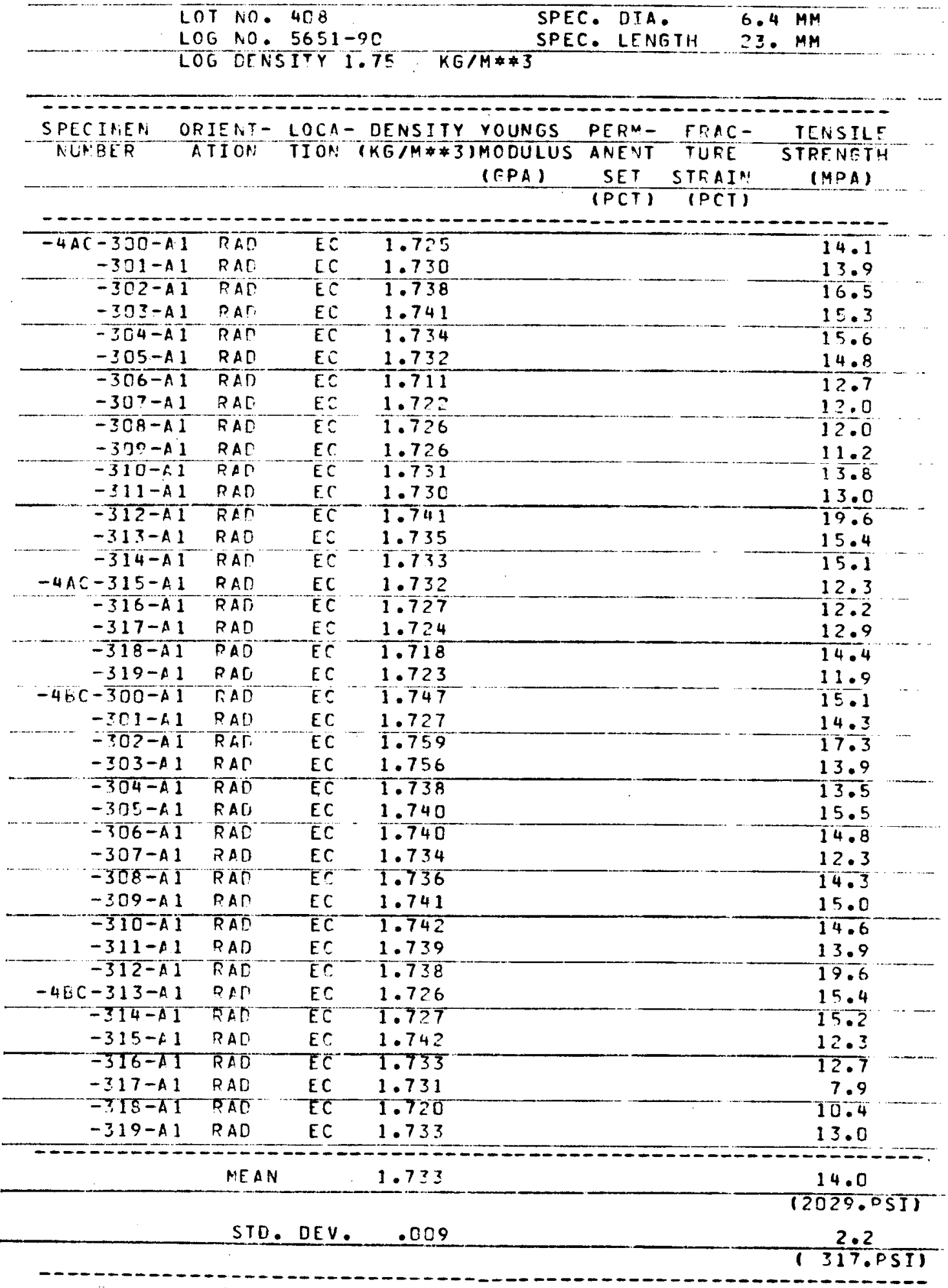


TABLE 47

STRENGTHS OF LARGE-SIZED TENSILE SPECIMENS, SLAB 4, RADIAL ORIENTATION, END-CENTER LOCATION

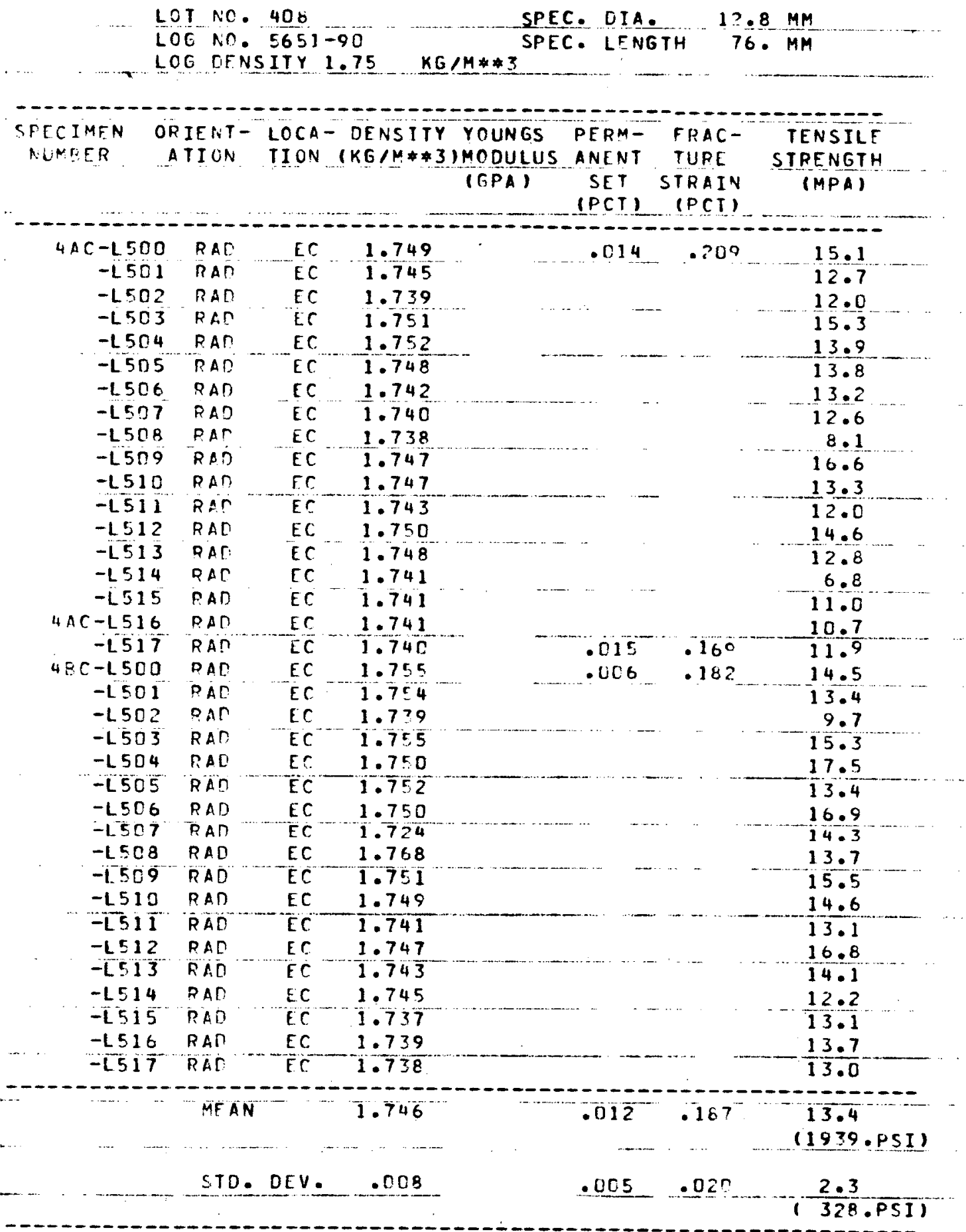


TABLE 48

STRENGTHS OF FOUR-POINT BEND SPECIMENS, SLAB 4, RADIAL ORIENTATION, END-CENTER LOCATION

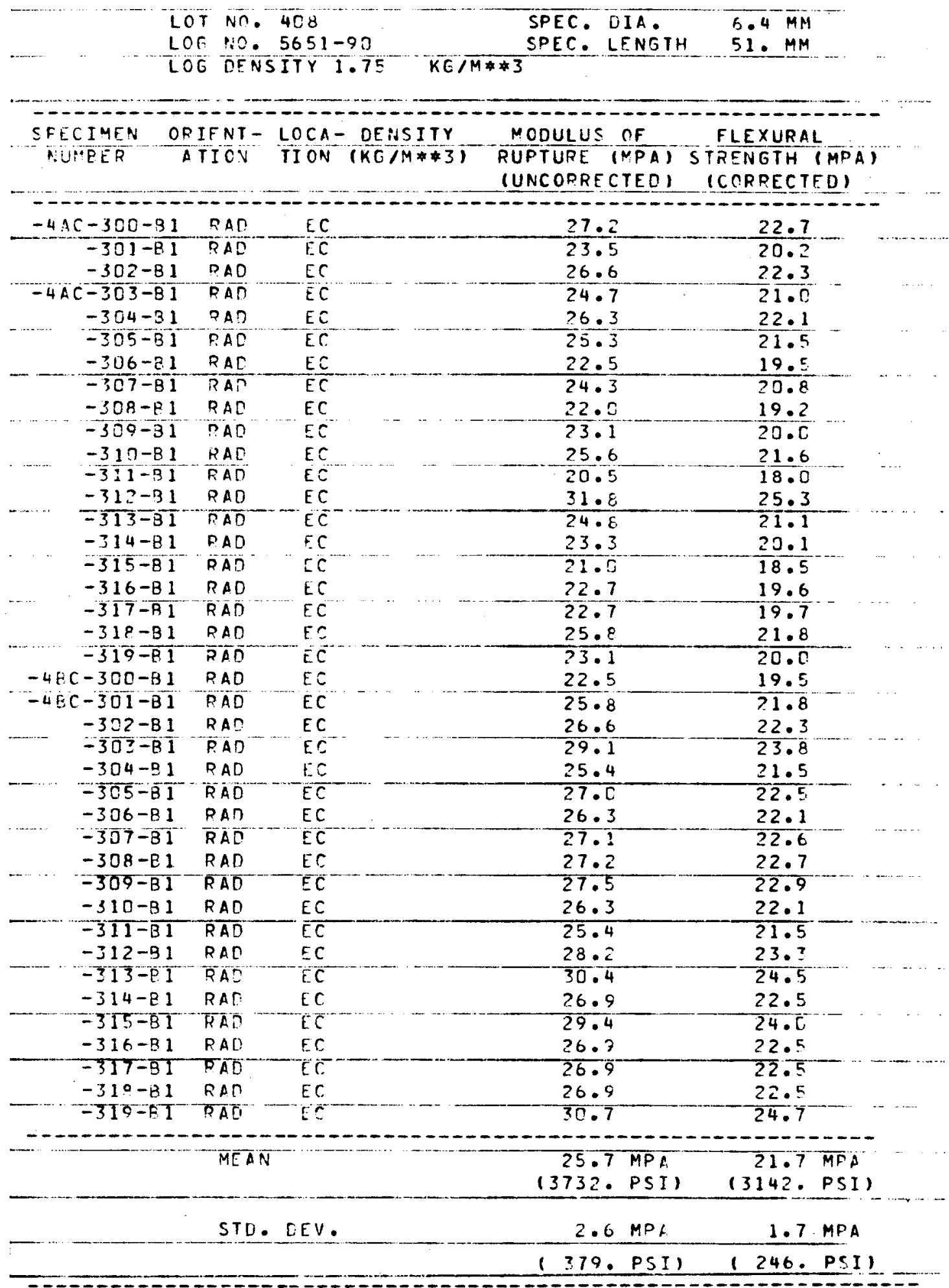


TABLE 49

SUMMARY OF STATISTICAL STUDY OF THE STRENGTH OF H-451 GRAPHITE

Log 5651-90 (GLCC Log 48), S1ab 1 (End of Parent Log)

\begin{tabular}{|c|c|c|c|c|c|c|c|c|c|}
\hline \multirow[b]{3}{*}{ Orientation } & \multirow[b]{3}{*}{$\begin{array}{l}\text { Location in } \\
\text { Parent Log }\end{array}$} & \multirow{3}{*}{$\begin{array}{r}\text { Type of } \\
\text { Specimen }\end{array}$} & \multirow{3}{*}{$\begin{array}{l}\text { No. of } \\
\text { Replicate } \\
\text { Specimens }\end{array}$} & \multicolumn{4}{|c|}{ Strength } & \multirow{2}{*}{\multicolumn{2}{|c|}{ Strength Ratio }} \\
\hline & & & & & Standard & Coefficient of & We1bull & & \\
\hline & & & & $\begin{array}{l}\text { Mean } \\
(\mathrm{MPa})\end{array}$ & $\begin{array}{c}\text { Deviation } \\
\text { (MPa) }\end{array}$ & $\begin{array}{c}\text { Variation } \\
(\%)\end{array}$ & $\begin{array}{c}\text { Modulus, } \\
\text { m }\end{array}$ & $\frac{\text { Small Tensile }}{\text { Large Tensile }}$ & $\frac{\text { Flexural }}{\text { Small Tensile }}$ \\
\hline \multirow[t]{2}{*}{ Axial } & End edge & $\begin{array}{l}\text { Small tensile } \\
\text { Large tensile } \\
\text { Flexural (a) }\end{array}$ & $\begin{array}{l}48 \\
47 \\
48\end{array}$ & $\begin{array}{l}16.4 \\
15.9 \\
24.7\end{array}$ & $\begin{array}{l}2.0 \\
2.2 \\
1.5\end{array}$ & $\begin{array}{r}12.2 \\
13.5 \\
6.3\end{array}$ & $\begin{array}{r}9.4 \\
8.1 \\
19.7\end{array}$ & 1.03 & 1.51 \\
\hline & End center & $\begin{array}{l}\text { Small tensile } \\
\text { Large tensile } \\
\text { Flexural(a) }\end{array}$ & $\begin{array}{l}40 \\
31 \\
25\end{array}$ & $\begin{array}{l}15.9 \\
15.3 \\
23.6\end{array}$ & $\begin{array}{r}2.4 \\
\cdot 1.8 \\
2.4\end{array}$ & $\begin{array}{l}15.4 \\
11.7 \\
10.2\end{array}$ & $\begin{array}{r}7.5 \\
8.9 \\
11.1\end{array}$ & 1.04 & 1.48 \\
\hline \multirow[t]{2}{*}{ Radial } & End edge & $\begin{array}{l}\text { Small tensile } \\
\text { Large tensile } \\
\text { Flexural (a) }\end{array}$ & $\begin{array}{l}47 \\
48 \\
46\end{array}$ & $\begin{array}{l}13.0 \\
12.1 \\
20.3\end{array}$ & $\begin{array}{l}1.9 \\
2.5 \\
2.7\end{array}$ & $\begin{array}{l}14.7 \\
20.3 \\
13.2\end{array}$ & $\begin{array}{l}7.2 \\
5.3 \\
8.0\end{array}$ & 1.07 & 1.56 \\
\hline & End center & $\begin{array}{l}\text { Small tensile } \\
\text { Large tensile } \\
\text { Flexural (a) }\end{array}$ & $\begin{array}{l}38 \\
36 \\
38\end{array}$ & $\begin{array}{l}12.2 \\
10.7 \\
20.3\end{array}$ & $\begin{array}{l}2.3 \\
1.7 \\
1.9\end{array}$ & $\begin{array}{r}18.8 \\
15.9 \\
9.4\end{array}$ & $\begin{array}{r}6.2 \\
7.2 \\
13.1\end{array}$ & 1.14 & 1.66 \\
\hline
\end{tabular}

${ }^{(a)}$ Corrected for nonlinear stress-strain relationship. 
TABLE 50

SUMMARY OF STATISTICAL STUDY OF THE STRENGTH OF H-451 GRAPHITE

Log 5651-90 (GLCC Log 48), Slab 2 (Midlength of Parent Log)

\begin{tabular}{|c|c|c|c|c|c|c|c|c|c|}
\hline \multirow[b]{3}{*}{ Orientation } & \multirow[b]{3}{*}{$\begin{array}{l}\text { Location in } \\
\text { Parent Log }\end{array}$} & \multirow[b]{3}{*}{$\begin{array}{l}\text { Type of } \\
\text { Specimen }\end{array}$} & \multirow{3}{*}{$\begin{array}{l}\text { No. of } \\
\text { Replicate } \\
\text { Specimens }\end{array}$} & \multicolumn{4}{|c|}{ Strength } & \multirow{2}{*}{\multicolumn{2}{|c|}{ Strength Ratio }} \\
\hline & & & & & Standard & Coefficient of & Weibull & & \\
\hline & & & & $\begin{array}{l}\text { Mean } \\
(\mathrm{MPa}) \\
\end{array}$ & $\begin{array}{c}\text { Deviation } \\
\text { (MPa) }\end{array}$ & $\begin{array}{c}\begin{array}{c}\text { Variation } \\
(\%)\end{array} \\
\end{array}$ & $\begin{array}{c}\text { Modulus, } \\
\text { m }\end{array}$ & $\frac{\text { Small Tensile }}{\text { Large Tensile }}$ & $\frac{\text { Flexural }}{\text { Small Tensile }}$ \\
\hline \multirow[t]{2}{*}{ Axial } & Midlength edge & $\begin{array}{l}\text { Small tensile } \\
\text { Large tensile } \\
\text { Flexural (a) }\end{array}$ & $\begin{array}{l}46 \\
48 \\
48\end{array}$ & $\begin{array}{l}18.2 \\
17.6 \\
24.8\end{array}$ & $\begin{array}{l}1.7 \\
1.7 \\
2.1\end{array}$ & $\begin{array}{l}9.4 \\
9.9 \\
8.3\end{array}$ & $\begin{array}{l}12.6 \\
11.8 \\
14.5\end{array}$ & 1.03 & 1.36 \\
\hline & Midlength center & $\begin{array}{l}\text { Small tensile } \\
\text { Large tensile } \\
\text { Flexural }(a)\end{array}$ & $\begin{array}{l}38 \\
32 \\
40\end{array}$ & $\begin{array}{l}15.0 \\
14.7 \\
22.6\end{array}$ & $\begin{array}{l}1.3 \\
1.1 \\
1.2\end{array}$ & $\begin{array}{l}8.6 \\
7.3 \\
5.1\end{array}$ & $\begin{array}{l}13.4 \\
15.2 \\
22.9\end{array}$ & 1.02 & 1.51 \\
\hline \multirow[t]{2}{*}{ Radial } & Midlength edge & $\begin{array}{l}\text { Small tensile } \\
\text { Large tensile } \\
\text { Flexural }(a)\end{array}$ & $\begin{array}{l}48 \\
48 \\
48\end{array}$ & $\begin{array}{l}15.2 \\
13.9 \\
21.3\end{array}$ & $\begin{array}{l}1.8 \\
2.0 \\
1.8\end{array}$ & $\begin{array}{r}11.9 \\
14.5 \\
8.3\end{array}$ & $\begin{array}{r}9.7 \\
8.0 \\
14.9\end{array}$ & 1.09 & 1.40 \\
\hline & Midlength center & $\begin{array}{l}\text { Small tensile } \\
\text { Large tensile } \\
\text { Flexural }(a)\end{array}$ & $\begin{array}{l}38 \\
35 \\
38\end{array}$ & $\begin{array}{l}12.3 \\
11.8 \\
19.9\end{array}$ & $\begin{array}{l}2.8 \\
1.1 \\
1.9\end{array}$ & $\begin{array}{r}22.6 \\
9.6 \\
9.6\end{array}$ & $\begin{array}{r}4.6 \\
12.4 \\
12.3\end{array}$ & 1.04 & 1.62 \\
\hline
\end{tabular}

${ }^{(a)}$ Corrected for nonlinear stress-strain relationship. 
TABLE 51

SUMMARY OF STATISTICAL STUDY OF THE STRENGTH OF H-451 GRAPHITE Log 5651-90 (GLCC Log 48), Slab 3 (Midlength of Parent Log)

\begin{tabular}{|c|c|c|c|c|c|c|c|c|c|}
\hline \multirow[b]{3}{*}{ Orientation } & \multirow[b]{3}{*}{$\begin{array}{l}\text { Location in } \\
\text { Parent Log }\end{array}$} & \multirow[b]{3}{*}{$\begin{array}{l}\text { Type of } \\
\text { Specimen }\end{array}$} & \multirow{3}{*}{$\begin{array}{c}\text { No. of } \\
\text { Replicate } \\
\text { Specimens }\end{array}$} & \multicolumn{4}{|c|}{ Strength } & \multirow{2}{*}{\multicolumn{2}{|c|}{ Strength Ratio }} \\
\hline & & & & & Standard & Coefficient of & Weibull & & \\
\hline & & & & $\begin{array}{l}\text { Mean } \\
\text { (MPa) }\end{array}$ & $\begin{array}{c}\text { Deviation } \\
(\mathrm{MPa})\end{array}$ & $\begin{array}{c}\text { Variation } \\
(\%)\end{array}$ & $\begin{array}{l}\text { Modulus, } \\
\text { m }\end{array}$ & $\frac{\text { Small Tensile }}{\text { Large Tensile }}$ & $\frac{\text { Flexural }}{\text { Small Tensile }}$ \\
\hline \multirow[t]{2}{*}{ Axial } & Midlength edge & $\begin{array}{l}\text { Small tensile } \\
\text { Large tensile } \\
\text { Flexural (a) }\end{array}$ & $\begin{array}{l}48 \\
48 \\
48\end{array}$ & $\begin{array}{l}17.0 \\
17.0 \\
25.8\end{array}$ & $\begin{array}{l}1.9 \\
1.7 \\
2.2\end{array}$ & $\begin{array}{r}11.4 \\
9.9 \\
8.4\end{array}$ & $\begin{array}{l}10.0 \\
11.9 \\
14.1\end{array}$ & 1.00 & 1.52 \\
\hline & Midlength center & $\begin{array}{l}\text { Small tensile } \\
\text { Large tensile } \\
\text { Flexural (a) }\end{array}$ & $\begin{array}{l}40 \\
31 \\
40\end{array}$ & $\begin{array}{l}13.7 \\
13.3 \\
22.8\end{array}$ & $\begin{array}{l}2.0 \\
1.1 \\
1.6\end{array}$ & $\begin{array}{r}14.4 \\
8.0 \\
6.8\end{array}$ & $\begin{array}{r}6.8 \\
14.4 \\
17.1\end{array}$ & 1.05 & 1.66 \\
\hline \multirow[t]{2}{*}{ Radial } & Midlength edge & $\begin{array}{l}\text { Small tensile } \\
\text { Large tensile } \\
\text { Flexural (a) }\end{array}$ & $\begin{array}{l}47 \\
24 \\
48\end{array}$ & $\begin{array}{l}14.1 \\
14.0 \\
22.8\end{array}$ & $\begin{array}{l}2.1 \\
1.3 \\
1.6\end{array}$ & $\begin{array}{r}15.2 \\
9.5 \\
7.0\end{array}$ & $\begin{array}{r}6.8 \\
12.1 \\
17.0\end{array}$ & 1.01 & 1.62 \\
\hline & Midlength center & $\begin{array}{l}\text { Small tensile } \\
\text { Large tensile } \\
\text { Flexural (a) }\end{array}$ & $\begin{array}{l}37 \\
36 \\
40\end{array}$ & $\begin{array}{l}13.0 \\
11.5 \\
21.1\end{array}$ & $\begin{array}{l}1.8 \\
1.4 \\
1.6\end{array}$ & $\begin{array}{r}13.6 \\
12.1 \\
7.5\end{array}$ & $\begin{array}{r}8.3 \\
9.1 \\
15.7\end{array}$ & 1.13 & 1.62 \\
\hline
\end{tabular}

${ }^{(a)}$ Corrected for nonlinear stress-strain relationship. 
TABLE 52

SUMMARY OF STATISTICAL STUDY OF THE STRENGTH OF H-451 GRAPHITE

Log 5651-90 (GLCC Log 48), Slab 4 (End of Parent Log)

\begin{tabular}{|c|c|c|c|c|c|c|c|c|c|}
\hline \multirow[b]{3}{*}{ Orientation } & \multirow[b]{3}{*}{$\begin{array}{l}\text { Location in } \\
\text { Parent Log }\end{array}$} & \multirow[b]{3}{*}{$\begin{array}{l}\text { Type of } \\
\text { Specimen }\end{array}$} & \multirow{3}{*}{$\begin{array}{l}\text { No, of } \\
\text { Replicate } \\
\text { Specimens }\end{array}$} & \multicolumn{4}{|c|}{ Strength } & \multirow{2}{*}{\multicolumn{2}{|c|}{ Strength Ratio }} \\
\hline & & & & & Standard & Coefficient of & Weibull & & \\
\hline & & & & $\begin{array}{l}\text { Mean } \\
(\mathrm{MPa})\end{array}$ & $\begin{array}{c}\text { Deviation } \\
(\mathrm{MPa})\end{array}$ & $\begin{array}{c}\text { Variation } \\
(\%)\end{array}$ & $\begin{array}{l}\text { Modulus, } \\
\text { m }\end{array}$ & $\frac{\text { Small Tensile }}{\text { Large Tensile }}$ & $\frac{\text { Flexural }}{\text { Small Tensile }}$ \\
\hline \multirow[t]{2}{*}{ Axial } & End edge & $\begin{array}{l}\text { Small tensile } \\
\text { Large tensile } \\
\text { Flexural (a) }\end{array}$ & $\begin{array}{l}48 \\
48 \\
48\end{array}$ & $\begin{array}{l}16.8 \\
16.7 \\
24.8\end{array}$ & $\begin{array}{l}2.0 \\
1.5 \\
2.0\end{array}$ & $\begin{array}{r}11.8 \\
9.2 \\
7.9\end{array}$ & $\begin{array}{l}10.0 \\
12.9 \\
14.9\end{array}$ & 1.01 & 1.48 \\
\hline & End center & $\begin{array}{l}\text { Small tenstle } \\
\text { Large tensile } \\
\text { Flexural (a) }\end{array}$ & $\begin{array}{l}40 \\
32 \\
39\end{array}$ & $\begin{array}{l}14.1 \\
13.1 \\
22.7\end{array}$ & $\begin{array}{l}2.0 \\
1.5 \\
2.3\end{array}$ & $\begin{array}{r}14.1 \\
11.6 \\
9.9\end{array}$ & $\begin{array}{r}8.2 \\
10.0 \\
11.7\end{array}$ & 1.08 & 1.61 \\
\hline \multirow[t]{2}{*}{ Radial } & End edge & $\begin{array}{l}\text { Small tensile } \\
\text { Large tenstle } \\
\text { Flexural (a) }\end{array}$ & $\begin{array}{l}48 \\
48 \\
48\end{array}$ & $\begin{array}{l}15.7 \\
14.6 \\
21.9\end{array}$ & $\begin{array}{l}1.8 \\
1.9 \\
1.9\end{array}$ & $\begin{array}{r}11.7 \\
12.7 \\
8.8\end{array}$ & $\begin{array}{r}9.9 \\
9.2 \\
12.9\end{array}$ & 1.08 & 1.39 \\
\hline & End center & $\begin{array}{l}\text { Small tensile } \\
\text { Large tensile } \\
\text { Flexura1 (a) }\end{array}$ & $\begin{array}{l}40 \\
36 \\
40\end{array}$ & $\begin{array}{l}14.0 \\
13.4 \\
21.7\end{array}$ & $\begin{array}{l}2.2 \\
2.3 \\
1.7\end{array}$ & $\begin{array}{r}15.6 \\
16.9 \\
7.8\end{array}$ & $\begin{array}{r}7.2 \\
6.2 \\
15.0\end{array}$ & 1.04 & 1.55 \\
\hline
\end{tabular}

(a) Corrected for nonlinear stress-strain relationship. 
TABLE 53

MEAN VALUES OF COEFFICIENT OF VARIATION AND WEIBULL MODULUS FOR STRENGTH OF H-451 GRAPHITE, LOG 5651-90

\begin{tabular}{c|l|c|c}
\hline Orientation & $\begin{array}{c}\text { Type of } \\
\text { Test }\end{array}$ & $\begin{array}{c}\text { Coefficient of } \\
\text { Variation } \\
(\%)\end{array}$ & $\begin{array}{c}\text { Weibull } \\
\text { Modulus, } \\
\mathrm{m}\end{array}$ \\
\hline Axial & Tensile & 11.2 & 10.7 \\
Axial & Bend & 7.9 & 15.8 \\
Radial & Tensile & 14.7 & 8.1 \\
Radial & Bend & 9.0 & 13.6 \\
\hline
\end{tabular}




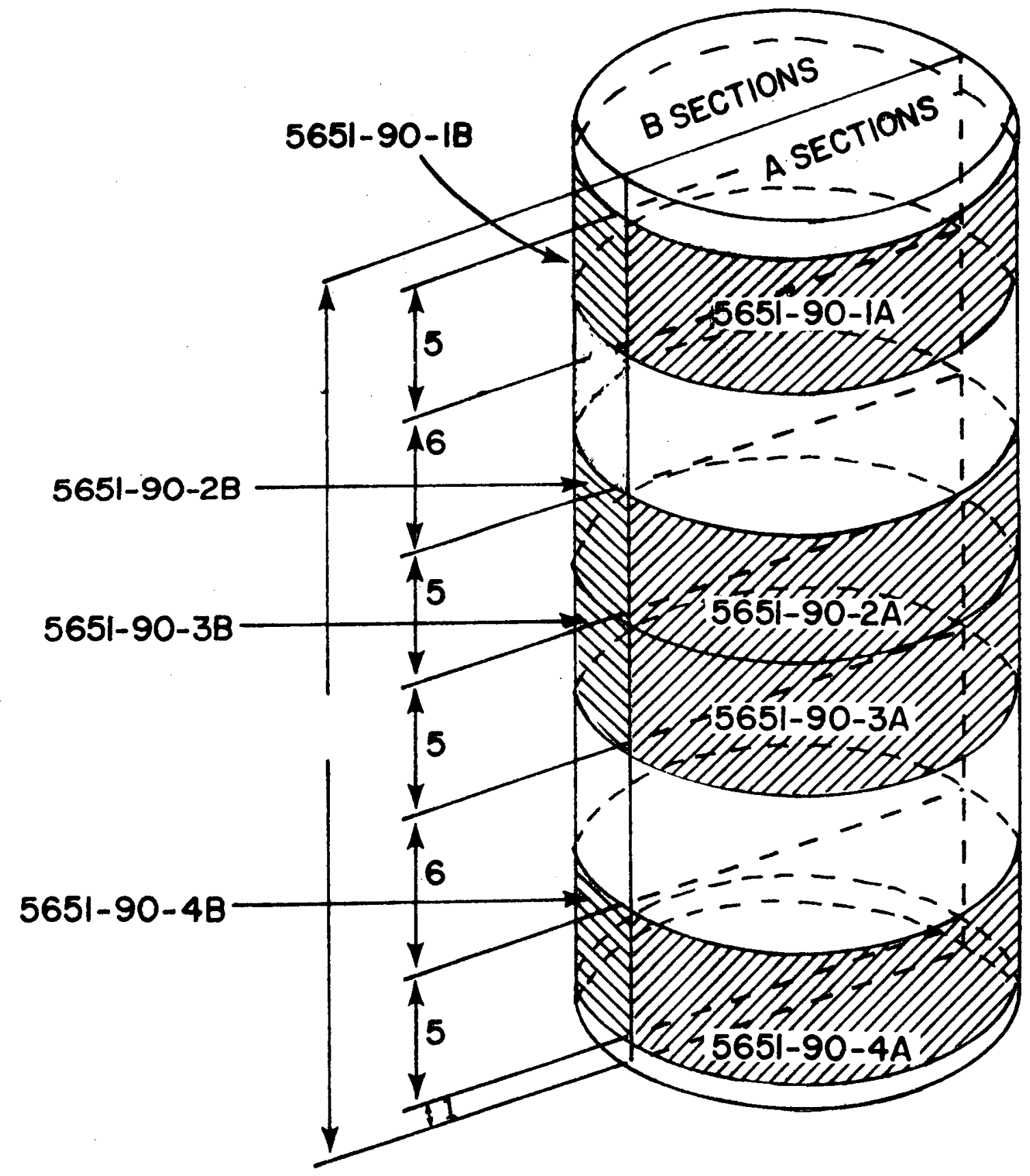

Fig. 1. Locations of slabs (shaded) for statistical strength testing in $\log 5651-90$ of $\mathrm{H}-451$ graphite 


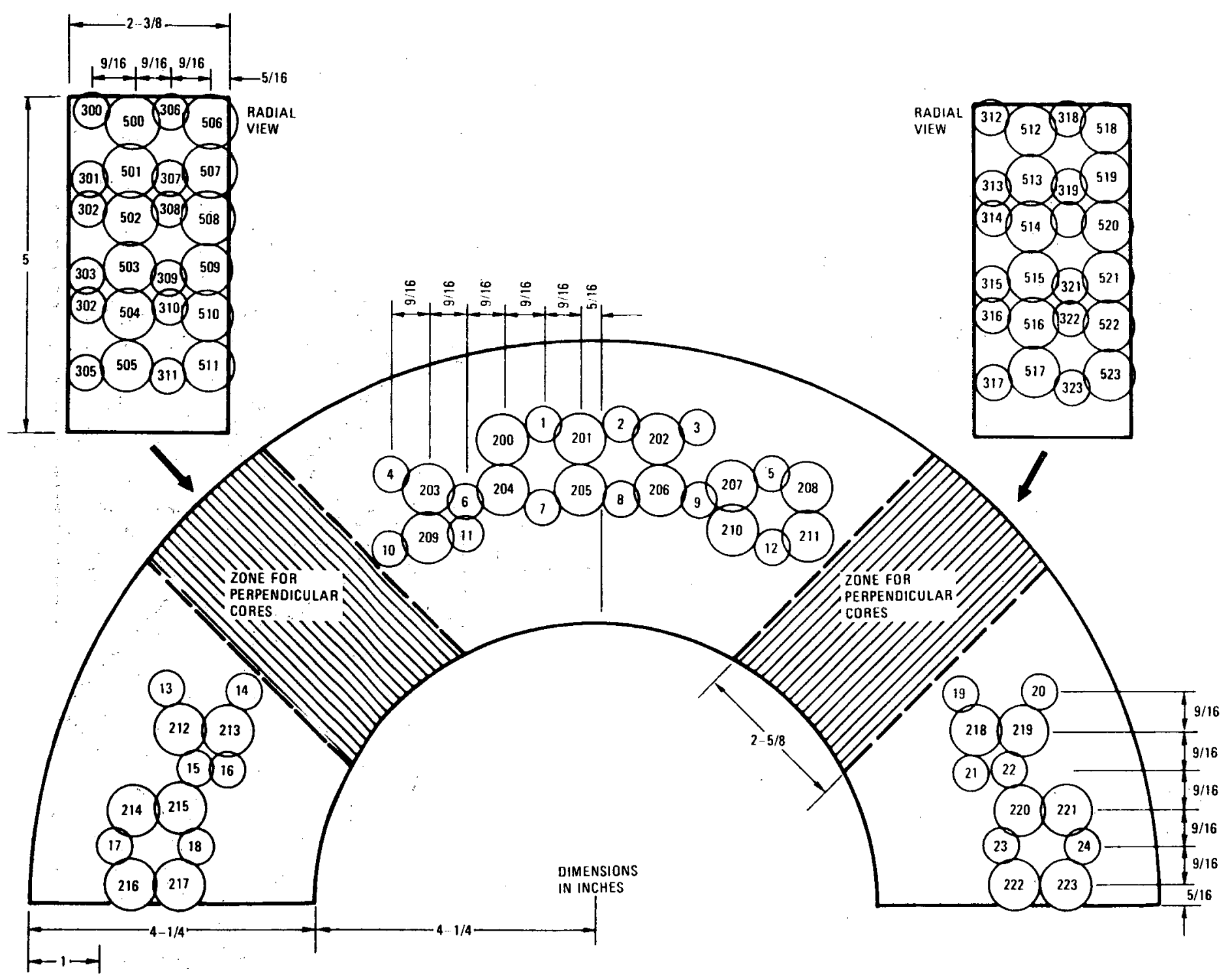

Fig. 2. Coring plan for edge zone of slab 


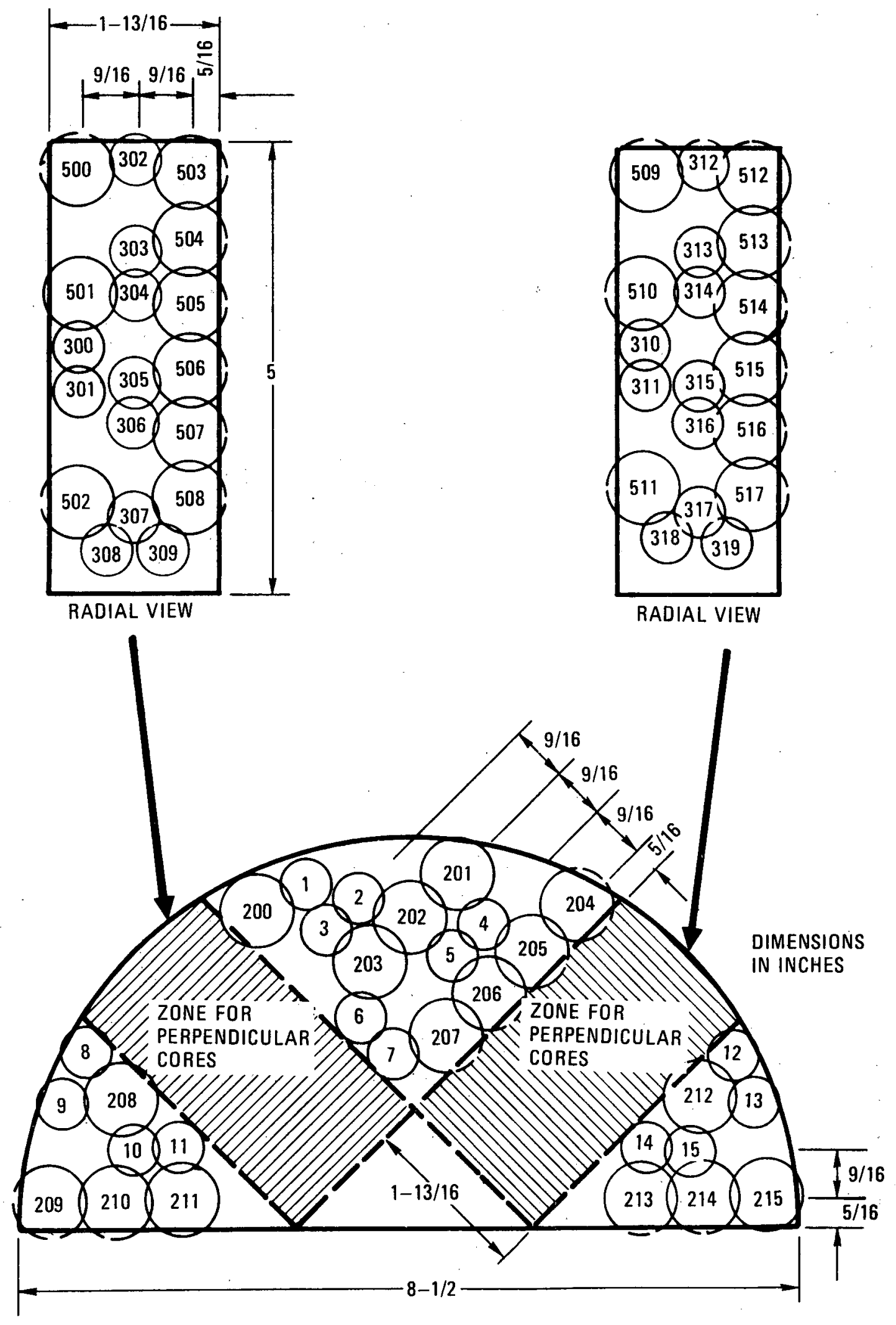

Fig. 3. Coring plan for center zone of slab 


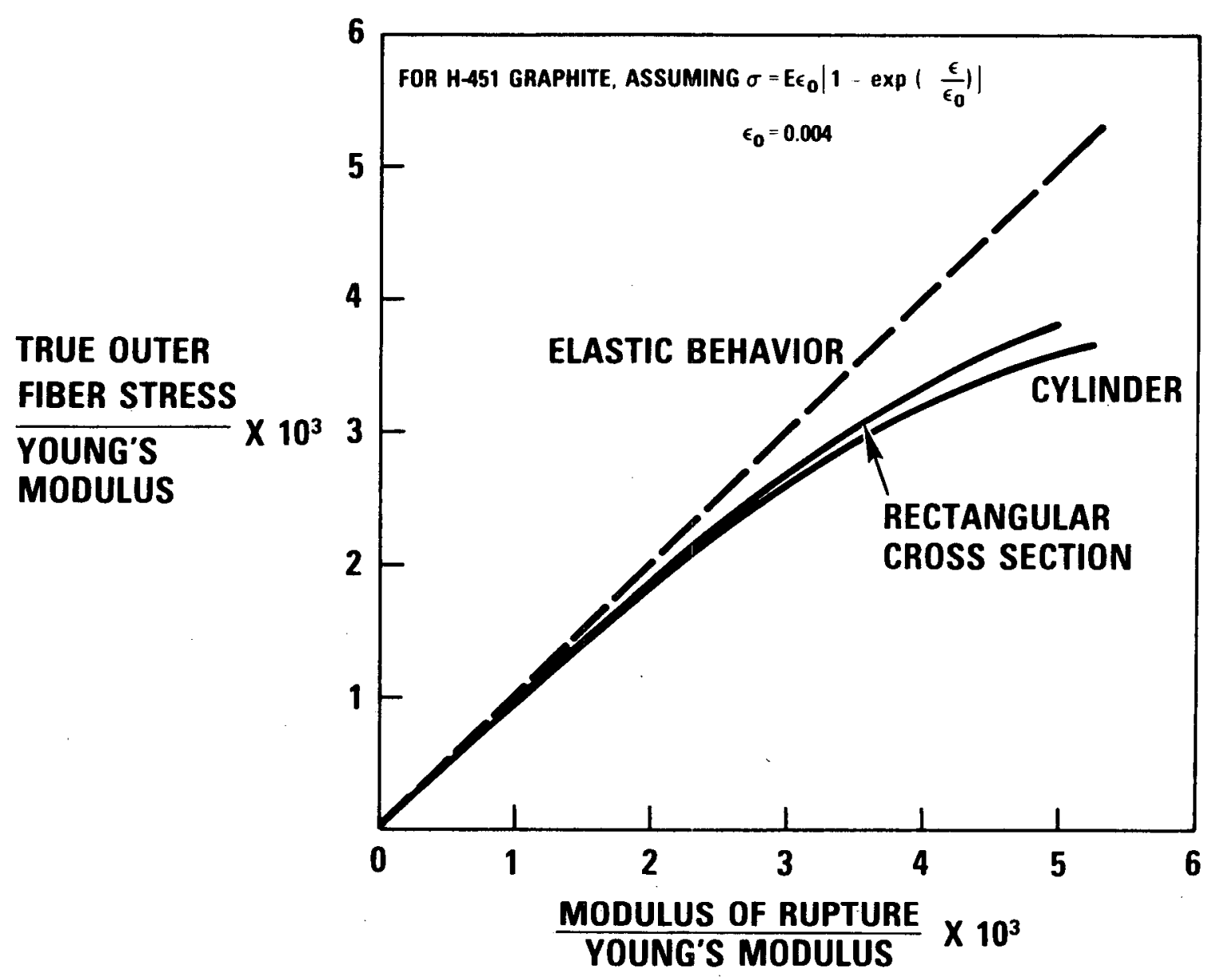

Fig. 4. Correction factors for bend-test data to allow for nonlinear stress-strain relationship (H-451 graphite) 


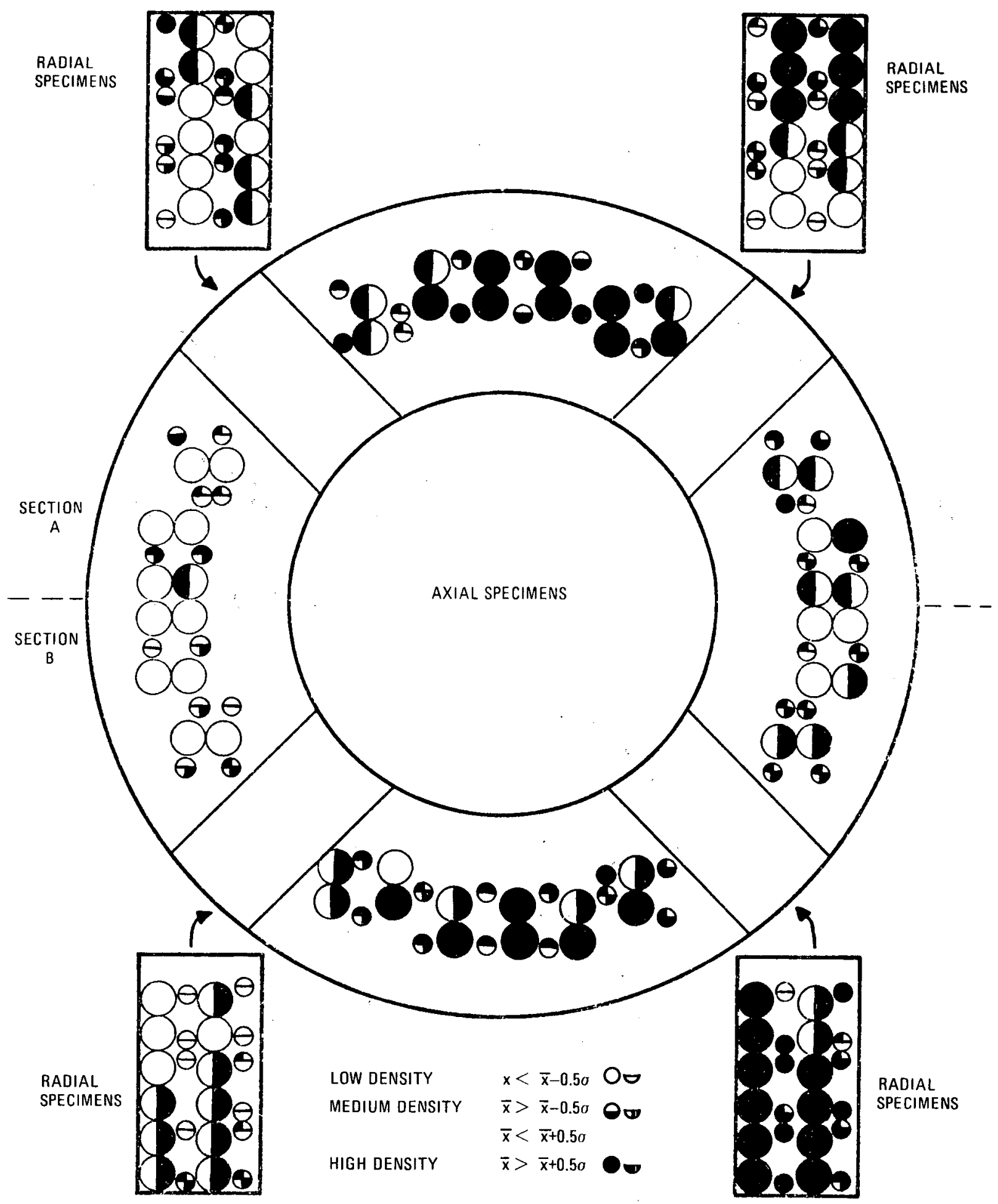

Fig. 5. Map of the distribution of density in slab 1, edge zone 


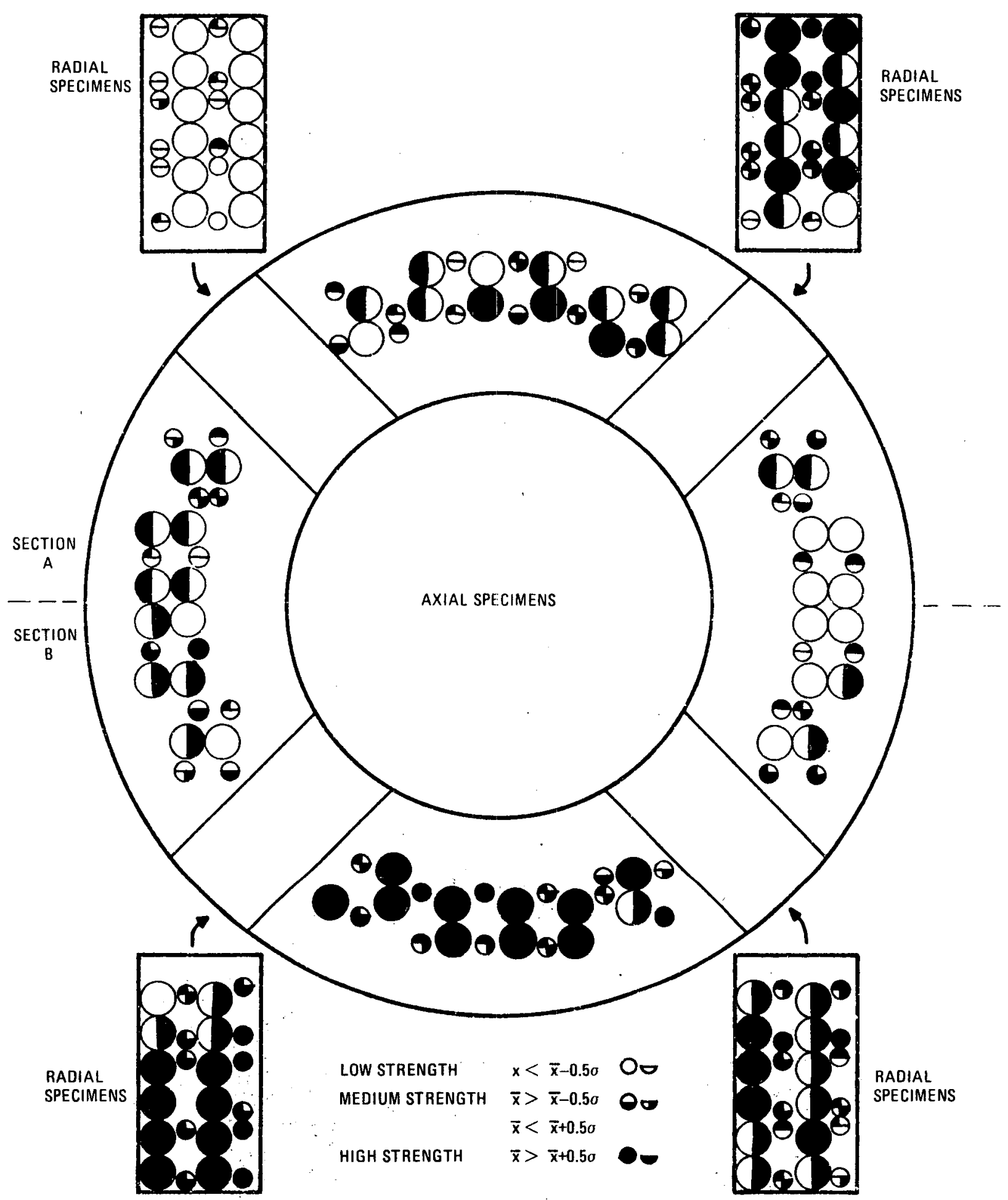

Fig. 6. Map of the distribution of strength in slab 1, edge zone 


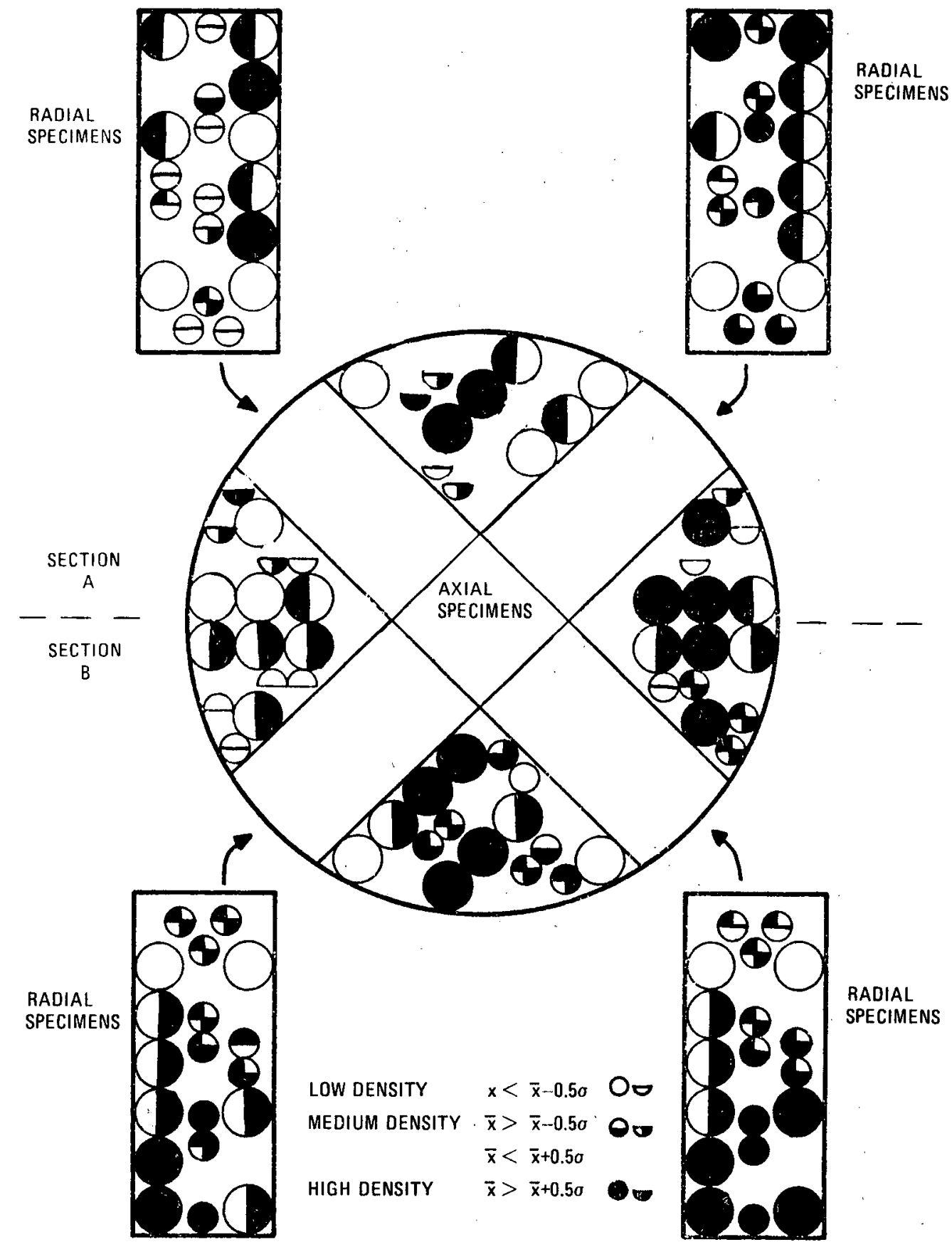

Fig. 7. Map of the distribution of density in slab 1, center zone 


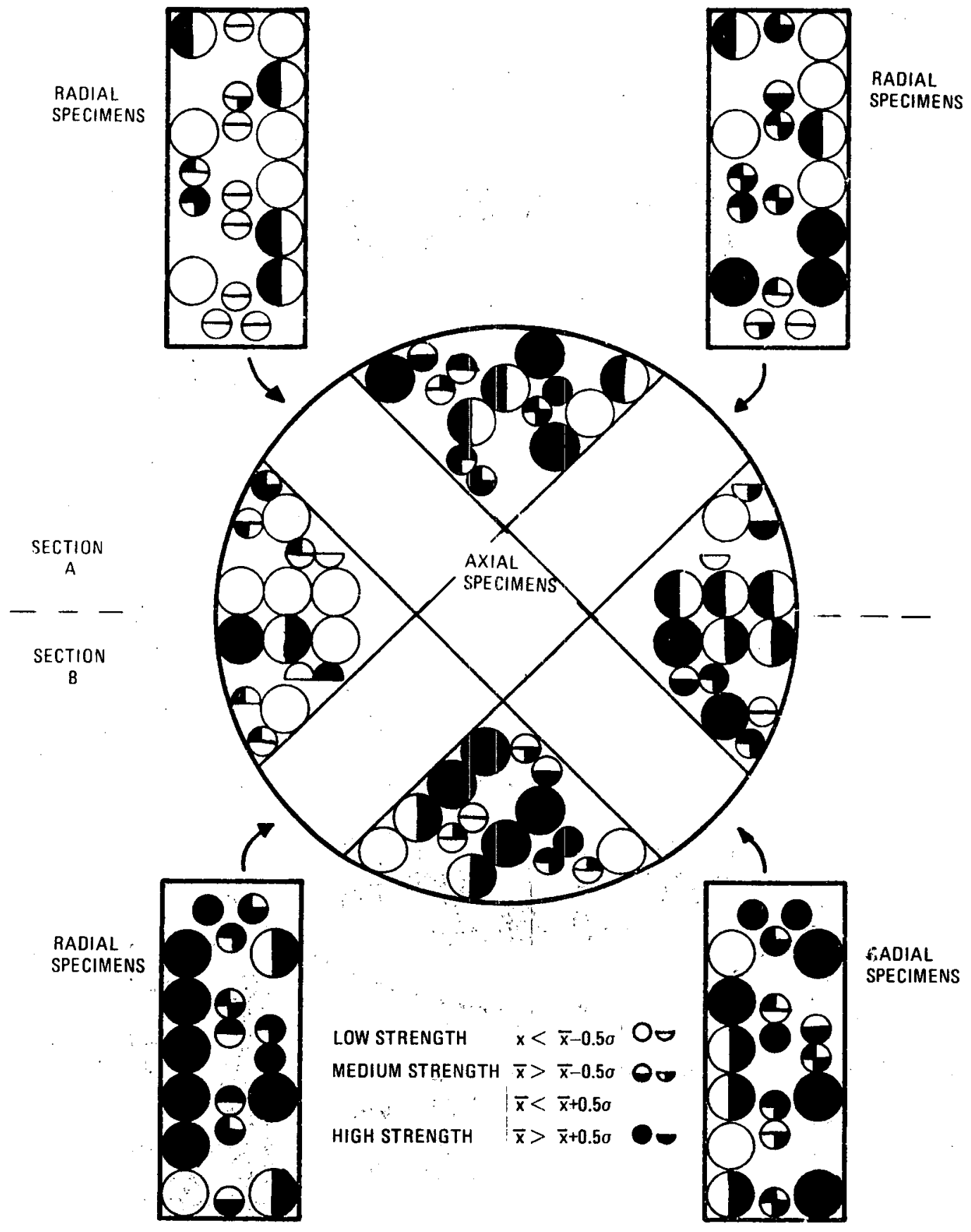

Fig. 8. Map of the distribution of strength in slab 1, center zone 


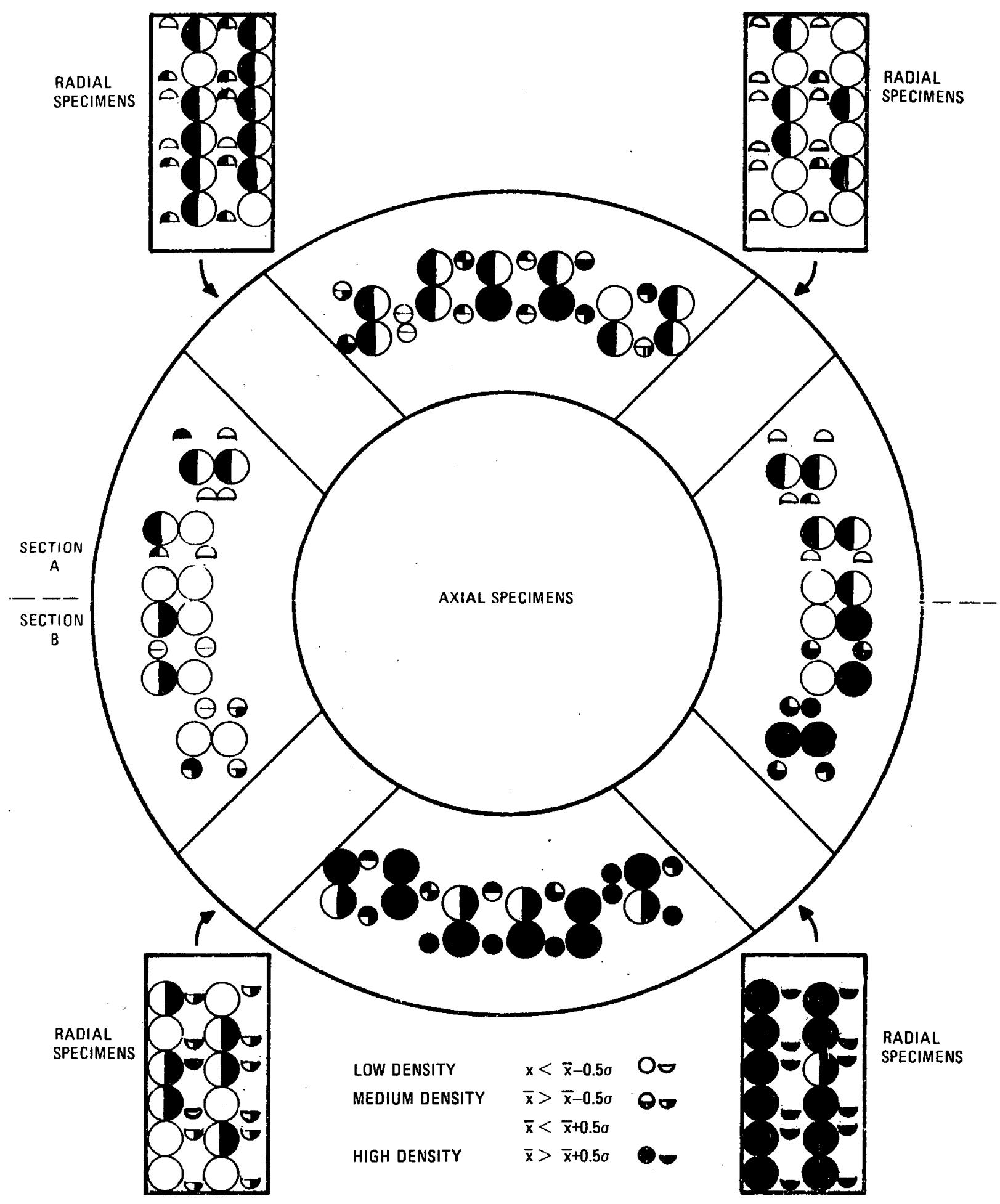

Fig. 9. Map of the distribution of density in slab 2, edge zone 


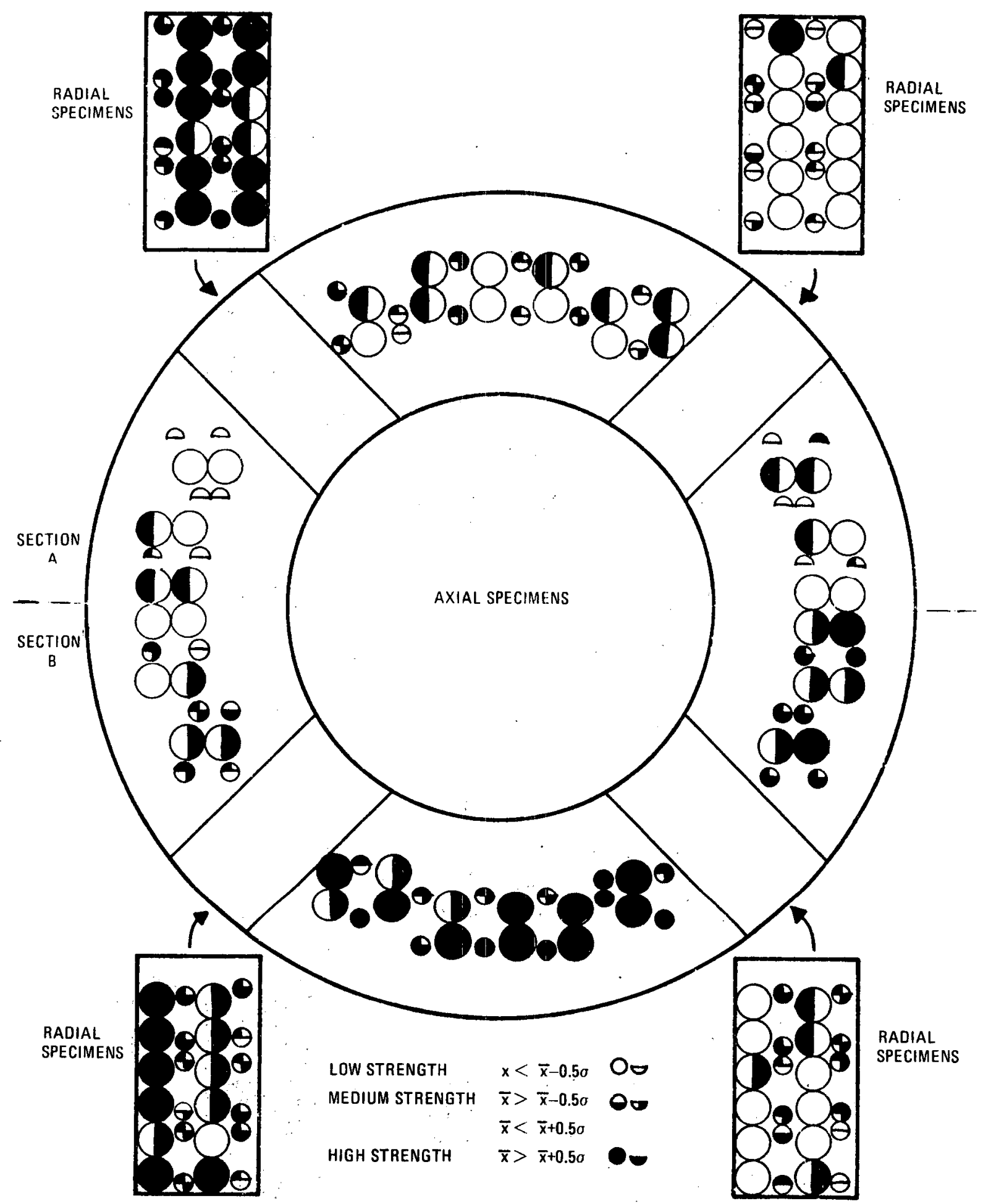

Fig. 10. Map of the distribution of strength in slab 2, edge zone 


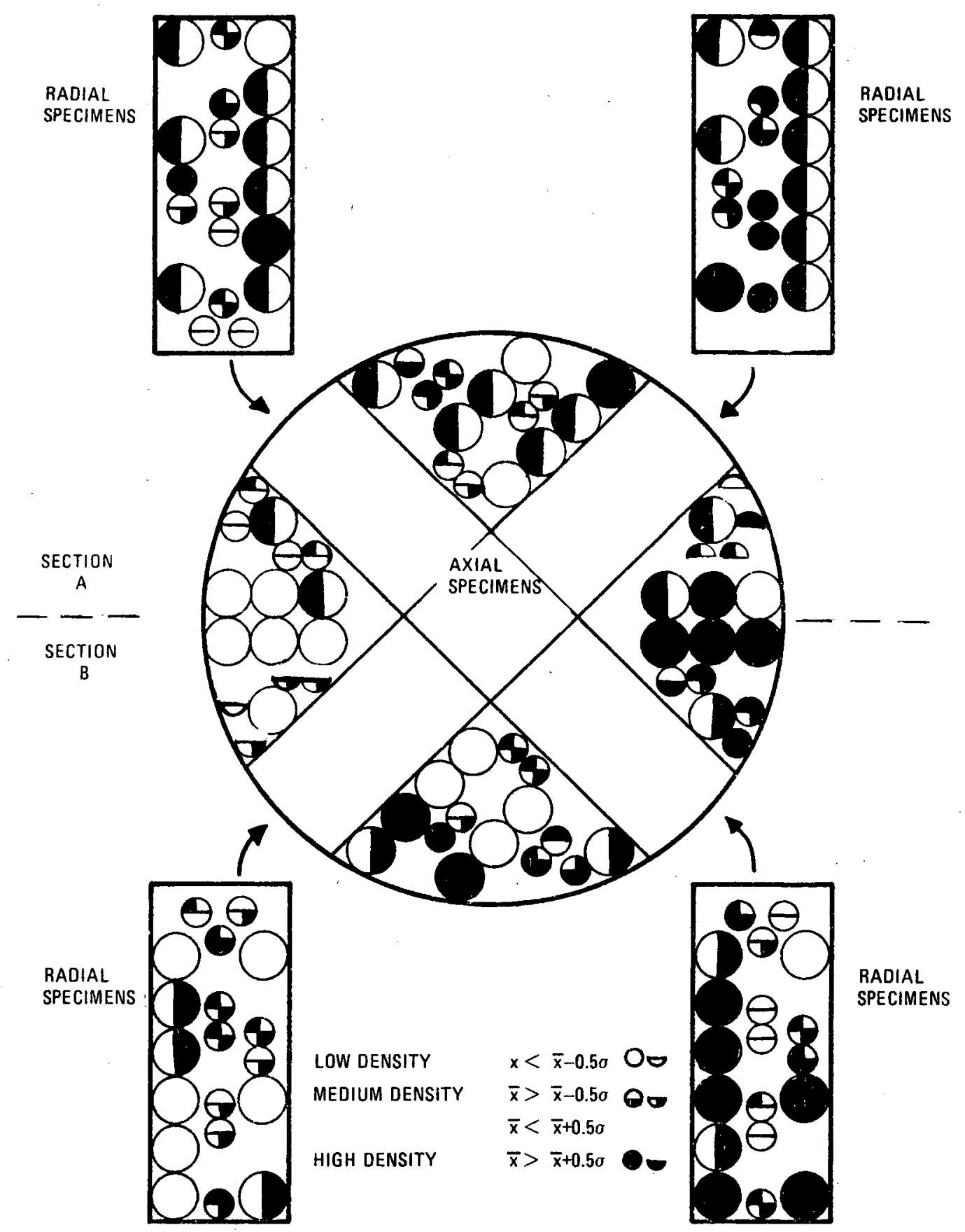

Fig. 11. Map of the distribution of density in slab 2, center zone 


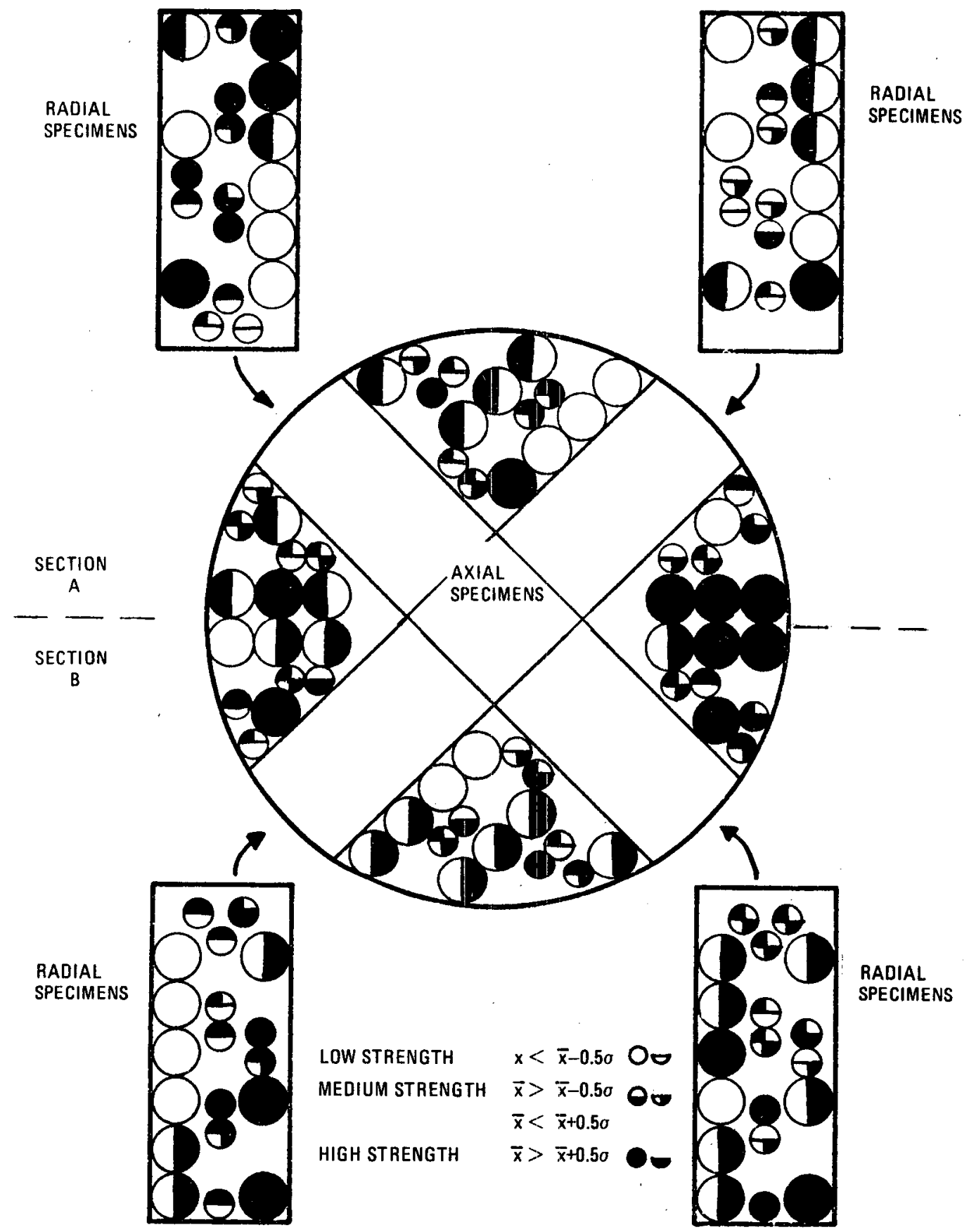

Fig. 12. Map of the distribution of strength in slab 2, center zone 


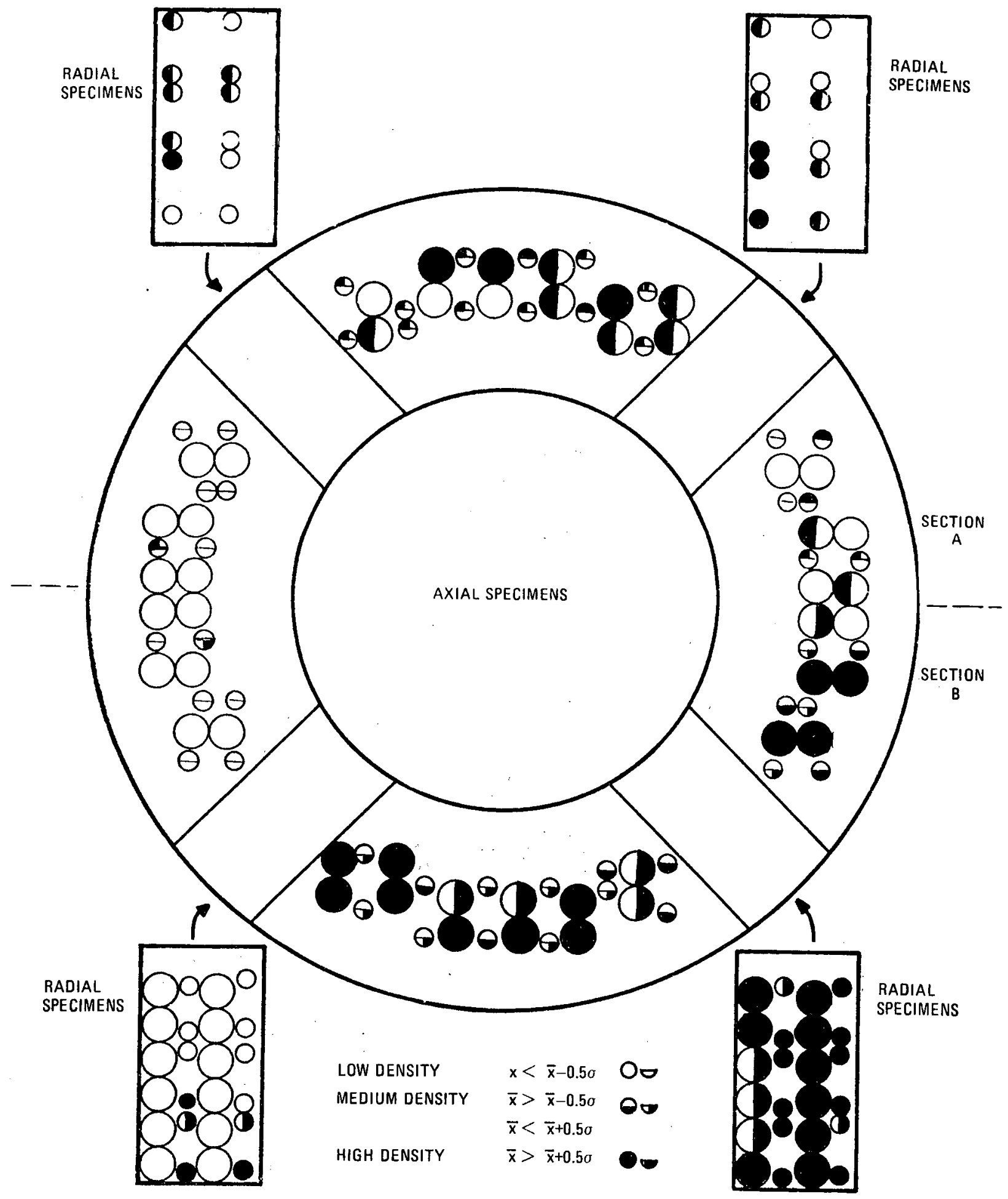

Fig. 13. Map of the distribution of density in slab 3, edge zone 


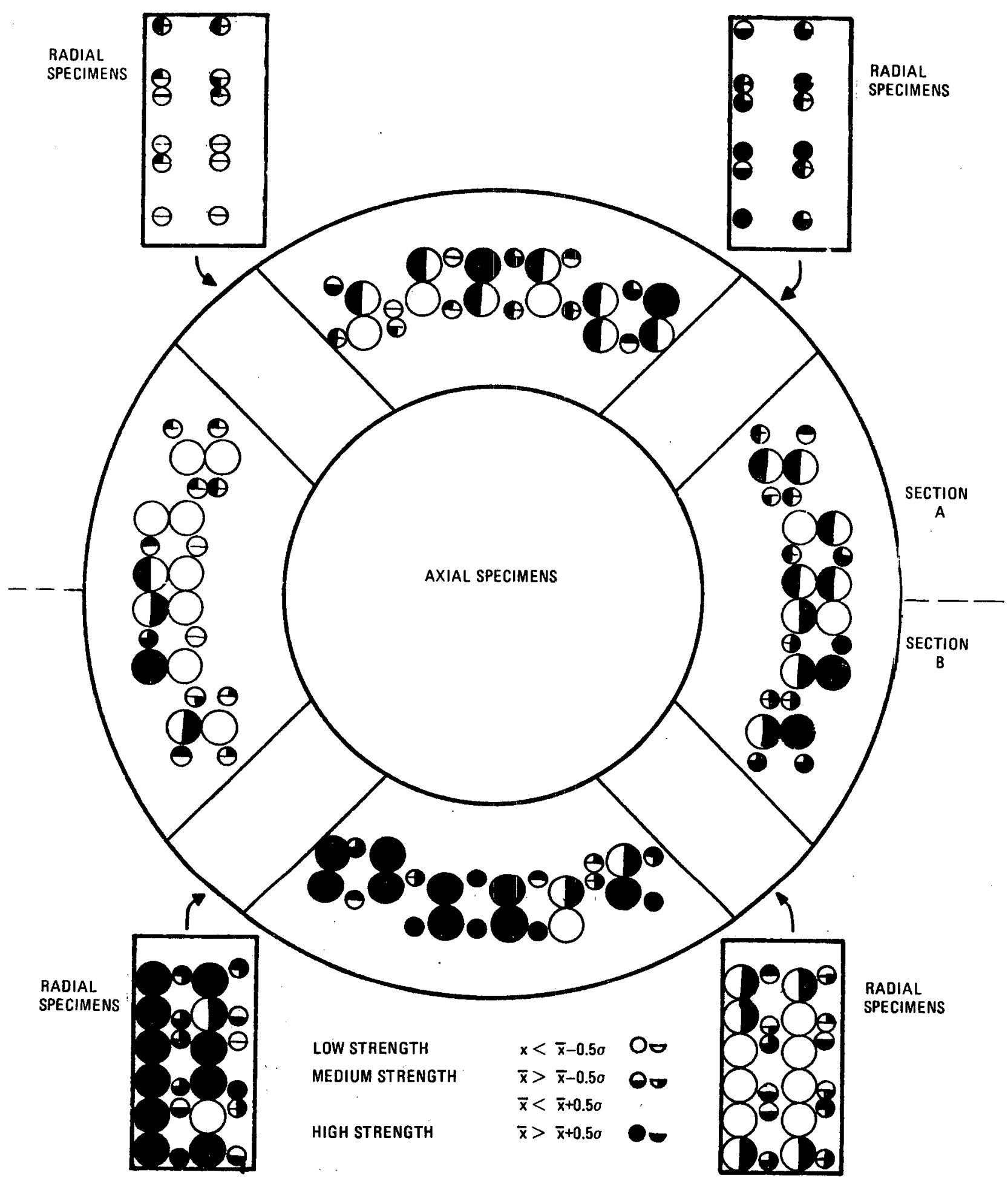

Fig. 14. Map of the distribution of strength in slab 3, edge zone 


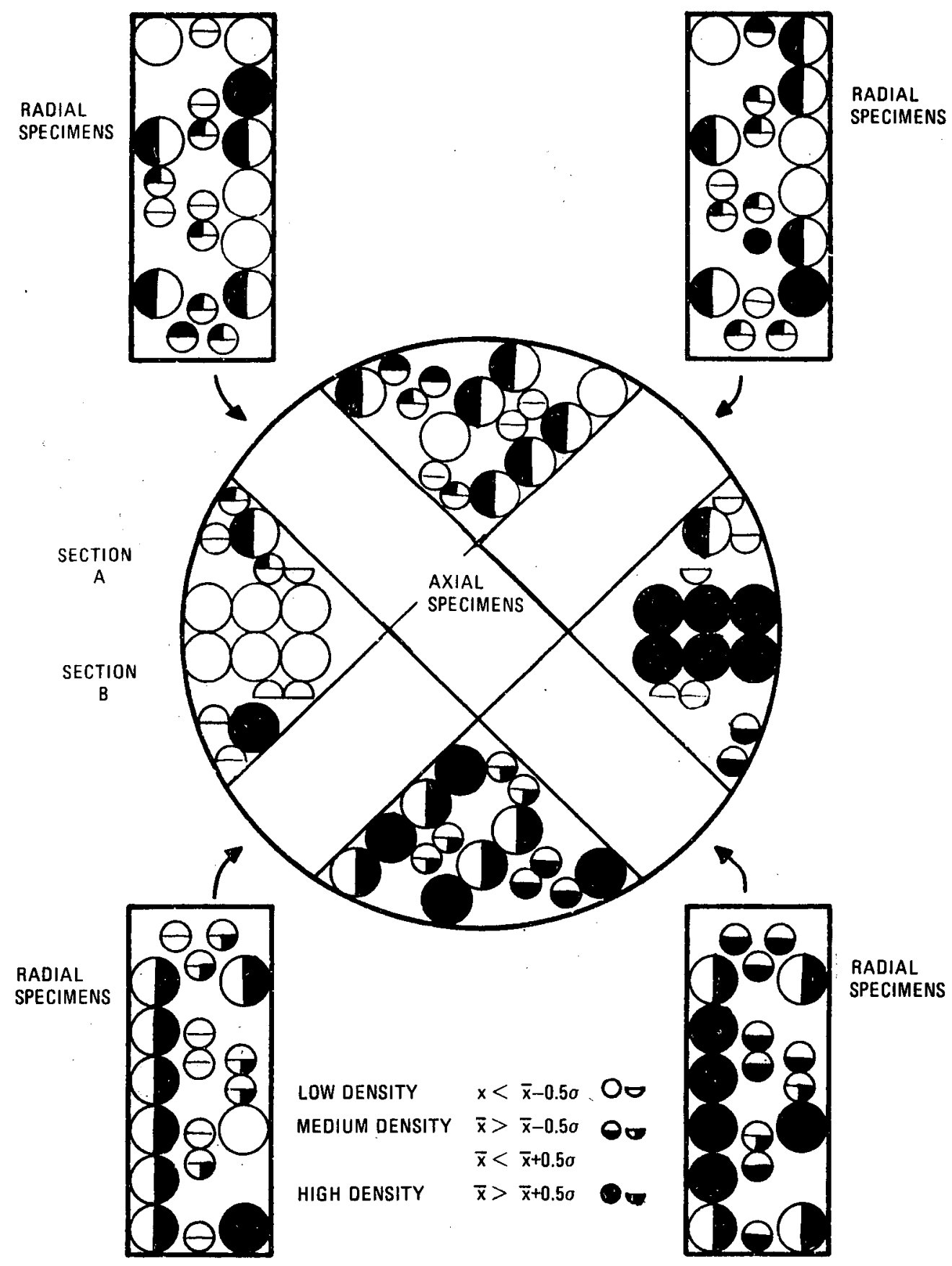

Fig. 15. Map of the distribution of density in slab 3, center zone 


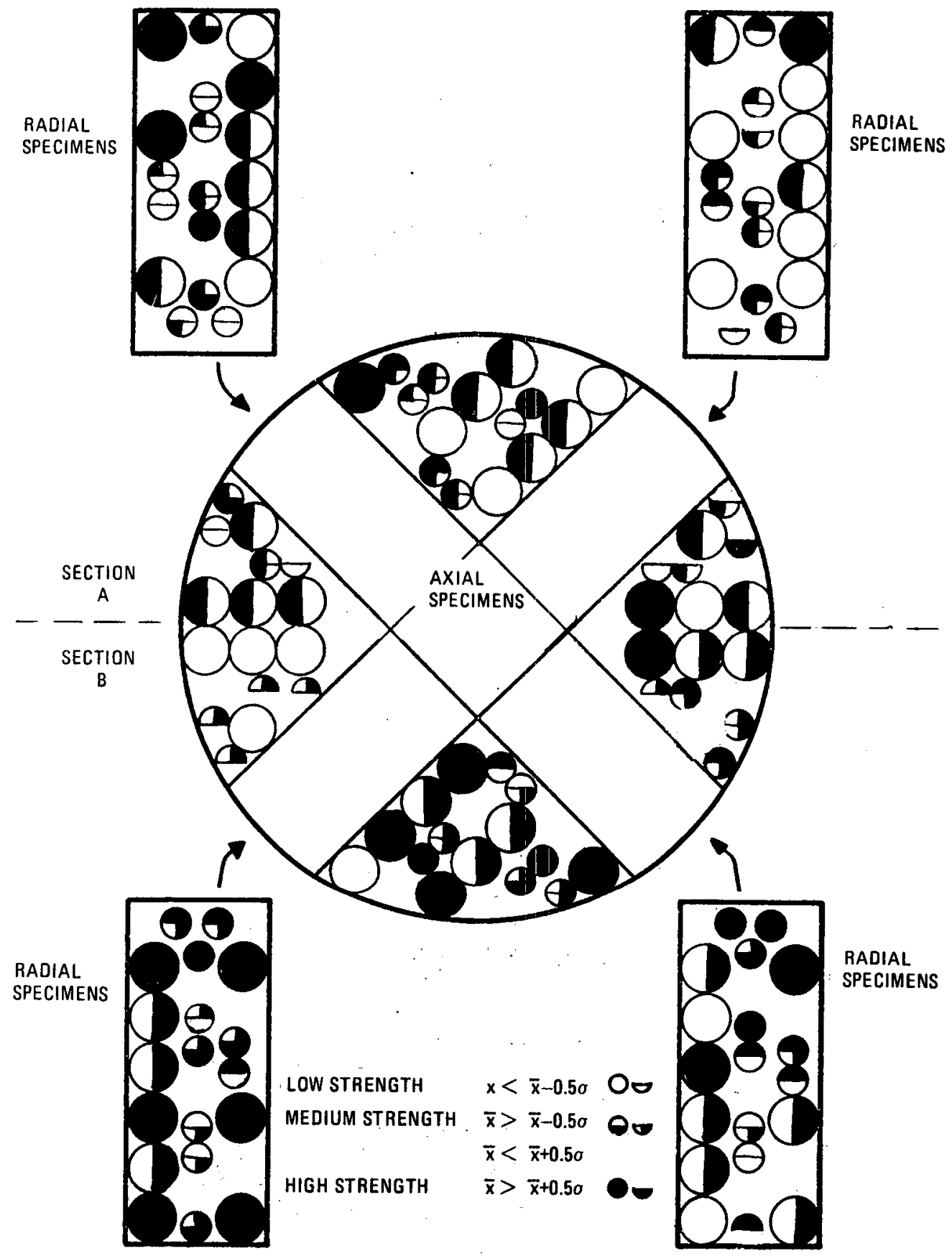

F1g. 16. Map of the distribution of strength in slab 3, center zone 


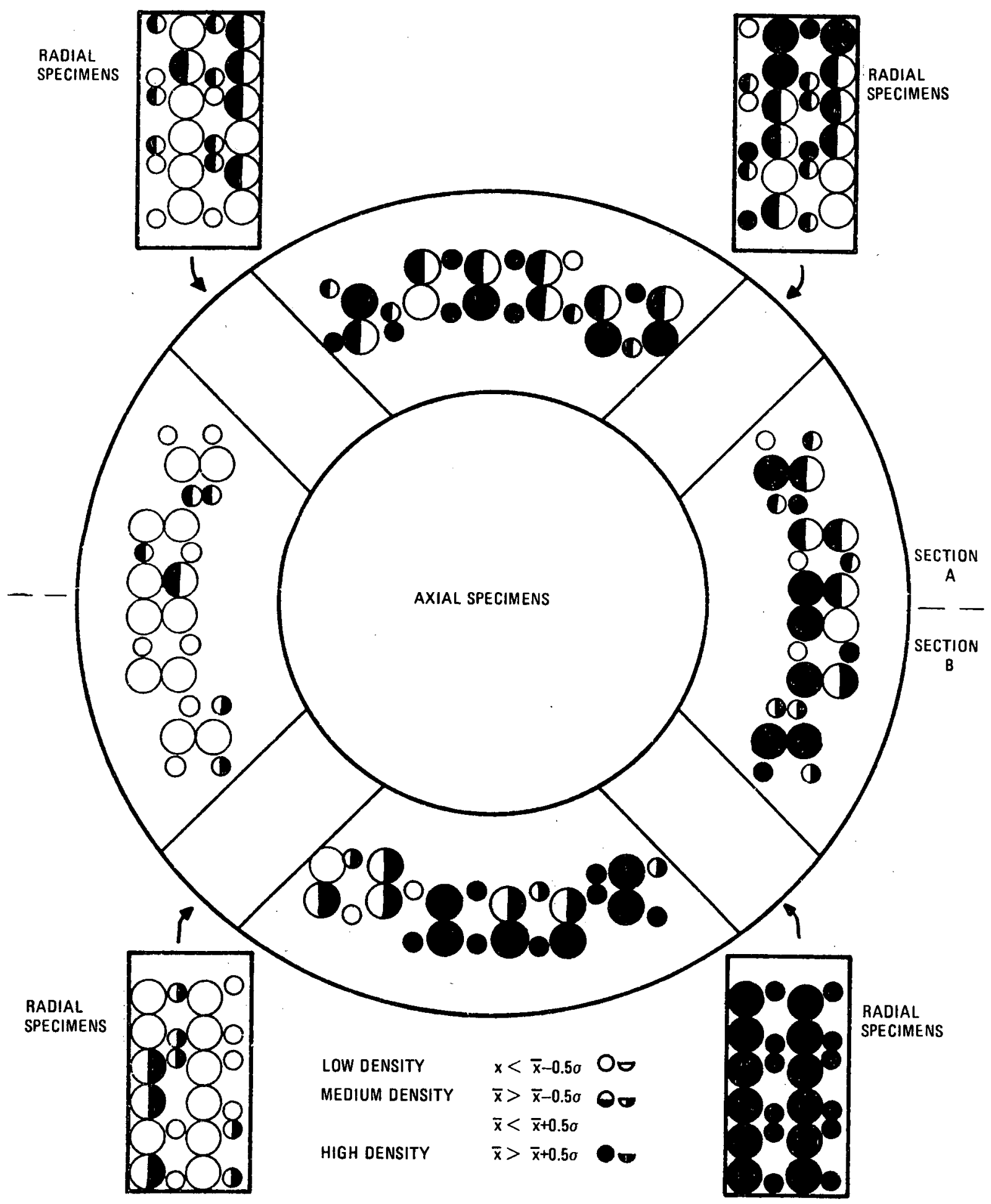

Fig. 17. Map of the distribution of density in slab 4, edge zone 


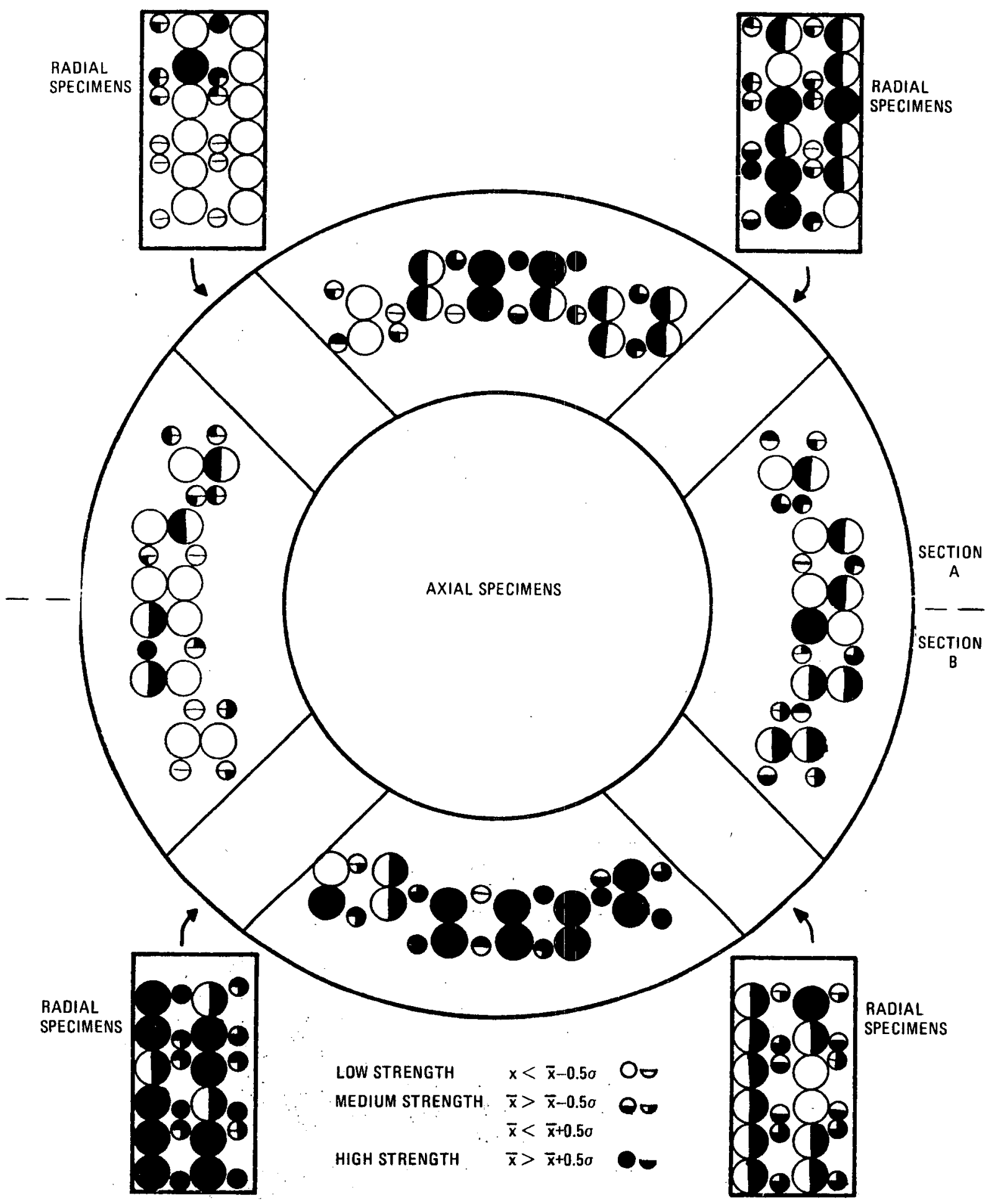

Fig. 18. Map of the distribution of strength in slab 4, edge zone 


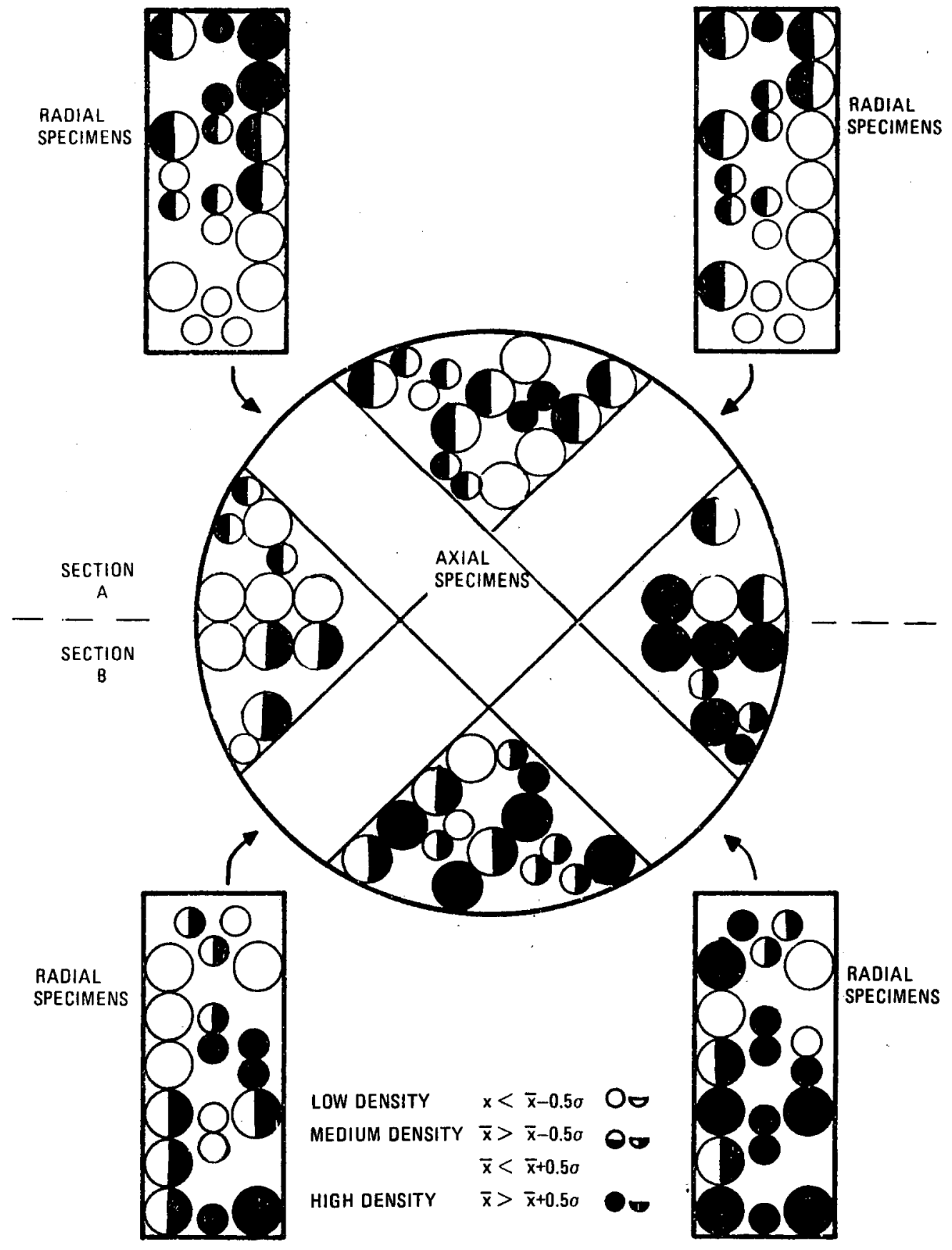

Fig. 19. Map of the distribution of density in slab 4, center zone 


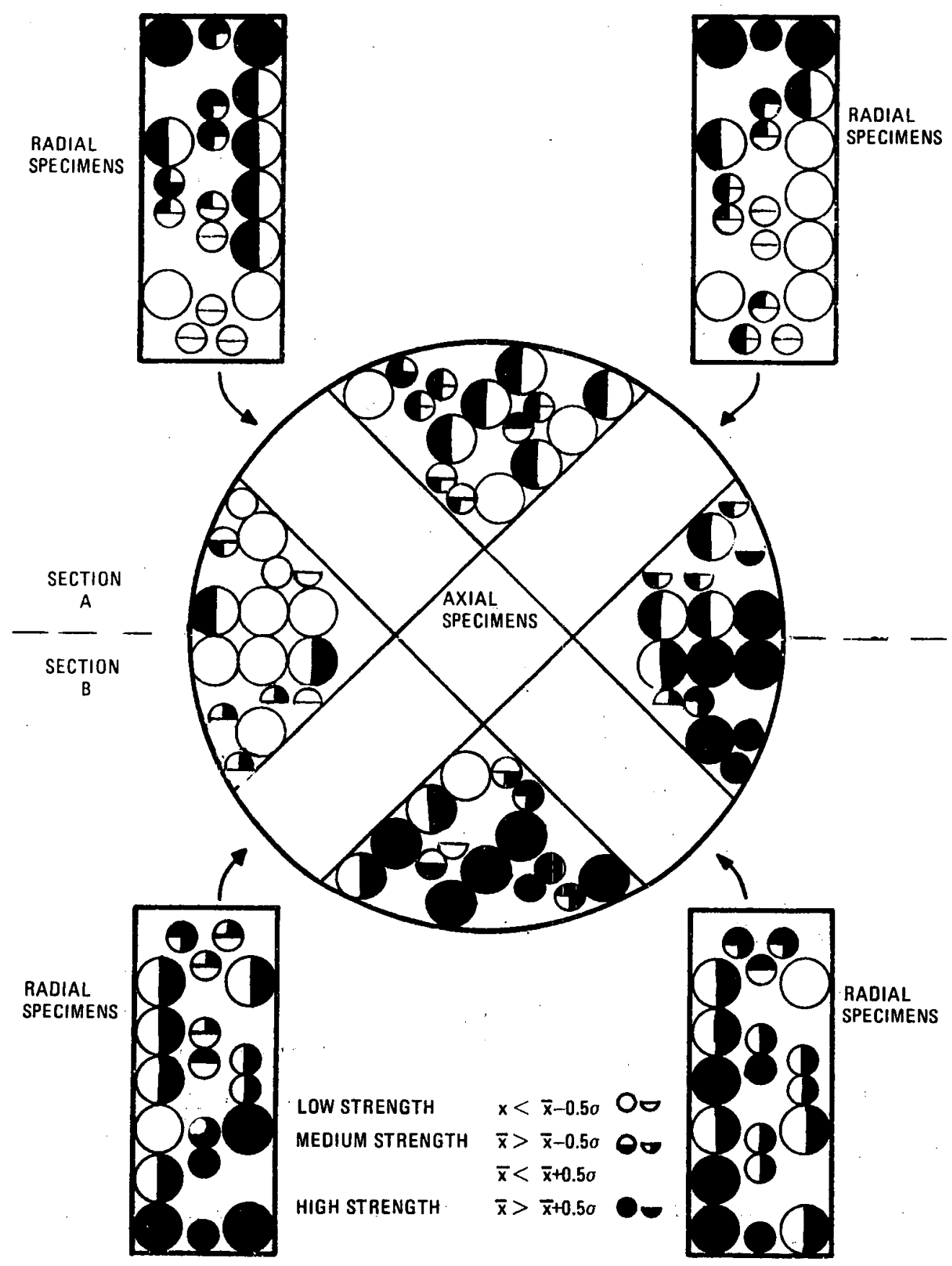

F1g. 20. Map of the distribution of strength in slab 4, center zone 


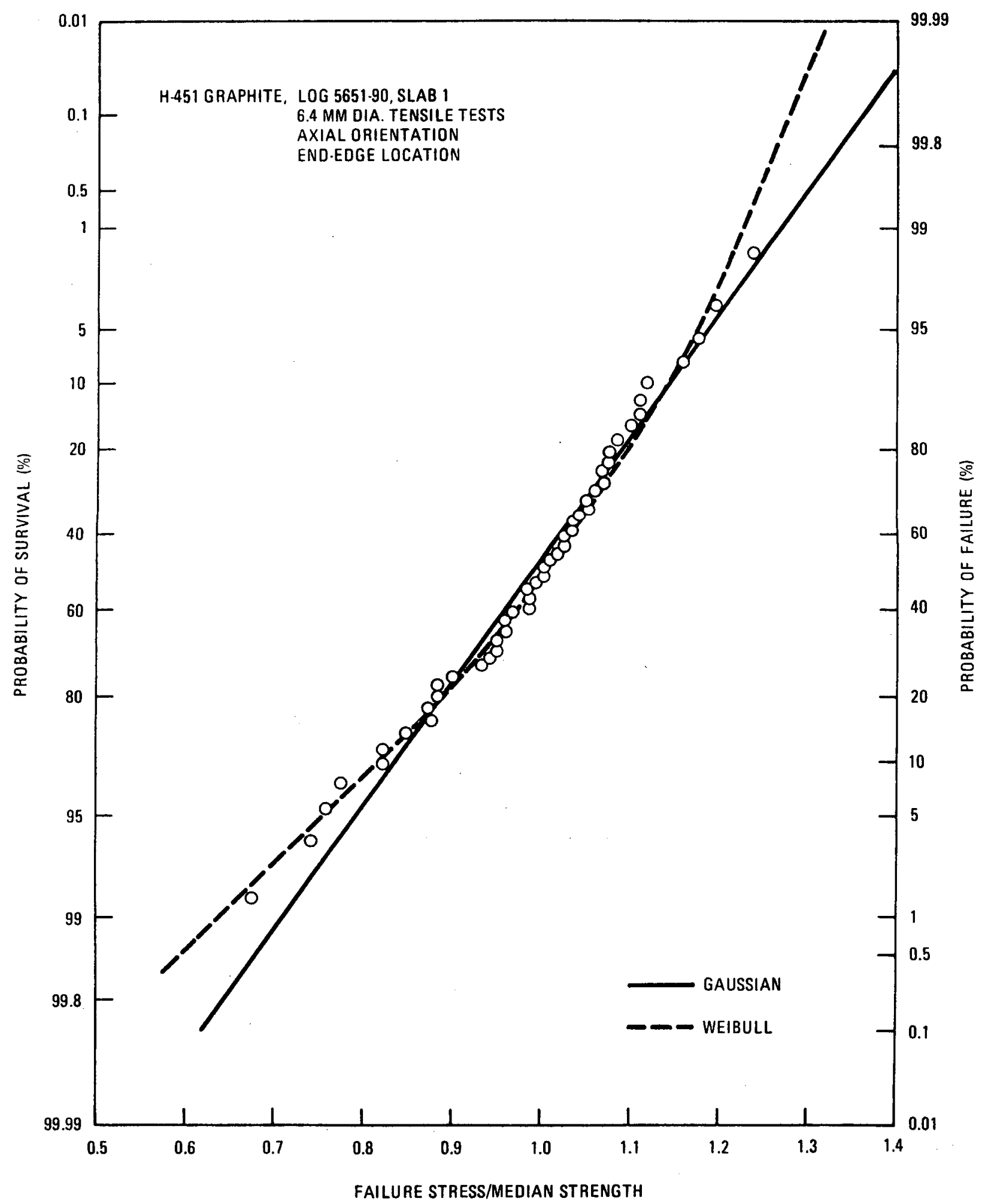

Fig. 21. Cumulative distribution curve for strength of small-sized tensile specimens, slab 1, axial orientation, end-edge location 


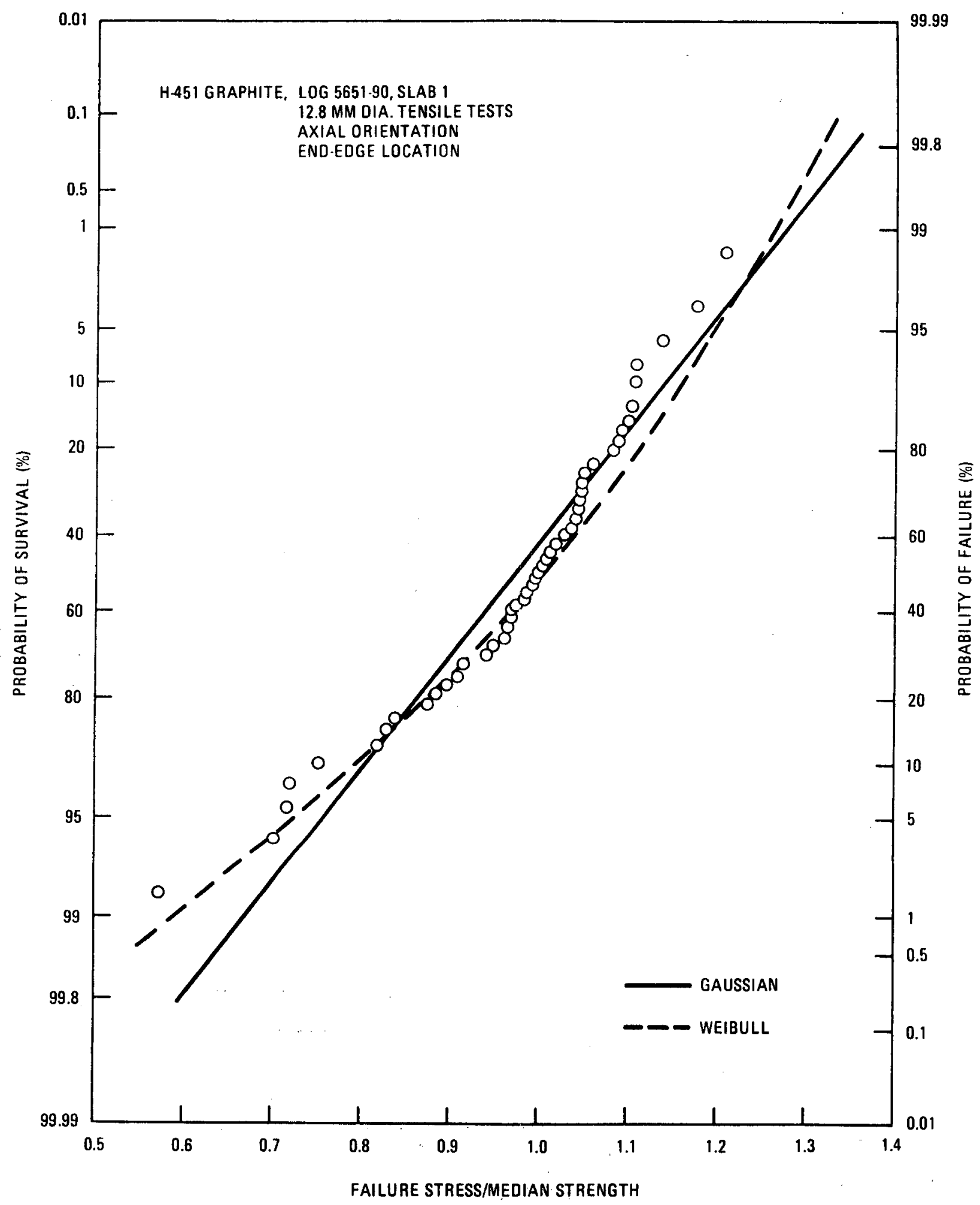

Fig. 22. Cumulative distribution curve for strength of large-sized tensile specimens, slab 1, axial orientation, end-edge location 


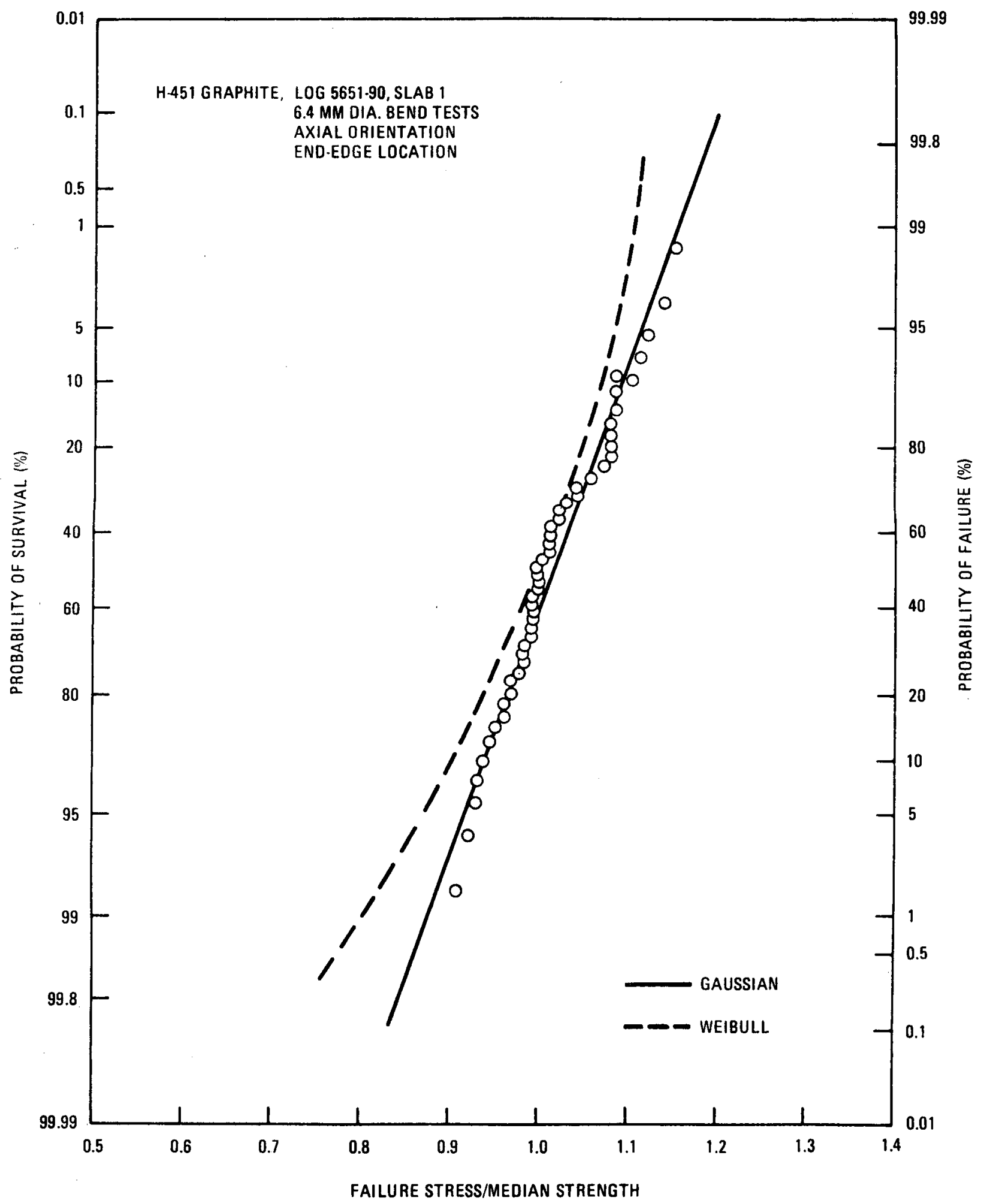

Fig. 23. Cumulative distribution curve for strength of four-point bend specimens, slab 1, axial orientation, end-edge location 


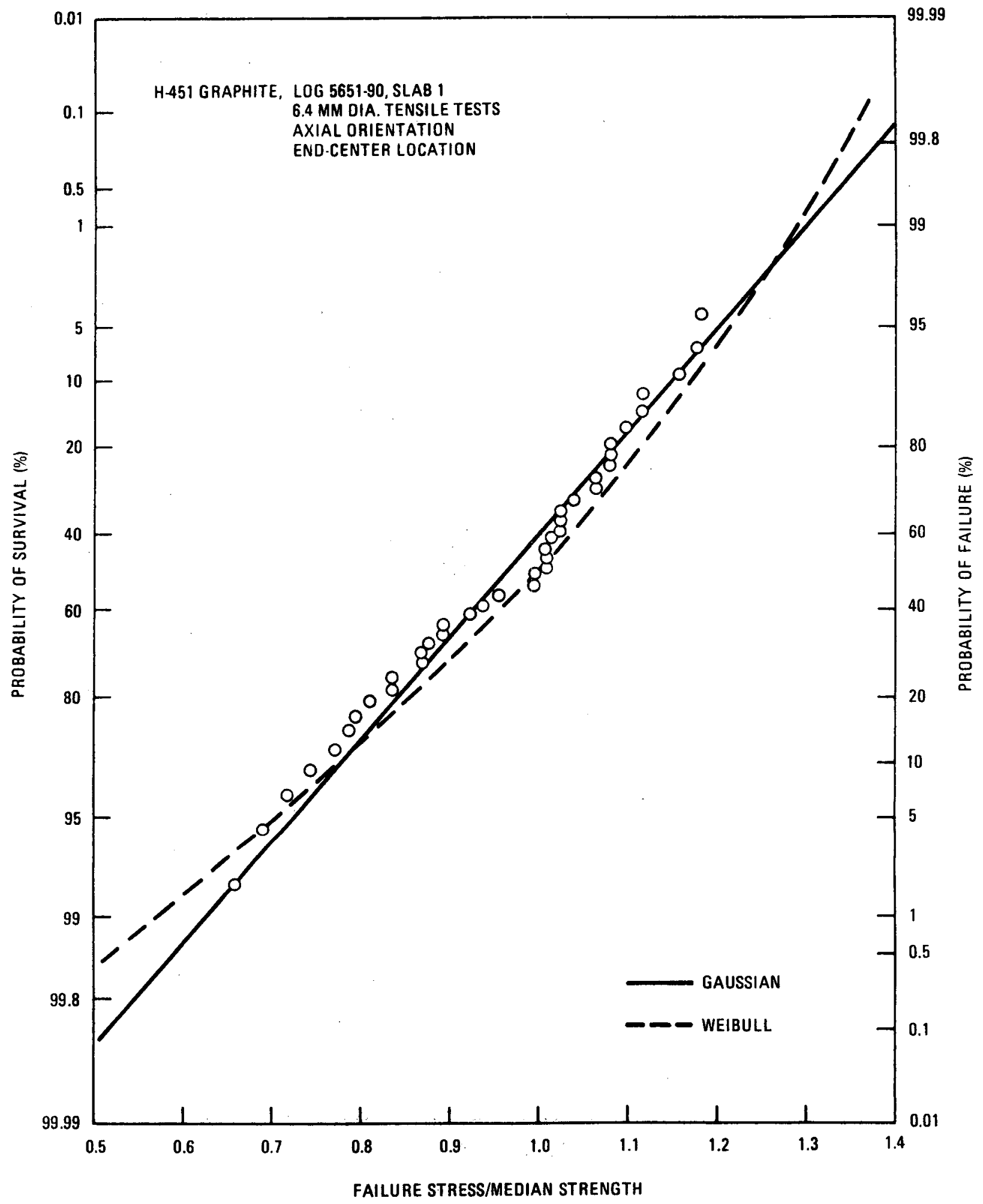

Fig. 24. Cumulative distribution curve for strength of smal1-sized tensile specimens, slab 1, axial orientation, end-center location 


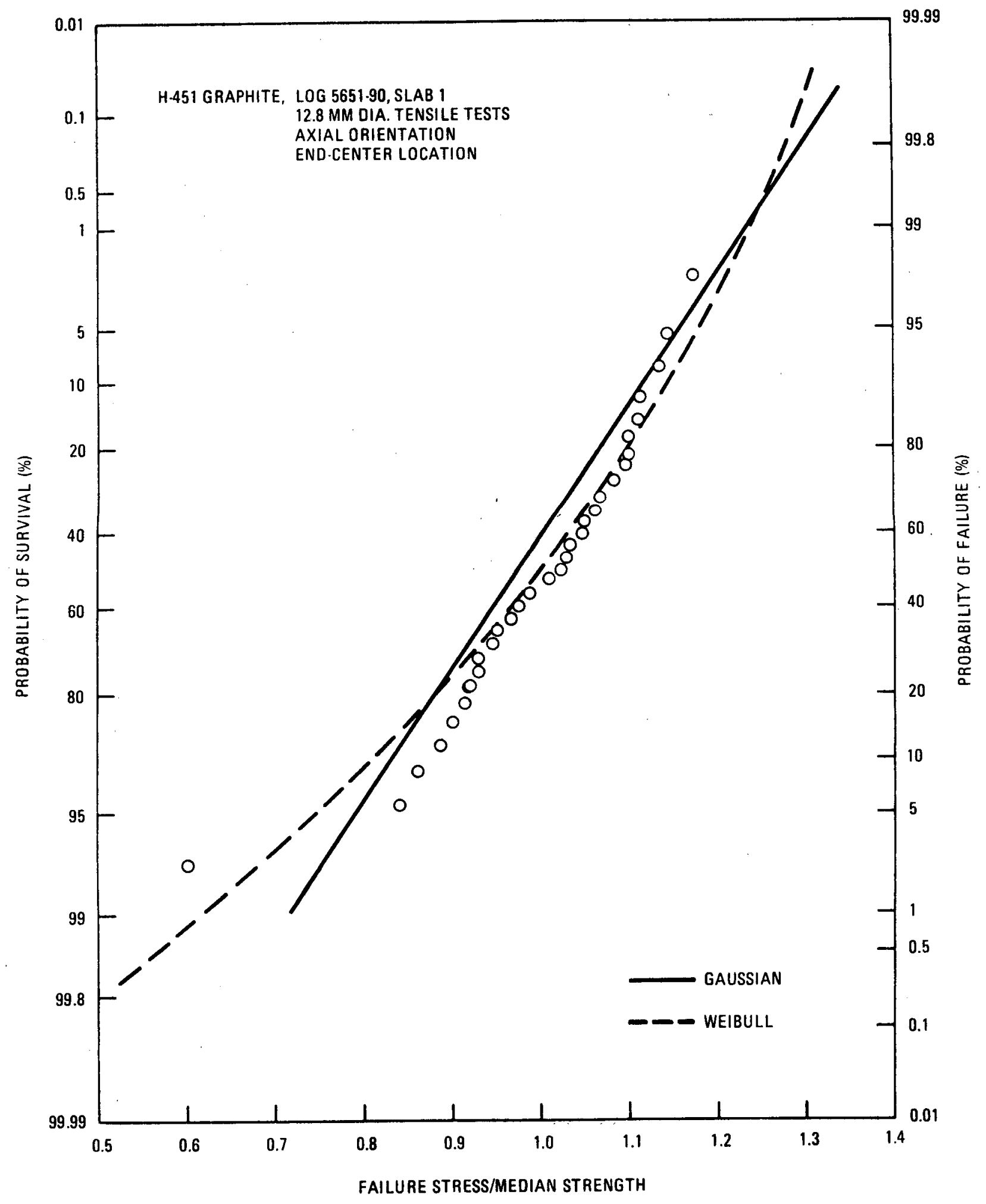

Fig. 25. Cumulative distribution curve for strength of large-sized tensile specimens, slab 1 , axial orientation, end-center location 


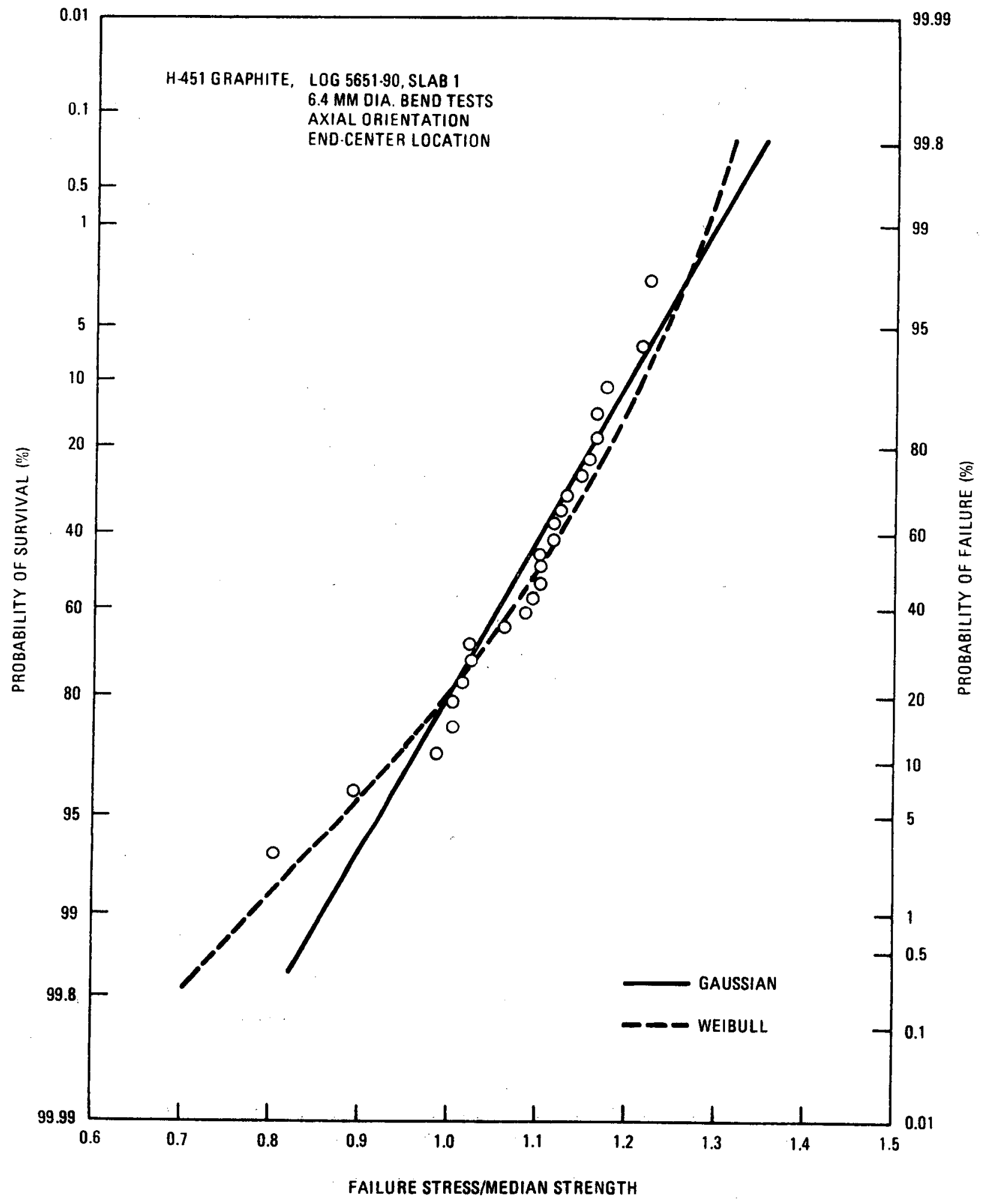

Fig. 26. Cumulative distribution curve for strength of four-point bend specimens, slab 1, axial orientation, end-center location 


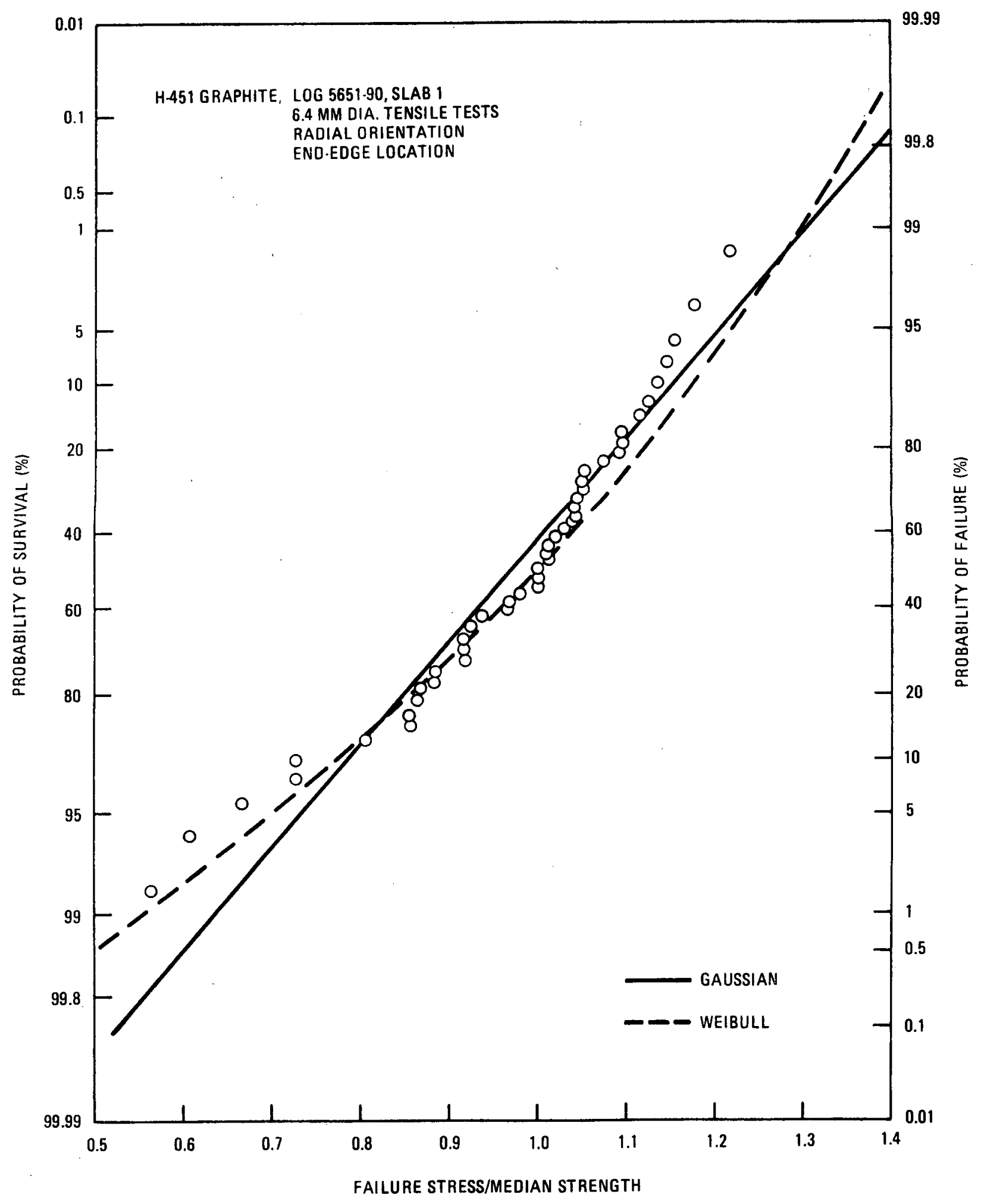

Fig. 27. Cumulative distribution curve for strength of small-sized tensile specimens, slab 1 , radial orientation, end-edge location 


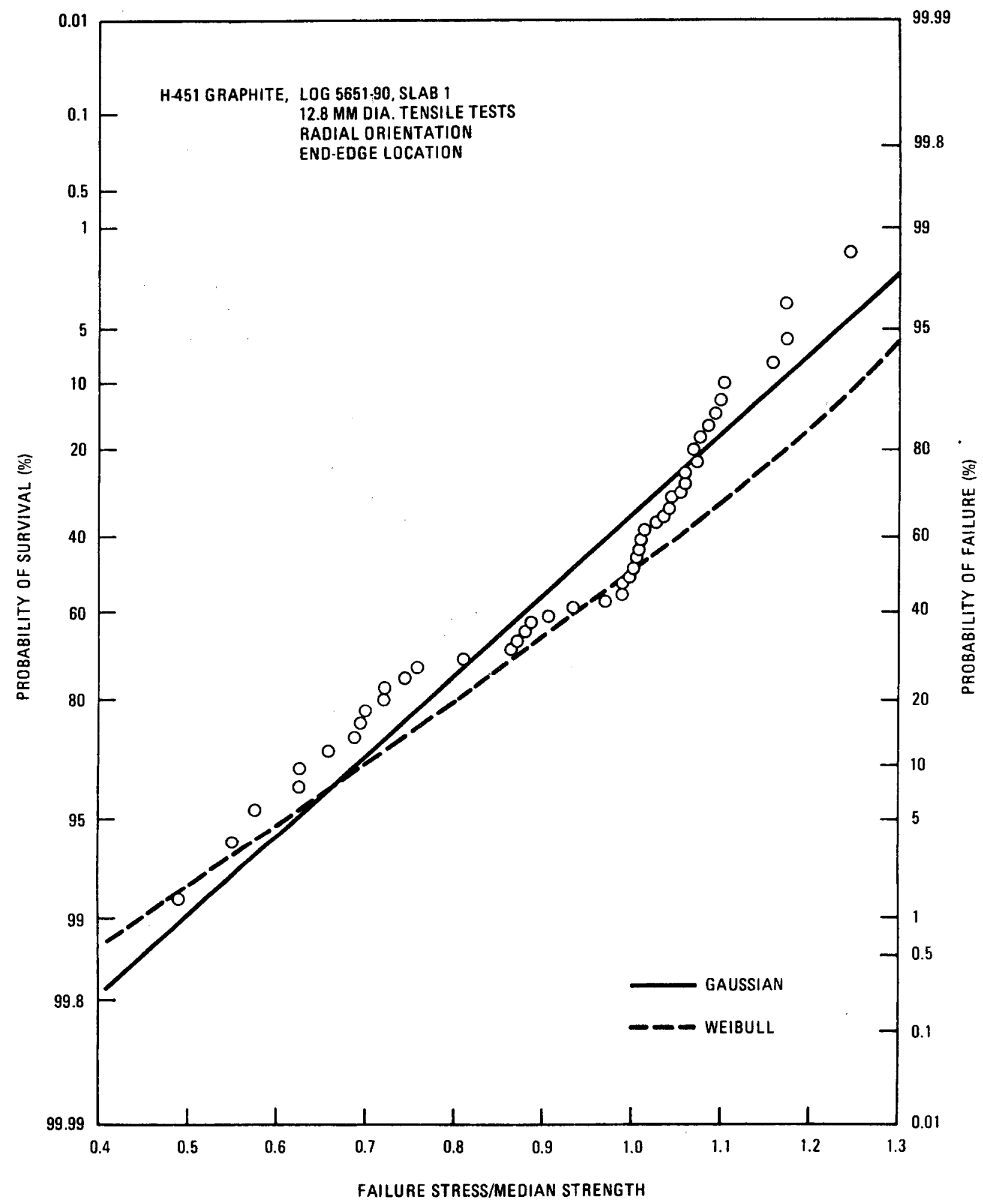

Fig. 28. Cumulative distribution curve for strength of large-sized tensile specimens, slab 1, radial orientation, end-edge location 


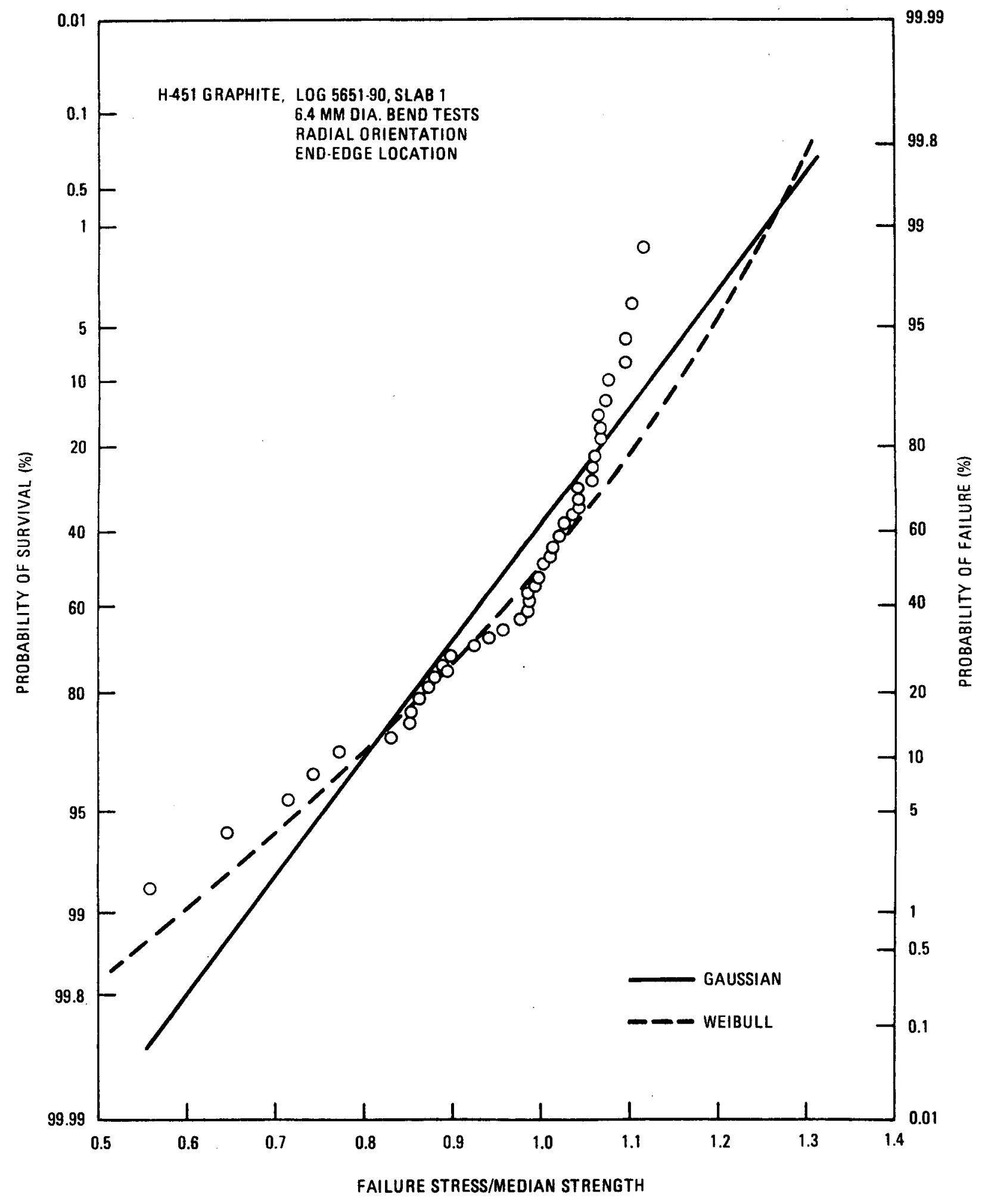

Fig. 29. Cumulative distribution curve for strength of four-point bend specimens, slab 1, radial orientation, end-edge location 


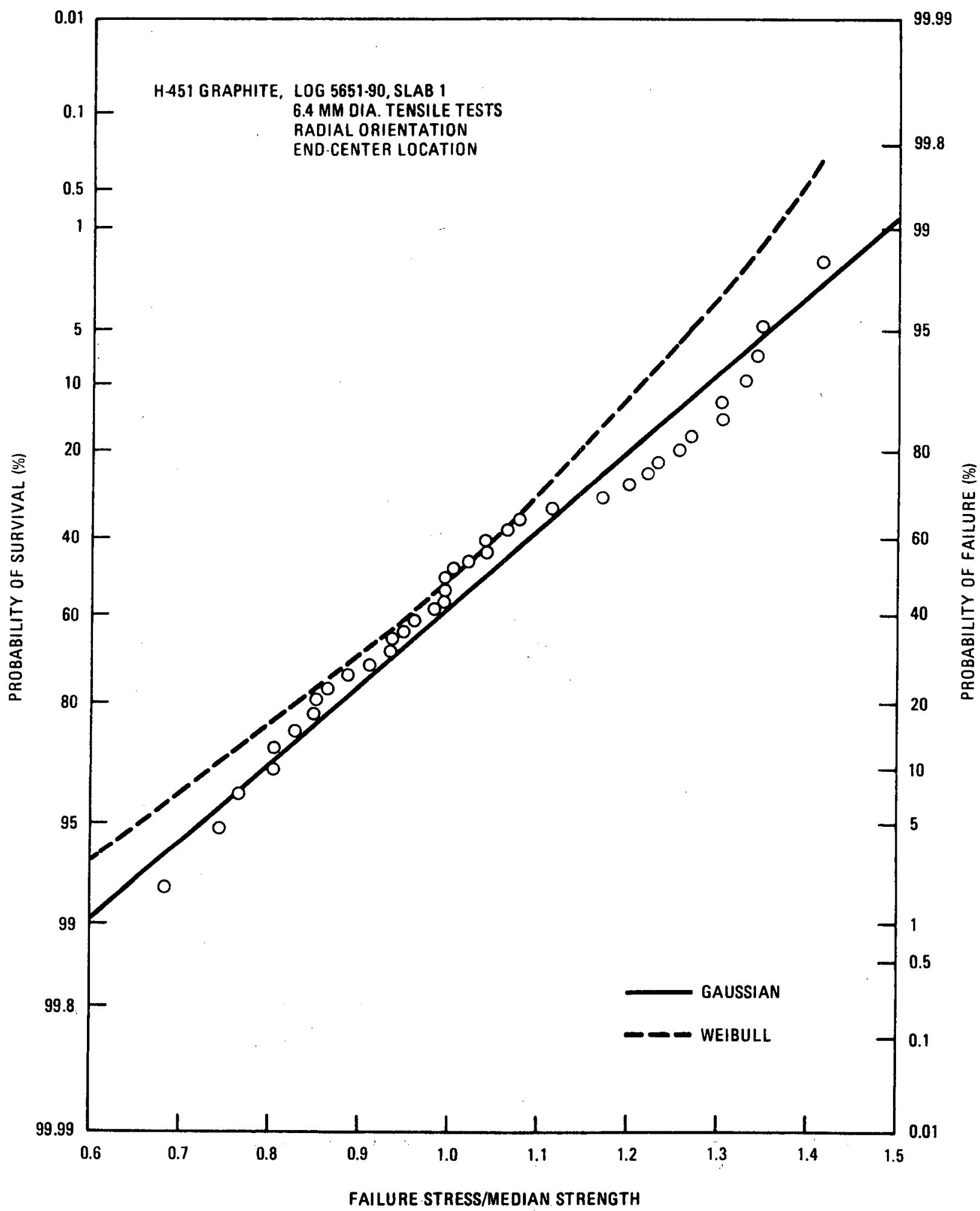

Fig. 30. Cumulative distribution curve for strength of small-sized tensile specimens, slab 1, radial orientation, end-center location 


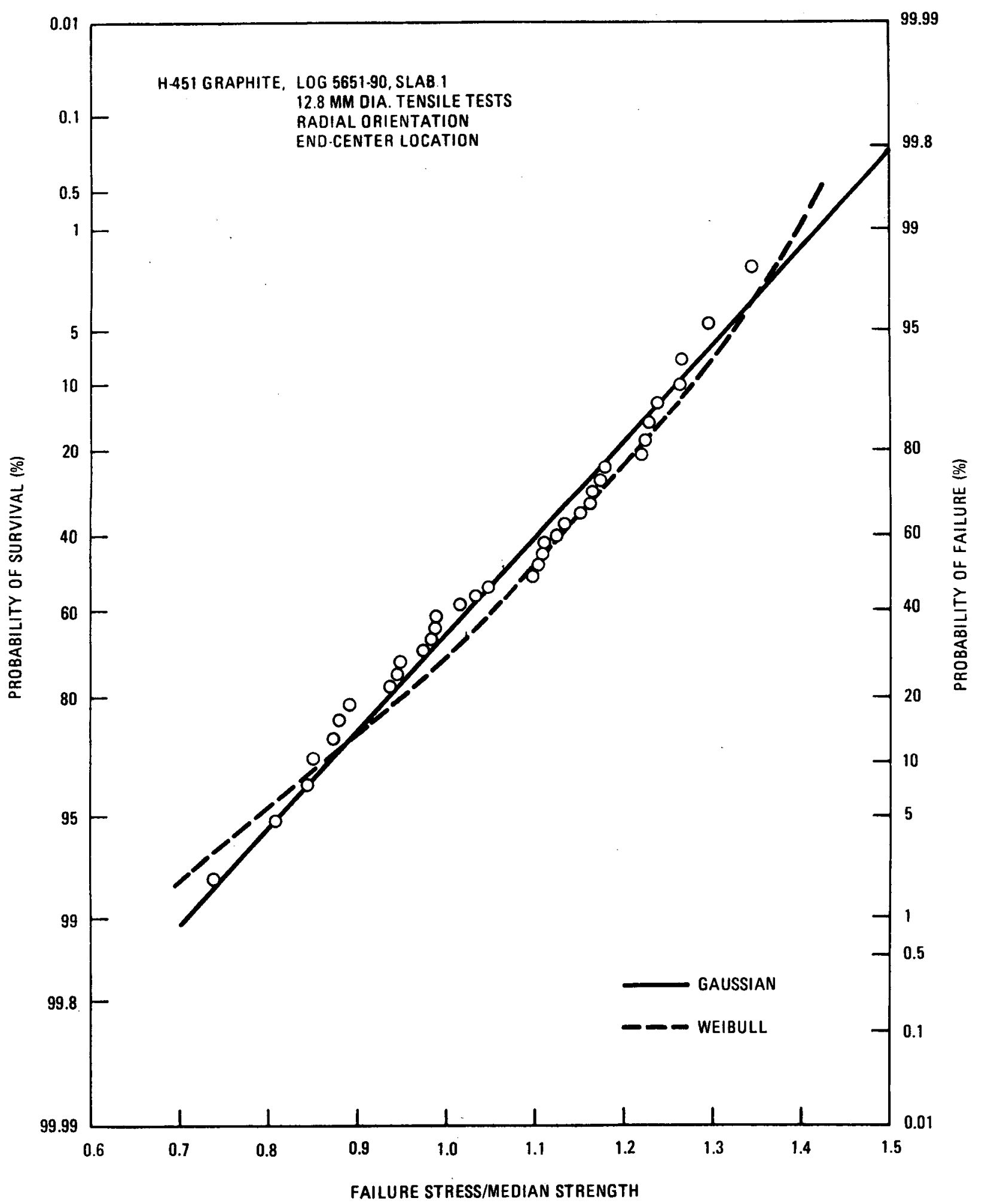

Fig. 31. Cumulative distribution curve for strength of large-sized tensile specimens, slab 1, radial orientation, end-center location 


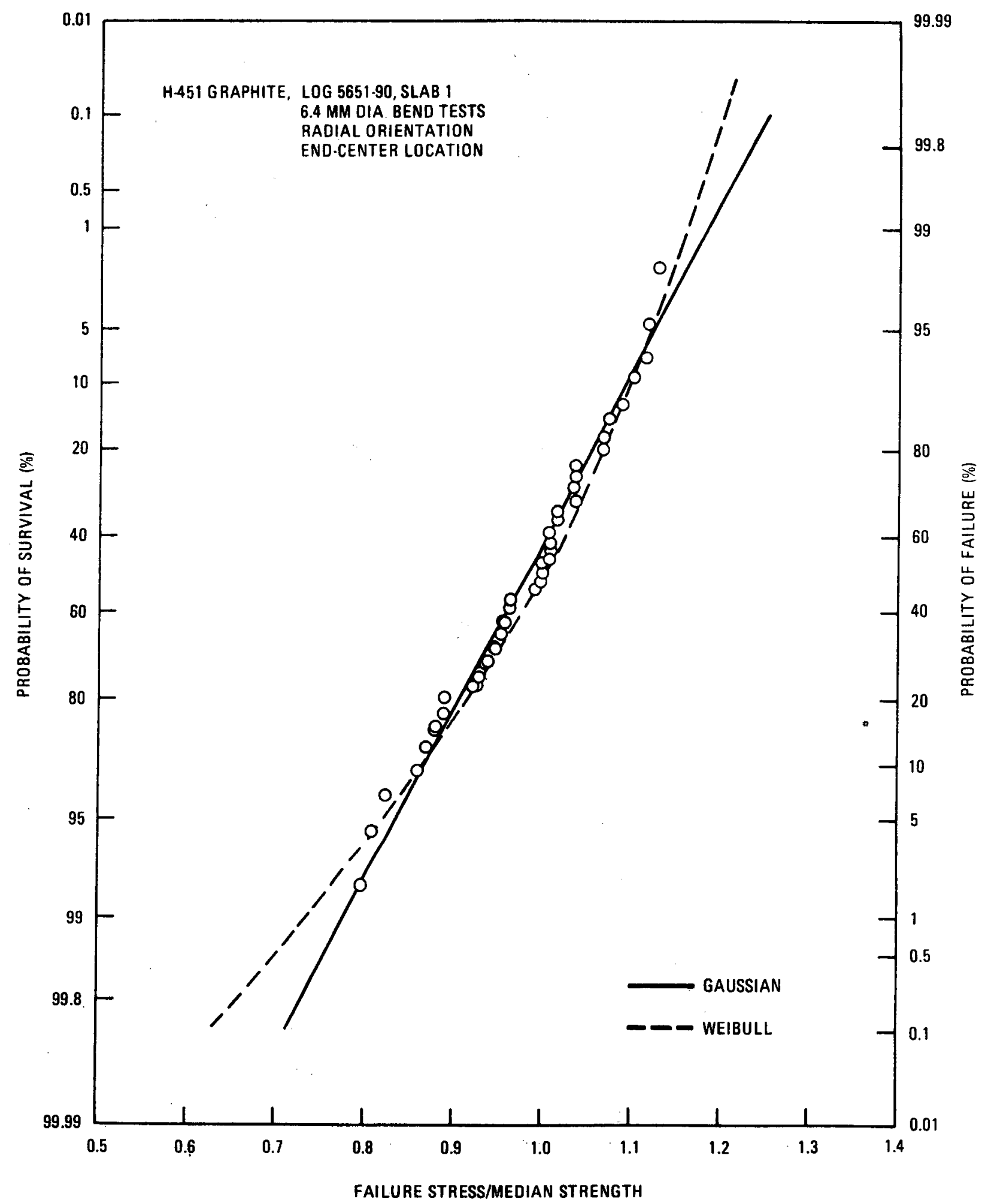

Fig. 32. Cumulative distribution curve for strength of four-point bend specimens, slab 1, radial orientation, end-center location 


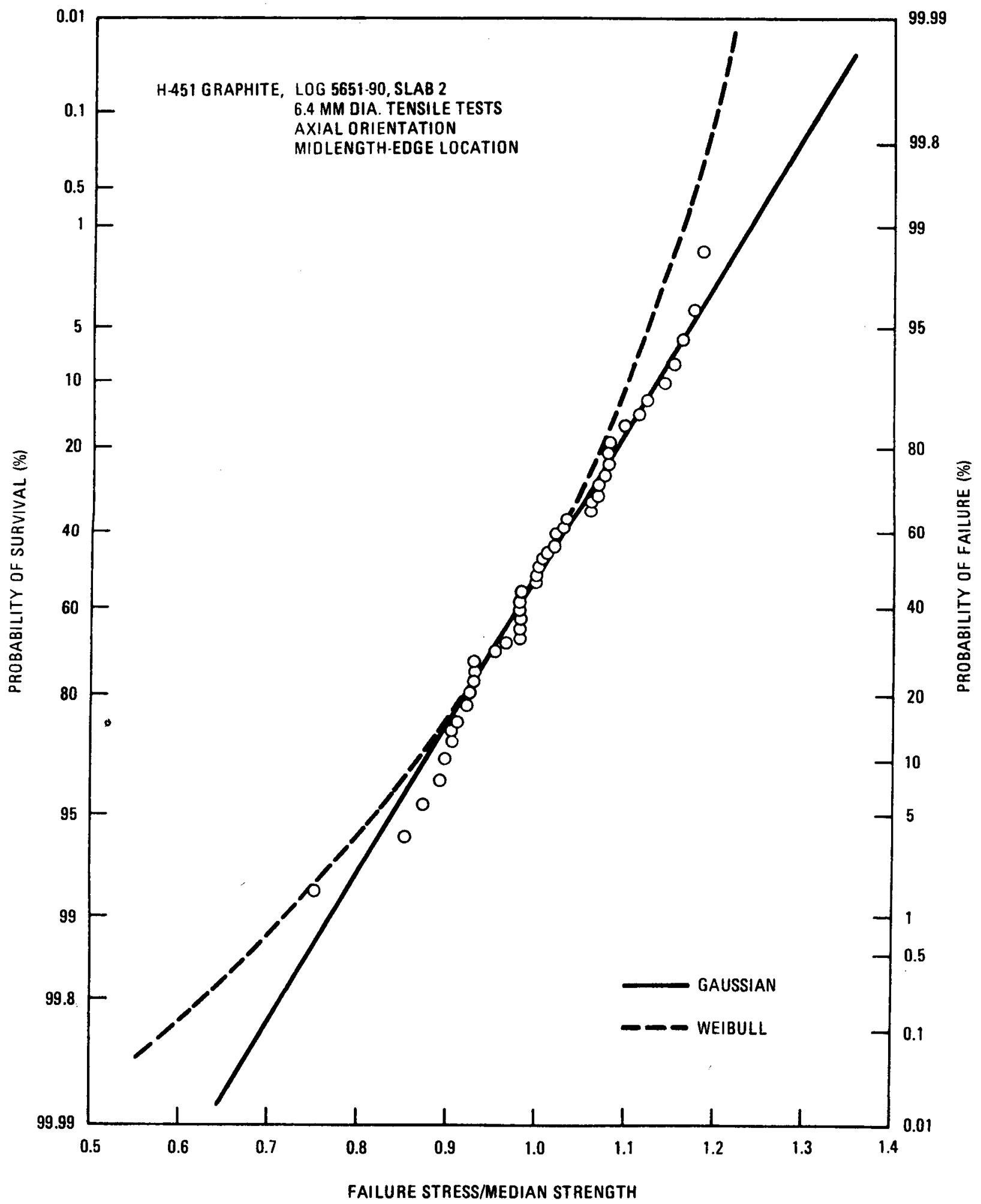

Fig. 33. Cumulative distribution curve for strength of small-sized tensile specimens, slab 2, axial orientation, midlength-edge location 


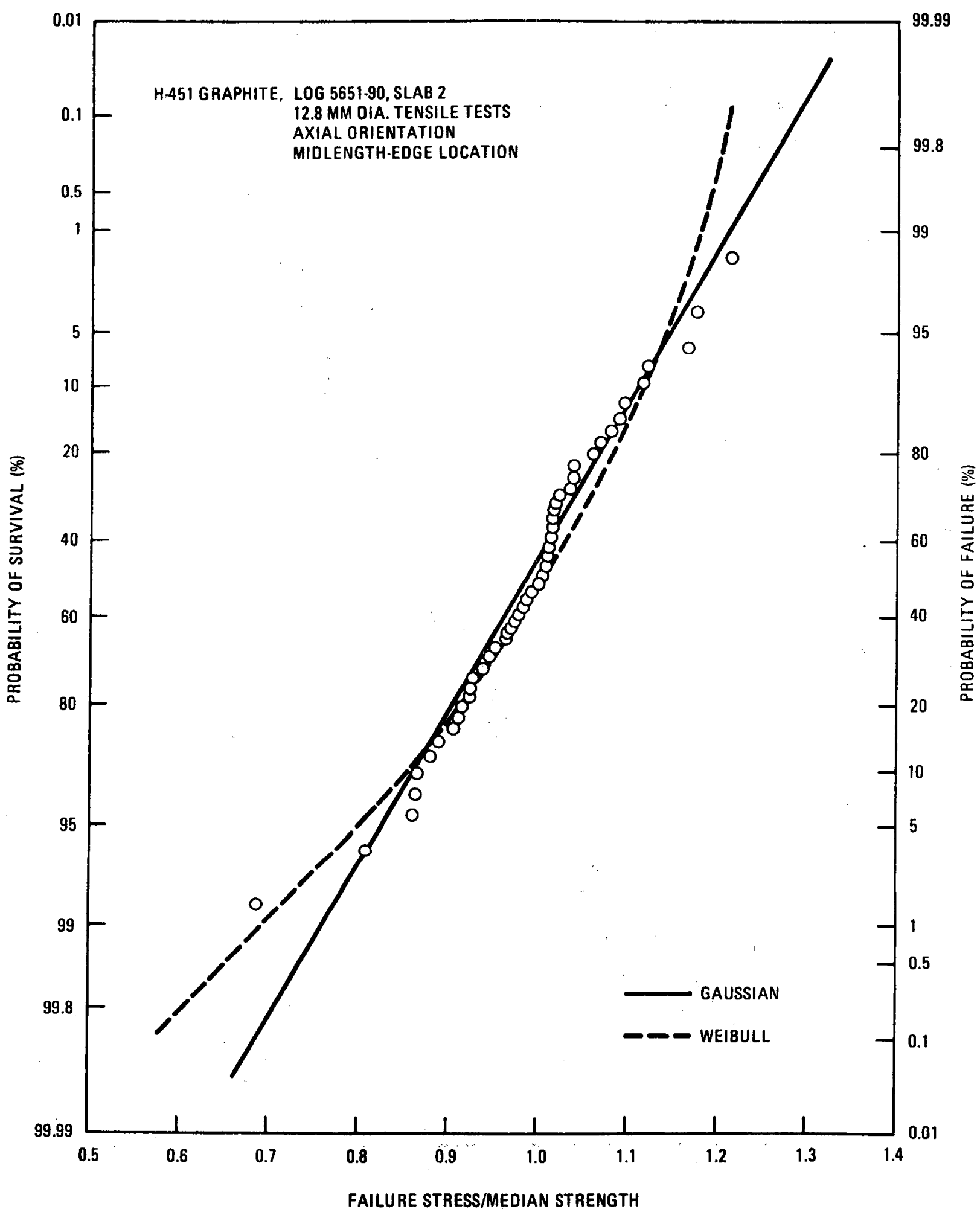

Fig. 34. Cumulative distribution curve for strength of large-sized tensile specimens, slab 2, axial orientation, midlength-edge location 


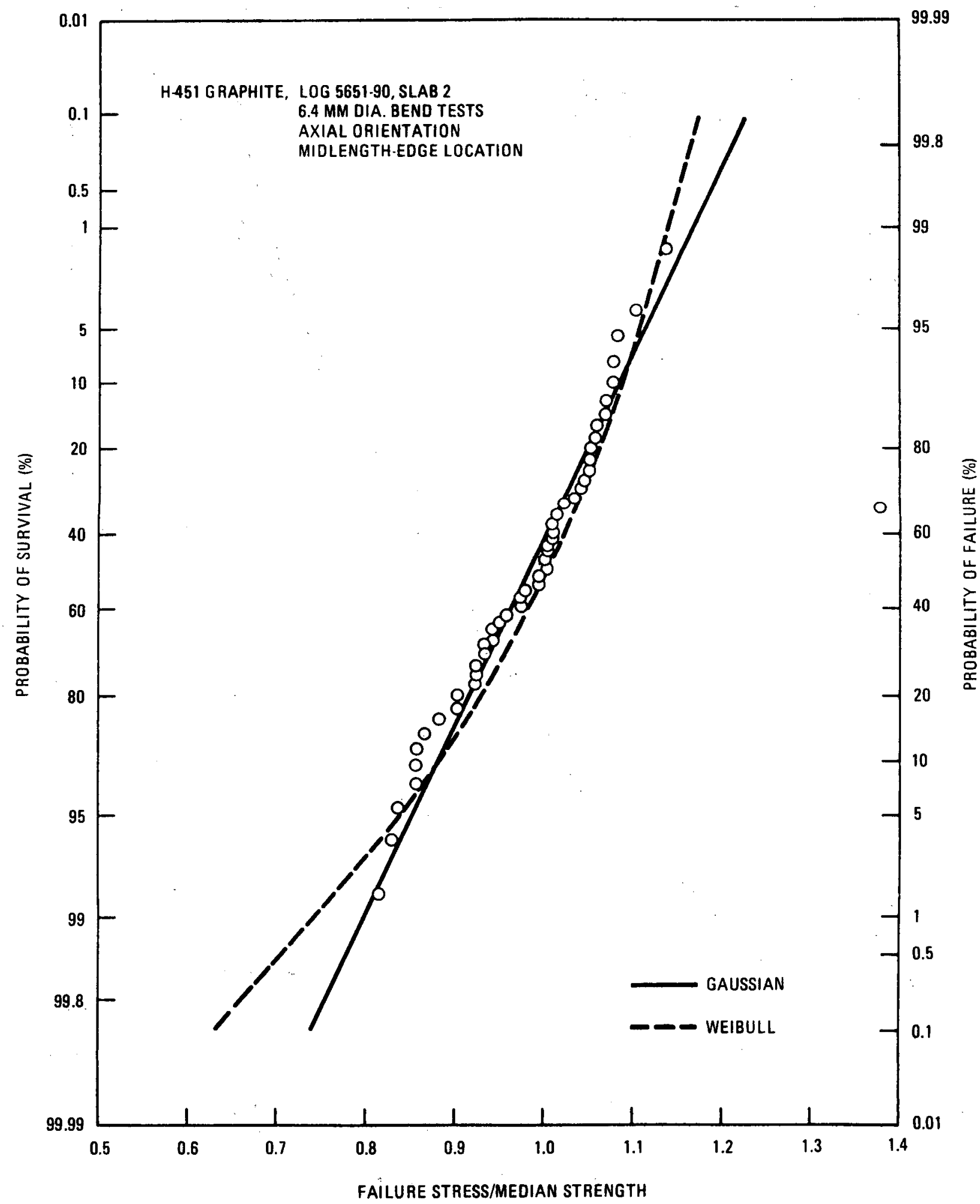

Fig. 35. Cumulative distribution curve for strength of four-point bend specimens, slab 2, axial orientation, midlength-edge location 


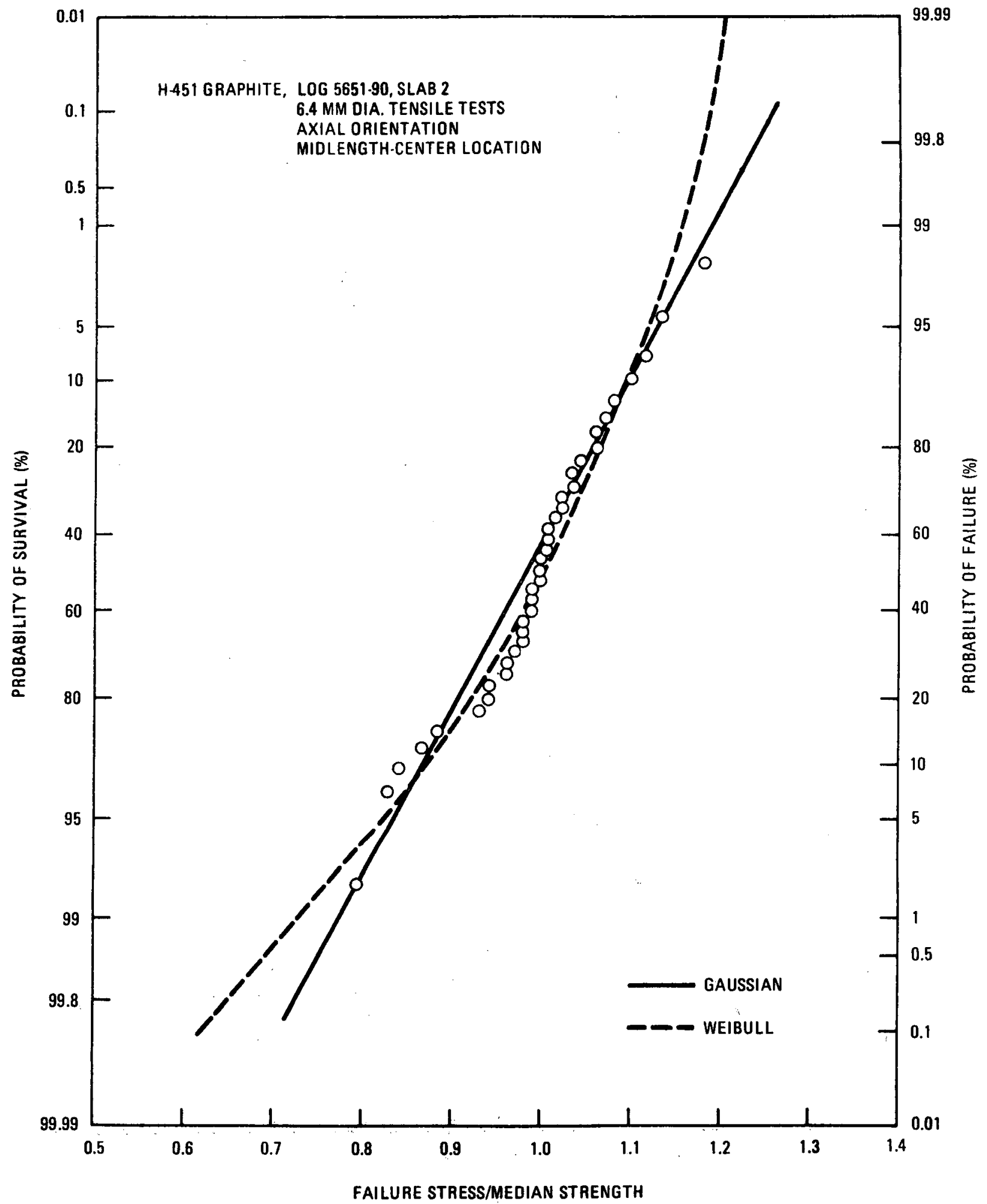

Fig. 36. Cumulative distribution curve for strength of sma11-sized tensile specimens, slab 2, axial orientation, midlength-center location 


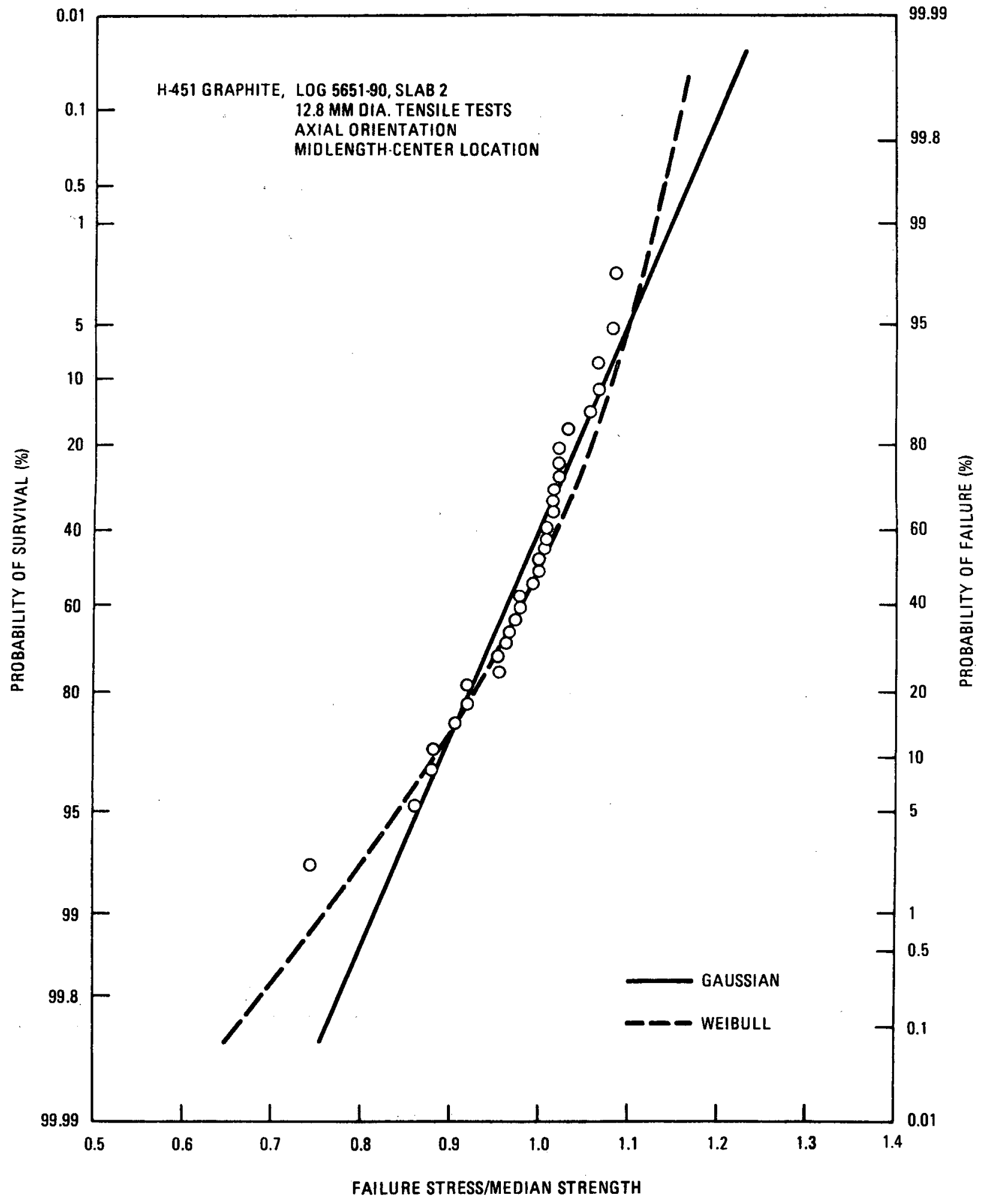

Fig. 37. Cumulative distribution curve for strength of 1arge-sized tensile specimens, slab 2, axial orientation, midlength-center location 


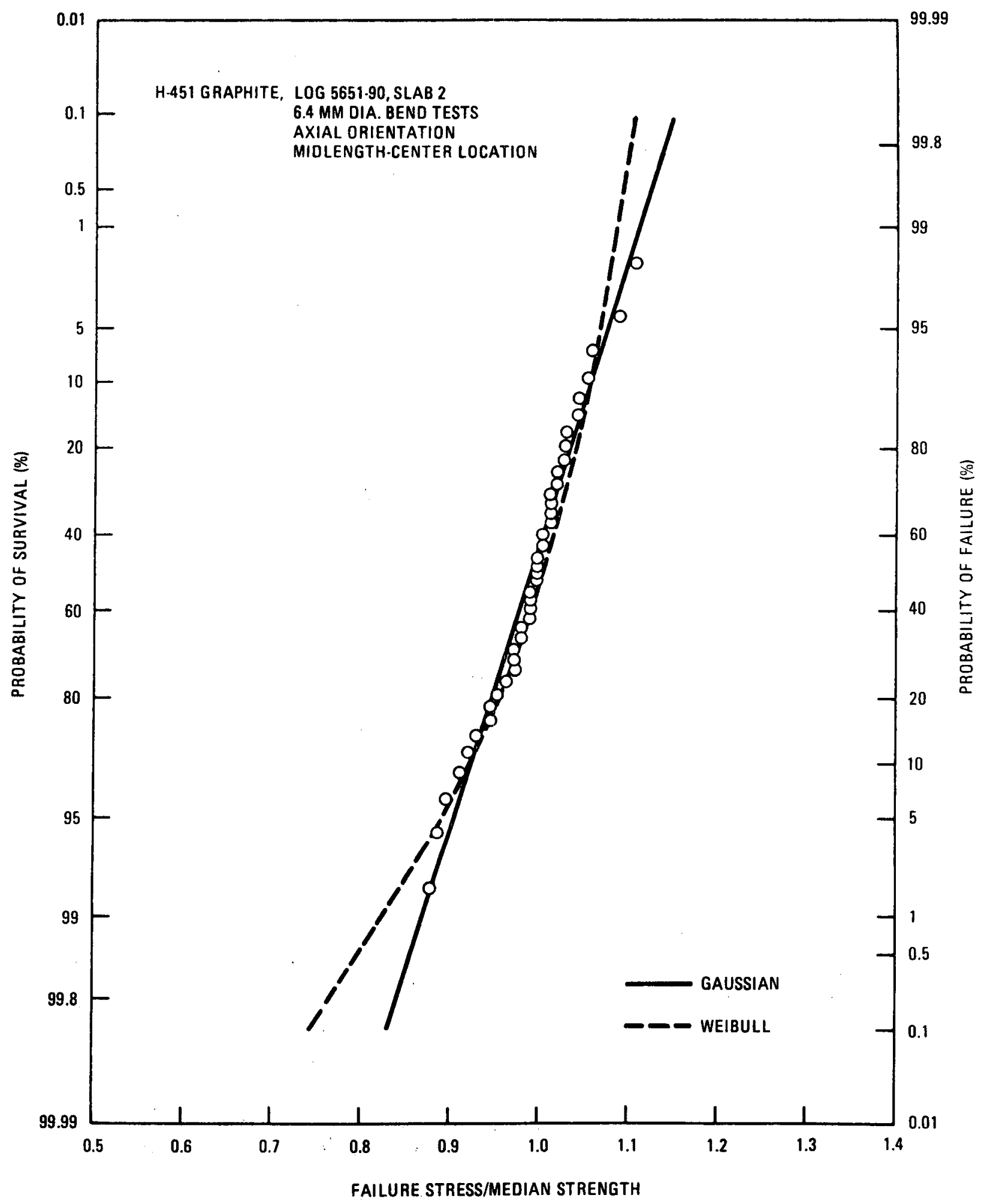

Fig. 38. Cumulative distribution curve for strength of four-point bend specimens, slab 2, axial orientation, midlength-center location 


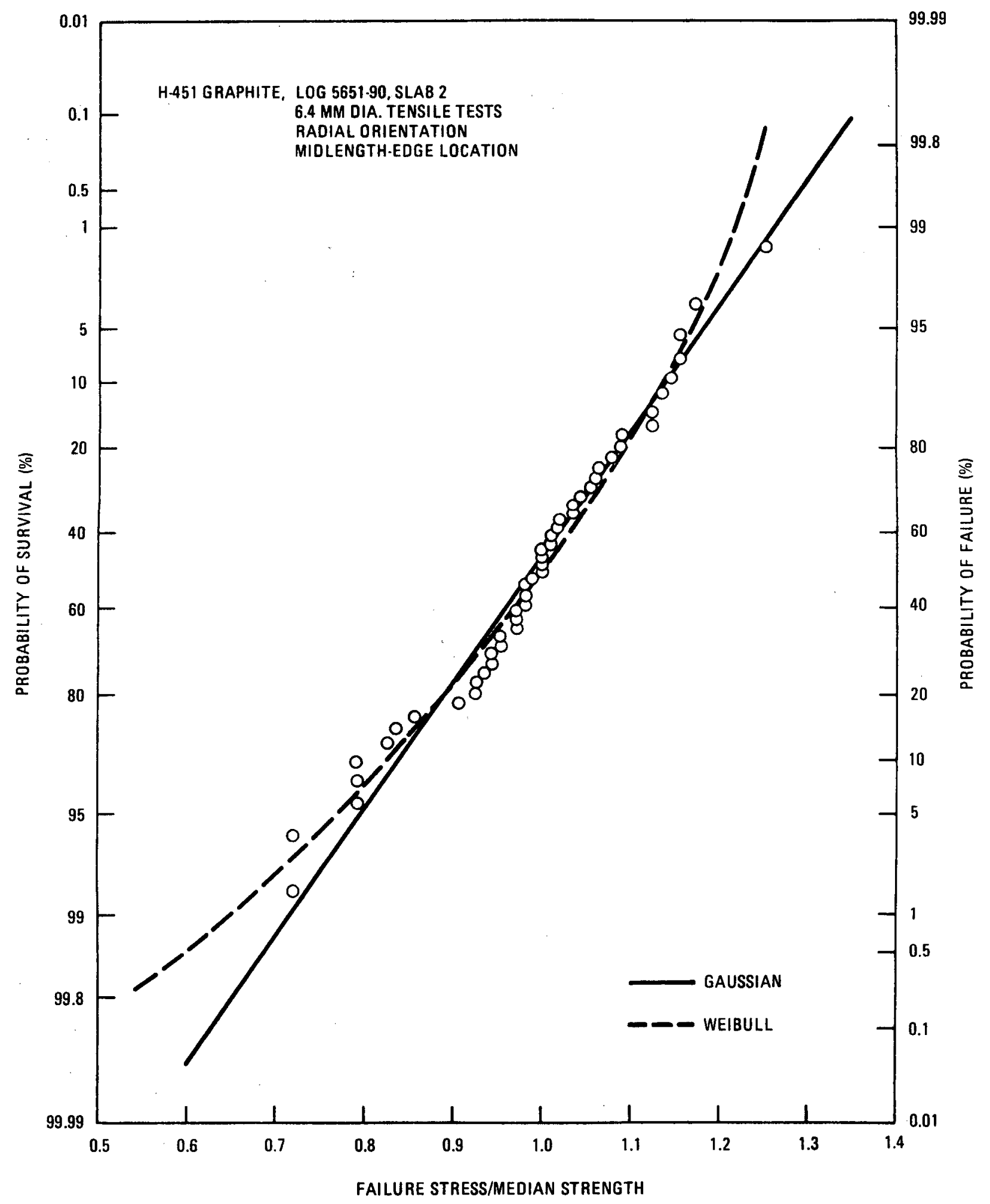

Fig. 39. Cumulative distribution curve for strength of smal1-sized tensile specimens, slab 2, radial orientation, midlength-edge location 


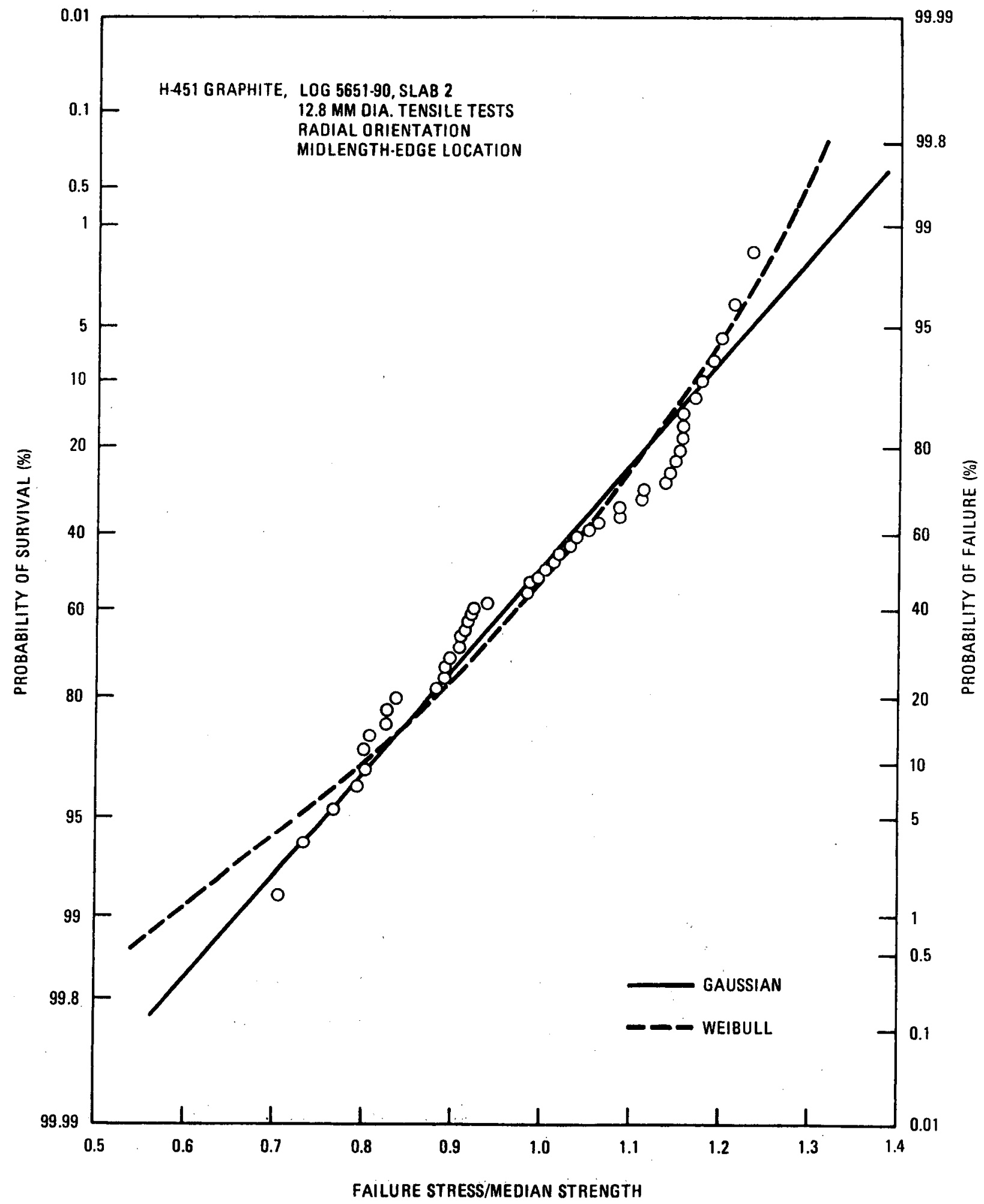

Fig. 40. Cumulative distribution curve for strength of large-sized tensile specimens, slab 2, radial orfentation, midlength-edge location 


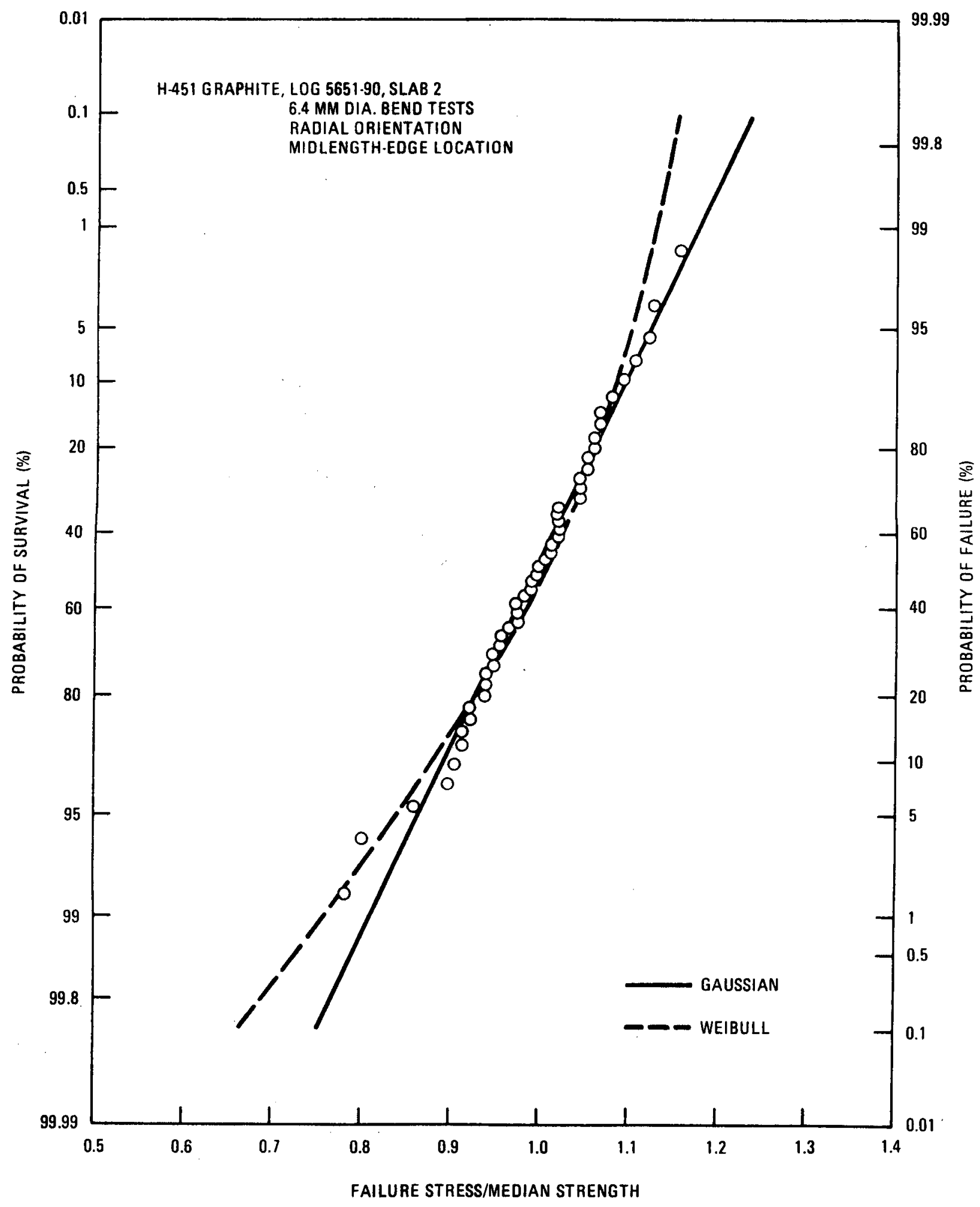

Fig. 41. Cumulative distribution curve for strength of four-point bend specimens, slab 2, radial orientation, midlength-edge location 


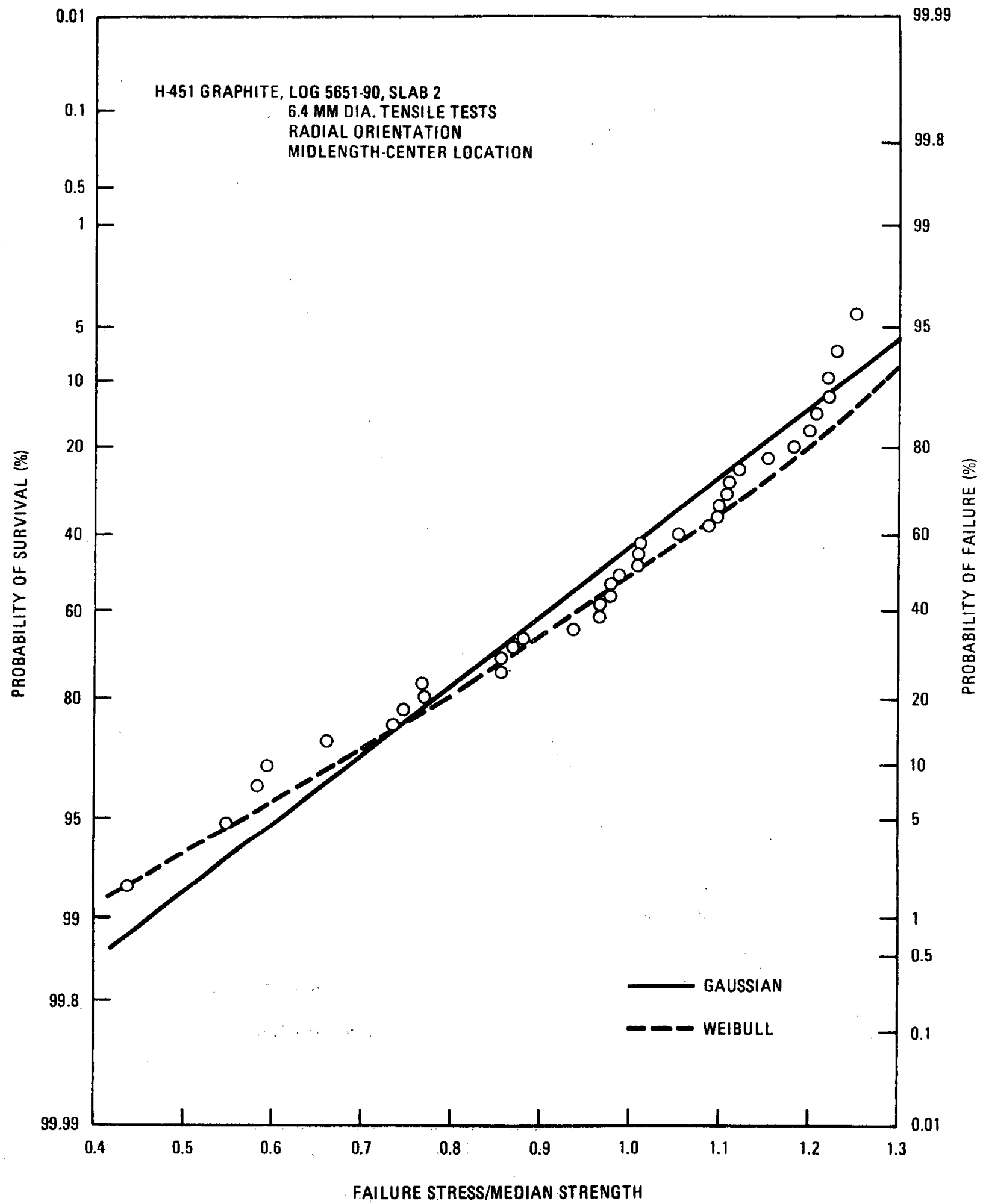

Fig. 42. Cumulative distribution curve for strength of sma11-sized tensile specimens, slab 2, radial orientation, midlength-center location 


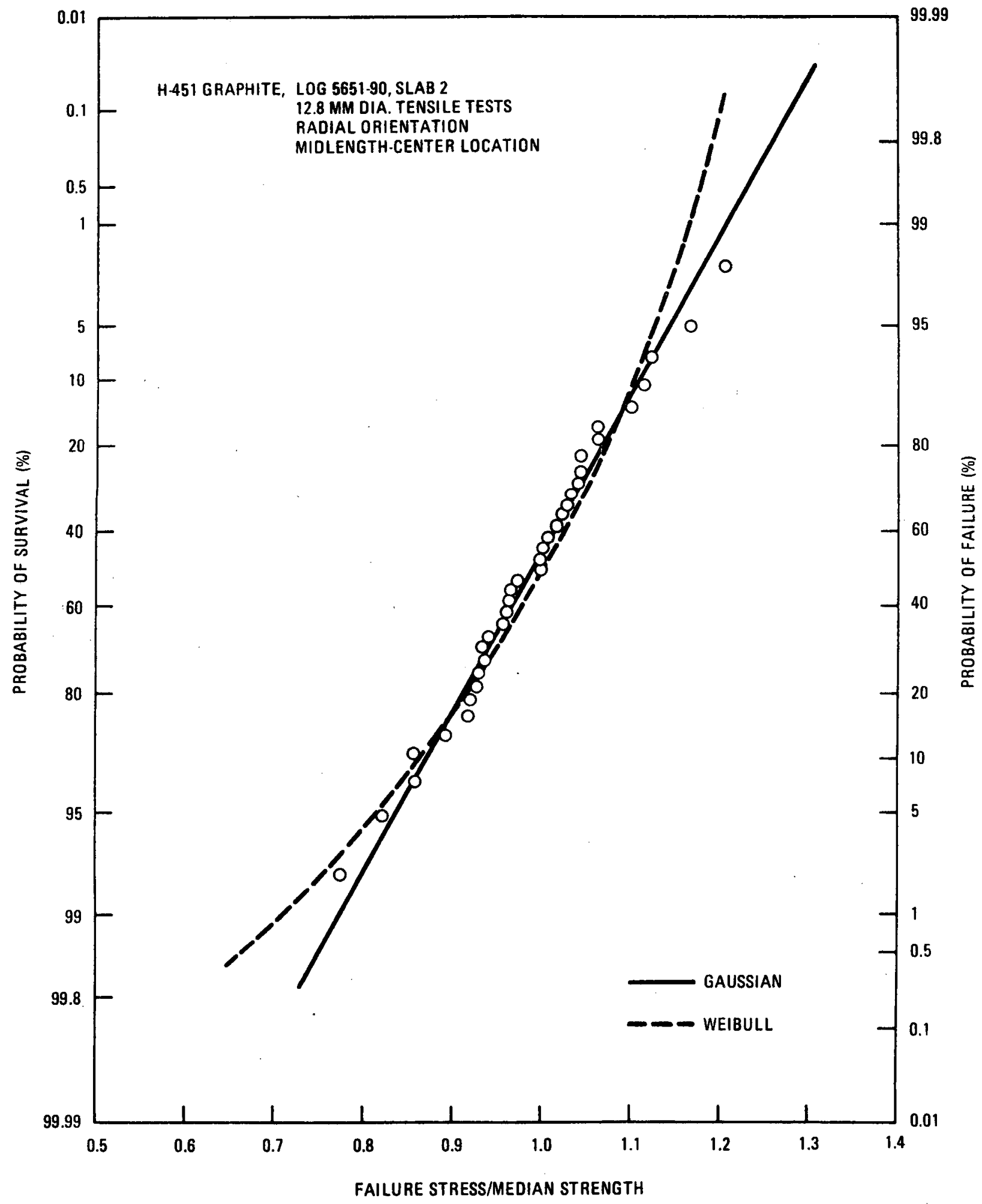

Fig. 43. Cumulative distribution curve for strength of large-sized tensile specimens, slab 2, radial orientation, midlength-center location 


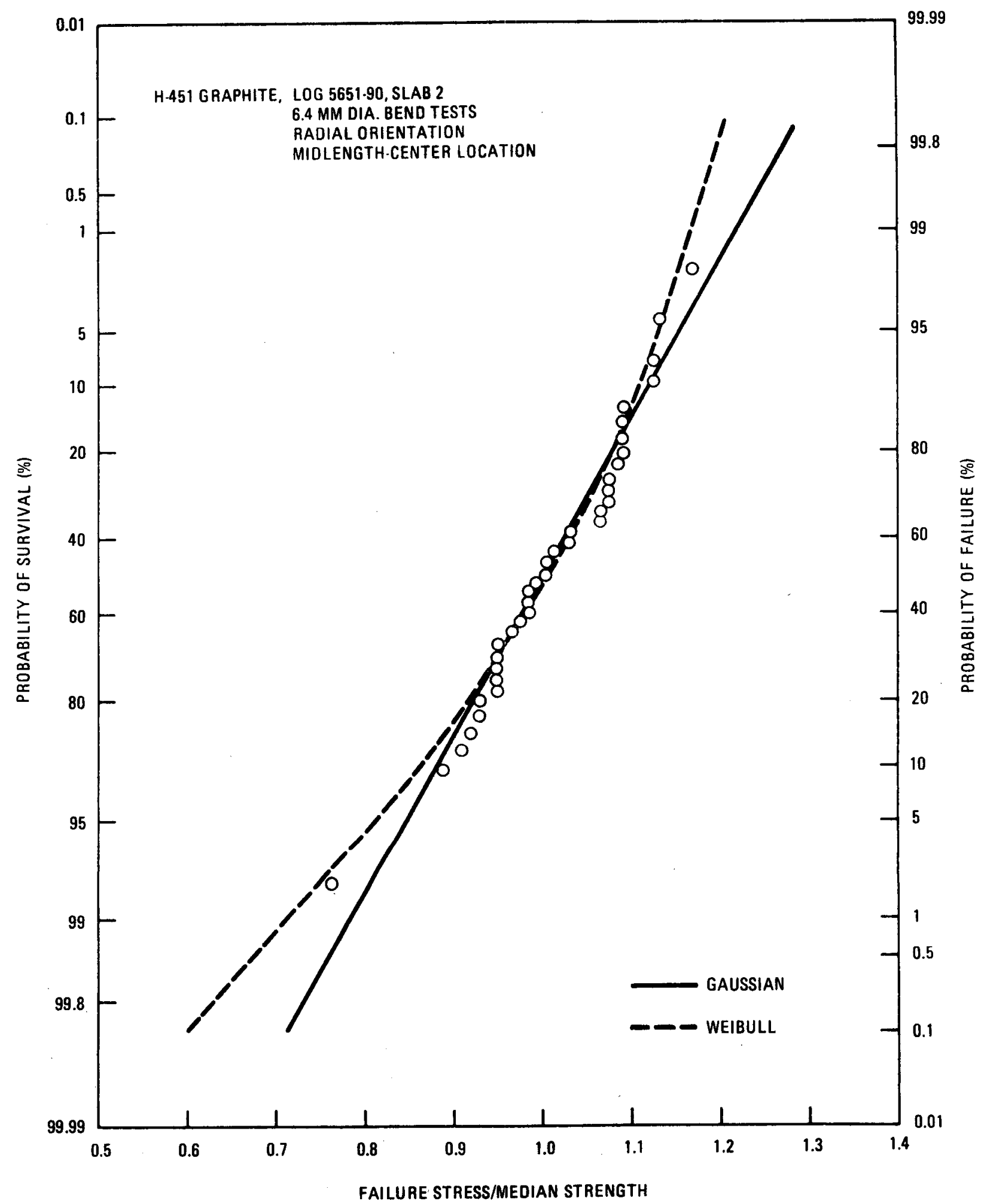

Fig. 44. Cumulative distribution curve for strength of four-point bend specimens, slab 2, radial orientation, midlength-center location 


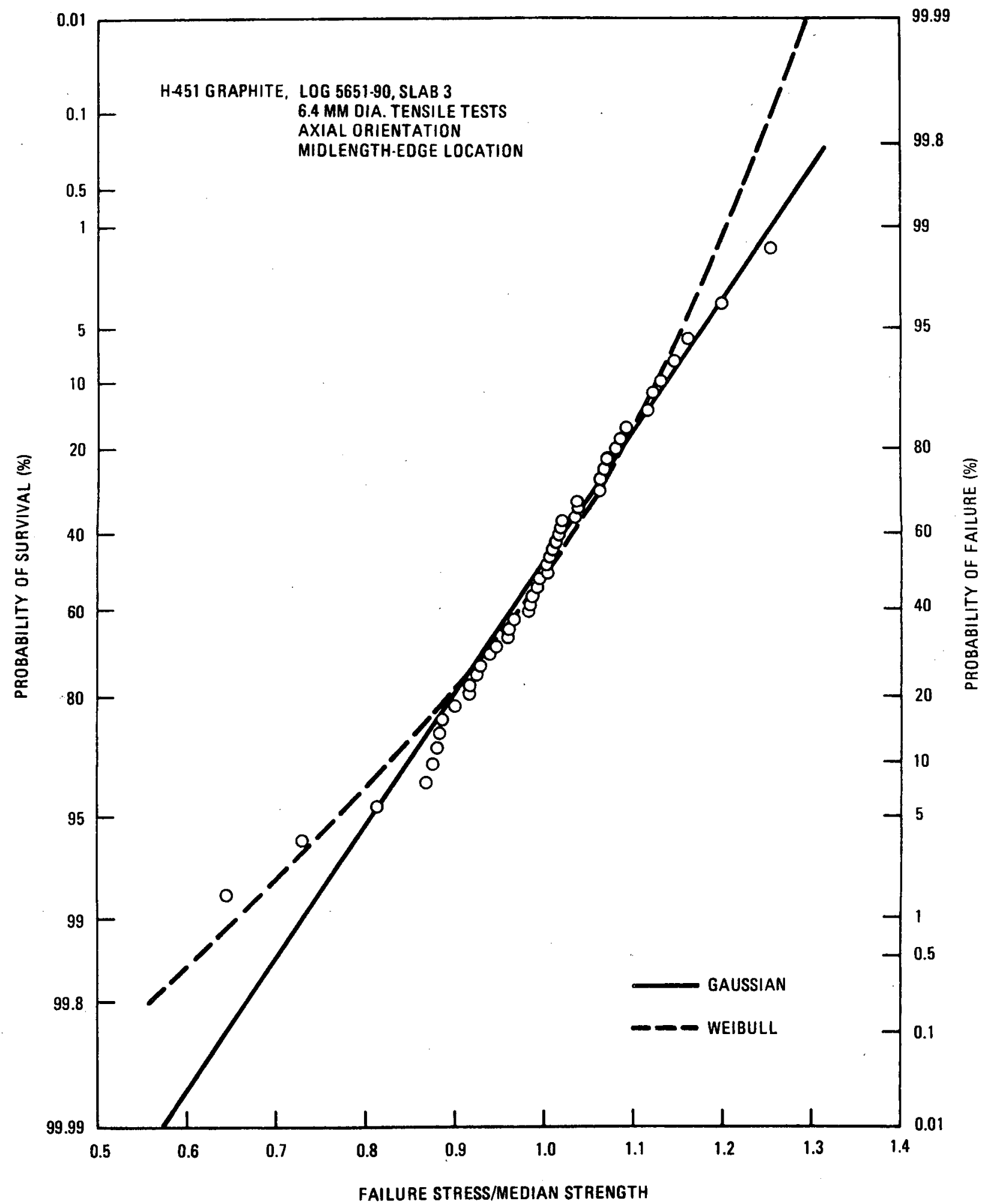

Fig. 45. Cumulative distribution curve for strength of small-sized tensile specimens, slab 3, axial orientation, mldlength-edge location 


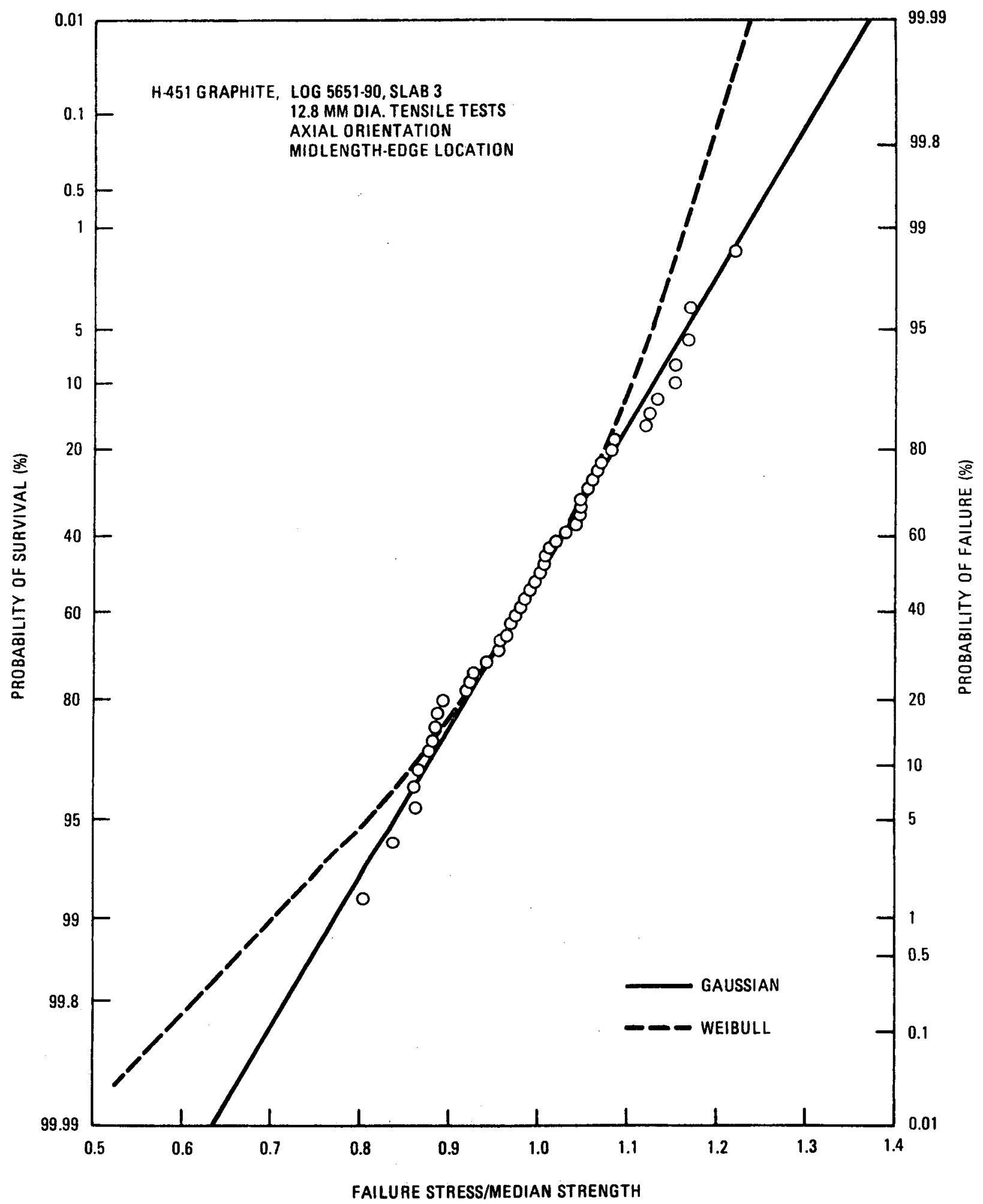

Fig. 46. Cumulative distribution curve for strength of large-sized tensile specimens, slab 3, axial orientation, midlength-edge location 


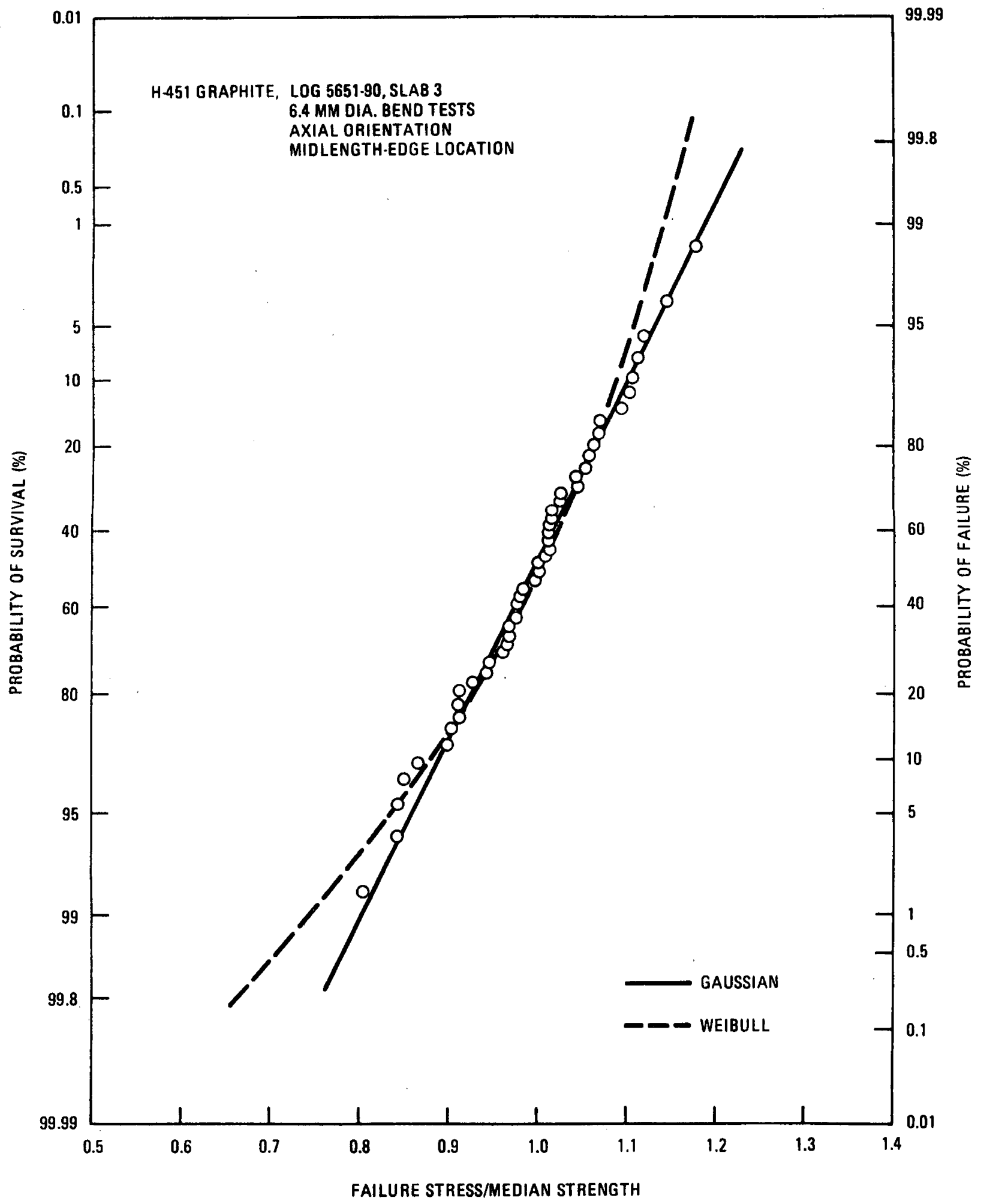

Fig. 47. Cumulative distribution curve for strength of four-point bend specimens, slab 3, axial orientation, midlength-edge location 


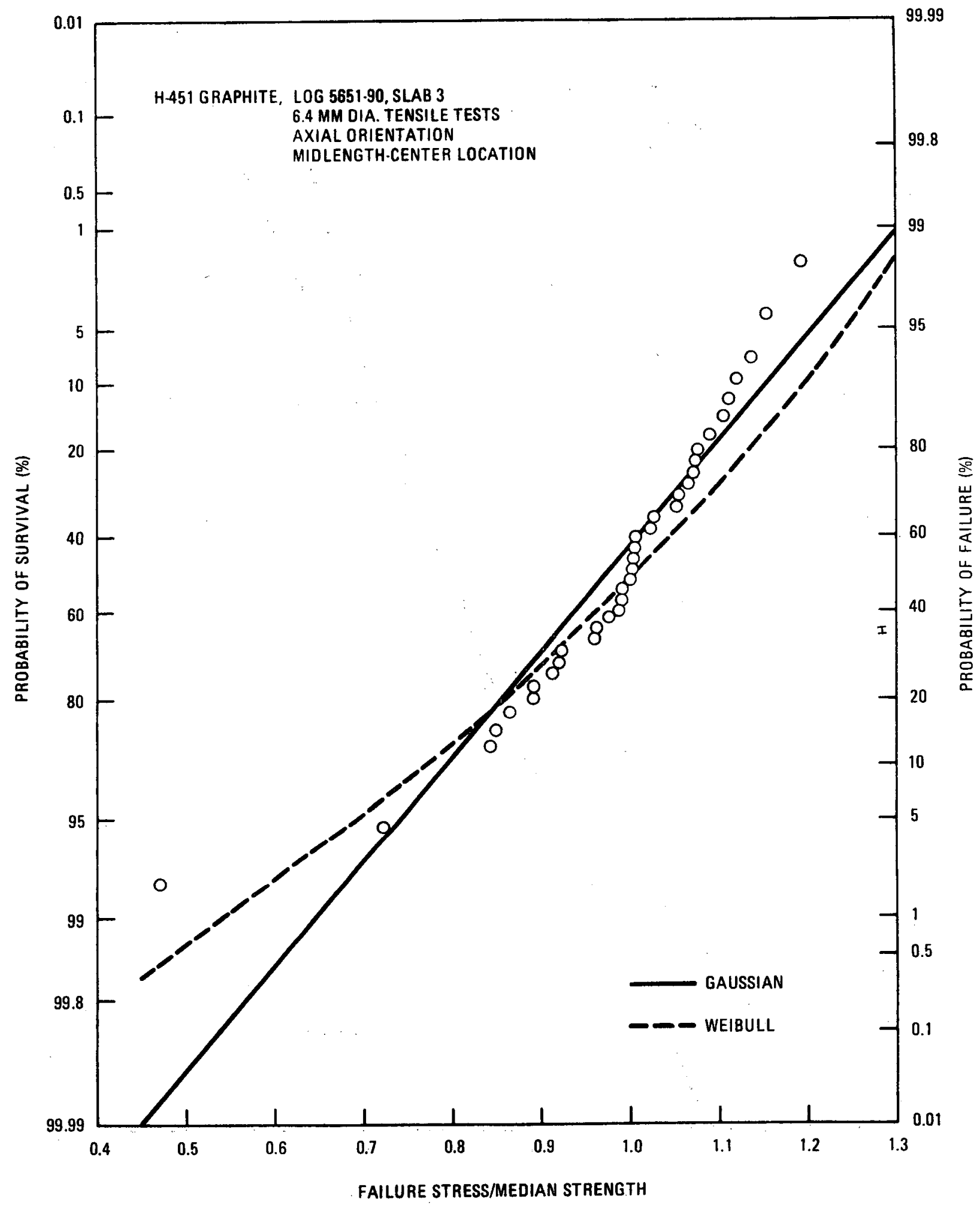

Fig. 48. Cumulative distribution curve for strength of small-sized tensile specimens, slab 3, axial orientation, midlength-center location 


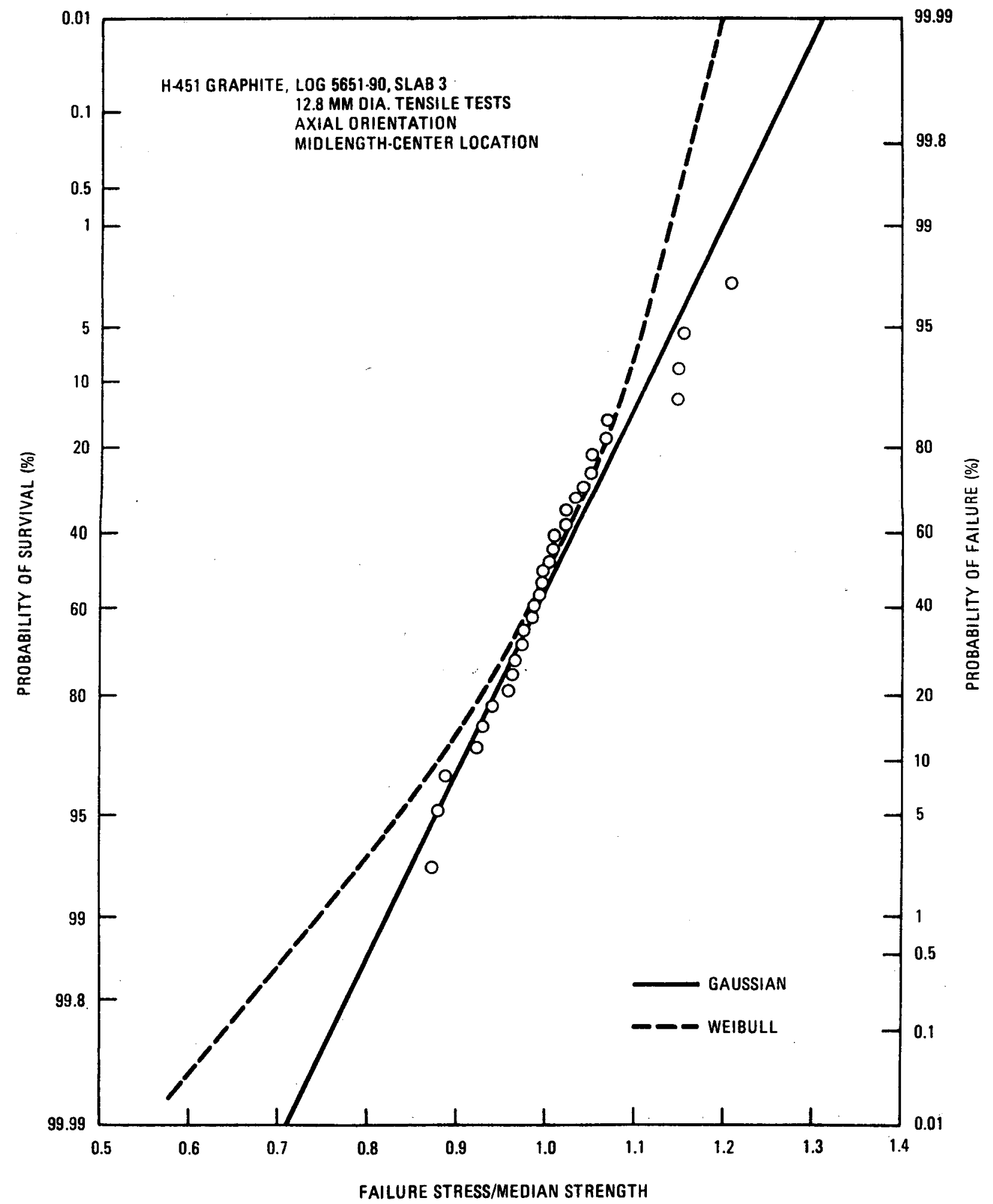

F1g. 49. Cumulative distribution curve for strength of large-sized tensile specimens, slab 3, axial orientation, midlength center location 


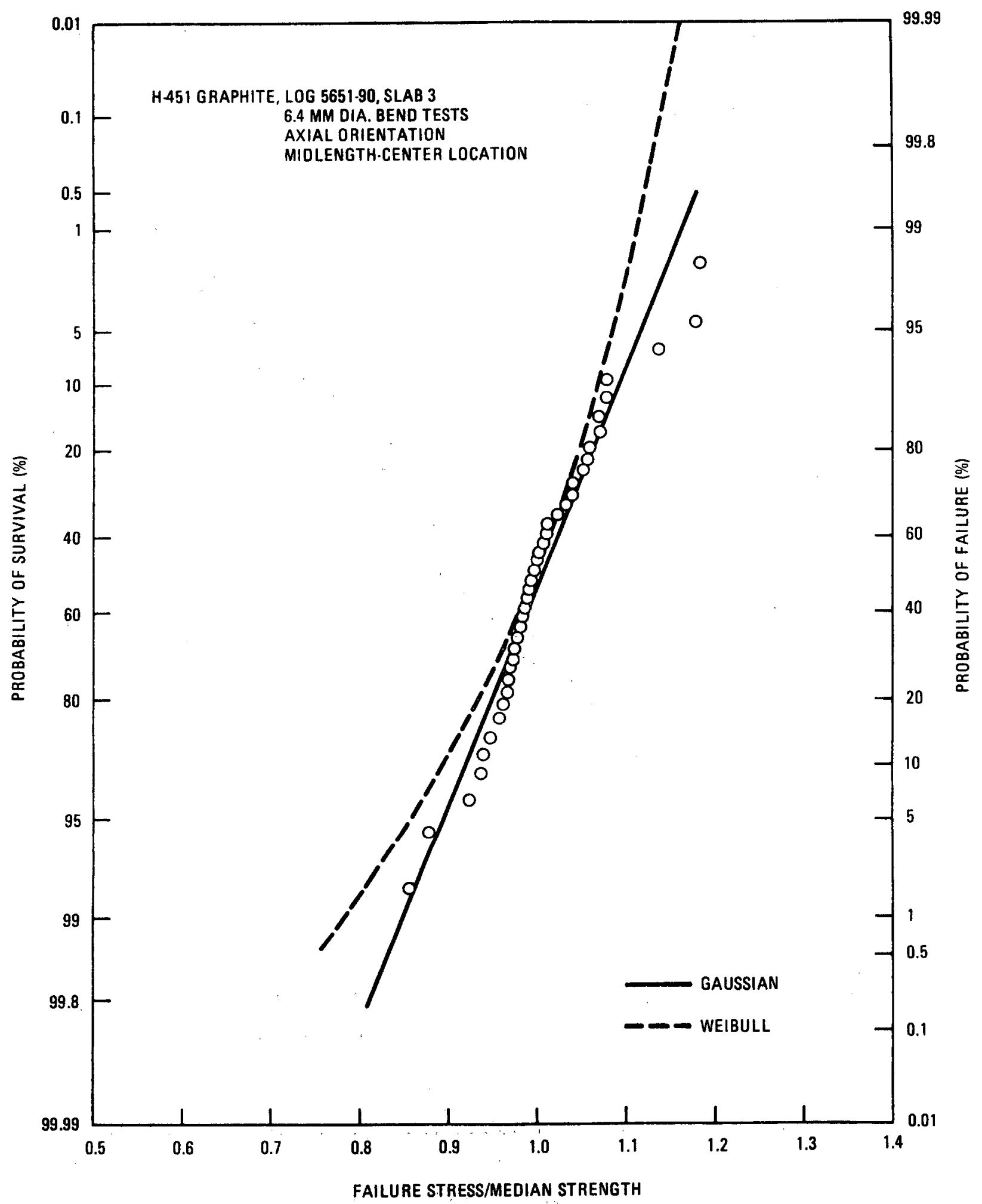

Fig. 50. Cumulative distribution curve for strength of four-point bend specimens, slab 3, axial orlentation, midlength-center location 


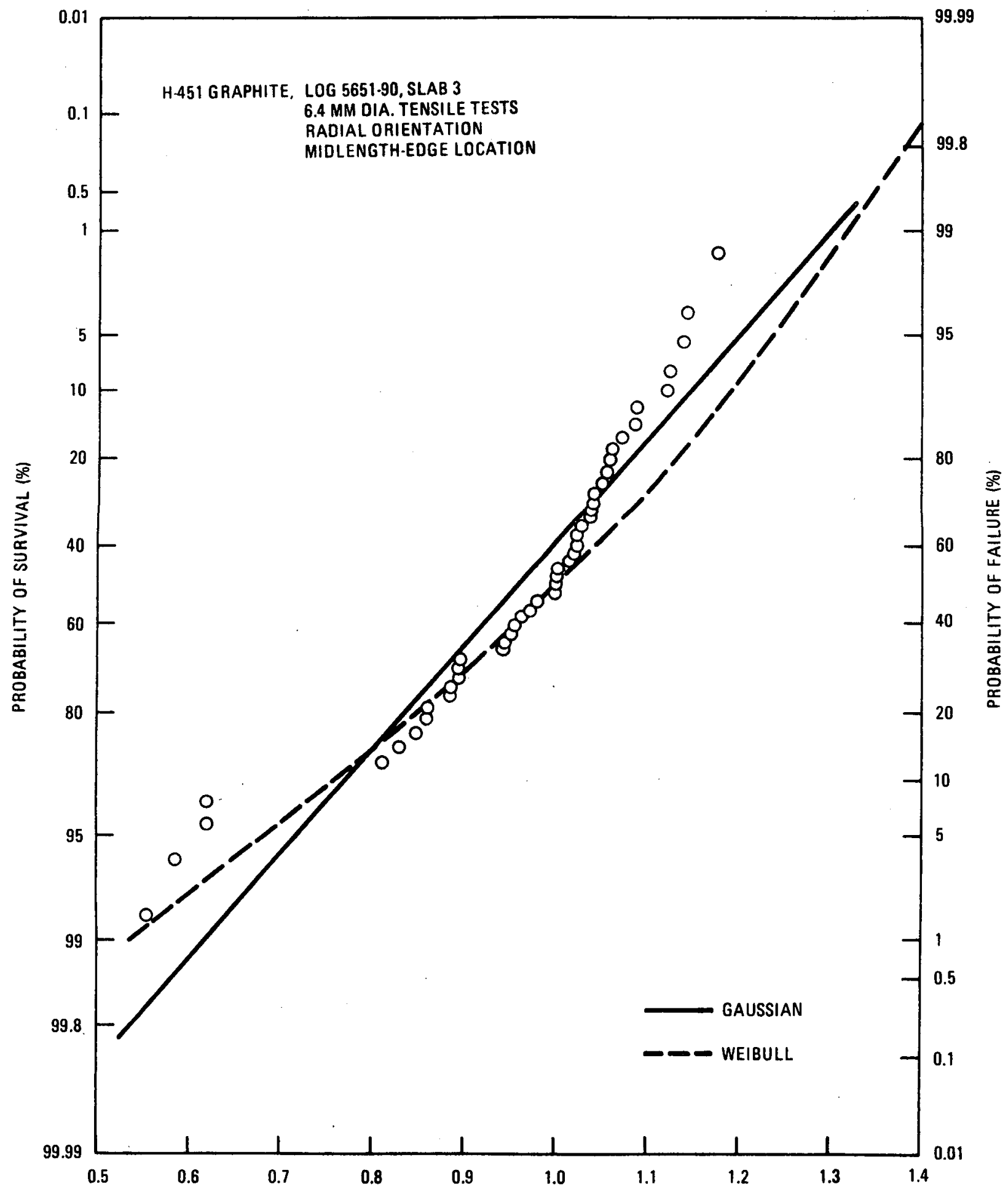

FAILURE STRESS/MEDIAN STRENGTH

Fig. 51. Cumulative distribution curve for strength of smal1-sized tensile specimens, slab 3, radial orfentation, midlength-edge location 


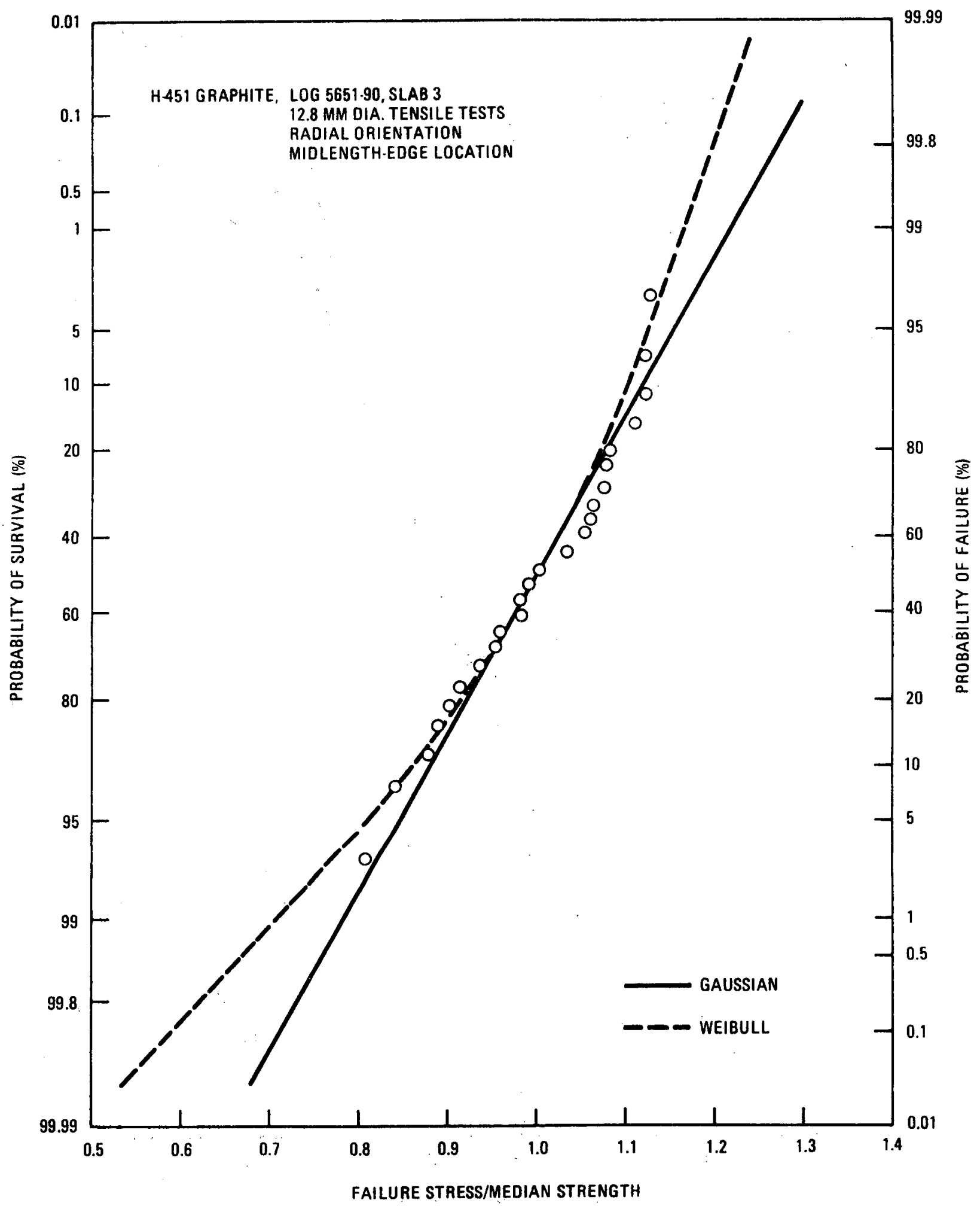

Fig. 52. Cumulative distribution curve for strength of large-sized tensile specimens, slab 3, radial orientation, midlength-edge location 


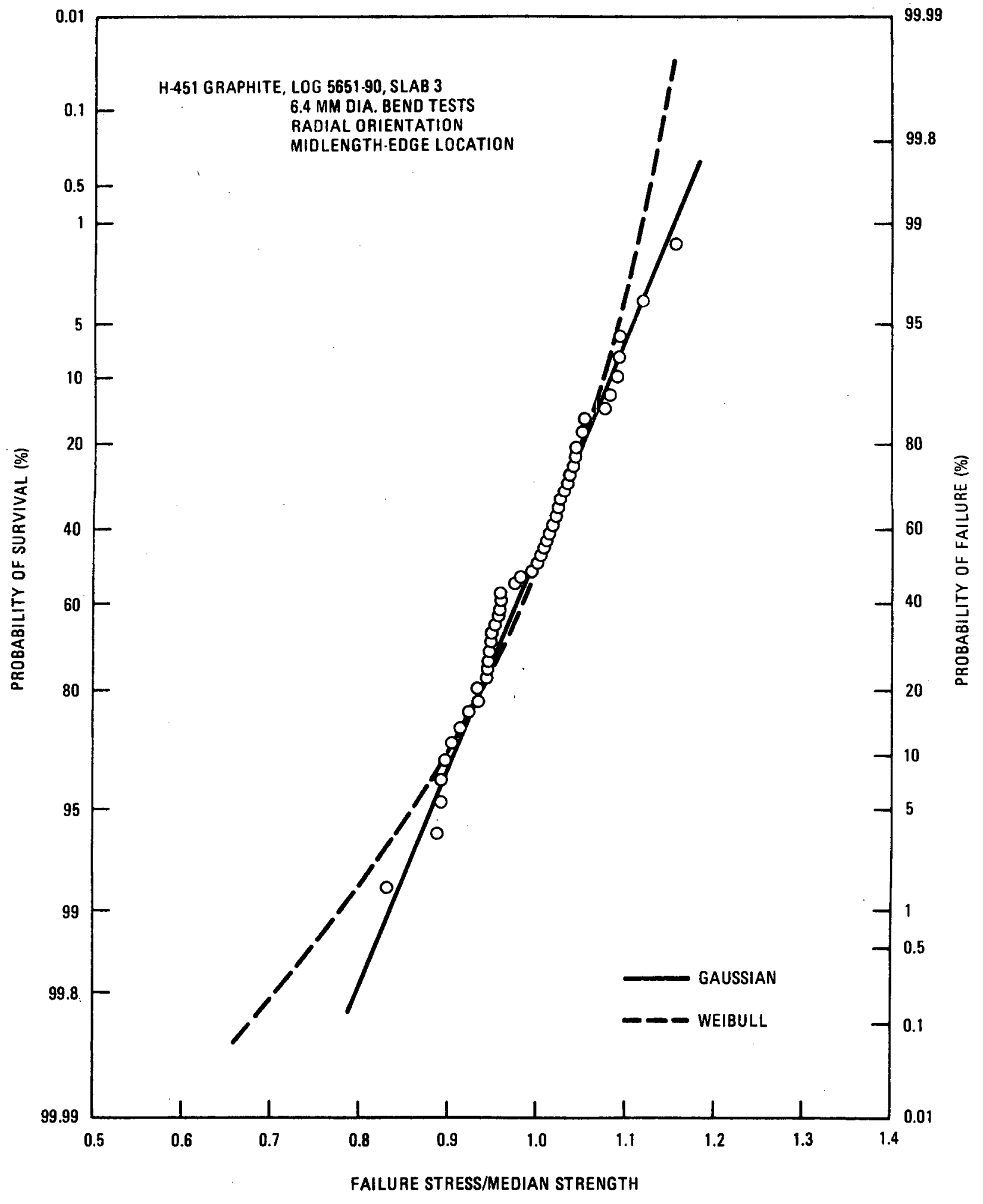

Fig. 53. Cumulative distribution curve for strength of four-point bend specimens, slab 3, radial orientation, midlength-edge location 


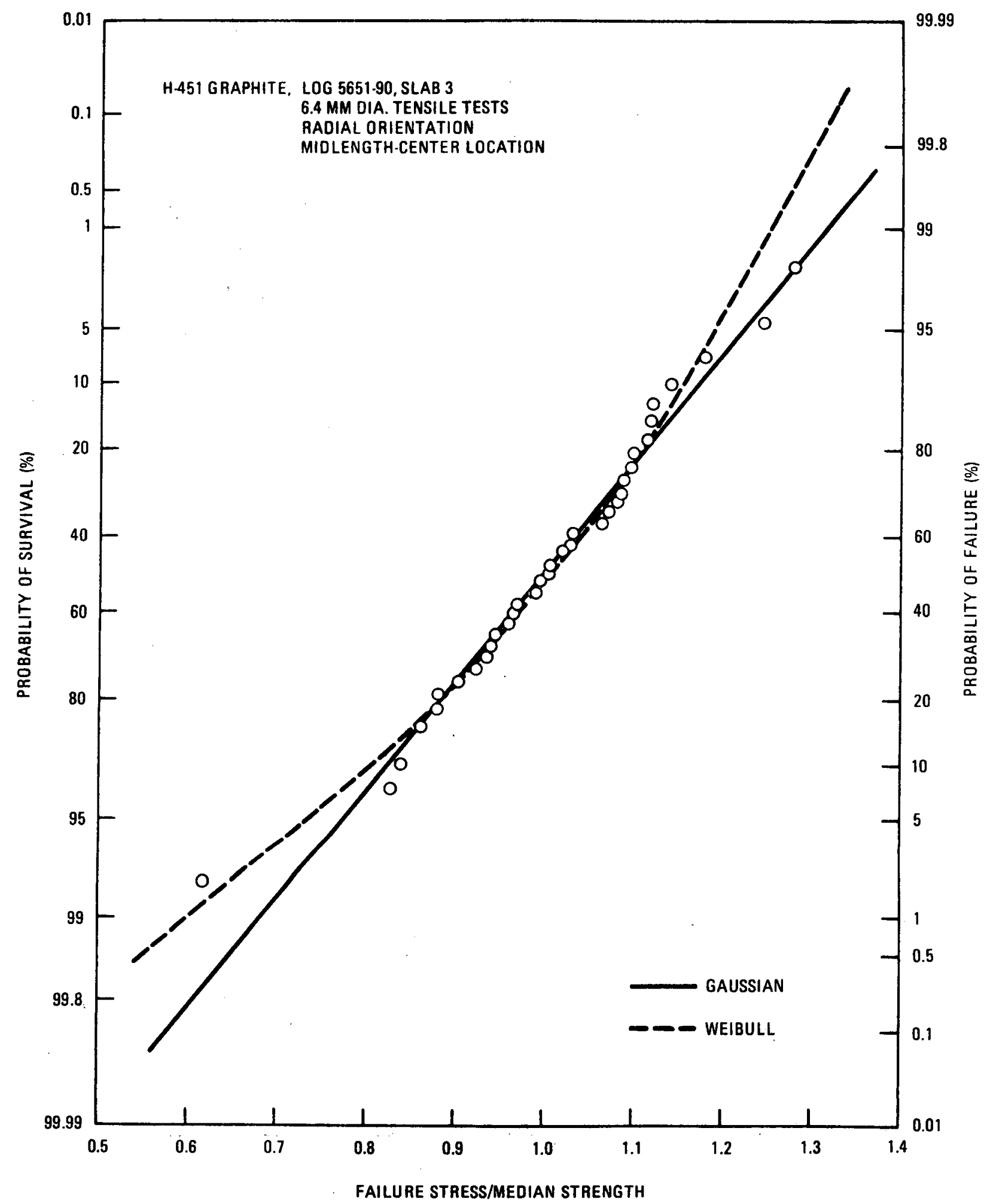

Fig. 54. Cumulative distribution curve for strength of small-sized tensile specimens, slab 3, radial orientation, midlength-center location 


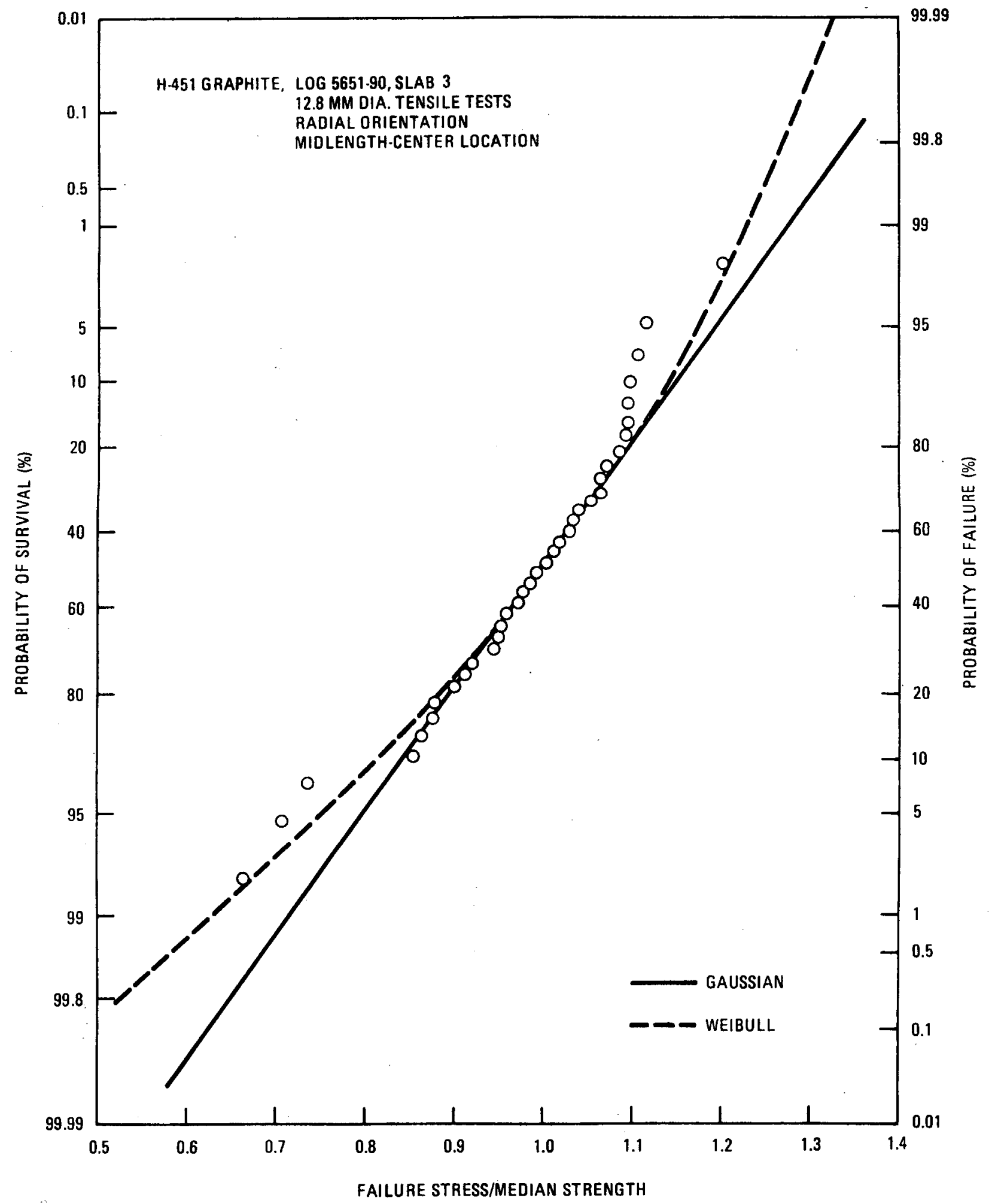

Fig. 55. Cumulative distribution curve for strength of large-sized tensile specimens, slab 3, radial orientation, midlength-center location 


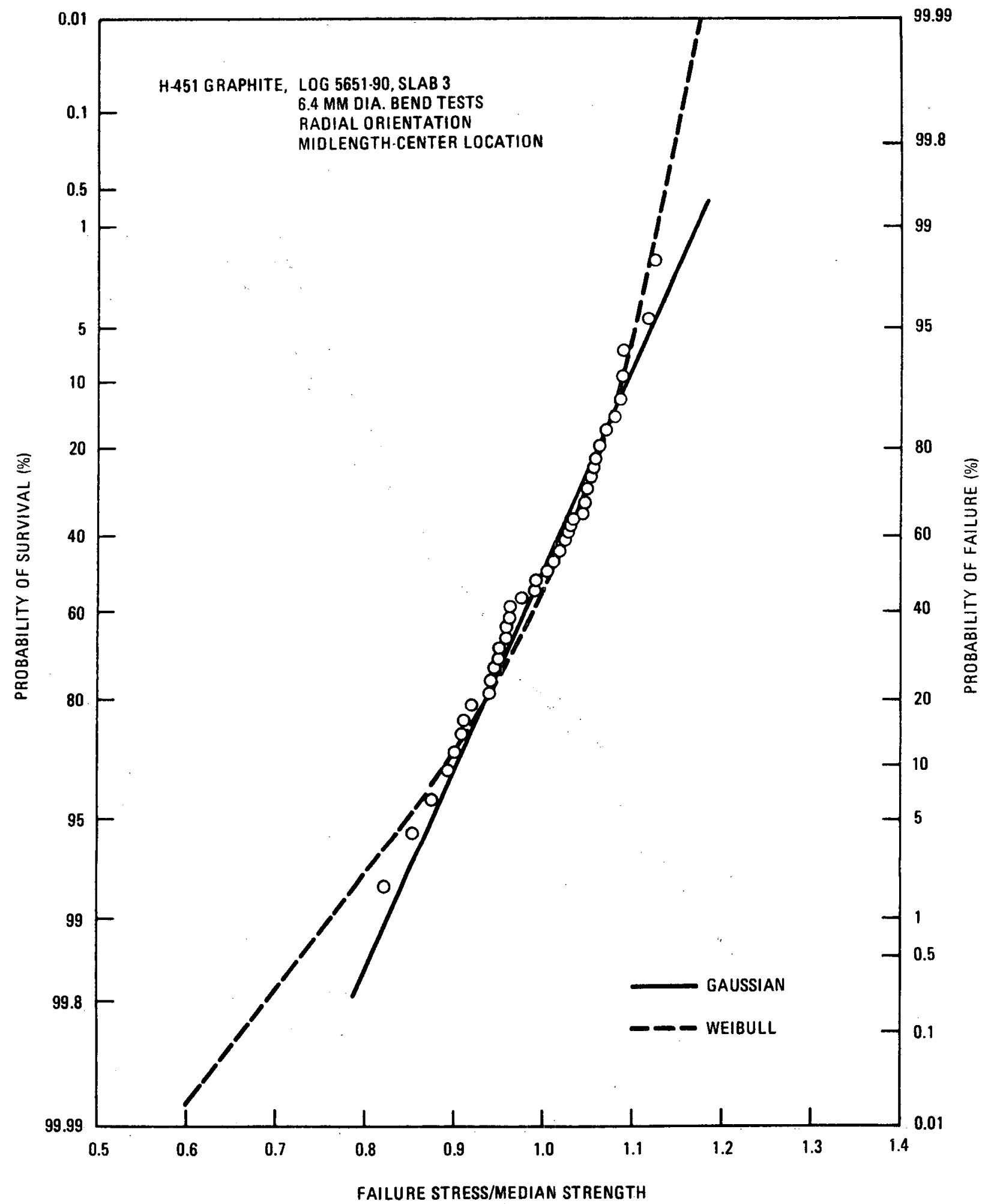

Fig. 56. Cumulative distribution curve for strength of four-point bend specimens, slab 3, radial orientation, midlength-center location 


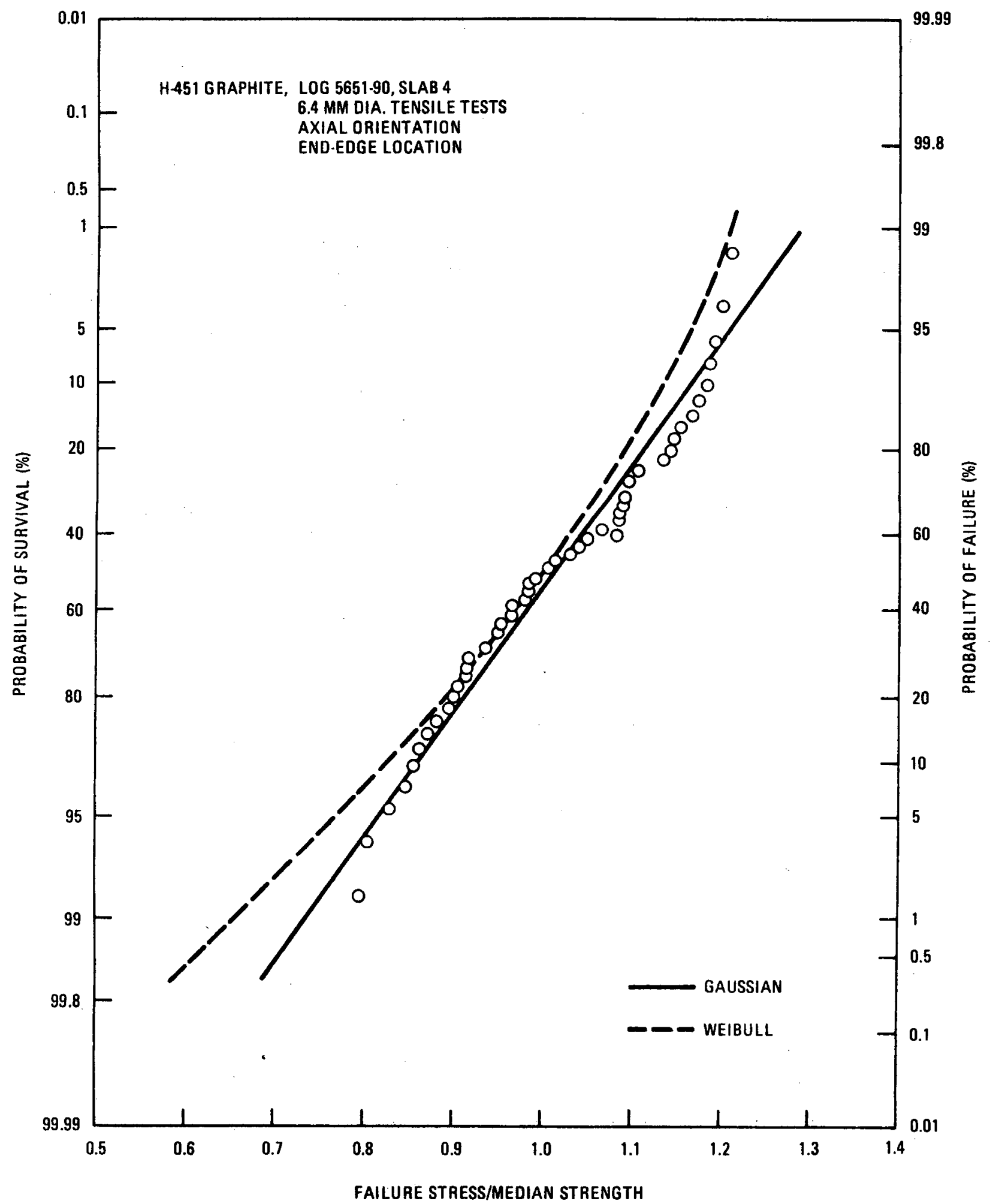

Fig. 57. Cumulative distribution curve for strength of small-sized tensile specimens, slab 4, axial ortentation, end-edge location 


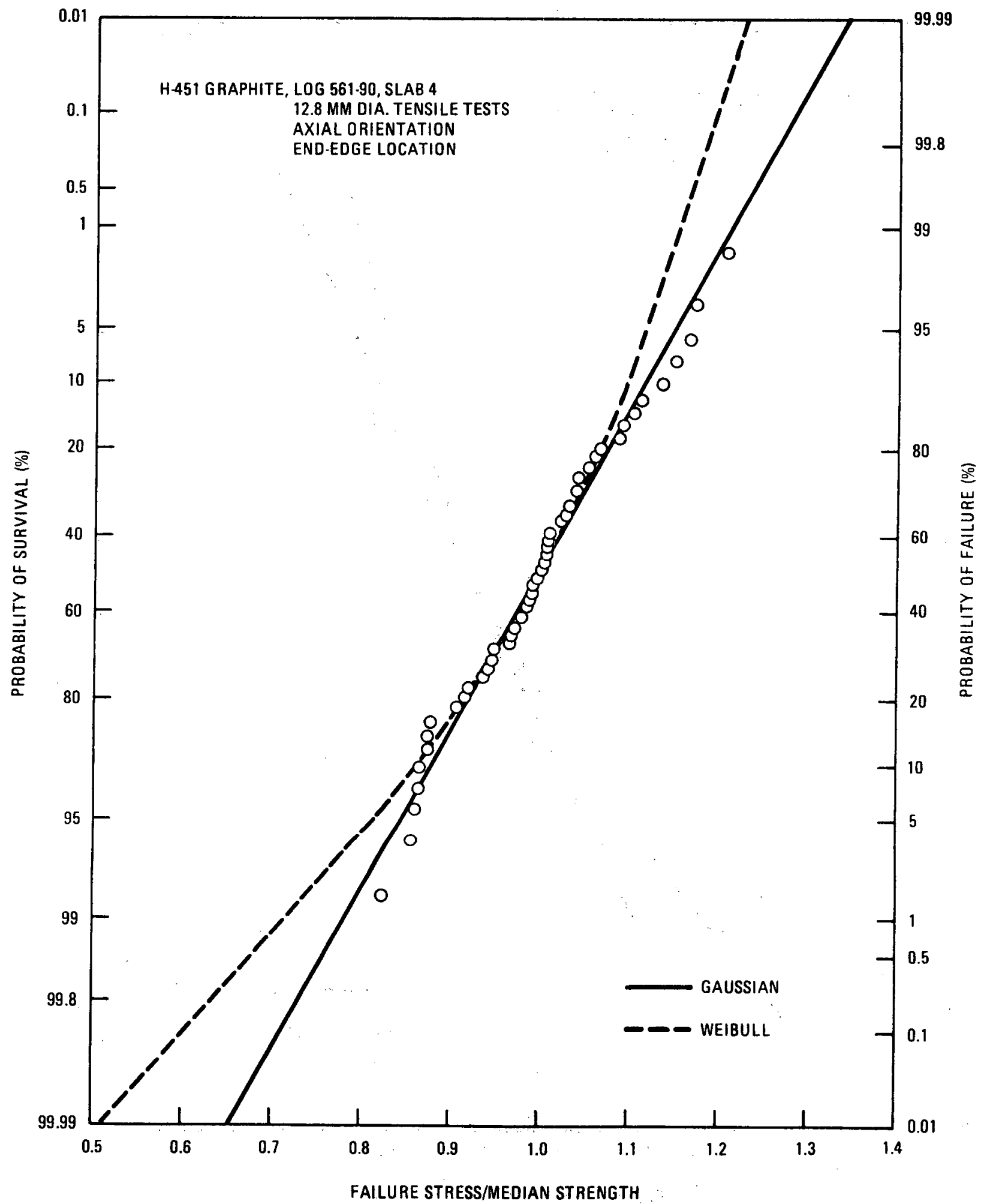

Fig. 58. Cumulative distribution curve for strength of large-sized tensile specimens, slab 4, axial orientation, end-edge location 


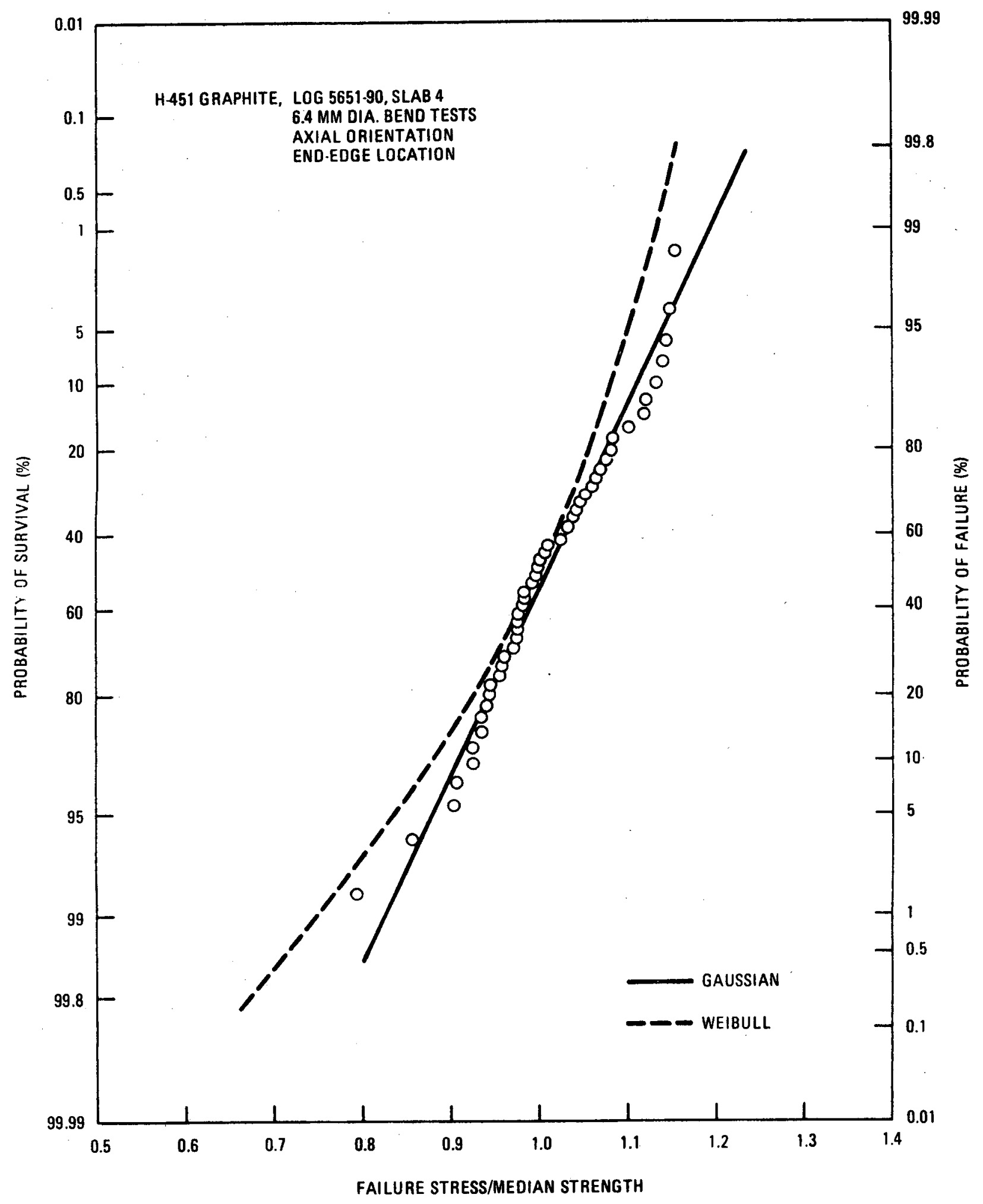

F1g. 59. Cumulative distribution curve for strength of four-point bend spectmens, slab 4, axial orientation, end-edge location 


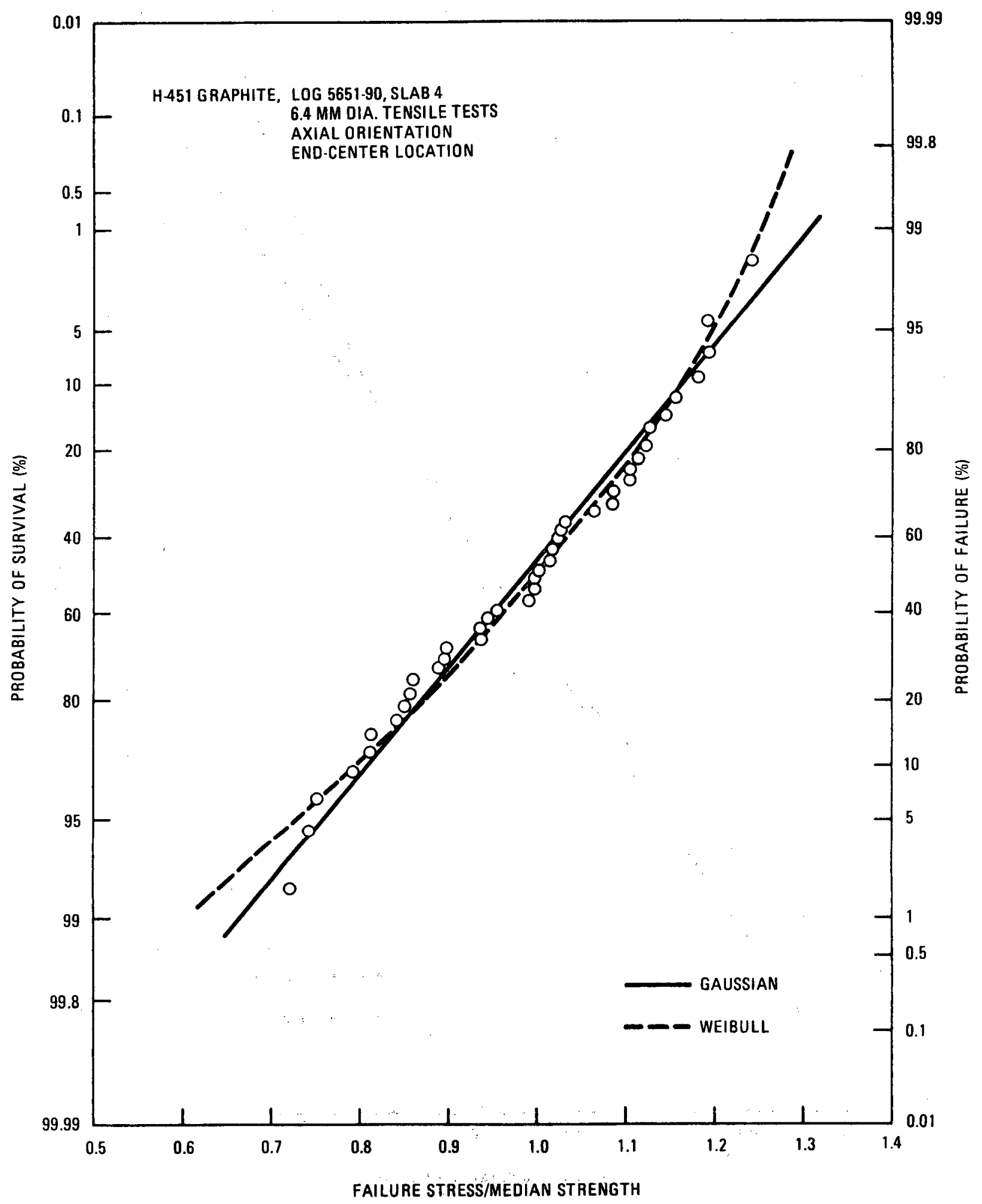

Fig. 60. Cumulative distribution curve for strength of smal1-sized tensile specimens, slab 4, axial orientation, end-center location 


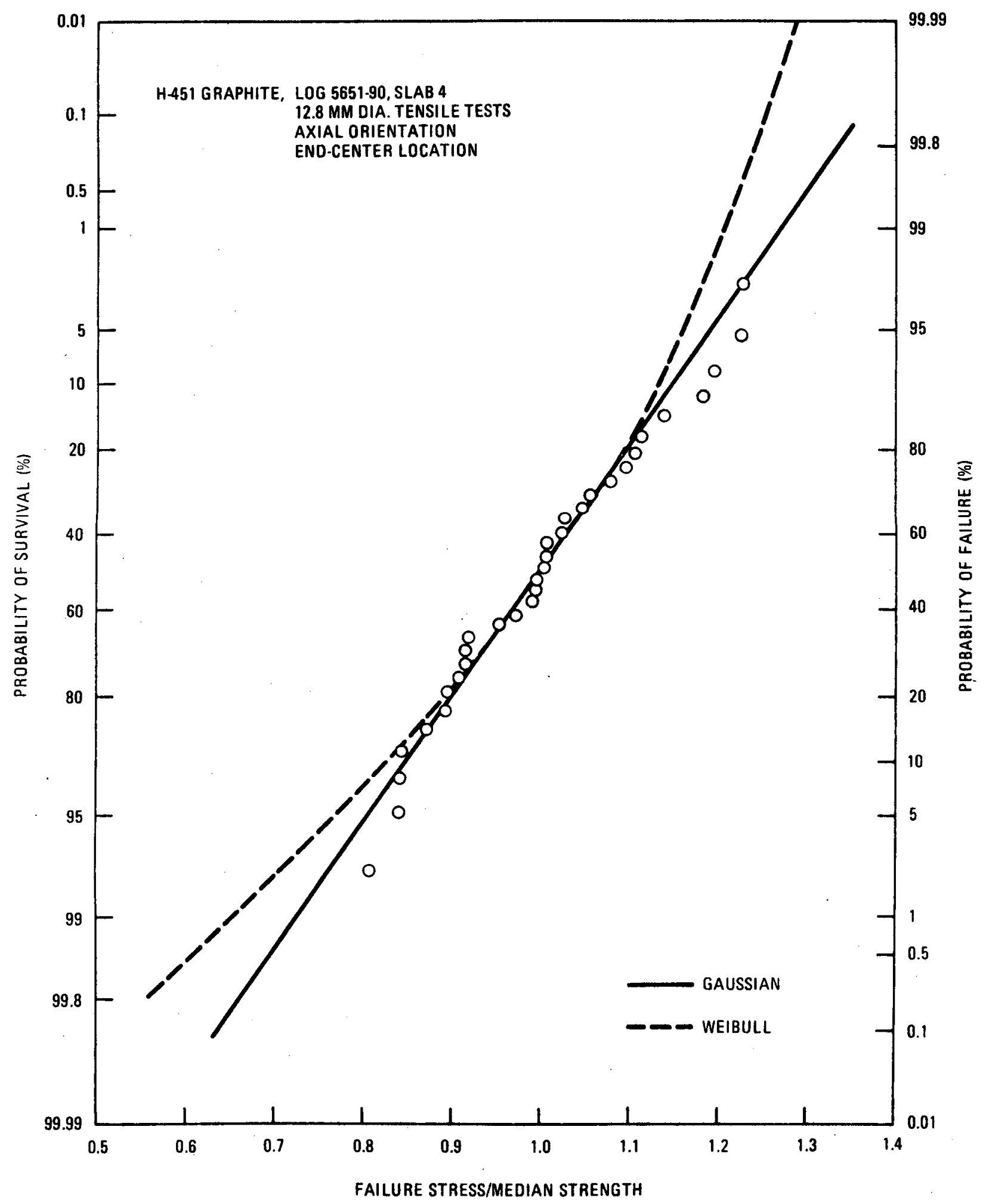

Fig. 61. Cumulative distribution curve for strength of large-sized tensile specimens, slab 4, axial orientation, end-center location 


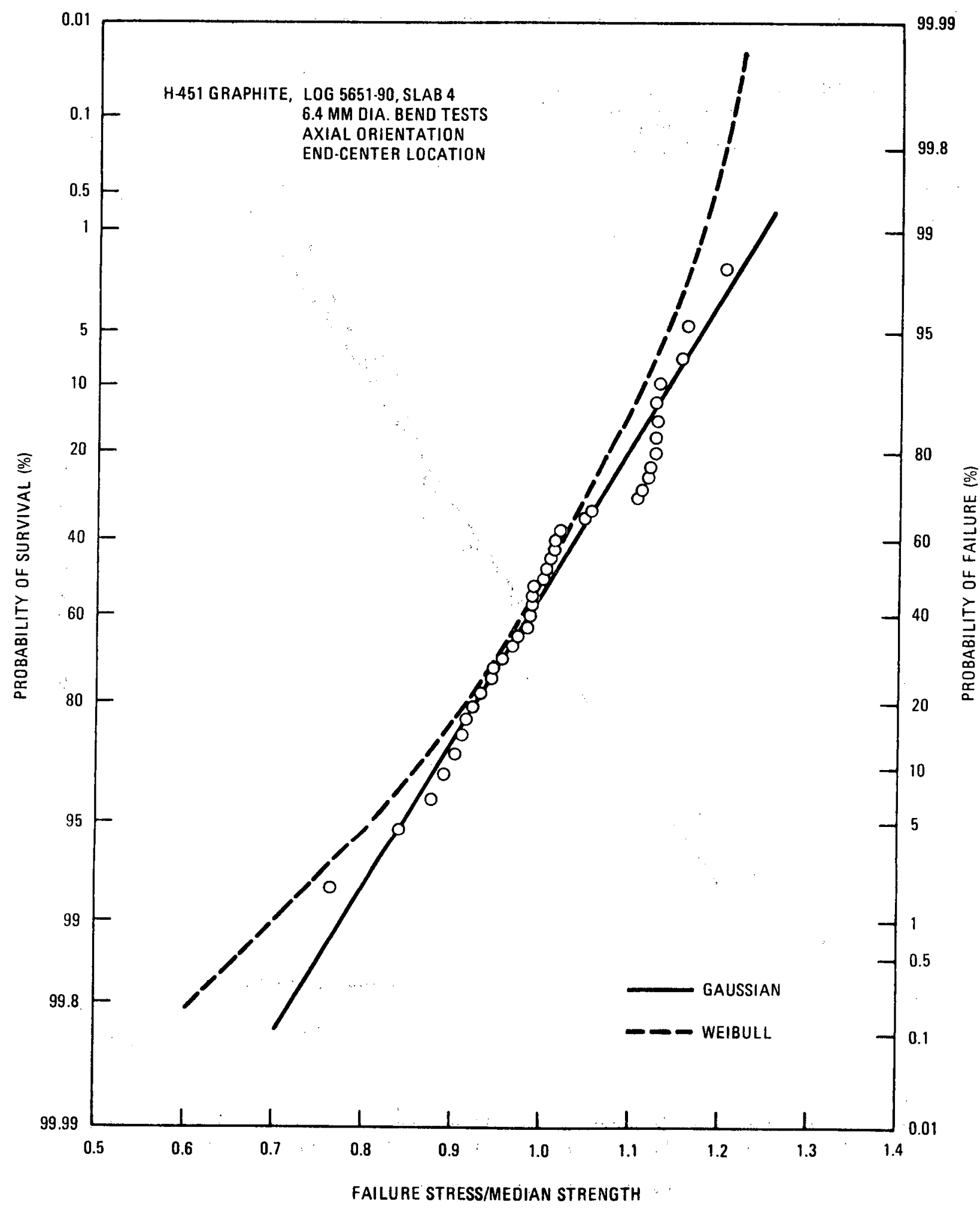

Fig. 62. Cumulative distribution curve for strength of four-point bend specimens, slab 4, axial orfentation, end-center location 


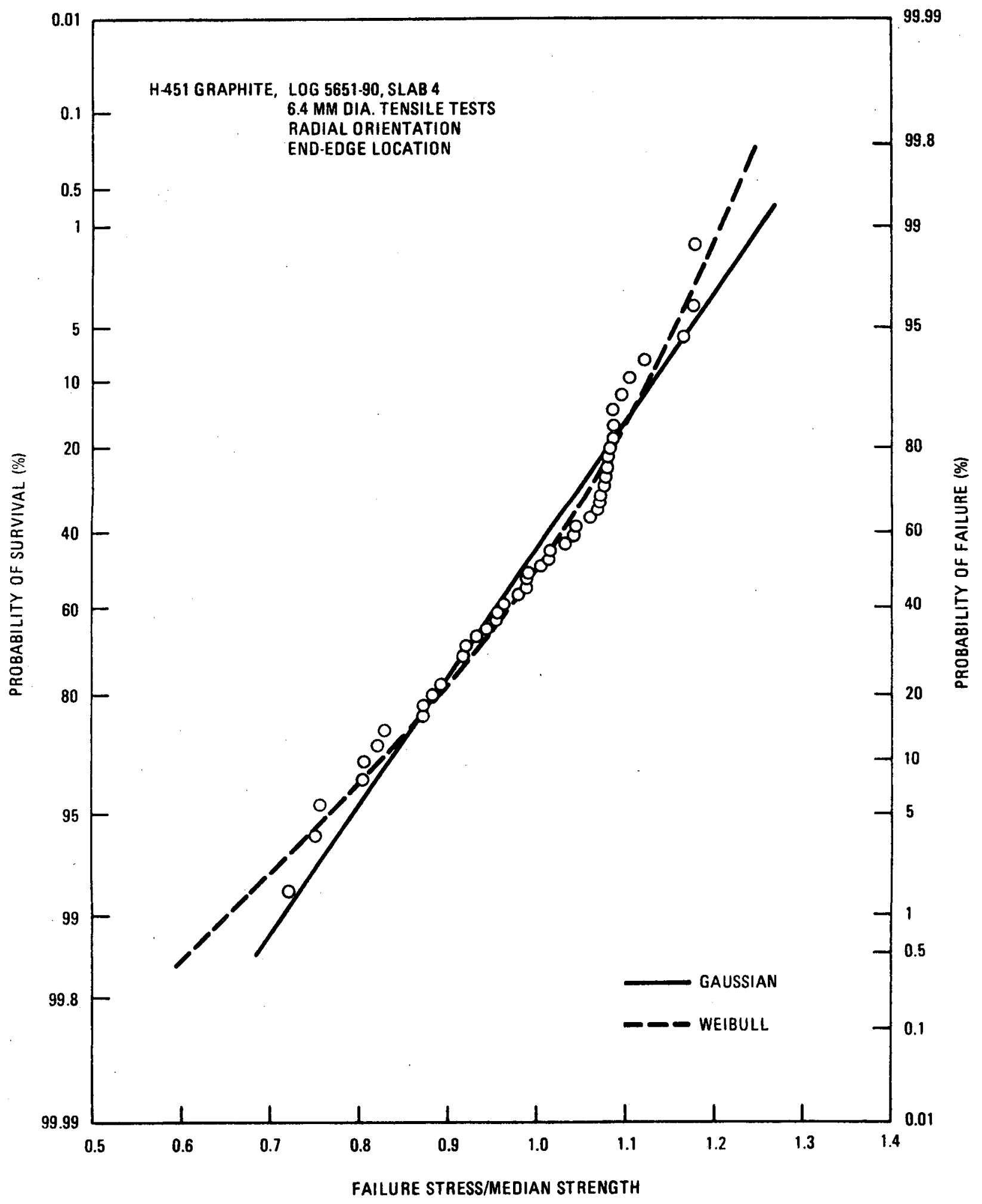

Fig. 63. Cumulative distribution curve for strength of sma11-sized tensile specimens, slab 4, radial orientation, end-edge location 


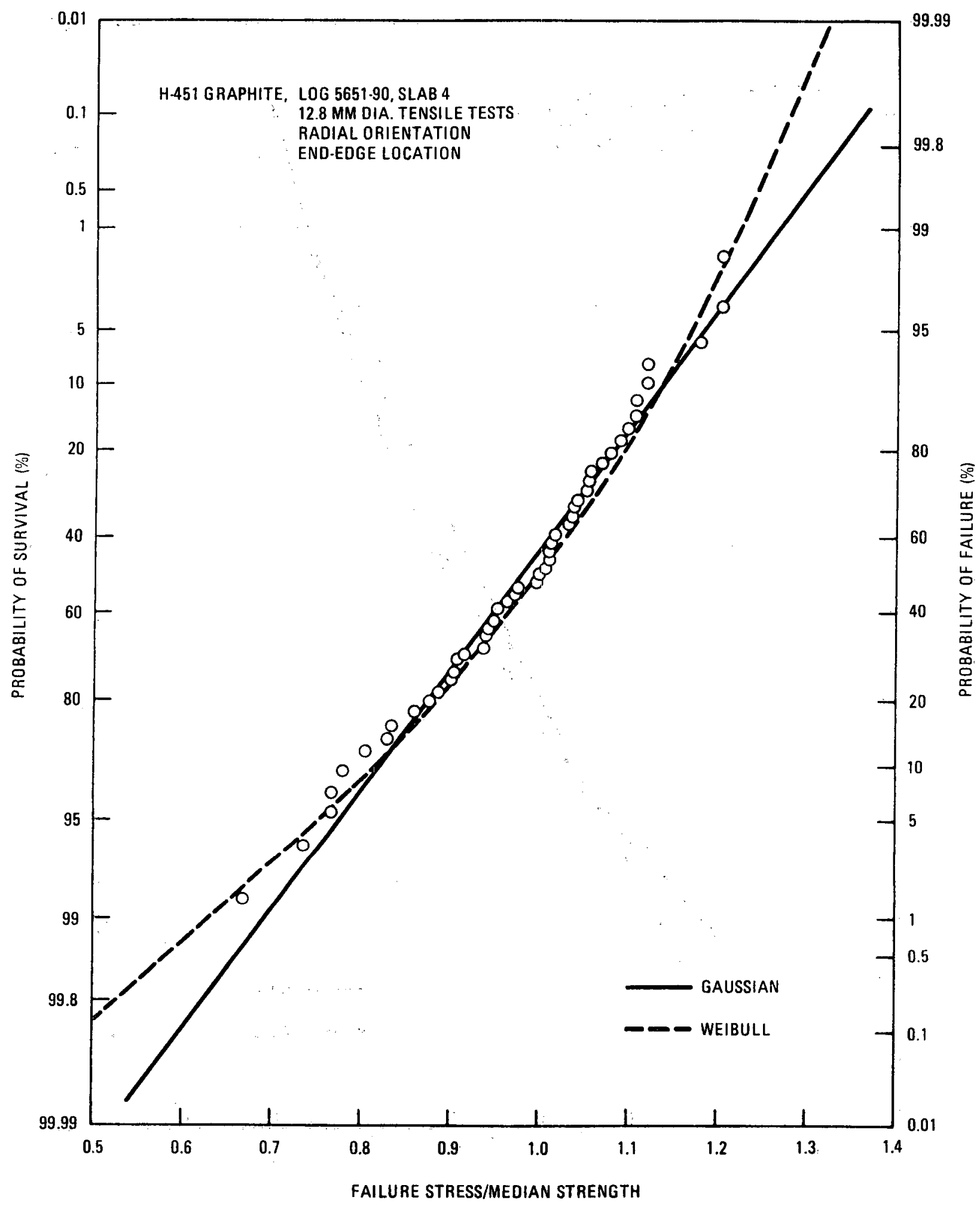

F1g. 64. Cumulative distribution curve for strength of large-sized tensile specimens, slab 4, radial orientation, end-edge location 


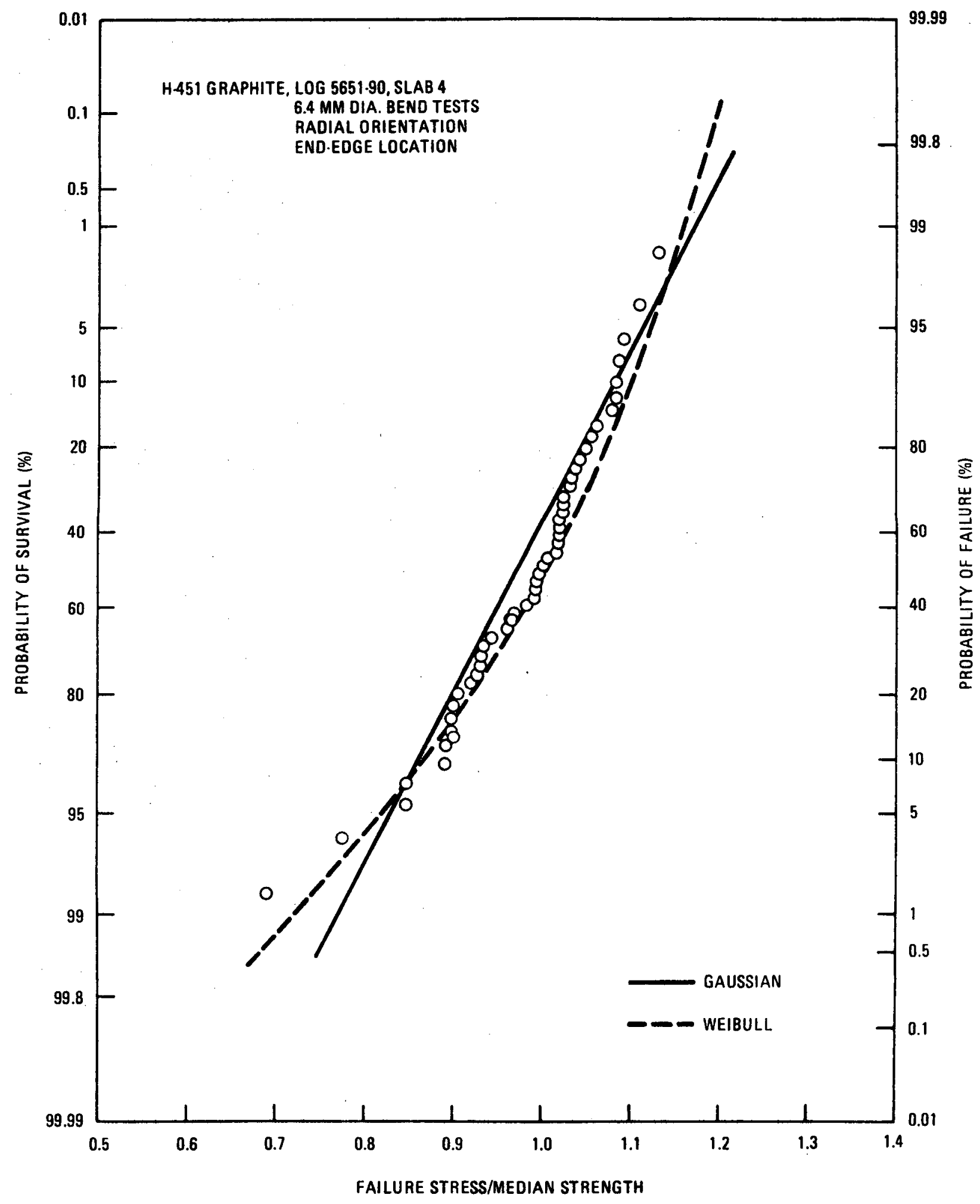

Fig. 65. Cumulative distribution curve for strength of four-point bend specimens, slab 4, radial orlentation, end-edge location 


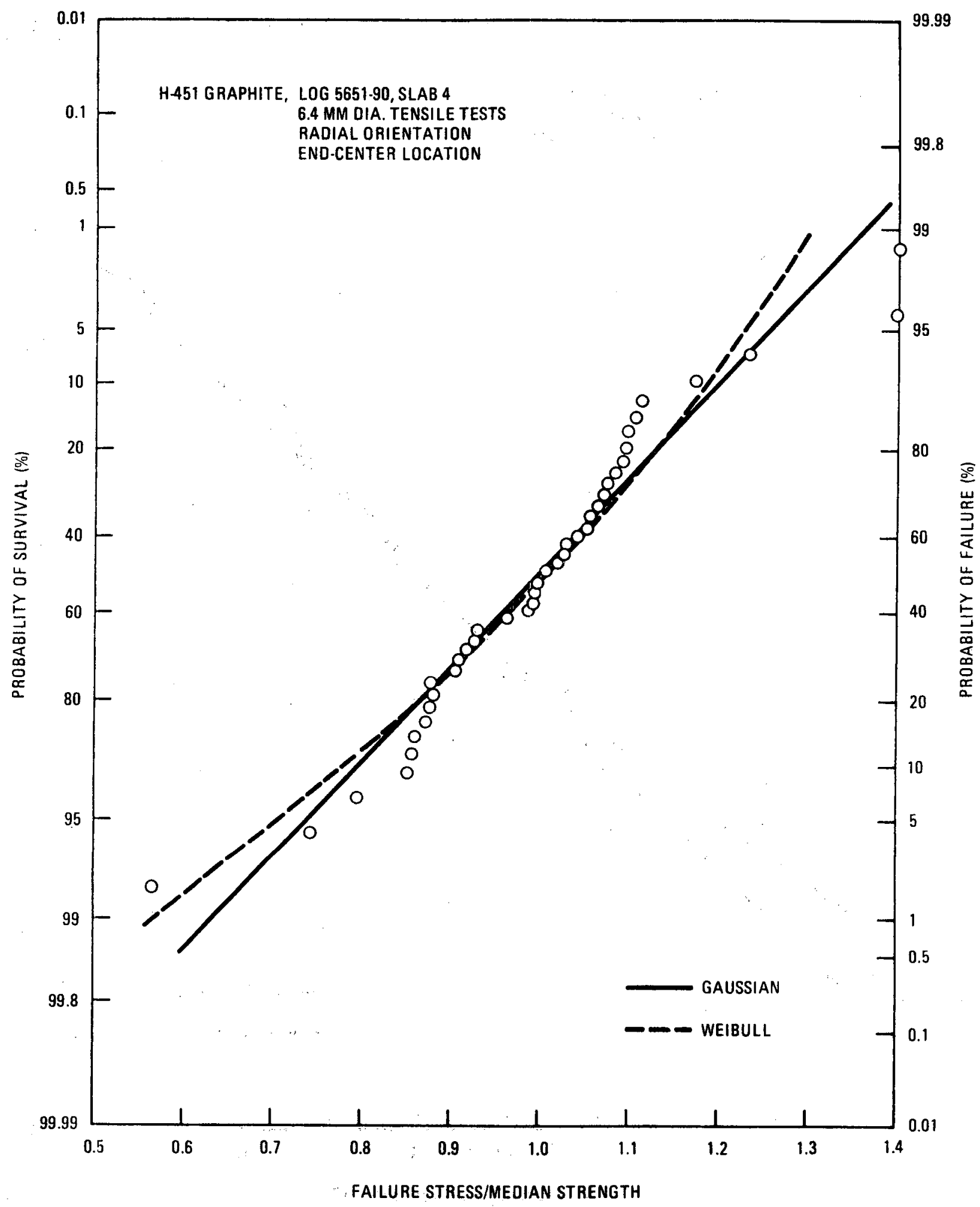

Fig. 66. Cumulative distribution curve for strength of sma11-sized tensile specimens, slab 4, radial orientation, end-center location 


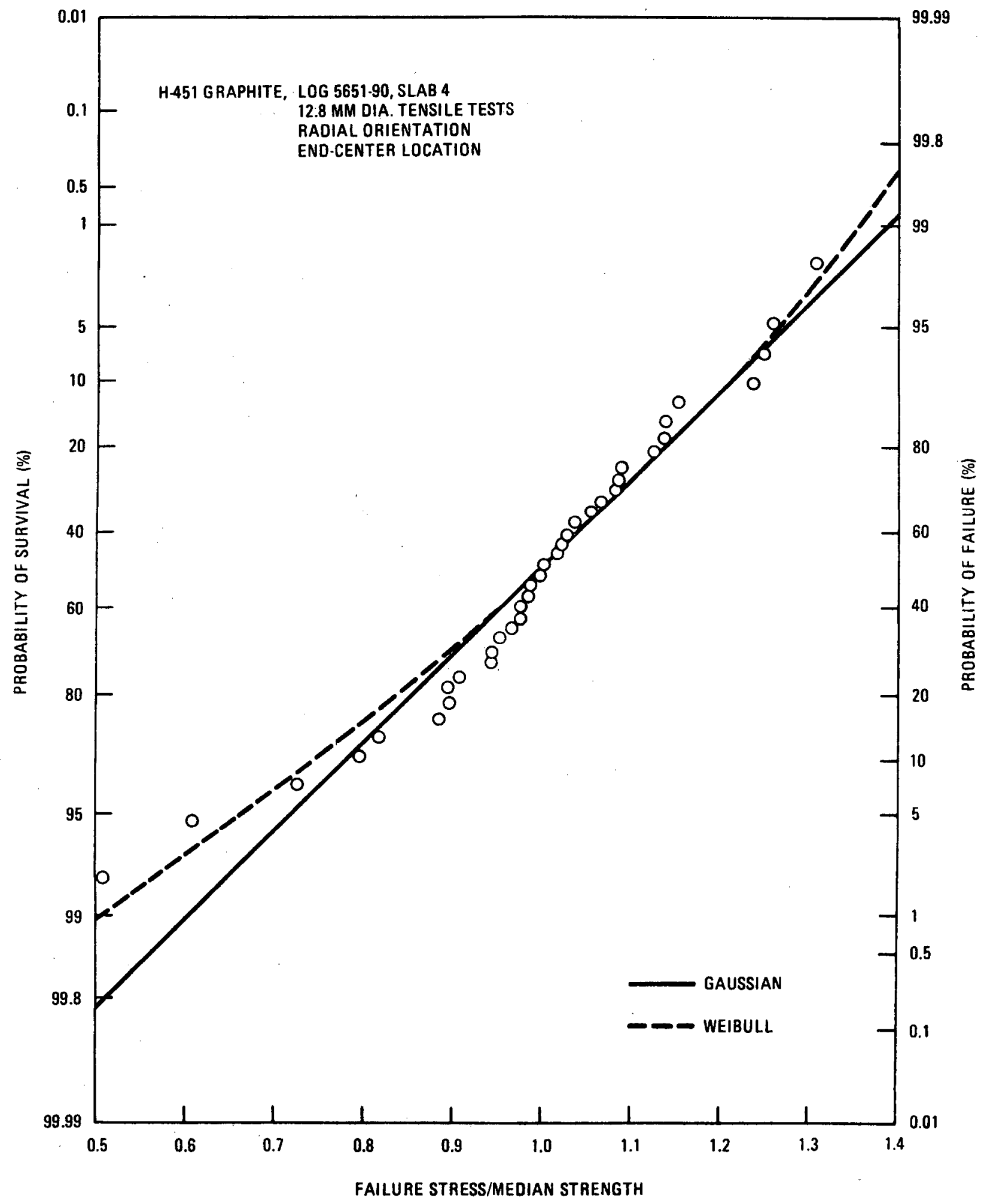

Fig. 67. Cumulative distribution curve for strength of large-sized tensile specimens, slab 4, radial orientation, end-center location 


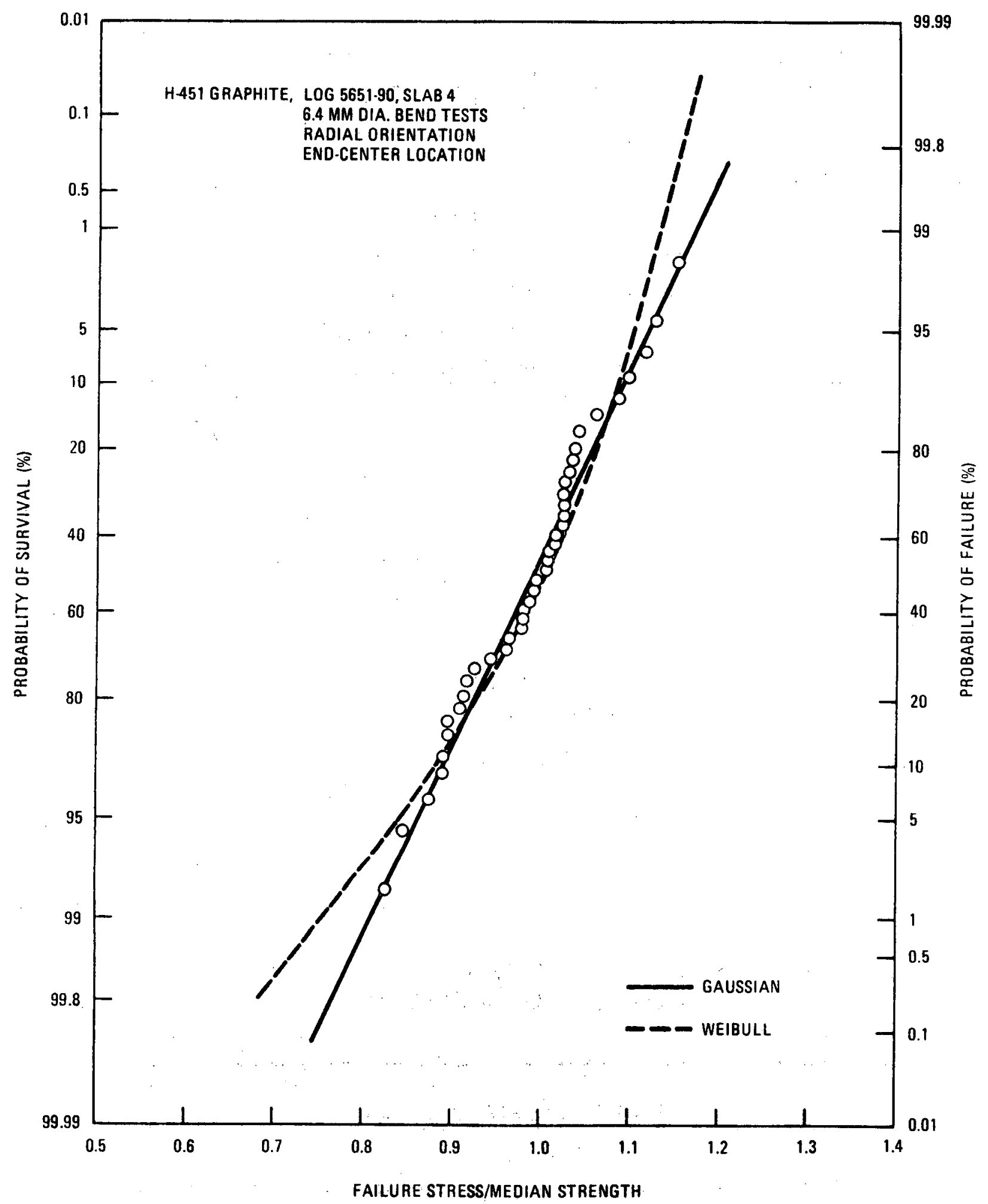

Fig. 68. Cumulative distribution curve for strength of four-point bend specimens, slab 4, radial orlentation, end-center location 


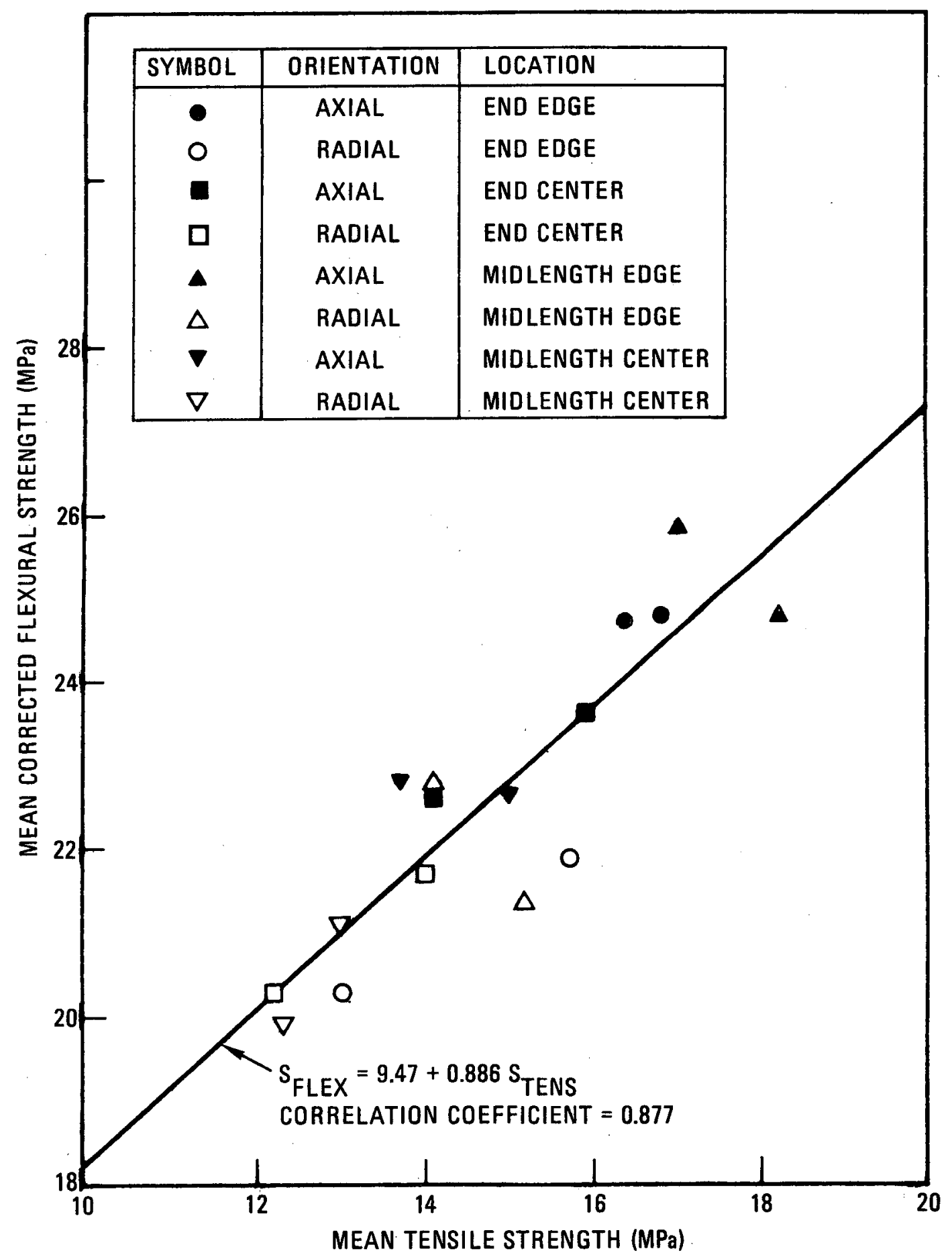

Fig. 69. Correlation between strength of flexural specimens and small (6.4 $\mathrm{mm}$ diameter) tensile specimens. Each datum point represents the mean for one orientation, slab, and zone (edge or center). 


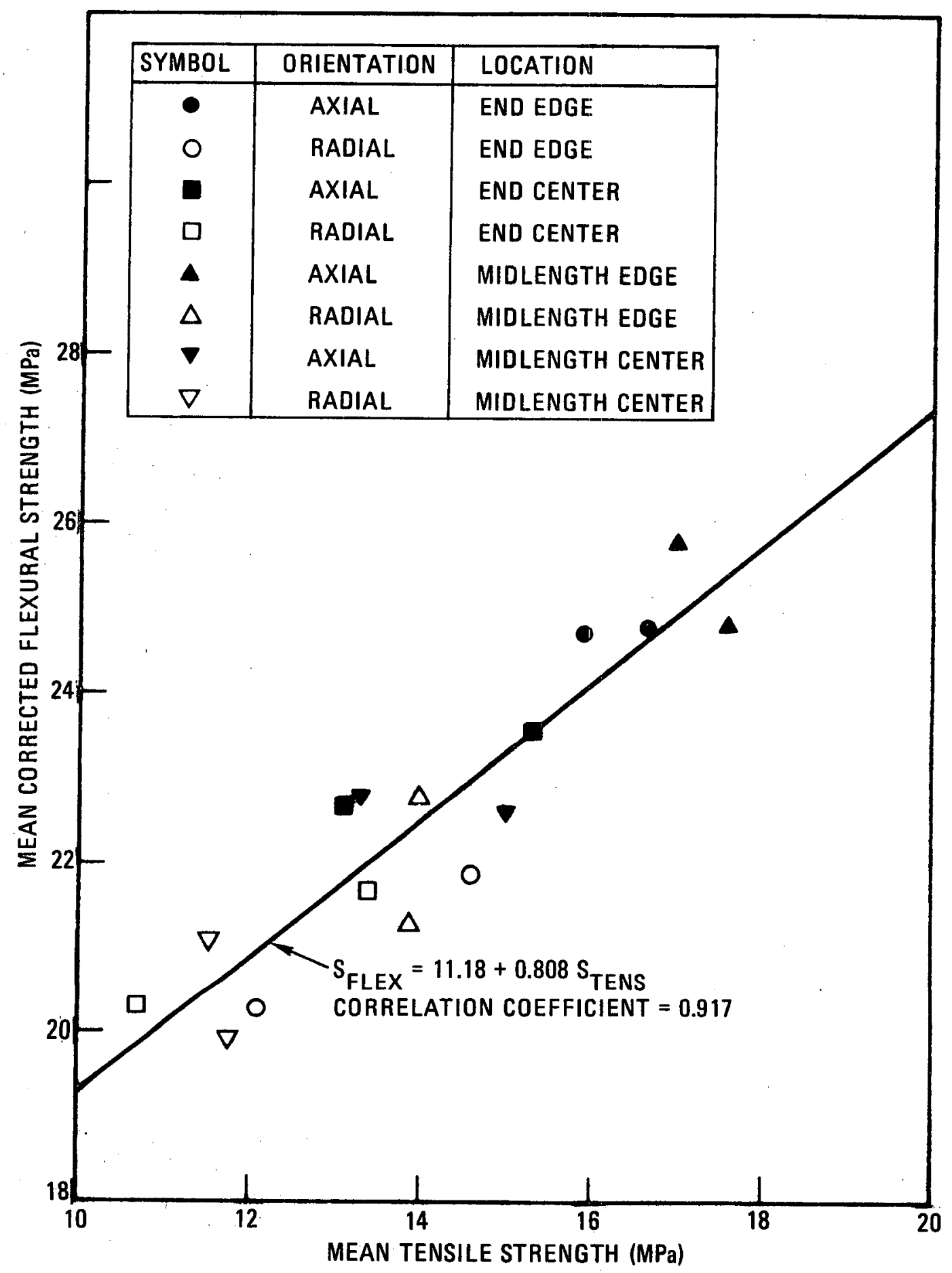

Fig. 70. Correlation between strength of flexural specimens and large $(12.8 \mathrm{~mm}$ diameter) tensile specimens. Each datum point represents the mean for one orientation, slab, and zone (edge or center). 